Technological University Dublin (TUD)

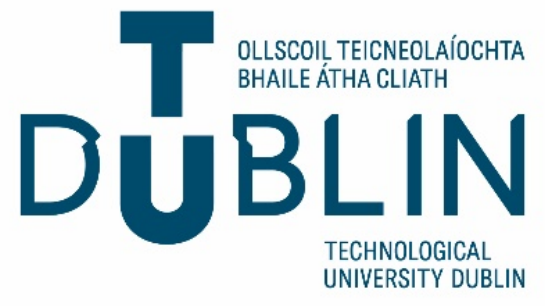

\title{
The relationship between Authentic Leadership, Work-related stress and Job motivation A Mixed Methods Study
}

Submitted by Asta Keil, Student ID: D17129481

A dissertation presented in partial satisfaction of the requirements for the degree of MSc in Leadership, Innovation and Technology

1st Class Honours awarded

Jun 2020 


\section{Acknowledgements}

First, I would especially like to thank and express my appreciation to my supervisor Dr Mary Kinahan. Mary has been a great source of advice, encouragement, and support during this process. I would also like to thank all the lecturers of TUD who were involved in this master's program for all your guidance and help, and for creating such an interesting and useful course. I have learned a lot that I can be applied in the workplace through this course.

Extraordinary thanks to my sister, Dr Tina Keil, for the endless advice and support she gave me during this course. What sister would give up an entire Christmas to teach her sister how to do statistical analysis? You are wonderful, Tina. I cannot thank you enough for your efforts.

I would also like to extend my sincere gratitude to all the participants and the participating organisation of this project. Without you, this research would not have been possible.

Last but not least, a warm thank you to all my friends and family for your support, encouragement and for listening to me moan about how much work this course has been. 


\begin{abstract}
Work-related stress (WRS) continues to present as a significant workplace hazard and is the cause of numerous employee and organisational issues (Kompier et al., 2000; O'Keefe et al., 2014; WHO, 2013). Moreover, there is an increase in WRS in the health care sector (see Russell et al., 2018). Studies have shown that WRS and related outcomes harm the quality of care received by users in health care settings (Boamah et al., 2017; Galletta et al., 2016; Van Bogaert et al., 2013; Wong \& M. Giallonardo, 2013). Due to the prevalence of management malfeasance, ethical conduct, or lack thereof in corporate and governance leadership, and increased societal challenges (e.g., economic downturn, climate change and corporate scandals etc.), attention towards Authentic Leadership (AL) is growing (Gardner et al., 2011; Neider \& Schriesheim, 2011; Walumbwa et al., 2008). However, although the research on perceptions and benefits of AL is growing, it remains limited, especially in the intellectual disability (ID) sector. This research demonstrates that poor leadership and stress can be significant contributors to decreased job motivation (JM), which in turn negatively affects staff and can have a substantial impact on the welfare of the people who avail themselves of ID services. Using a multi-strategy research design, this study examined the relationship between AL, WRS, and JM in the intellectual disability sector in Ireland. Overall results showed that perceived AL of one's supervisor significantly decreased WRS and improved JM. The results demonstrate the important role leaders have in preventing negative employee, service user and organisational outcomes.
\end{abstract}




\section{Contents}

ACKNOWLEDGEMENTS .II

ABSTRACT III

CONTENTS IV

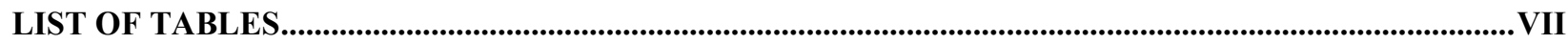

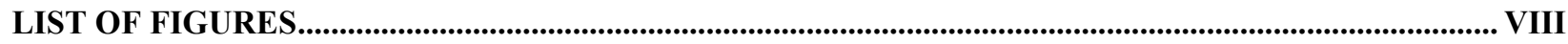

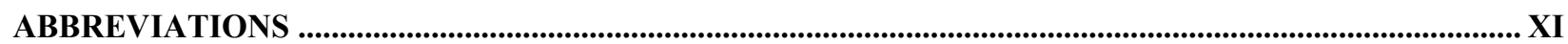

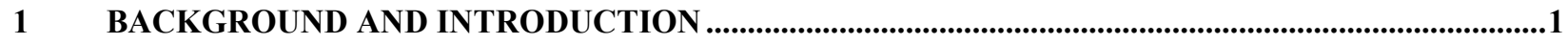

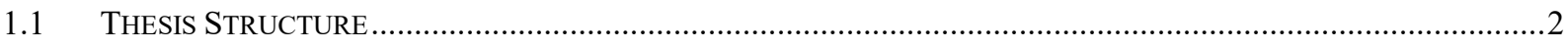

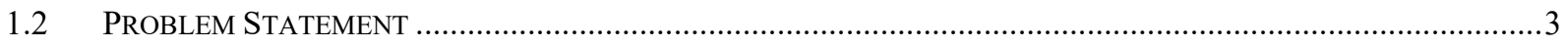

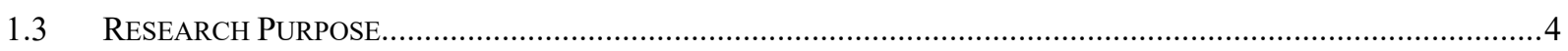

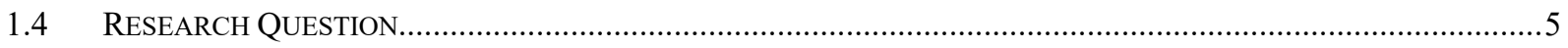

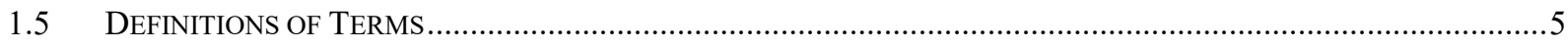

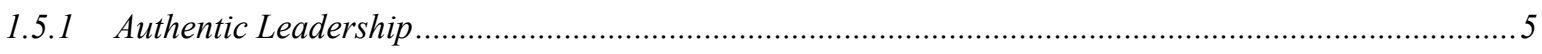

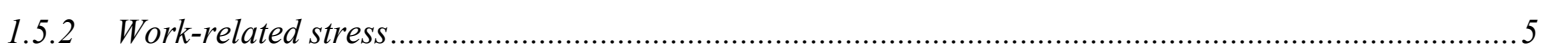

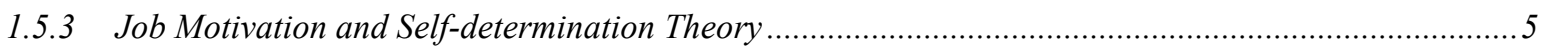

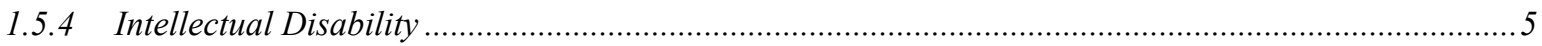

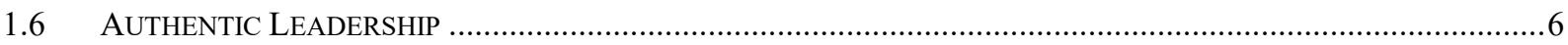

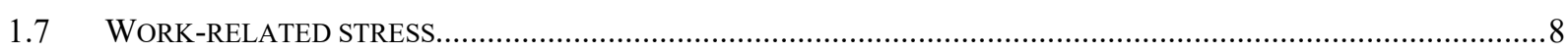

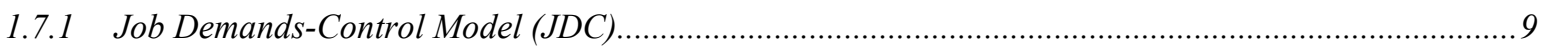

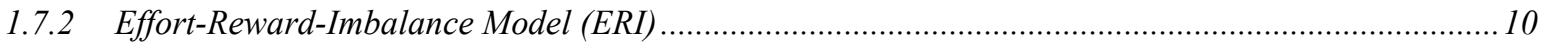

1.7.3 Job demands-resources (JD-R) model..................................................................................... 11

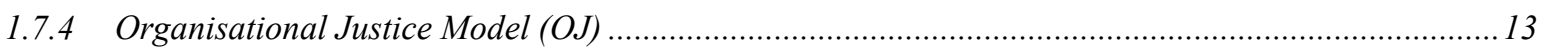

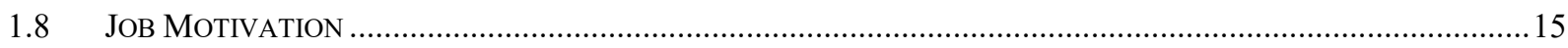

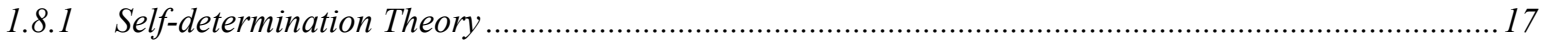

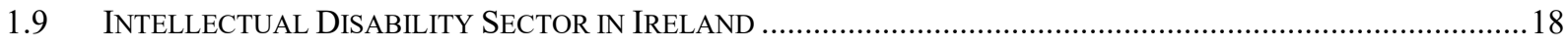

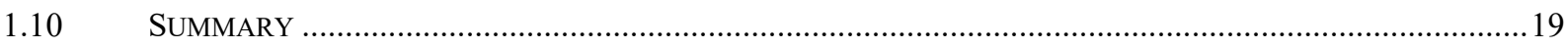

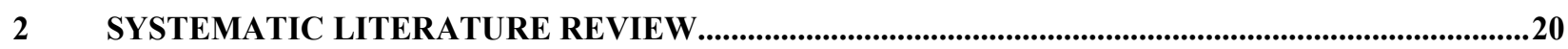

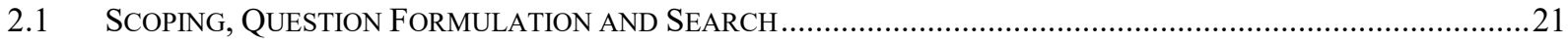

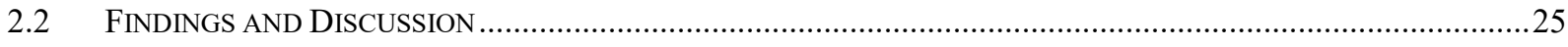

2.2.1 Relationship between Authentic Leadership and Job Motivation ...................................................25

2.2.2 Relationship between Authentic Leadership and Work-related stress............................................28

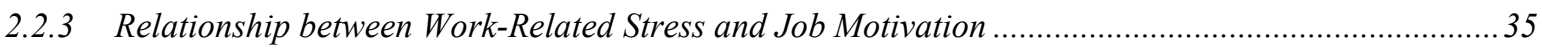

2.3 BIAS AND LIMITATIONS........................................................................................................................ 


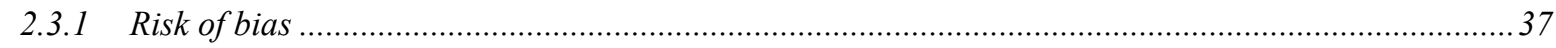

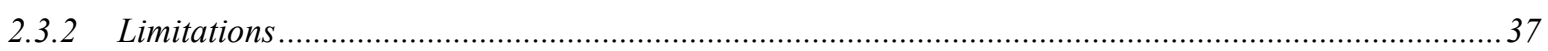

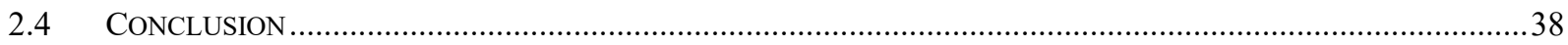

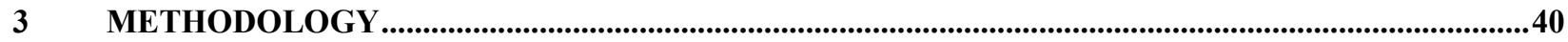

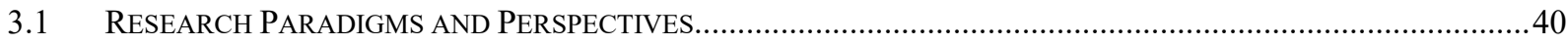

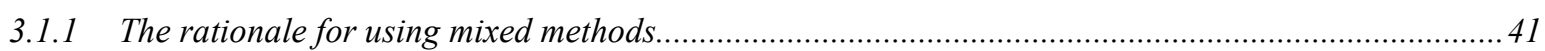

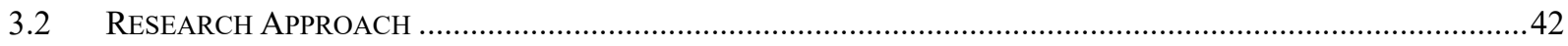

3.3 StRATEGY FOR CONNECTING QuANTITATIVE AND QUALITATIVE DATA ..............................................43

4 STUDY ONE: THE RELATIONSHIP BETWEEN AUTHENTIC LEADERSHIP, WORK-RELATED STRESS, AND JOB MOTIVATION (A QUANTITATIVE ANALYSIS) ...................................................44

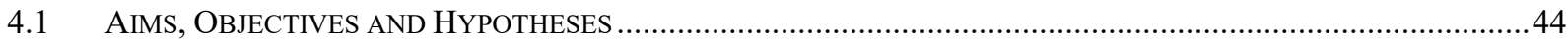

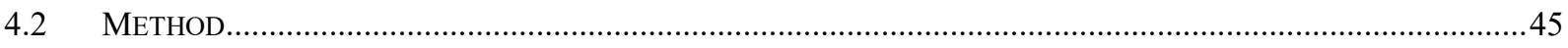

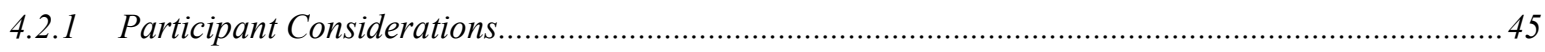

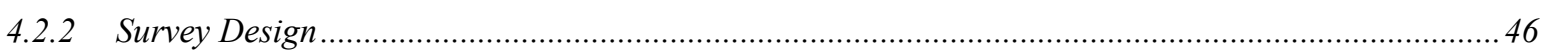

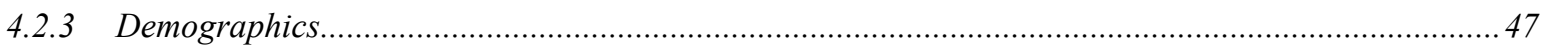

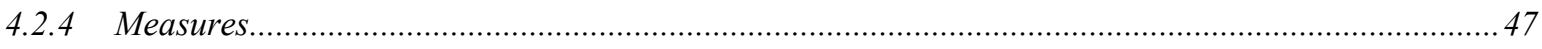

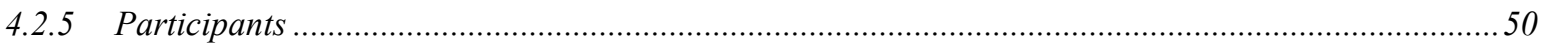

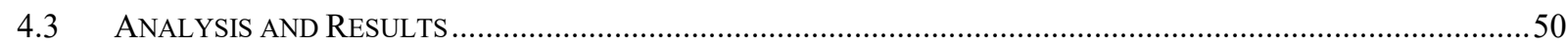

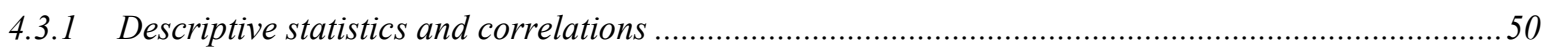

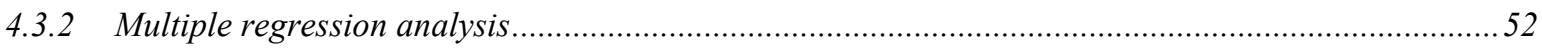

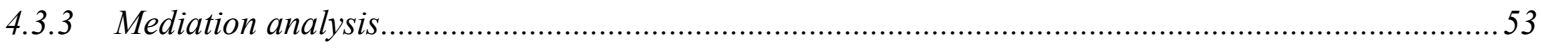

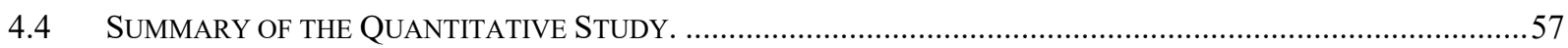

5 STUDY TWO: RELATIONSHIP BETWEEN AUTHENTIC LEADERSHIP, STRESS AND JOB MOTIVATION (A QUALITATIVE ANALYSIS) ........................................................................................59

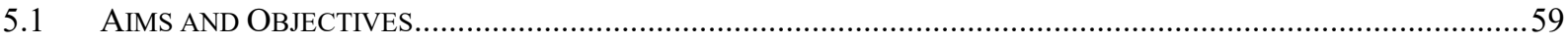

5.2 METHOD

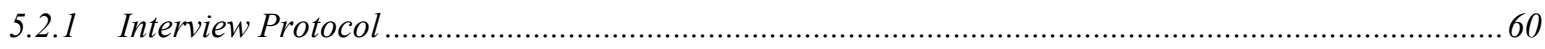

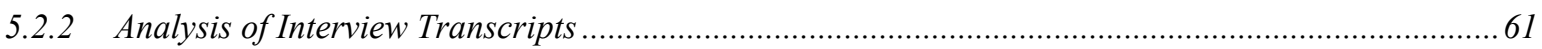

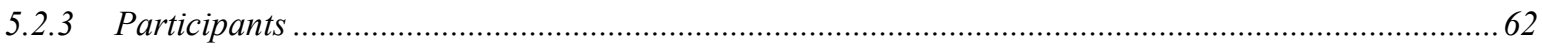

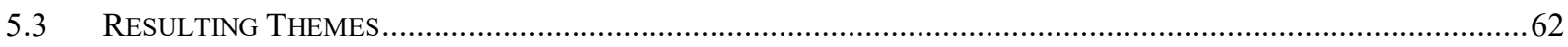

5.3.1 Theme One: When authentic leadership is perceived as increasing stress and reducing motivation...63

5.3.2 Theme Two: When authentic leadership is perceived as reducing stress and increasing motivation. .66

5.3.3 Theme Three: Stressful experiences indirectly linked to AL ........................................................ 71

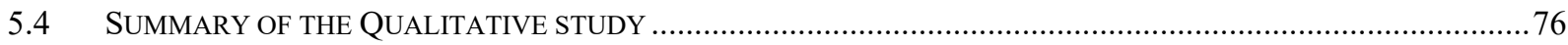

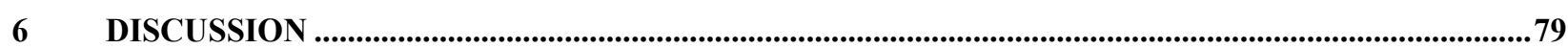

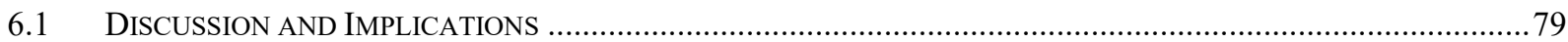




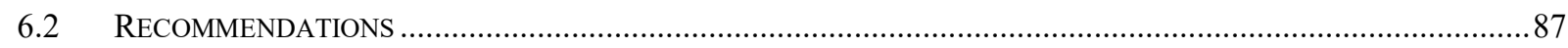

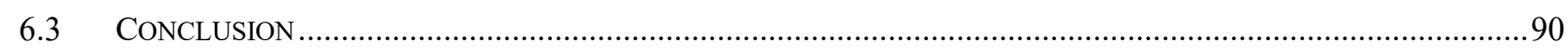

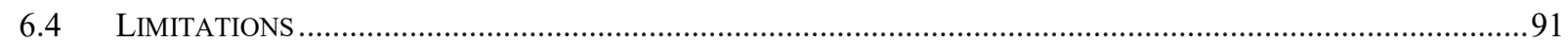

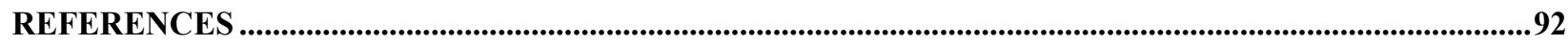

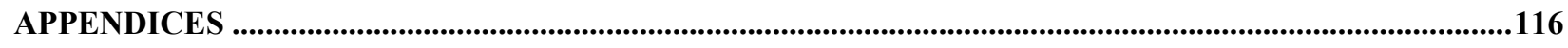

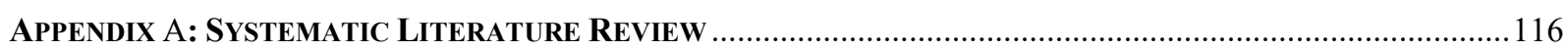

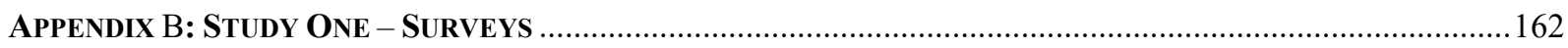

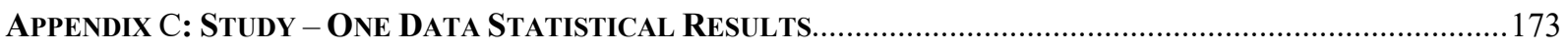

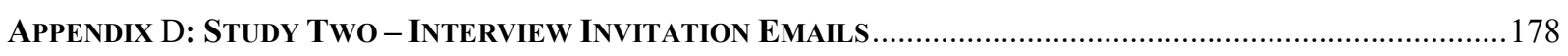

APPENDIX E: STUDY TWO - PARTICIPANT INFORMEd CONSENT .................................................................. 180

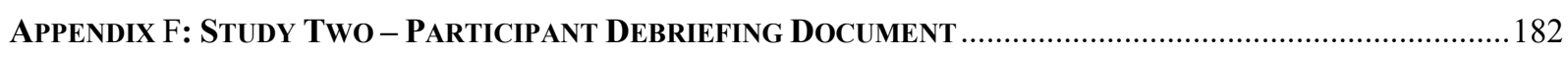

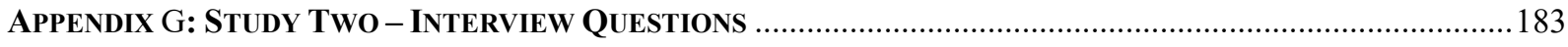

APPENDIX H: STUDY TWO - INTERVIEW AUTHENTIC LEADERSHIP DEFINITION ......................................... 185

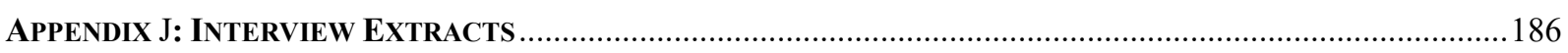

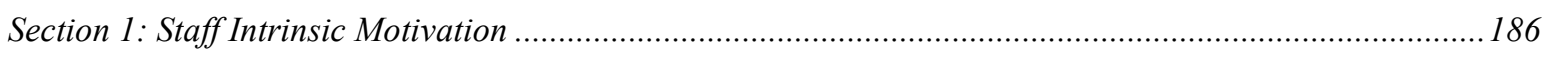

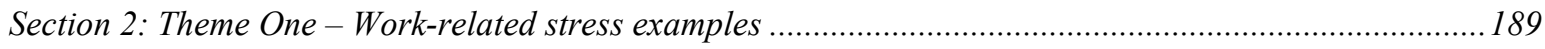

Section 3: Theme One - Non-Authentic Leadership Behaviours .............................................................. 191

Section 4: Them Two - An example of motivational positive work-related stress ......................................... 194

Section 5: Theme Two - An example of reduced stress in improved motivation............................................. 195

Section 6: Theme Two - Reported Authentic Leadership Behaviours ....................................................... 196

Section 7: Theme Three - work-related stress and Demotivation examples................................................201

Section 8: Theme Three - Positive Authentic Leadership examples .........................................................206

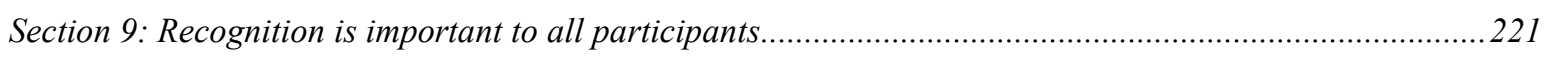

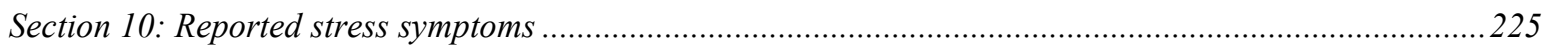

AUTHORSHIP STATEMENT ...................................................................................................................................226 


\section{List of Tables}

Table 1: AL construct dimensions description, adapted from Walumbwa et al. (2008).

Table 2: Reported work-related stress causes, symptoms and feelings, Authentic and Non-

Authentic Behaviours 77

Table 3: Revised SLR principles by Denver and Transfield (2009)..... 116

Table 4: CIMO Concepts 118

Table 5: CIMO concepts search terms (keywords)

Table 6: Database Search Terms 120

Table 7: Academic journal databases searched 126

Table 8: Database Search Results, Search Date: 16 Jun 2019. 127

Table 9: Filters applied to academic database searched in table 7 ......... 130

Table 10: SLR Data Extraction.

Table 11: Study 1-Amotivation items

Table 12: Participant Education, Study 1

Table 13: Means, Standard Deviations and Correlations - Study 1

Table 14: Regression Analysis Summary for Authentic Leadership predicting Work-related stress -

Study 1

Table 15: Regression Analysis Summary for Authentic Leadership Sub-Dimension Self-awareness predicting Work-related stress - Study 1

Table 16: Regression Analysis Summary for Authentic Leadership Sub-Dimension Internalised Moral Perspective predicting Work-related stress - Study 1

Table 17: Regression Analysis Summary for Authentic Leadership Sub-Dimension Relational Transparency predicting Work-related stress - Study 1

Table 18: Regression Analysis Summary for Authentic Leadership Sub-Dimension Balanced Processing predicting Work-related stress - Study 1 


\section{List of Figures}

Figure 1: Job strain model. Adapted from R. A. Karasek (1979) ............................................... 10

Figure 2: The Job Demands - Resources Model. Adapted from Bakker and Demerouti (2007).. 12

Figure 3: The self-determination continuum of work motivation (Gagné \& Deci, 2005) ............. 18

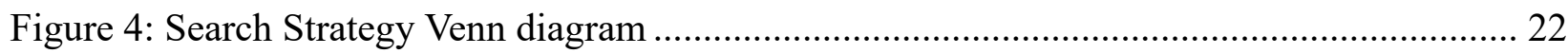

Figure 5: PRISMA flow diagram of database search and results............................................. 24

Figure 6: Factors influencing new graduate nurse burnout development, job satisfaction, and patient care quality: A time-lagged study. The resulting model (Boamah et al., 2017). 30

Figure 7: The effects of authentic leadership, six areas of work-life, and occupational coping selfefficacy on new graduate nurses' burnout and mental health: A cross-sectional study. The resulting model (Laschinger et al., 2015)

Figure 8: The influence of authentic leadership on newly graduated nurses' experiences of workplace bullying, burnout and retention outcomes: A cross-sectional study. The resulting model (Laschinger et al., 2012)

Figure 9: Authentic leadership and employee well-being: The mediating role of attachment insecurity. Hypostasised model (Rahimnia \& Sharifirad, 2015)

Figure 10: Authentic leadership and employee well-being: The mediating role of attachment insecurity. The resulting model (Rahimnia \& Sharifirad, 2015).

Figure 11: Visual Model for Mixed-Methods Sequential Explanatory Design Procedures.

(Ivankova et al., 2006)

Figure 12: Visual Model for Mixed-Methods Sequential Explanatory Design Procedures modified for this study. Adapted from (Ivankova et al., 2006)

Figure 13: Mediation Model

Figure 14: Survey Email Invitation 46

Figure 15: Mediation between Authentic Leadership and autonomous motivation through workrelated stress. The direct effect (c-prime) is reported in brackets. 
Figure 16: Mediation between Authentic Leadership - Self-awareness and autonomous motivation through WRS. The direct effect (c-prime) is reported in brackets. 54

Figure 17: Mediation between Authentic Leadership - Internalised moral perspective and autonomous motivation through WRS. The direct effect (c-prime) is reported in brackets. 55

Figure 18: Mediation between Authentic Leadership - Relational transparency and autonomous motivation through WRS. The direct effect (c-prime) is reported in brackets. 56

Figure 19: Mediation between Authentic Leadership - Balanced processing and autonomous motivation through work-related stress. The direct effect (c-prime) is reported in brackets. ....... 56 Figure 20: Authentic Leadership Development Model (Luthans \& Avolio, 2003) 89

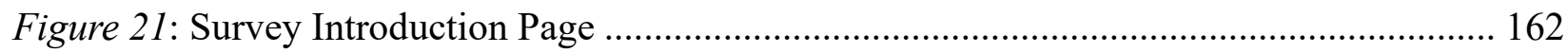

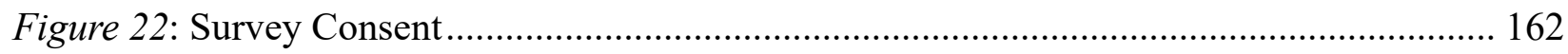

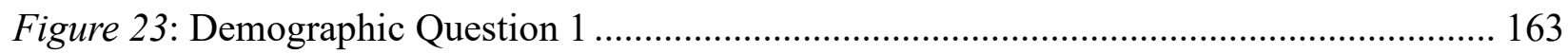

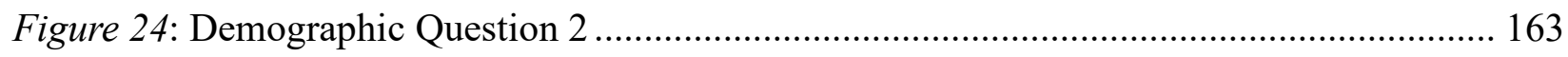

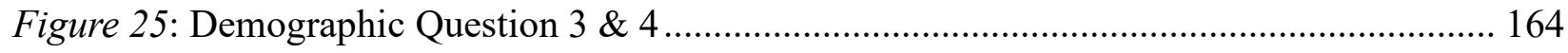

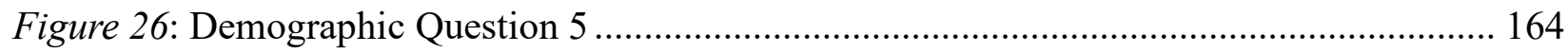

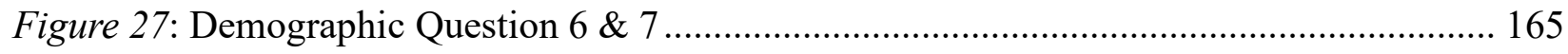

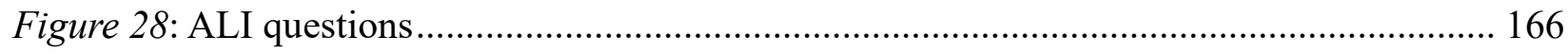

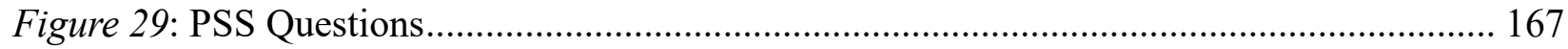

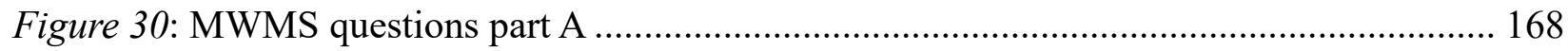

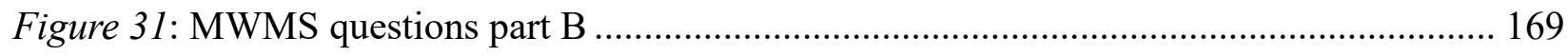

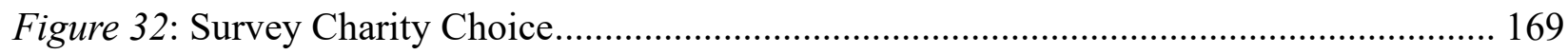

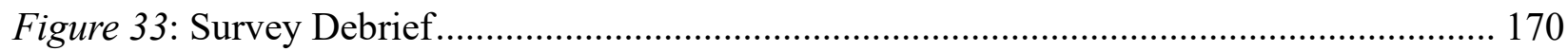

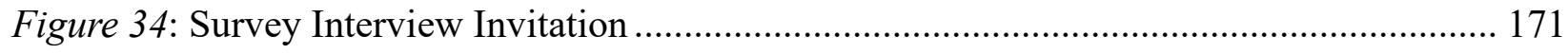

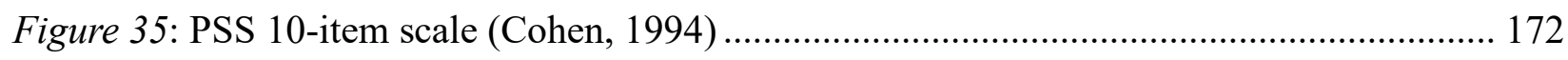

Figure 36: Study 1 - Histogram of Amotivation.............................................................. 173 


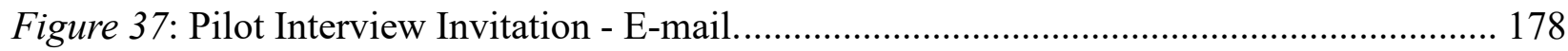

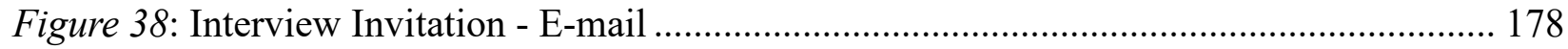

Figure 39: Interview to survey participants who have not been selected - E-mail .................. 179 


\section{Abbreviations}

\begin{tabular}{|c|c|}
\hline Abbreviation & Meaning \\
\hline $\mathrm{AL}$ & Authentic Leadership \\
\hline ALB & Authentic Leadership sub-dimension "Balanced processing." \\
\hline ALI & Authentic Leadership Index \\
\hline ALM & Authentic Leadership sub-dimension "Internalised moral perspective." \\
\hline ALQ & Authentic Leadership Questionnaire \\
\hline ALR & Authentic Leadership sub-dimension "Relational transparency." \\
\hline ALS & Authentic Leadership sub-dimension "Self-awareness." \\
\hline AM & Autonomous Motivation \\
\hline CIMO & Context, Intervention, Mechanisms, Outcomes \\
\hline $\mathrm{CM}$ & Controlled Motivation \\
\hline CRD & Centre for Reviews and Dissemination \\
\hline ERI & Effort-Reward-Imbalance \\
\hline HSE & Health Service Executive \\
\hline ID & Intellectual Disability \\
\hline JDC & Job Demands-Control \\
\hline JDCS & Job Demand-Control-Support \\
\hline$J D-R$ & Job Demands-Resources \\
\hline JM & Job Motivation \\
\hline LMX & Leader - Member Exchange \\
\hline LSS & Lean Six Sigma \\
\hline MWMS & Multidimensional Work Motivation Scale \\
\hline NGO & Non-Governmental Organisation \\
\hline OCB & Organisational Citizenship Behaviour \\
\hline OJ & Organisational Justice \\
\hline OSCE & Occupational Coping Self-Efficacy \\
\hline $\mathrm{PICO}$ & Population, Intervention, Comparison, Outcomes \\
\hline PSS & Perceived Stress Scale \\
\hline PsyEmp & Psychological Empowerment \\
\hline PTSD & Post-Traumatic Stress Disorder \\
\hline SDT & Self-Determination Theory \\
\hline SLR & Systematic Literature Review \\
\hline WB & Withdrawal behaviours \\
\hline WRS & Work-related stress \\
\hline
\end{tabular}




\section{Background and Introduction}

Research has found that WRS has a significant negative impact on the quality of the services provided in the intellectual disability sector (Hatton et al., 1999; McLean \& Andrew, 1999; Mutkins et al., 2011). Moreover, staff well-being should be considered highly important in order to provide a high-quality service for people with an intellectual disability (Devereux et al., 2009; Rice \& Rosen, 1991). One stressor that is specifically relevant to the intellectual disability sector is the pressure that frontline staff sometimes face when dealing with service-users who present challenging behaviour, which in turn can also negatively impact job-satisfaction (Deveau \& McGill, 2014; Jenkins et al., 1997). This raises the question "What can leaders of intellectual disability organisations do to mitigate against WRS and ensure staff stay motivated in order to provide the best service possible?"

It is widely acknowledged that poor management communication and perceived unfair treatment are major factors in WRS (Bhui et al., 2016; Madlock, 2008). Furthermore, Bhui et al. (2016) found evidence for a direct relationship between leadership styles and stress, while Madlock (2008) found strong evidence for a link between supervisor communicator competence and employee satisfaction. Additionally, Lepine, Podsakoff and Lepine (2005) found that although challenging work can increase JM, hindrance stressors (such as organisational politics, red tape, role ambiguity and job insecurity) can have a significant negative relationship with motivation.

Indeed, a multitude of studies have found a relationship between leadership and taskspecific or interpersonal WRS (Gupta \& Beehr, 1979; Harms et al., 2017; Kessler et al., 2013). In Europe, emerging psychosocial risks, which are linked to how work is organised and managed, have contributed to an overall increase in WRS (EU-OSHA, 2015; Eurofound, 2010). More specifically, in Ireland, WRS has doubled between 2010 and 2015. The highest number of 
employees experiencing WRS in Europe was reported by the health sector, followed by public administration staff (Russell et al., 2018). Reduced job-satisfaction can lead to reduced work productivity, demotivation, impaired performance and increased staff turnover (Cartwright \& Cooper, 2014; Cooper, Cartwright, et al., 1996; Fairbrother \& Warn, 2003; Faragher, 2005; Jenkins et al., 1997).

There are many different leadership styles, some well-established, others new and emerging: for example, charismatic/transformational, transactional, shared/distributed, laissezfaire, authentic, passive and destructive (see Anderson \& Sun, 2017; Eagly et al., 2003). Although the concept of authenticity has received renewed attention in recent years (see Rahimnia \& Sharifirad, 2015), research on AL in relation to WRS and its effects on motivation, specifically within the context of the ID sector, remains scant.

\subsection{Thesis Structure}

This thesis consists of six main sections. Firstly, the introduction and background section explore the problem being addressed by this study, and the main concepts of the research area are discussed in some detail. Secondly, the literature review examines previous research conducted in the areas of AL, WRS, and JM. Specifically, the literature review is a systematic literature review (SLR). The methodology, scoping, and question formulation of the SLR are also covered in this section. This leads to the third section, which outlines the research approach, philosophical foundations and strategy taken to conduct this study. However, as this research consists of two studies (a quantitative and a qualitative study), the method for each are discussed separately in the following sections. Section four covers the quantitative study (study one) and outlines the aims, objective, hypotheses, method, analysis and finally, the results. Section five covers the qualitative study (study two) and contains the aims, objectives, method, and results. Lastly, section six discusses the research findings and how they relate to the literature, outlines the implications of 
these findings, and finally discusses the recommendations and limitations.

\subsection{Problem Statement}

There is broad recognition of the negative impact of WRS on employees' health and wellbeing (Kompier et al., 2000; O’Keefe et al., 2014; WHO, 2013). For organisations, industry and the economy, the cost and effects of WRS come in the form of significant levels of lost workdays (Cox et al., 2000; Kompier et al., 2000; Milczarek et al., 2009). In 2005, within the European Union, the European Agency for Safety and Health at Work estimates the cost of WRS to be in the region of at least 20 billion euros annually (Milczarek et al., 2009). In addition, they also reported that at least 40 million workers are affected by job stress across 15 member states, including Ireland. However, the report reveals the prevalence of stress in Ireland to be among the lower of those countries included in the report at $16 \%$, while Greece reported the highest level of stress at $55 \%$ and the United Kingdom reported the lowest at $12 \%$.

In 2018, the Economic and Social Research Institute (ESRI) conducted a comprehensive comparative study of WRS in Ireland and the UK. The report outlined that stress in the workplace is of considerable concern and is on the increase (Russell et al., 2018). The report is an 'evidencebased report', which was based on data from the European Working Conditions Survey (EWCS), carried out in 2010 and 2015, and examined the working conditions associated with WRS (ParentThirion et al., 2017).

In the area of human services, a study conducted in the UK found a close relationship between commitment, satisfaction, stress and control over one's work (McLean \& Andrew, 1999). The study found that when staff have higher stress, they become less committed to their work. Similarly, in Ireland, a study found that the turnover rate of social workers in the area of child protection was high due to burnout (Redmond et al., 2011). In addition, a study carried out on 232 care workers in the intellectual disability sector in the United States found that stressed workers 
are more likely to be depressed. They found that work overload and lack of involvement in organisational decision-making were key stressors (Gray-Stanley et al., 2010). Lastly, Hatton et al. (2001) found that job strain was among the factors directly associated with intended turnover in the intellectual disability sector in the UK. They found that bureaucracy, lack of staff support, role ambiguity, and working longer hours were among the factors associated with job strain. Next the purpose of the research is discussed.

\subsection{Research Purpose}

As outlined in the rationale above, poor leadership and stress can be major contributors to decreased JM, satisfaction, and performance. This not only affects staff but also, more importantly, can also have a major impact on the welfare of the people who avail of the services provided by intellectual disability organisations. Therefore, the aim of this research is to examine the relationship between perceived AL, WRS, and JM, using a mixed-methods approach (i.e., an online questionnaire, followed by semi-structured interviews).

Specifically, the objectives are to examine the relationship between perceived AL, WRS, and JM, and given such a relationship, to formally test to what extent WRS mediates the relationship between AL and JM. The results of this research will provide information to the management of intellectual disability organisations that informs them about work-place wellbeing. More broadly, it may also provide useful data for policymakers and add to the existing body of knowledge. 


\subsection{Research Question}

The overall research question that this project aims to address is "To what extent does AL contribute to follower (specifically direct line reports or supervisors) WRS and JM in the context of the intellectual disability sector in Ireland?" How the findings relate to the current body of knowledge and related theories will also be examined.

\subsection{Definitions of Terms}

In this section, a brief definition of the main concepts underlying this project is given. However, in the following section, these concepts are explained in greater detail.

\subsubsection{Authentic Leadership}

AL is a style of leadership that focuses on positive, honest, and open relationships. Authentic leaders are deeply self-aware, manage based on evidence, lead with the heart and are highly ethical and genuine people (Avolio \& Gardner, 2005).

\subsubsection{Work-related stress}

WRS is a person's negative reaction to excessive work pressures, either physical or psychological (HSE, 2009).

\subsubsection{Job Motivation and Self-determination Theory}

JM describes an individual's level of determination and desire to carry out tasks within their place of work. While self-determination theory (SDT) is a specific motivation theory that describes the level of motivation a person has on a continuum between amotivation (lack of any motivation) and intrinsic motivation (doing a task because it is fun or of interest to the individual) (Deci \& Ryan, 1985).

\subsubsection{Intellectual Disability}

The World Health Organisation (WHO, 2020) defines intellectual disability as "a significantly reduced ability to understand new or complex information and to learn and apply 
new skills (impaired intelligence)". One of the major causes of intellectual disability is attributed to genetic factors resulting in syndromes such as Asperger syndrome, Down's syndrome, and Fragile $\mathrm{X}$ syndrome. In addition, intellectual disability can be caused by traumatic brain injury (HSE, 2018b; Iqbal et al., 2016).

\subsection{Authentic Leadership}

Inspired by the issues of management malfeasance, ethical conduct, or lack thereof in corporate and governance leadership and increased societal challenges (e.g. economic downturn, climate change, terrorism etc.) a theoretical model of "Authentic Leadership" was created and developed by Luthans and colleagues in the 2000s (Gardner et al., 2011; Neider \& Schriesheim, 2011; Walumbwa et al., 2008). The need for a new ethical form of leadership style was recognised by other well-known leadership authors (Cashman, 2003, 2008; George et al., 2007; George, 2003). In an extensive literature review of what makes an authentic leader, Gardner, Cogliser, Davis and Dickens (2011) concluded that if a leader is to be truly authentic, they must "do so in a way that honours their core values, beliefs, strengths - and weaknesses" (p. 1142).

According to the model of AL, the end objective of authentic behaviours is committed, motivated and fulfilled workers (Avolio \& Gardner, 2005; Shirey \& Shirey, 2006; Wong \& Cummings, 2009). There are four dimensions that together form the paradigm of AL theory, as outlined by Avolio and Gardner (2005): self-awareness, relational transparency, internalised moral perspective and balanced processing (see Table 1 for a description of each dimension). In addition, Mortier, Vlerick and Clays (2016) explain that by being empathetic (a trait of authenticity), leaders motivate staff, who in turn perform well and create positive outcomes, resulting in employee retention.

This research is based on the validated multidimensional model of the AL construct developed by Walumbwa et al. (2008), namely the Authentic Leadership Questionnaire (ALQ), as 
opposed to any other definition of authenticity or AL. The authors state that the ALQ "measure for important work-related attitudes and behaviours, beyond what ethical and transformational leadership offered" and is based on extant social psychological and authenticity theories (p. 89). In addition, they say that AL at its core embodies the role of internalised moral perspective. They draw these theories from various research, including that of Deci and Ryan (2000), Eigel and Kuhnert (2005), and Kernis (2003). The four dimensions of AL outlined above make up the ALQ construct: see Table 1 for more details of each dimension. The ALQ comprises four questions for each dimension that make up a questionnaire with a total of 16 items (Neider \& Schriesheim, 2011; Walumbwa et al., 2008).

According to Neider and Schriesheim (2011), there are some concerns regarding the ALQ. Firstly, the full item scale is copyrighted and is not readily available; secondly and more importantly, they argue that the construct validity of the questionnaire is overly reliant on subjective judgments and contains other validation issues, including two correlation errors or socalled "garbage parameters". Due to the issues found with the validity of the ALQ, they revalidated the ALQ and named it the "Authentic Leadership Inventory (ALI)", which has two questions removed and now consists of a 14-item scale (Neider \& Schriesheim, 2011). However, both the ALQ and the ALI measure the construct developed by Walumbwa et al. (2008). The four constructs of AL are described below (see Table 1). The ALI measure was used for this research (see section 4.2.4). 
Table 1: AL construct dimensions description, adapted from Walumbwa et al. (2008).

\begin{tabular}{ll}
\hline AL dimension & Description \\
\hline Self-awareness & To be deeply aware of how one makes sense of the world around them. To \\
use this understanding to make sense of how one views oneself and how \\
this view changes over time. To have a deep understanding of oneself and \\
one's strengths and weaknesses, including an awareness of the impact of \\
oneself and one's dealings with others. \\
\begin{tabular}{ll} 
Relational & To present one's true and authentic self to others: in other words, to not be \\
Transparency & fake, but rather to be oneself. To be transparent and be the most honest \\
(ALR) & version of oneself. This enables others to trust, because, when one openly \\
& discloses information and expresses one's real thoughts and feelings with \\
& emotional intelligence, others are more likely to trust them. \\
\hline Balanced & To make decisions based on logic and sound evidence in an objective and \\
Processing (ALB) & rational manner while seeking other views to challenge one's deeply held \\
& position and viewpoint. \\
\hline Internalised & To self-regulate one's internal moral standards and values. To assess \\
Moral Perspective & one's internal moral standards against group, organisational and societal \\
pressures and to live by these standards every day.
\end{tabular} \\
\hline
\end{tabular}

\subsection{Work-related stress}

Stress is a person's response to a stressor: that is, an external event or condition that causes stress or a biological or chemical agent (Franks, 1994; Sato et al., 2006) that can have a psychological, physiological or behavioural result (O’Driscoll \& Cooper, 2001; Sulsky \& Smith, 2005). The relationship with a stressor and how humans or other organisms respond to stress is known as the "stress response", understanding of which originated from the work of H. Selye in the 1930s (Szabo et al., 2012). Although most stress is perceived as unfavourable, some stress can have positive features, such as personal growth and development: for example, professionals may experience stress after a promotion or a student during exam time (Franks, 1994). 
According to Leka, Cox, and Griffiths (2003), WRS occurs when people's work demands and pressures are not matched by their knowledge and abilities, to the point that they are unable to cope. Russell, Maître, Watson, and Fahey (2018) outlined job stressors or demands to include emotional demands (dealing with angry clients or colleagues), time pressure, bullying, physically demanding work, effort-reward imbalance and long working hours. As this research is only concerned with WRS, this issue is explored in more detail next. Four well-established theoretical approaches or job stress models that look at the causes and consequences of WRS are discussed below.

\subsubsection{Job Demands-Control Model (JDC)}

The JDC model was developed by Karasek (1979), and consists of two elements, i.e., “job demands" and "job control". Job demands are defined as psychological stressors related to excessive work allocation, unexpected tasks, or task conflict. However, Karasek explains that 'job demands' are not only concerned with job intensity but also relate to other aspects of work, such as personal conflict, specific career problems or fear of unemployment. Job control is defined as 'job decision latitude' and incorporates the authority to decide how one will do one's work and the opportunity to learn new skills or be creative in work (Karasek, 1979).

Ganster and Fusilier (1989) explain that people desire autonomy over how they perform their work, such as the order of task completion, how tasks are completed and flexibility in working hours. Moreover, people have an innate desire to have a level of personal control within the organisation where they work, which is defined as the belief that they have control over change (Greenberger \& Strasser, 1986). About ten years after its initial development, the JDC model was extended to include workplace social support from peers and supervisors. This was done to act as a buffer against the negative impact of job stress and the model became known as the "Job Demand-Control-Support (JDCS) model (Ganster \& Fusilier, 1989; Theorell \& Karasek, 
1990). According to Griffin and Clarke (2011), the relationship between high work demand, stressors and negative psychological well-being has been found in a multitude of research. The JDC model is categorised into four quadrants (see Figure 1).

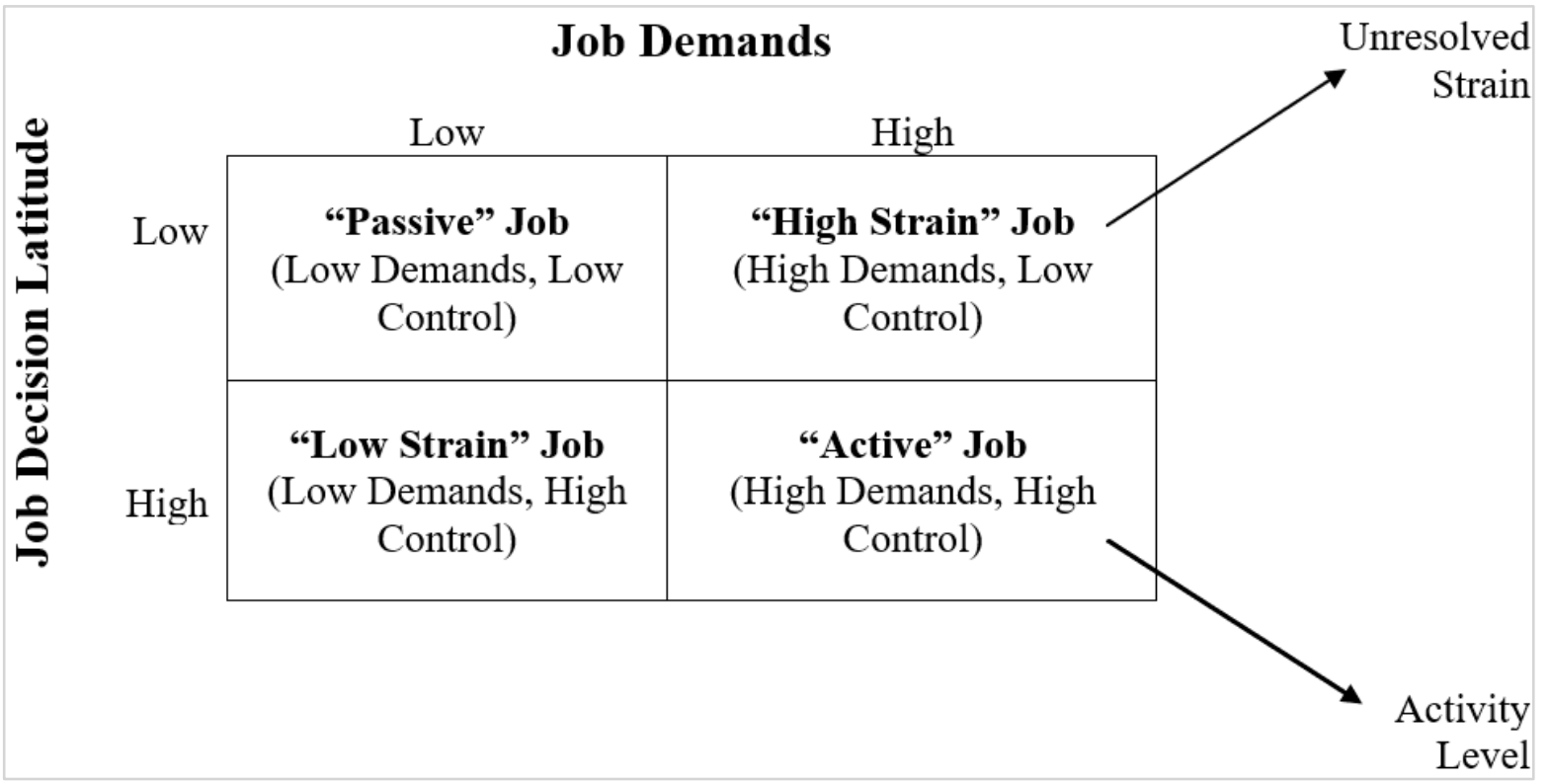

Figure 1: Job strain model. Adapted from Karasek (1979)

\subsubsection{Effort-Reward-Imbalance Model (ERI)}

Siegrist (1996) expanded the JDC model with his own model, which is concerned with the imbalance of effort expended by the employee, both intrinsic and extrinsic, and the reward received: for example, fear of job loss, job instability, lack of support, excessive workload, time pressures, frequent interruptions and rewards received, i.e. monetary compensation, status, power, control, and opportunity. Siegrist (1996) suggests that an imbalance in these areas can lead to stress, which in turn can lead to poor health, including increased cholesterol and hypertension, both contributing factors to coronary heart disease. However, a recent reexamination of the ERI-Model found that the impact of working conditions, such as overcommitment, on physical health was quite small in comparison to its effects on mental health (Kunz, 2019). 


\subsubsection{Job demands-resources (JD-R) model}

Bakker and Demerouti (2007, p. 311) describe both the ERI and the JDC model as a "laundry-list approach to predict employee well-being" and argue that the control element of the JDC model only acts as a partial buffer for the impact of job demands in regard to employee well-being. While examining the strengths and weaknesses of the JDC and ERI models, Bakker and Demeroute elaborate on the models, which they argue do not adequately consider the complexities of working organisations due to the lack of variables considered. In addition, they observe that these models only consider adverse outcomes such as stress, burnout, and ill-health. Therefore, these models may not be suitable for every job type, depending on the characteristics, nature, and risk factors of the profession.

The JD-R model developed by Demerouti, Bakker, Nachreiner and Schaufeli (Demerouti et al., 2001) has two main components: firstly “job demands”, which encompass physical workload, time pressure, recipient contact, the physical environment and shift work; and secondly “job resources" such as feedback, rewards, job control, participation, job security and supervisor support. Demerouti et al. $(2007 ; 2001)$ found that excessive job demands can lead to exhaustion and that insufficient job resources can lead to disengagement from work. Moreover, where employees became sufficiently disengaged from work and were physically and/or emotionally exhausted, they were more likely to suffer from burnout syndrome (Bakker \& Demerouti, 2007).

The JD-R model was developed on the basis that every occupation has specific risks associated with job stress; however, irrespective of the profession, all professions are covered by their definition of job demands and job resources: thereby, the model offers a suitable occupational stress model for all occupations (Bakker \& Demerouti, 2007). They outline that job demands are any "physical, psychological, social or organisational aspects of the job that require sustained physical and psychological (cognitive and emotional) effort or skills and therefore is 
associated with certain physiological and/or psychological costs" (Bakker \& Demerouti, 2007), whereas job resources help with reducing job demands, aid in achieving goals and stimulate personal development and learning. In addition, Bakker and Demeroute (2007) also point out that job resources come from different levels within the organisation: for example, the task level (task significance/variety, performance feedback and autonomy), the interpersonal and social relations level (support from colleagues/supervisor and team climate) and the organisation level (remuneration, career advancement, participation in decision making and job security). In addition, the model also looks at two underlying psychological processes, i.e. strain and motivation, indicating that when job demands are high, strain increases, which has adverse organisational outcomes. In turn, when job resources are high, motivation increases, which has positive organisational outcomes (see Figure 2).

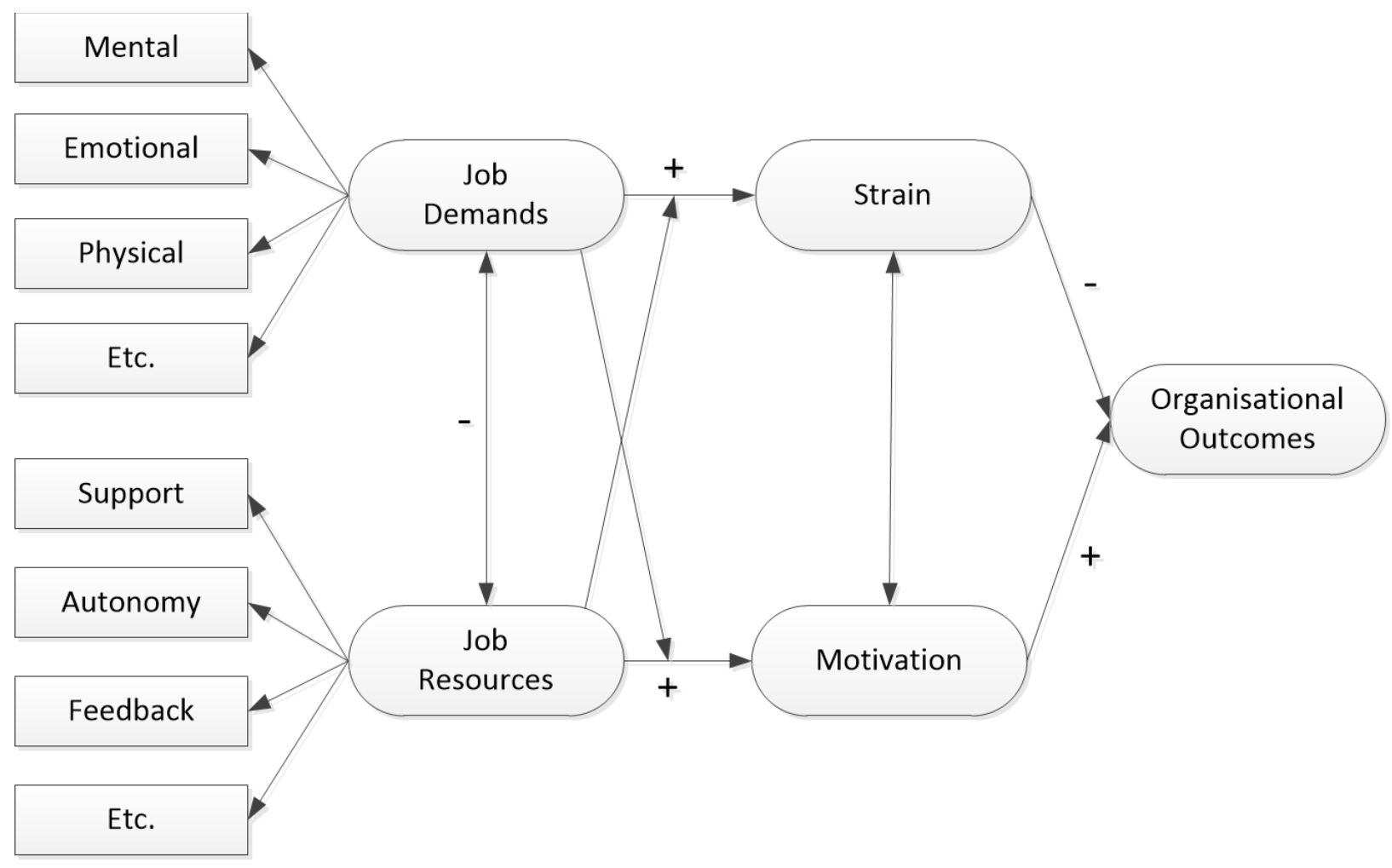

Figure 2: The Job Demands - Resources Model. Adapted from Bakker and Demerouti (2007) 


\subsubsection{Organisational Justice Model (OJ)}

Colquitt, Greenberg, and Zapata-Phelan (2005) organised various organisational justice dimensions, which have been defined and developed by numerous theorist during the $21^{\text {st }}$ century, into what they refer to as the integrative wave. There are three distinctive waves in this model that make up the collective integrative wave, as outlined below.

The distributive justice wave: Deriving from equity theory, distributive justice is concerned with the equitable allocation of resources, such as equitable pay for hours worked across group members (pay in proportion to contribution and relative to that of others), recognition for work done (not taking credit for someone else's work or giving credit where credit is due) and fair distribution of shifts/hours (Barsky \& Kaplan, 2007; Colquitt et al., 2005; Greenberg, 2004). Greenberg (2004) suggests that it is essential to consider the complex nature of how people process unfairness. Whether unfairness is perceived or real, it can cause a considerable amount of stress in followers, and although executives are limited in what they can do to improve employee health, they can do much to ensure they do not trigger the perception of inequality among employees (Greenberg, 2004). Greenberg refers to the work of psychologist R. S. Lazarus, specifically the "Cognitive Appraisal Model", and explains that people will process more than one variable in their evaluation of fair treatment. Take, for example, someone who is comparably qualified yet is paid less than another. If the payment has been calculated relatively and transparently according to policy and is therefore justified, under such circumstances, less pay may not necessarily be perceived as unfair (Greenberg, 2004). This ties in with the next justice wave - procedural justice - and can lead one to the conclusion that if leaders are open and transparent in their decision-making regarding the distribution of resources, it can mitigate against employees' perceived unfairness. 
The procedural justice wave: The idea of procedural justice followed that of distributive justice in the early 1980s and is about the fair and consistent implementation and execution of processes, procedures and policies, especially those that are used to resolve conflict or disputes (Colquitt et al., 2005). Greenberg (2004) lists the following sources of procedural justice in organisations: "voice in decision making, opportunity to correct errors of judgement, equal and unbiased application of rules and decisions made based on accurate information” (p. 355). Moreover, the distribution and procedural justice waves are linked and interact with each other: that is, fair procedural justice can buffer the stress caused by the unfair distribution of resources. In contrast, unfair procedural justice can exacerbate the problem of unfair distribution of resources and lead to high levels of emotional exhaustion, depression and anxiety (Greenberg, 2004).

The interactional justice wave: The essence of interactional justice is concerned with the interpersonal treatment and communication (e.g., dignity and respect) that a follower receives from their supervisor or the organisation (Colquitt et al., 2005; Greenberg, 2004). Colquitt et al. (2005, pp. 29-30) outlined four antecedents of "fair interpersonal treatment", based on the unpublished research of R. J. Bies in 1985, namely: truthfulness (being open, honest, transparent and candid), justification (provide an adequate explanation for why a decision is made), respect (treat people with respect, politeness and dignity) and propriety (refrain from asking questions regarding sex, race, age or religion). Indeed, Judge and Colquitt (2004), in their study of 174 faculty members across 23 American universities, found that where both procedural and interactional justice were lacking, workers experienced higher levels of stress. They also found that the stress increased where staff had more conflict between family and work-life.

The integrative wave. The integrative wave proposed by Colquitt, Greenberg, and ZapataPhelan (2005) is the collective model of organisational justice and is an integration of the three 
waves of organisational justice outlined above. Each wave is the work of numerous scholars, developed over half a century of research, demonstrating the complexities of perceptions of fairness (Judge \& Colquitt, 2004). They proposed that this combined evolution means that these theories work best in conjunction with each other.

The complexities of the perception and feeling of unfairness, however, do not end here. Barsky and Kaplan's (2007) research explores an important aspect of positive and negative state (the experience of positive or negative feelings and emotions) and trait (the tendency to experience those feelings and emotions consistently across time and situations). The authors hypothesised that positive 'state and trait affect' will be positively related to reports of the three waves of organisational justice and that negative 'state and trait affect' will be negatively related to reports of the three waves of organisational justice. In their meta-analysis, Barsky and Kaplan (2007) found that both their hypotheses significantly correlated with all three types of justice perceptions. These findings add further evidence to the complexities of perceived employee just and unjust feelings of fairness and organisational justice.

In conclusion, WRS, how and why it occurs and how individuals perceive it is a complex issue which involves numerous variables and constructs. As the models above explain, WRS can come from a variety of situations, such as excessive workload, not being given enough autonomy over how one works, lack of opportunity, lack of support, incivility or inequitable treatment, to mention just a few. WRS is an international problem that negatively affects the employer, employee and service users or customers (Reckinger et al., 2005). Therefore, it is in the interest of all parties to eliminate it from the workplace.

\subsection{Job Motivation}

Motivation is a complex concept due to the substantial variety of definitions and measurements presented by evidence (Howard et al., 2016). Moreover, Kleinginna and Kleinginna 
(1981) collected approximately 98 defining statements about motivation. The difficulty in defining motivation is multifaceted because it comprises numerous aspects (Pinder, 2008). Nevertheless, in his book "Work Motivation in Organisational Behaviour", Pinder (2008) offers the following definition of work motivation.

Work motivation is a set of energetic forces that originate both within as well as beyond an individual's being, to initiate work-related behaviour, and to determine its form, direction, intensity, and duration. (Pinder, 2008, p. 11)

A common theme in motivation theory is the differentiation between intrinsic motivation (motivation driven by the joy or interest of the task) and extrinsic motivation (performing the task only for the outcome it yields and not because of the desire to do it) (Deci \& Ryan, 2000; Ryan \& Koestner, 1999; Wilson \& Lassiter, 1982). One of the earliest and still relevant theories of work motivation is Maslow's 'Hierarchy of Needs' (1970), which proposes that humans' basic physiological needs must first be satisfied before self-actualisation can be realised. Maslow developed a five-tier model of human needs that acknowledges that humans' low-level needs, such as food and warmth, must be met before higher levels can be achieved, with the highest level being self-actualisation (achieving one's full potential). Since then, there have been several notable work motivation theories, for example:

- $\quad$ McClellan's needs achievement theory (see Pardee, 1990).

- $\quad$ McGregor's theory "X" and theory "Y" (see McGregor 1960).

- $\quad$ Alderfer's existence, relatedness and growth (ERG) theory (see Yang, Hwang, and Chen 2011).

- Hertzberg's Two-Factor Hygiene theory (see Pardee, 1990).

- $\quad$ Goal-setting theory (see Lunenburg, 2011). 
This list is not exhaustive; each of the theories has relevance. However, it is beyond the scope of this thesis to discuss all these theories. However, self-determination theory can and has been directly used as a theory of work motivation in organisations (Deci, Olafsen and Ryan, 2017). Furthermore, Deci, Olafsen and Ryan (2017) explain that there are links between motivation, performance and wellness in organisations. They also explain that SDT differentiates between the various types of motivation: i.e. autonomous and controlled motivation. Therefore, SDT is further explored below.

\subsubsection{Self-determination Theory}

Self-determination theory focuses on the continuum from intrinsic motivation to amotivation of various types of behavioural regulations realised by a person (Deci \& Ryan, 1985). In addition, self-determination requires three innate psychological needs (autonomy, competence and relatedness) that must be satisfied in order to become self-motivated and foster mental health and well-being (Deci \& Ryan, 1985, 2000).

Deci and Ryan (2000) refer to 'autonomy' or the individual's desire of a free will to act; they refer to 'competence' as having the ability and feeling to adequately perform or interact; and lastly, they define 'relatedness' as being able to relate or feel close and connected to the task or interaction. Within the self-determination continuum, extrinsic motivation is described as ranging in levels of regulation, starting with integrated regulation (that is, to be motivated by goals and values) and ending with external regulation (that is, to be motivated purely by reward or punishment). See Figure 3 for the complete self-determination continuum model. 


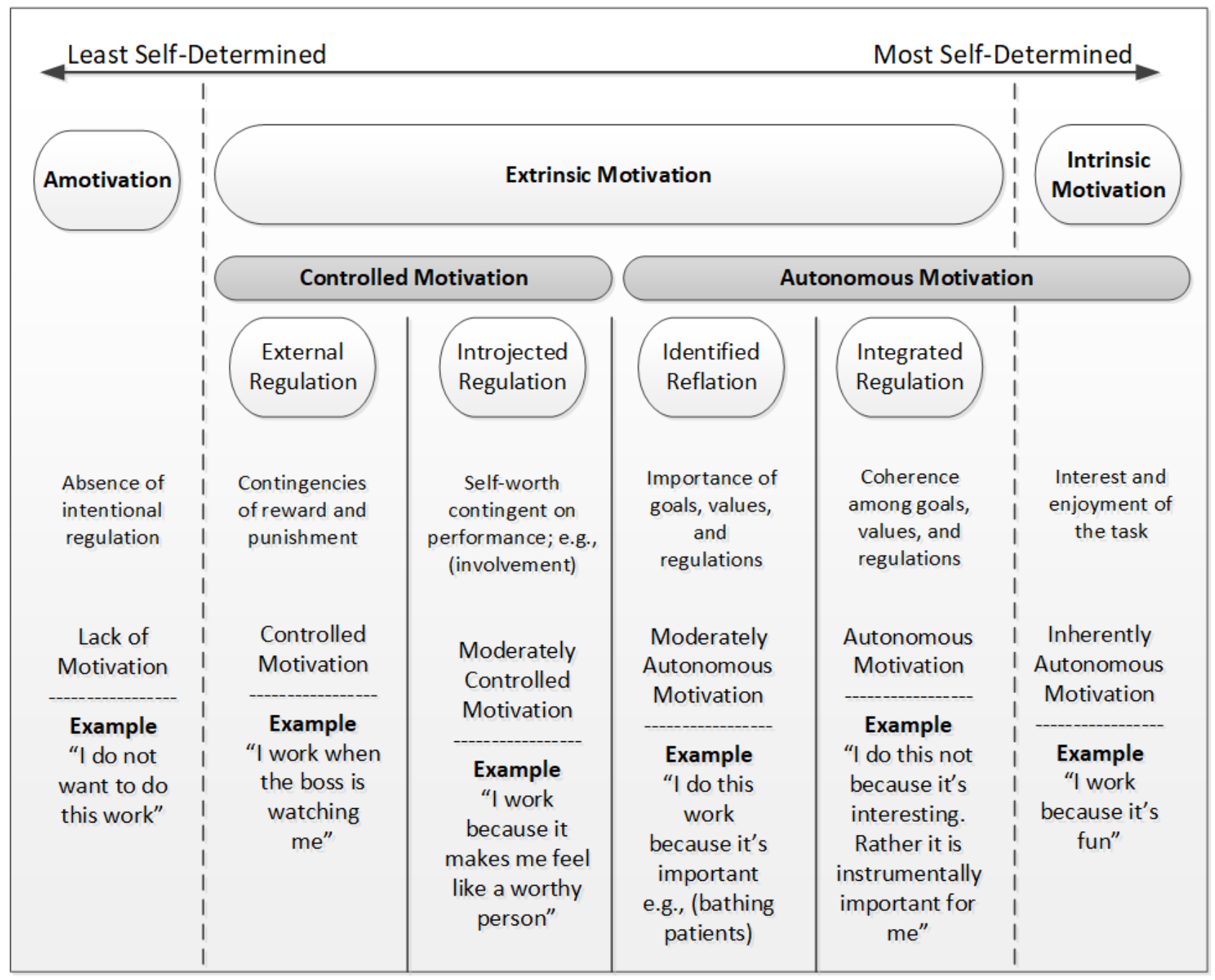

Figure 3: The self-determination continuum of work motivation (Gagné \& Deci, 2005)

As depicted in the diagram above (see Figure 3), SDT can be examined from various levels of motivation, from amotivation to intrinsic motivation, or from autonomous to controlled motivation. This lends itself to examining the intricacies of what motivates employees in greater detail and helps to differentiate what motivates people.

\subsection{Intellectual Disability Sector in Ireland}

In Ireland, the Health Service Executive (HSE) gives funding to organisations that provide services to people with an intellectual disability (HSE, 2018a). These organisations largely fall into two categories, namely section 38 or section 39 organisations. Section 38 organisations are 
not-for-profit, while section 39 is for-profit (HSE, 2017; OGCIO, 2014). However, both receive HSE funding. Moreover, section 38 employees "are classified as public servants [and] are subject to the pay-scales approved for public servants" (OGCIO, 2014). Intellectual disability services generally provide a variety of services, including day-services, individualised support, community support, residential care, and respite. Individualised support is about providing tailored services to help enable people to live a fully included life in the community (FedVol, 2013).

\subsection{Summary}

The importance of a positive leadership style such as AL, reducing stress and ensuring staff stay motivated in the workplace was explored above. Prior to conducting the mixed-method empirical research, i.e. study one (online survey) and study two (interviews), a systematic literature review was conducted. The SLR was conducted as a separate and standalone piece of research; its methodology is summarised below, and its findings are then reported in full. 


\section{Systematic Literature Review}

The primary focus of this SLR is to provide evidence-based information to executive-level leaders and policymakers on the research topic, which will aid their decision-making and actions to positively impact organisational outcomes. The intention is that the SLR and the research that follows will provide evidence that can be used to ultimately improve the lives of people who use intellectual disability services.

The foundations of SLRs were derived from the medical sciences and they first emerged in 1975, named initially 'meta-analysis' (EPPI-Centre, n.d.). Cochrane urged health practitioners to consider evidence-based practice in medicine in 1972, from which SLRs emerged (Rosenberg et al., 1996). SLRs are more rigorous than traditional literature reviews because they reduce subjectivity and bias and are more representative of the study topic (Petticrew \& Roberts, 2006).

As explained by Petticrew and Roberts (2006), not all studies are methodologically sound to the point that we can be entirely confident of the findings and their claims to be the absolute truth. Therefore, a systematic review of a large body of studies allows the researcher to make sense of the information on a topic and to give a more rounded overview of previous research pertaining to a research question.

Although initially SLRs were used in the medical sciences, in more recent years, many other fields have been producing SLRs, including education, social care and organisational studies (Denyer \& Tranfield, 2009). Four core principles that are typically applied to SLRs are that they should be replicable, exclusive, aggregative and algorithmic (Denyer \& Tranfield, 2009). A revised set of principles, more suitable for the field of management and organisational studies, is also provided by Denyer and Transfield (2009) and outlined in the appendix (see Table 3 in Appendix A).

Leading on from the principles to which an SLR should adhere, Denyer and Tranfield 
(2009) outlined five steps that are important in order to complete an SLR: a) question

formulation, b) the locating of studies c) study selection and evaluation, d) analysis and synthesis, and lastly e) reporting and use of the results.

While adhering to the principles, the methodology used to produce this SLR will apply these five steps. In addition, reporting the SLR will include a flow diagram as per the reporting guidelines set out by PRISMA (Preferred Reporting Items for Systematic Reviews and MetaAnalyses) (Moher et al., 2009): see Figure 5.

\subsection{Scoping, Question Formulation and Search}

To conceptualise and define the scope of the SLR, a Venn diagram was created (see Figure 4). To aid in the formulation of a research question for the SLR, a CIMO (context, intervention, mechanisms and outcomes) table was created (see Denyer et al., 2008). The CIMO format is an adaptation of the well-known PICO (population, intervention, comparison and outcomes) format used to formulate clinical questions (Pawson, 2006). While developing the CIMO, the researcher kept a focus on the organisation with which this research is concerned, namely an organisation that provides services to adults with intellectual disabilities (see Table 4 in Appendix A). 


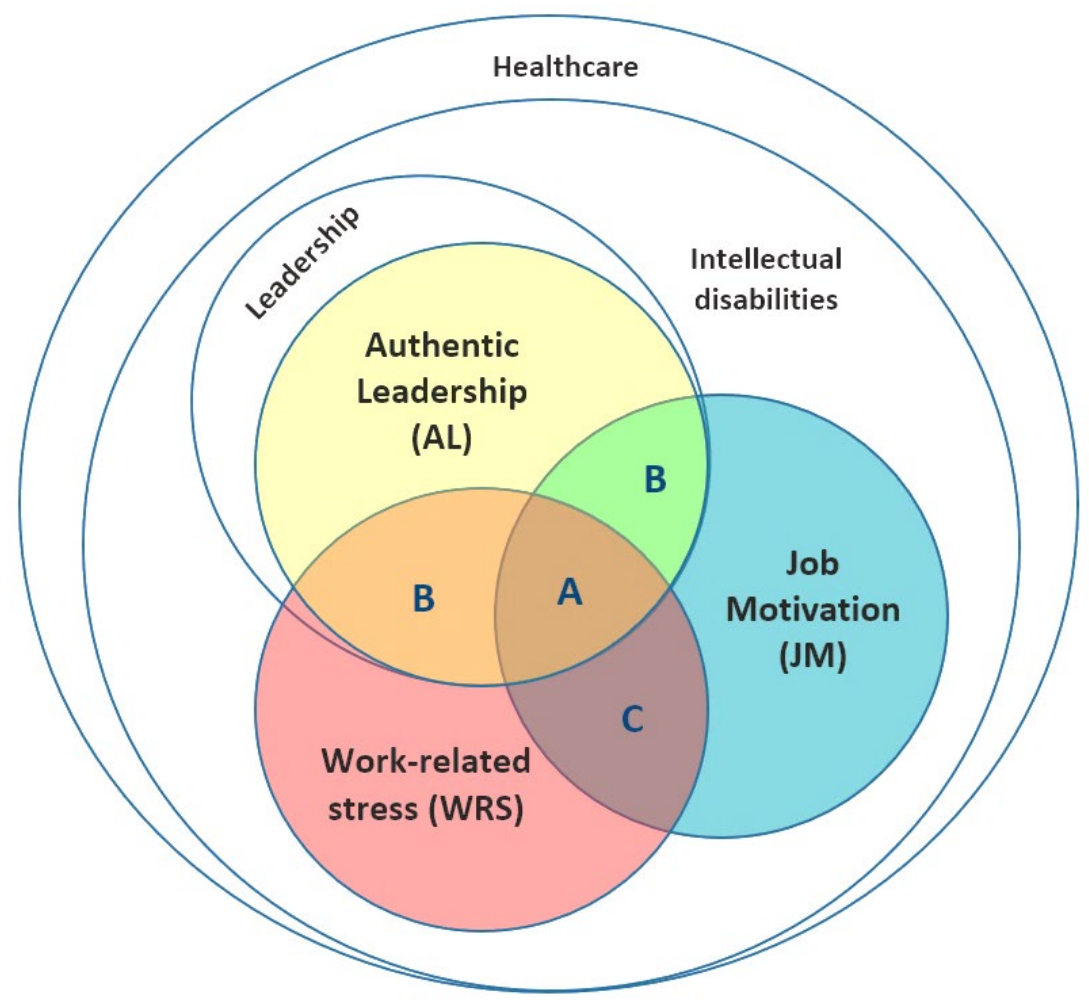

Figure 4: Search Strategy Venn diagram

A search result rated A as per the Venn diagram is classed as a study that incorporates all three variables - AL, WRS and JM. In contrast, a study about either 'AL and WRS' or 'AL and JM' would be a good result, but less favourable than an A-rated find, and would therefore be classed as B-rated. A study that only explores WRS and JM is still relevant but not as important as an A- or B-rated result and would therefore be classed as C-Rated.

On the periphery, studies in the context of the intellectual disability sector are more favourable than those in other health care sectors, while studies in the health care sector are more favourable than studies in other industries. Thereby, this Venn diagram visually highlighted the most important results and aided the researcher in creating the search criteria.

Because the research question has a crossover of disciplines from leadership, organisational, social and health-related fields, multidisciplinary databases were used to search for material (see Appendix A, Table 7 for a full list of academic journal databases searched). 
Due to the complexity of the Boolean search terms (see Appendix A, Table 6), only databases that had the functionality to facilitate this complexity were searched. There are several resources where an evidence-based practitioner might look for sources. Barends, Rousseau and Briner (2014) suggest that the four primary sources are: scientific literature, organisational data, professional practitioners and stakeholders. Denyer and Transfield (2009) expand on this to explain that material can come from many sources, including journals, books, conference papers, seminars, workshops and more. To ensure inclusion of as much variety of knowledge as possible, the database filters are not overly restrictive (see Appendix A, Table 9 for filters applied to each database). However, only peer-reviewed material was included in the SLR. The reason for this is that peer-reviewed articles must meet the required standard of the journal before being accepted. Peer-reviewed articles will be checked to ensure that the research question is meaningful and that they draw accurate conclusions (Kelly et al., 2014).

A Boolean search (see Appendix A, Table 6) was created based on the main concepts and search terms identified through the CIMO exercise (see Table 4), the Venn diagram (see Figure 4) and the keywords identified through the scoping exercise (see Appendix A, Table 5). The searches were undertaken on $16^{\text {th }}$ June 2019 (see Appendix A, Table 6 for a full list of search terms and Appendix A, Table 8 for a count of all search results, where a single search result equates to one reference to a study, article or book).

In total, eight out of the $\mathrm{N}=27$ search criteria, searched across each database (see Appendix A, Table 8) encompassing a total of $\mathrm{N}=5,673$ search results were exported from the databases into the reference management software Zotero. After removal of all duplicates, a total of $\mathrm{N}=1,498$ unique references remained. These were then exported to a Microsoft Excel spreadsheet for screening and selection. 
To be included in the SLR, a paper had to meet one of the following criteria: a) address the relationship between AL and followers' WRS, b) address the relationship between AL and followers' JM, or c) address the relationship between WRS and JM.

All included studies are listed in the data extraction table, which briefly summarises each paper (see Appendix A, Table 10). The search, exclusion and inclusion process are outlined in the PRISMA flow chart below (see Figure 5).

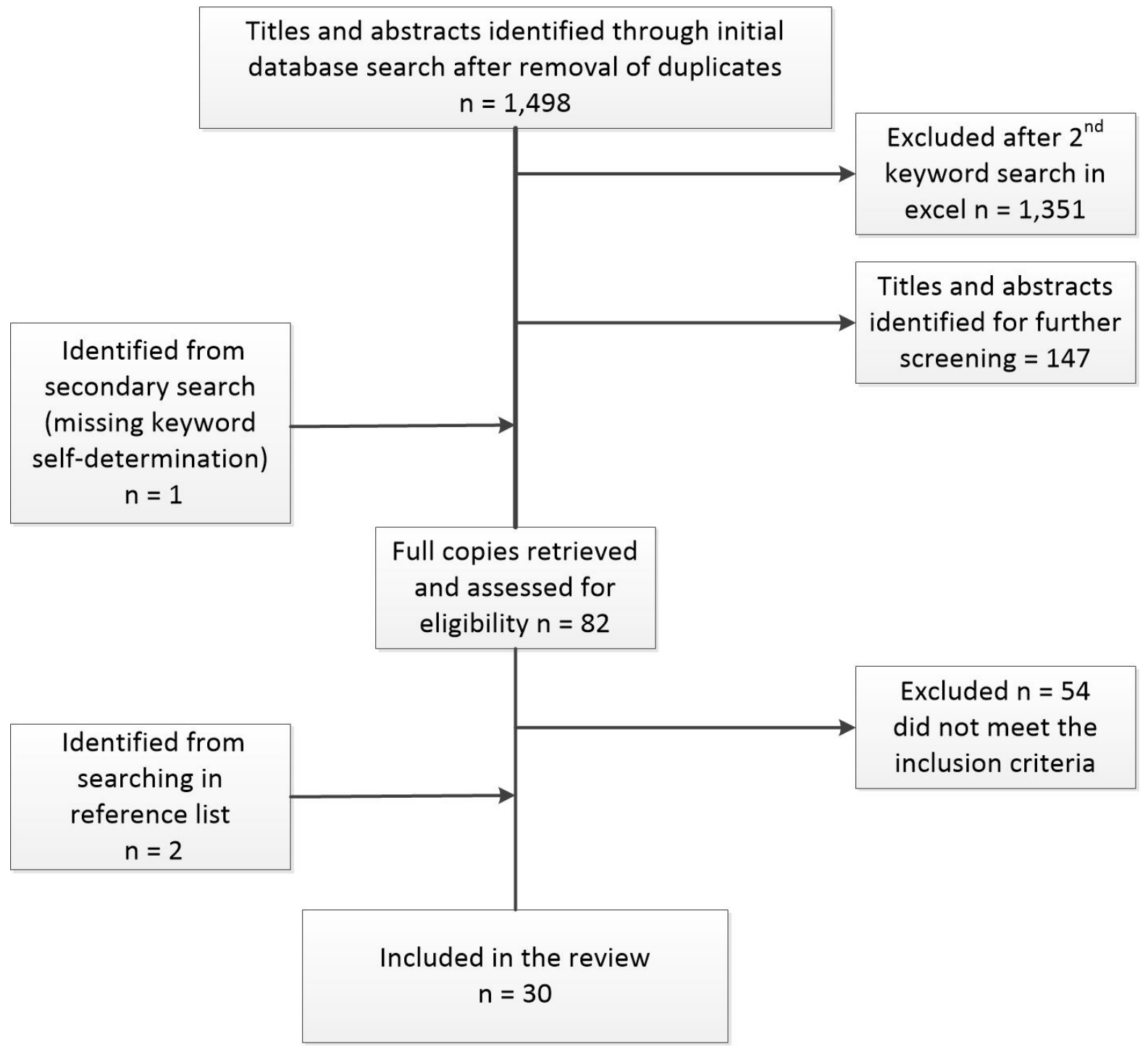

Figure 5: PRISMA flow diagram of database search and results. 


\subsection{Findings and Discussion}

\subsubsection{Relationship between Authentic Leadership and Job Motivation}

Studies that specifically examined the relationship between AL and JM were few. No studies that looked at this relationship in the intellectual disability sector were found during the SLR. However, there were studies that examined AL and Psychological Empowerment (PsyEmp) as a mediator between $\mathrm{AL}$ and organisational outcomes, including proactive behaviour, work engagement, employee creativity, organisational citizenship behaviour (OCB) and withdrawal behaviours (WB) in various sectors.

Spreitzer developed a measurement tool of PsyEmp based on the work of Thomas and Velthouse (1990) who defined PsyEmp as an encompassment of four cognitive elements (meaning, self-determination, competence, and impact) that together make up intrinsic motivation (Seibert et al., 2011). Meaning refers to the value and purpose one attaches to work-related tasks and matters (Yukl \& Becker, 2006). Self-determination refers to doing a task by choice because one wants to, rather than feeling obliged to or having to, and can be described as the essence of intrinsic motivation (Yukl \& Becker, 2006). Competence is the level of skill and self-efficacy one has to accomplish a task, while lastly, Impact is the perception of how much difference one's efforts will make (Yukl \& Becker, 2006). Therefore, based on these definitions, PsyEmp is akin to intrinsic motivation. However, according to Lee and Koh (2001), PsyEmp is a somewhat ambiguous, unique concept and is not the same as motivation, self-determination or other nouns.

They argue that being empowered to do something does not mean one is necessarily motivated to do something. Nevertheless, for the purpose of this SLR and given the shortage of studies that look at AL and motivation, PsyEmp is considered to be sufficiently closely related to intrinsic motivation to be included in the SLR for the purpose of determining whether there is a 
relationship between AL and JM.

Studies conducted in the United Arab Emirates (oil industry), Korea (for-profit organizations) and Israel (teaching) found that increased demonstration of AL had a positive impact on employees' PsyEmp, which in turn increased their OCB (AL Sahi AL Zaabi et al., 2016; Joo \& Jo, 2015; Shapira-Lishchinsky \& Tsemach, 2014). A time-lagged study of $N=275$ follower-supervisor dyads conducted across two private sector organisations in China explored the relationship between AL and proactive behaviour while testing whether PsyEmp is a mediator between the two (Zhang et al., 2018). Their results found that the direct effect of AL on proactive behaviour was not significant; however, PsyEmp, acting in a mediating role, did have a positive effect on proactive behaviour. Moreover, a study examining each of the four PsyEmp elements found a strong relationship between AL and self-determination, followed closely by impact, while meaning and competence were also positively related, albeit less strongly (Marič et al., 2017). In addition, PsyEmp was found to mediate the impact of AL on creativity in Pakistani nongovernment organisations (Mubarak \& Noor, 2018). Although the above studies did not specifically examine JM, the evidence does suggest that AL may have a direct and positive impact on improving JM.

Studies conducted in Pakistan - one in academia and the other in the private sector -looked at $\mathrm{AL}$ and the mediating effect of intrinsic motivation on creativity and work engagement, respectively. Both yielded positive results and found AL to increase employee motivation, which in turn improved creativity and work engagement (Ahmad et al., 2015; Hidayat, 2016). A further large-scale study conducted on Chinese follower-supervisor dyads examined the moderating effect of intrinsic motivation between authentic and authoritarian leadership (Shu, 2015). The results showed that when employees were highly motivated, work engagement increased, irrespective of leadership style. However, when employee motivation was low, AL's effectiveness 
on work engagement was not significant. Moreover, authoritarian leadership decreased work engagement. This shows that although AL only has a minimum impact on people with low motivation, it is a more effective leadership style than authoritarian leadership.

Guerrero, Lapalme, and Séguin (2015) hypothesised that a safety climate would mediate the relationship between the chair's AL style and non-executives' pro-organisational motivation. Their results revealed that a participative safety climate partially mediates the relationship between AL and pro-organisational motivation and accounts for $56 \%$ of the variance.

Finally, the last study discussed in this section looks at the interactions of authentic leaders and authentic followers (Leroy et al., 2015). The study looks explicitly through the lens of SDT to determine the mediating role of employees' individual needs satisfaction between authentic followership and work role performance, with AL acting as a moderator between authentic followership and basic needs satisfaction. This study found a positive relationship between AL and employees' basic needs satisfaction. In addition, basic needs satisfaction mediates the relationship between authentic followership and followers' work performance, while AL moderates this relationship. Their findings suggest that the combined effect of authentic leaders and authentic followers will enhance followers' basic needs satisfaction, and thereby, motivation will increase.

In conclusion, the above studies examined AL and motivation, specifically intrinsic motivation, through various constructs, including PsyEmp and SDT. The studies looked at these constructs in various ways, including motivation as a mediator and moderator of a wide range of organisational outcomes. All the outcomes investigated promoted positive organisational outcomes, such as increased productivity, motivation, OCB and work-engagement, to some degree. The findings above support hypothesis $\mathrm{H} 1 \mathrm{~b}$ : that there is a relationship between AL and JM, mainly intrinsic motivation. Nevertheless, the literature is scant, and therefore the research 
proposed by this study will add valuable data in the context of the intellectual disability sector, specifically in Ireland.

\subsubsection{Relationship between Authentic Leadership and Work-related stress}

Few studies investigated a direct relationship between AL and WRS, with many studies looking through the lens of other constructs (e.g., burnout, well-being, bullying and turnover). As burnout was a central concept, it is briefly introduced below.

Maslach (2003) described burnout as a syndrome made up of three elements that can occur to people in the workplace: emotional exhaustion (a stress response), depersonalisation or cynicism (negativity toward colleges and/or the job) and reduced personal accomplishment or inefficacy. Work-related stress and its causes, such as role ambiguity and conflict, are antecedents of burnout (Gil-monte et al., 1993; Lee \& Ashforth, 1990). Leiter and Maslach (2003a) explain that burnout is an accumulation of occupational stressors. Although the initial burnout scale (Maslach \& Jackson, 1981) was aimed at the human services and educational occupations, it was later updated to cover all occupations (Leiter \& Maslach, 2003a). The new burnout inventory (Areas of Work-life Scale) included six aspects of work (i.e., workload, control, reward, community, fairness and values) and was validated through a longitudinal study, which found strong evidence for the relationship to each of the original three factors: exhaustion, cynicism and efficacy. The results indicate that burnout is an important and relevant concept in relation to WRS. The results of studies, including those that looked at burnout, are discussed below.

Five of the nine studies that looked at the relationship between burnout and AL were conducted in the nursing sector (Boamah et al., 2017; Laschinger et al., 2013; Laschinger \& Fida, 2014a, 2014b; Spence Laschinger et al., 2019). More specifically, the studies examined various organisational and personal outcomes (e.g., turnover, health outcomes such as mental health and 
post-traumatic stress disorder (PTSD), work satisfaction, structural empowerment and quality of care received by patients). Laschinger and Fida (2014b), for example, found an association between workplace bullying and burnout, which in turn increased staff turnover. In a later study, Laschinger et al. (2019) found evidence that burnout increased the risk of PTSD. However, they also found that AL positively promoted healthy working conditions and acted as a buffer against adverse health outcomes. Laschinger et al. (2013) looked at AL with the mediating effect of structural empowerment on two of the dimensions of burnout (emotional exhaustion and cynicism). According to Kanter (2008), structural empowerment is organisational facilitation to empower employees with support, information, resources and opportunities to learn and develop. This study found support for the validity of structural empowerment and AL theory. Its findings indicated that AL could help prevent emotional exhaustion and cynicism in the workplace. Another study examined whether burnout mediated the relationship between AL and mental health (Laschinger \& Fida, 2014a). The results showed that AL is an important element in creating a positive working environment which helps to prevent burnout and has a positive impact on employees' mental health. Finally, Boamah, Read and Laschinger (2017) looked at an important outcome in addition to personal or organisation outcomes: that of quality of care received by patients. Their time-lagged study first looked at the direct link between AL and structural empowerment, followed by the mediating effects of short-staffing and work-life interference between structural empowerment and burnout. In the second phase, the direct impact of burnout on job satisfaction and nurse-assessed quality of care was examined. In addition, they also examined the moderating effect of short-staffing on work-life interference and job satisfaction on nurse-assessed quality of care (see Figure 6) for an illustration of this model. The study found a strong positive relationship between AL and structural empowerment. Structural empowerment was negatively related to short-staffing and work-life interference, which impacted 
staff burnout, which in turn was negatively associated with job satisfaction and nurse-assessed quality of care.

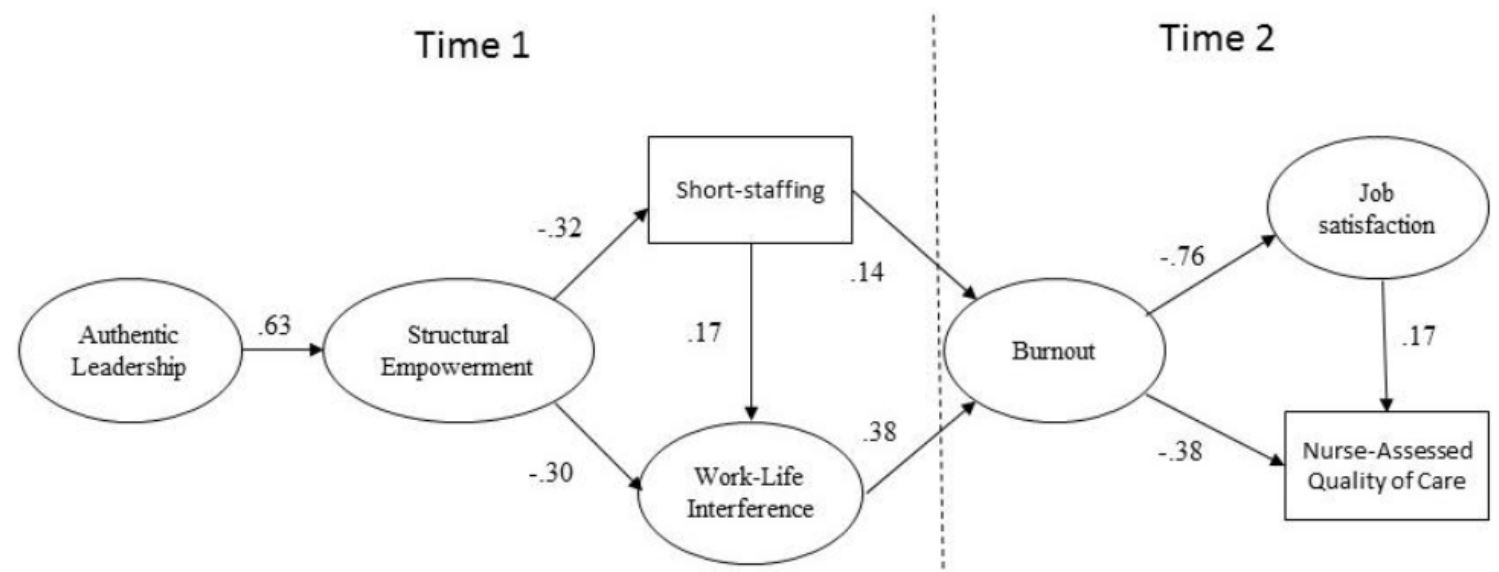

Figure 6: Factors influencing new graduate nurse burnout development, job satisfaction, and patient care quality: A time-lagged study. The resulting model (Boamah et al., 2017)

An additional study investigated burnout in Canadian nurses; however, unlike the other studies discussed above, this study looked at burnout using the six areas of the work-life survey and the Maslach Burnout Inventory-general survey (Laschinger et al., 2015). The six domains that make up 'areas of work-life' (a construct of job stress and burnout) are: workload, control, reward, community, fairness, and values (Leiter \& Maslach, 2003b). Specifically, this study examined the links between AL and burnout through areas of work-life, occupational coping selfefficacy (OSCE) and the subsequent impact on mental health (see Figure 7).

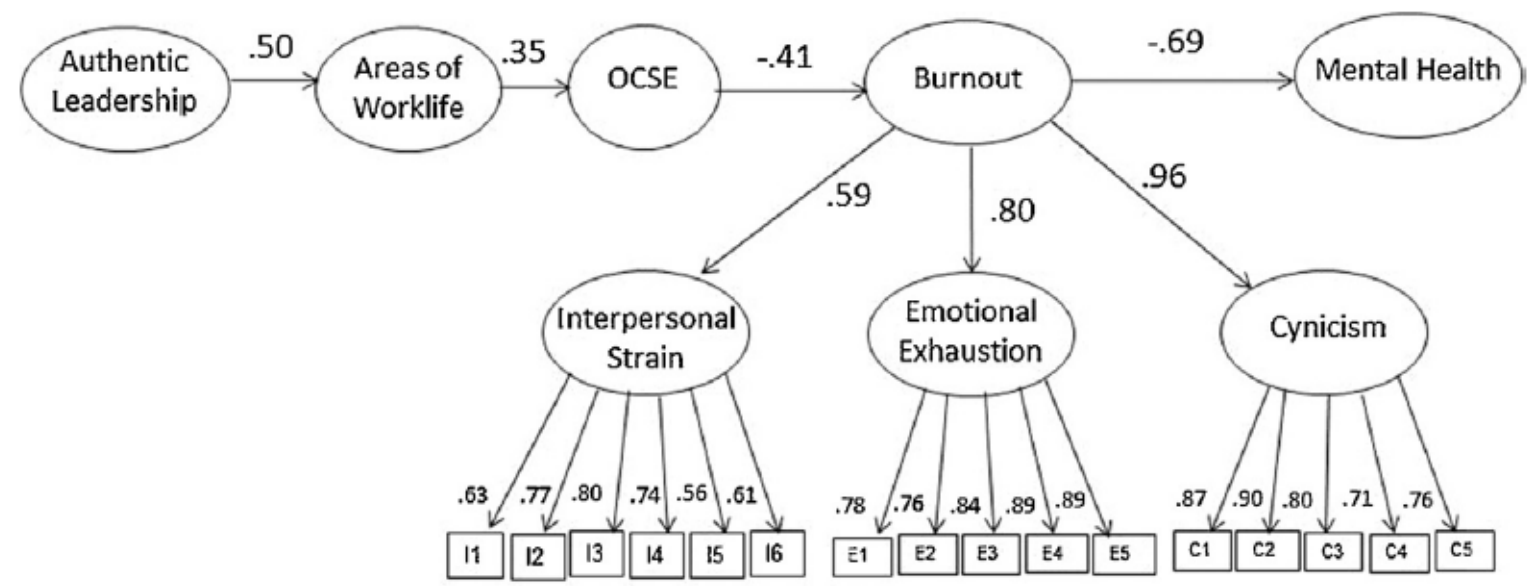

Figure 7: The effects of authentic leadership, six areas of work-life, and occupational coping self-efficacy on new graduate nurses' burnout and mental health: A cross-sectional study. The resulting model (Laschinger et al., 2015) 
The model shows that AL has a positive impact on the six areas of work-life, which in turn impacted OSCE negatively, while OSCE has a negative impact on burnout. Subsequently, burnout showed to have a negative impact on nurses' mental health. This study provides further evidence that AL has a positive impact on nurses' and organisational outcomes.

Another mediation study on Canadian nurses, conducted by Spence Laschinger, Wong and Grau (2012), hypothesised that workplace bullying mediates the relationships between AL and emotional exhaustion (a dimension of burnout), and between AL and job satisfaction, which in turn impacts turnover intentions. The study found support for each element of the hypotheses, and also found a direct link between AL and job satisfaction, as illustrated in the model below (see Figure 8). 


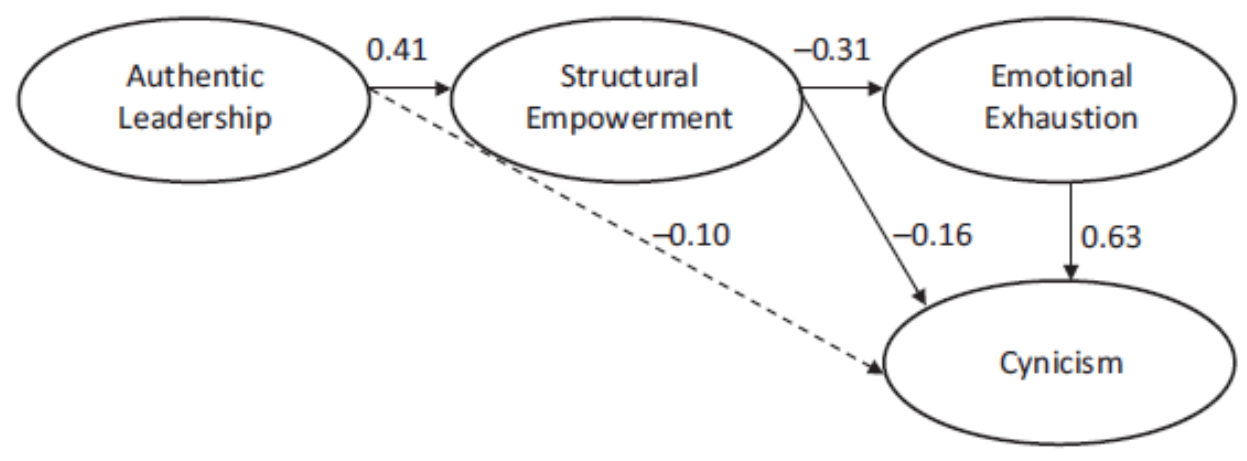

Final model: experienced nurses. The dotted line represents a path added to final model.

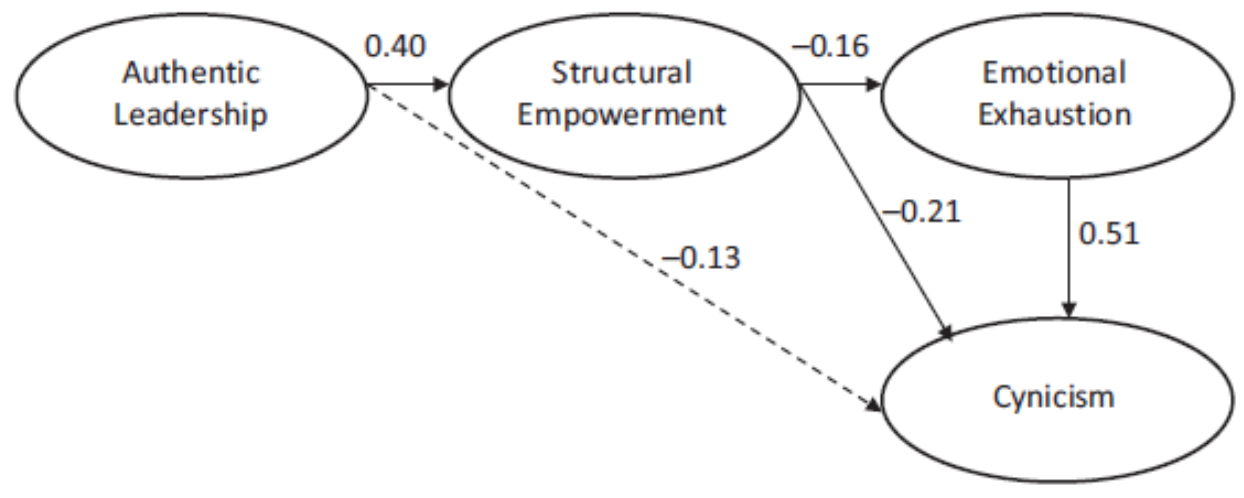

Final model: new graduate nurses. The dotted line represents a path added to final model.

Figure 8: The influence of authentic leadership on newly graduated nurses' experiences of workplace bullying, burnout and retention outcomes: A cross-sectional study. The resulting model (Laschinger et al., 2012)

Studies in Pakistan by Adil and Kamal $(2018,2019)$ conducted a mediation analysis in relation to AL and burnout and various other constructs, including job-related affective wellbeing, PsyCap, promotive psychological ownership and preventative and psychological ownership. These studies found AL to be an important leadership style in helping to prevent burnout. 
Jeong, Lee and Kim (2017) conducted a mediation study in South Korea on travel agent tour operators to investigate supervisor and organisation trust as a mediator of AL and burnout. The result of this study supported their hypothesis that the four dimensions of AL would have a positive impact on supervisor and organisational trust, which in turn would have a negative effect on the three dimensions of burnout.

A time-lagged study of $\mathrm{N}=406$ Canadian nurses conducted by Nelson et al. (2014) aimed to verify whether the work climate mediates the relationship between AL and psychological wellbeing at work. Although psychological well-being is the counterpart to constructs such as stress, mental health and burnout (Nelson et al., 2014), it is a valid construct to include in the SLR, because if AL can promote psychological well-being, then it can be logically argued that it will have the opposite effect on stress. Generally, Blake, Blayney, Loera, Rowlett and Schmidt (2012) describe that a positive work climate will encourage work-life balance, accountability, individual worth, empowering staff and encouraging a trusting work environment. Nelson et al. (2014) found that AL influences psychological well-being at work through the impact of AL on generating a positive work climate.

A study of teachers, conducted in Malaysia, investigated the relationship between the effects of the AL behaviours of headmasters and teachers' job stress (Noor \& Abdullah, 2019). This was one of the few studies that looked at the link between supervisors' AL and followers' stress directly rather than through another construct. The study found a moderately significant negative correlation between AL and teachers' job stress. The results showed that the internal moral perspective was the most significant predictor component of AL. However, a study carried out in Iran on $\mathrm{N}=212$ health care workers found the relationship between AL and both perceived work stress and stress symptoms to be insignificant (see Figure 9 and 10) for their hypothesised and resulting model (Rahimnia \& Sharifirad, 2015). The study did, however, find that attachment 
insecurity fully mediates the relationship between AL and the two variables of well-being related to stress (perceived stress and stress symptoms), while only partially mediating the relationship between AL and job satisfaction.

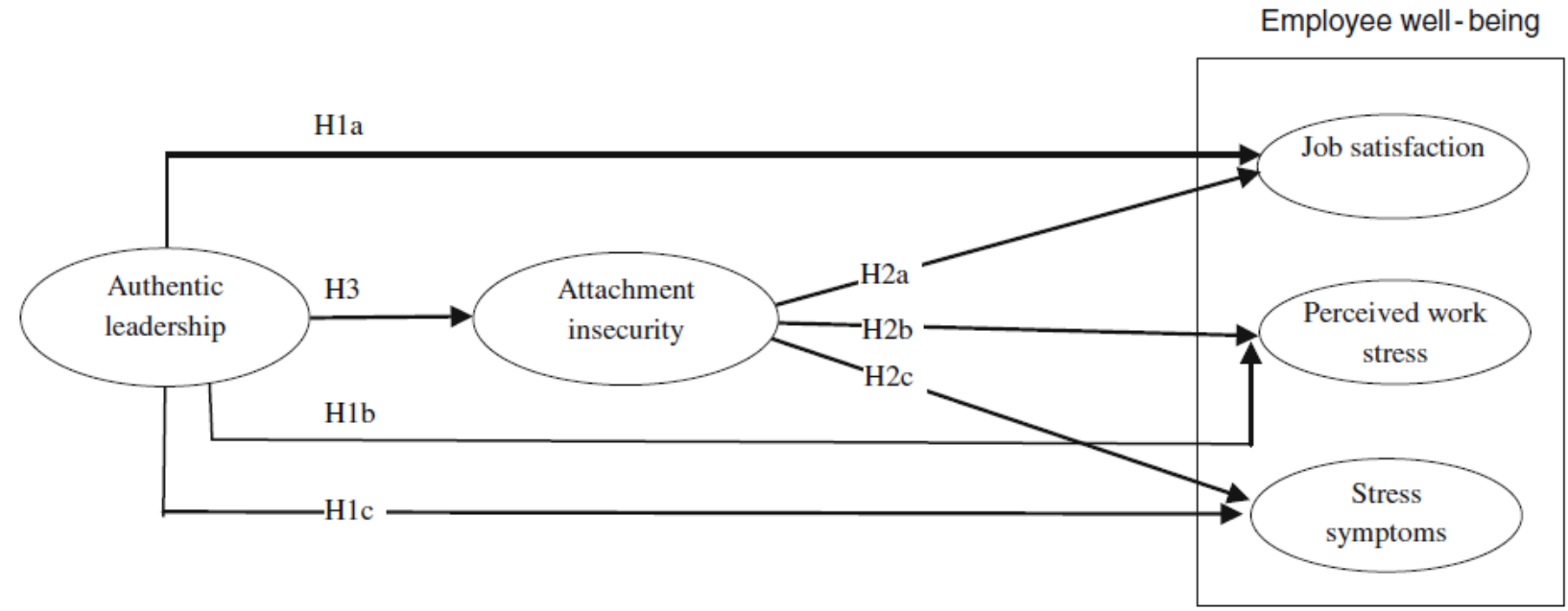

Figure 9: Authentic leadership and employee well-being: The mediating role of attachment insecurity. Hypostasised model (Rahimnia \& Sharifirad, 2015)

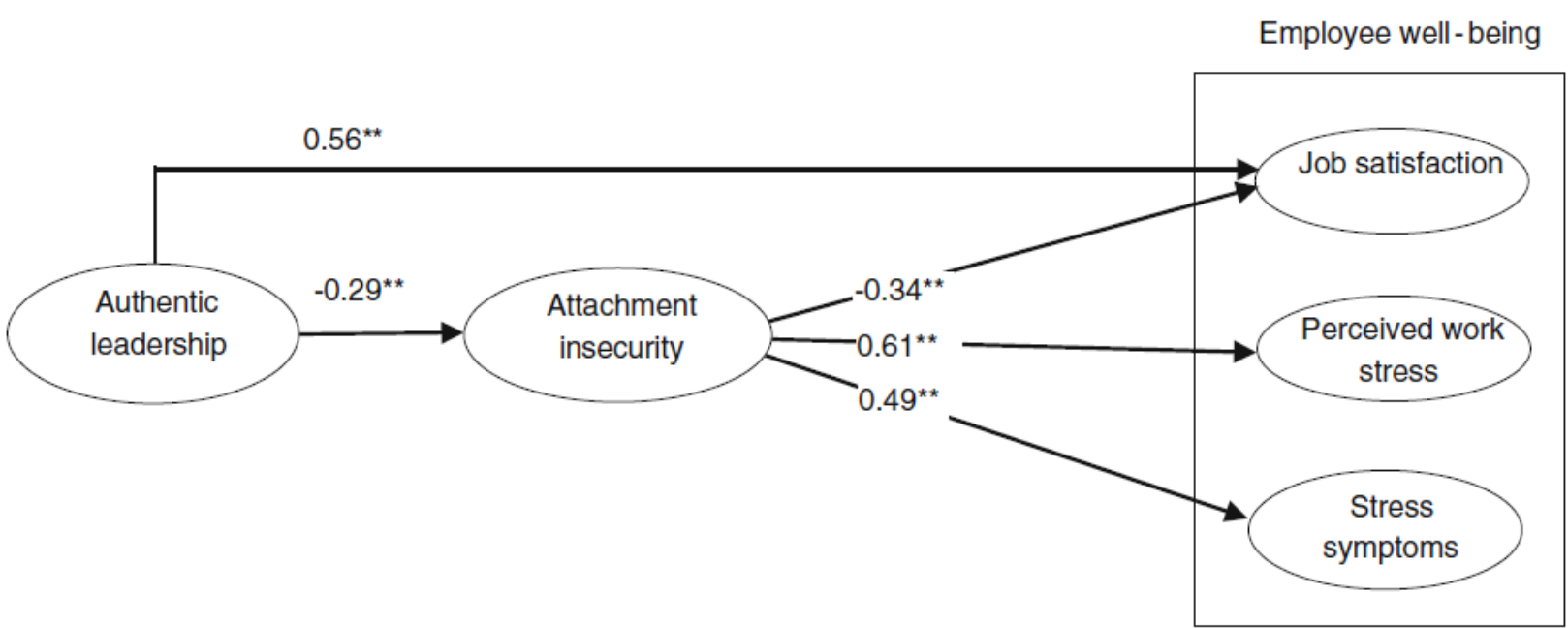

Figure 10: Authentic leadership and employee well-being: The mediating role of attachment insecurity. The resulting model (Rahimnia \& Sharifirad, 2015).

A study conducted in the United States and Canada across various organisations explored $\mathrm{AL}$ in relation to follower fairness perceptions and follower well-being (stress, turnover intention and organisational commitment) at the group and individual levels (Kiersch \& Byrne, 2015). This mediation model found support for the JDC model developed by Karasek (1979), as discussed in 
the introduction section. The researchers found that employees who perceive that they have control, that the demands put upon them are held constant and that they are supported are less likely to be stressed. They also found that AL makes a significant difference in creating this environment. In addition, they found that employees considering leaving an organisation consider not only individual but also shared views of the work-climate created by authentic leaders. Lastly, a study conducted in Israel on certified public accountants found that followers who perceive their managers to demonstrate AL behaviours experience more affective commitment, which in turn leads to less perceived role-stress and intention to leave (Shapira-Lishchinsky \& Tsemach, 2014).

The above findings provide evidence of the relationship between AL and WRS through related constructs such as burnout, well-being, bullying and turnover. The findings support hypothesis H1a: that perceived AL is associated with WRS. Furthermore, the findings show that AL can reduce the levels of stress experienced by employees. This is supportive of hypothesis H2: increased AL predicts reduced WRS. Nevertheless, the research did not find any studies conducted in the intellectual disability sector. However, there have been some studies of this topic in the health-care sector, mainly involving nurses in Canada. Although the research is growing, it remains relatively limited. Therefore, this study intends to explore the relationship between AL and stress, to better understand the problem in the context of the intellectual disability sector.

\subsubsection{Relationship between Work-Related Stress and Job Motivation}

There were few studies that explored the relationship between motivation and stress. However, two studies found were conducted in the intellectual disability sector, although not in Ireland. The first was conducted by Hickey (2014b), and specifically looked at the relationship between prosocial motivation (the desire to partake in work that benefits others), stress, and burnout in direct support workers within the intellectual disability services in Canada. 
The study found that the positive aspect of working with the people whom they serve had a significant positive impact on workers levels of stress, and subsequent burnout was caused by other aspects of the job. Most significantly, prosocial motivation was found to buffer the impact of emotional exhaustion and depersonalisation.

A study by Merrick, Grieve and Cogan (2017) was also conducted in the intellectual disability sector, specifically with workers providing support for adults with autism, across six organisation in the United Kingdom. This study looked at the relationship between motivational orientation hedonic (extrinsic orientated happiness) or eudaimonic (intrinsic orientated happiness), service-users' challenging behaviours (type and frequency) and psychological impacts. The study found that staff whose motivation was orientated toward eudaimonic motivation were significantly less likely to experience anxiety and had higher levels of life satisfaction. Eudaimonic motivation was also found to moderate the impact of exposure to challenging behaviours.

The final work in this review consists of three studies, two of which were cross-sectional and one cross-lagged, in Norwegian based industries (Kuvaas et al., 2017). The authors looked at the impact of motivation on performance, commitment, turnover intention, burnout, and workfamily conflict. They found across all three studies that intrinsic motivation was positively associated with performance and affective commitment, but was negatively associated with continuance commitment, turnover intention, burnout, and work-family conflict. Meanwhile, extrinsic motivation was negatively related or unrelated to performance and affective commitment and positively associated with continuance commitment, turnover intention, burnout, and work-family conflict across all three studies.

The above limited yet partially relevant studies lend specific support for hypothesis H1c: WRS is associated with JM. The evidence suggests that it is mainly autonomous and intrinsic 
motivation that are associated with stress. Moreover, the findings suggest several negative organisational outcomes when staff are stressed, including lack of commitment, reduced performance, and turnover intentions. Overall, the literature review lends support to the hypotheses proposed in this study.

\subsection{Bias and Limitations}

\subsubsection{Risk of bias}

An important element of transparency when producing an SLR is to make explicit one's own values, belief and assumptions on the SLR topic (Denyer \& Tranfield, 2009). Admittedly, my personal perception, based on my limited knowledge of the research topic, is that AL will help to reduce followers' WRS and not decreased JM, although I have no views on how significant these effects might be. Being mindful of this, great care has been taken to include relevant papers regardless of the results.

By the very nature of an SLR, which promotes sourcing and synthesising information from a diverse array of primary research, bias is reduced when compared to just reviewing one single study (Gough \& Thomas, 2012, p. 3). To mitigate against publication bias, the Centre for Reviews and Dissemination (CRD, 2009) advises that research from any publication should be considered. However, Denyer and Tranfield (2009) suggest that to avoid bias, journal ratings should not be used as a basis for exclusion. Journal rankings are included in the results table for transparency but were not used as inclusion or exclusion criteria.

\subsubsection{Limitations}

There are several limitations to this SLR. Firstly, the inclusion of studies was limited to published studies. While some unpublished studies relevant to the subject were found through snowballing, it was decided not to include them. Although concentrating only on peer-reviewed studies ensures quality, including unpublished work can help to reduce potential publication bias 
(Rothstein et al., 2005). Secondly, only one person was involved in the review and study selection. According to Moher et al. (2015), an independent reviewer in the study selection process will mitigate bias the researcher may have with regard to what studies are included, while disagreements should be resolved by a third party (Moher et al., 2015).

Although some longitudinal studies were found, most were limited to a single time point. Longitudinal studies provide important data on cumulative effects over a period of time (Rajulton, 2001). Further, all the longitudinal studies included were focused on WRS. A metaanalysis of longitudinal studies about the role of occupational stressor-strain effects found that samples sizes under 500 do not give reliable results regarding the lagged effects of stress (Ford et al., 2014). In addition, this study also found that synchronous psychological, occupational stressors-strain effects strengthen over time. Taris and Kompier (2014) explain that sometimes workers can become used to some forms of stress rather quickly, and the effects can then be short-lived. This suggests that studies focusing on a single point in time can also be useful for studying WRS and motivation. Finally, only studies written in English were included, leading to restrictions in the number of relevant studies included.

\subsection{Conclusion}

In summary, this SLR highlights the growing personal and organisational problems surrounding employee stress and decreased motivation in the workplace. Overall, the results of the reviewed studies suggest that AL style and behaviours have a positive impact on WRS and JM in that staff managed by authentic leaders are less likely to be stressed or unmotivated in the workplace. Moreover, by addressing issues of WRS and lack of JM, many organisational outcomes - such as productivity, turnover of staff, and quality of care for customers, patients, or services users (depending on the industry) - can be improved.

However, the research found was in a variety of organisational and industry settings, with 
little research in the intellectual disability sector. Moreover, none of the studies were conducted in Irish intellectual disability organisations. In addition, the overall research regarding AL and its direct effects on WRS is scant. Therefore, this proposed study will add valuable insight into the topic and is hoped to inform the intellectual disability sector in Ireland. 


\section{Methodology}

This section outlines the research methodology approach. First, the research paradigms and perspectives are discussed, followed by the chosen research approach. Next, the strategy for connecting the qualitative and quantitative study is discussed. Some of the more specific research methods used that relate to studies one and two are outlined in sections four and five. Finally, issues related to reliability and validity are discussed throughout the document, where relevant, and ethical considerations are also discussed.

\subsection{Research Paradigms and Perspectives}

Robson and McCartan (2016) explain that there are two main paradigms in research: the quantitative, which is historically linked to positivism, and the qualitative, which is underpinned by various philosophical approaches, including constructionism and interpretivism (pp. 20-24). However, this research uses both qualitative and quantitative methods: i.e. mixed methods or multi-strategy design. Johnson and Onwuegbuzie (2004) explain that philosophically, mixed methods is regarded as the third research movement, using a pragmatic, logical research approach which includes both induction (the discovery of patterns) and deduction (testing of hypotheses). Johnson and Onwuegbuzie (2004) state that "the bottom line is that research approaches should be mixed in ways that offer the best opportunities for answering important research questions" (p. 16). Therefore, a pragmatic research approach was taken for this study.

The multi-strategy design was used for the purpose of benefiting from the strengths of qualitative and quantitative research while mitigating their weaknesses. There are three major perspectives on the argument surrounding the quantitative-qualitative paradigm: purists, situationists and pragmatists (Rossman \& Wilson, 1985). Onwuegbuzie and Leech (2005) describe each as being on a continuum where purists do not believe quantitative and qualitative 
research should be mixed, while pragmatists are at the opposite end of the scale, and situationists are somewhere in the middle.

Bryman (2009) notes that behind the philosophy of a pragmatist are researchers who view themselves as being free to use any types of research methods and data sources, within reason, that will get the job done with as much rigour and comprehensiveness as possible. Sieber (1973) advocated multi-strategy design to exploit the strengths of both epistemologies, in order to better understand social phenomena. In addition, Tashakkori and Teddlie (2010) indicated that the pragmatist paradigm is favoured for mixed method research, as they found 13 different authors who suggested it as being the most suitable philosophy. Below, the rationale for using a multistrategy design is explored.

\subsubsection{The rationale for using mixed methods}

Creswell and Plano Clark (2011) advocate having at least one justification for using mixed method research. Moreover, they note that it should be clearly stated. This study used mixed methods for a number of reasons. The first was to counterbalance the limitations incurred by a single strategy design and draw from the strengths of both qualitative and quantitative methods (Bryman, 2006; Robson \& McCartan, 2016). The second reason was to triangulate the findings. Triangulation helps to validate or invalidate the findings, by cross-examining the results and ascertaining corroboration, convergence and/or correspondence between quantitative and qualitative data (Bryman, 2006, 2009; Robson \& McCartan, 2016; Schoonenboom \& Johnson, 2017). Thirdly, combining quantitative and qualitative findings builds a more complete and comprehensive portrayal of the phenomena: while quantitative data helps to generalise about the population, qualitative data can illustrate specific examples of people's experiences (Bryman, 2006; Robson \& McCartan, 2016). Lastly, the findings from qualitative and quantitative data will be used to complement each other by seeking clarification, elaboration. enhancements and 
illustration between the results of one method and another (Greene et al., 1989).

\subsection{Research Approach}

This study used a fixed mixed methods design: that is, each stage was planned and predetermined at the outset of the study (Creswell \& Plano Clark, 2011; Meissner et al., 2010). In addition, the study was conducted using the sequential explanatory design, as outlined by Ivankova, Creswell and Stick (2006) (see Figure 11), with some small alterations to suit this study, as explained below (see Figure 12). The unaltered sequential explanatory design model first collects quantitative data, followed by full data analysis, prior to collecting any qualitative data. The modified model used in this study also first collected the quantitative data; however, only descriptive data analysis was conducted: that is, basic statistics such as mean, mode and median were calculated (Field, 2018). This was done for the purpose of using the descriptive data to aid the development of the semi-structured interview questions to follow. In addition, the researcher is of the opinion that knowing the results of the quantitative data prior to conducting the interviews may cause bias. Therefore, not doing a full data analysis prior to conducting the interviews somewhat mitigates the potential bias caused by knowing the results of the quantitative study prior to the qualitative data collection.

Generally, in a sequential explanatory design, priority is given to the quantitative data, followed by integration of the two, while using the qualitative data to explain the findings of the quantitative data during the interpretative stage (Creswell, 2003; Robson \& McCartan, 2016). However, although this study gives priority to the quantitative data with regard to sequence, the quantitative and qualitative data will be equally weighted, and one will not take priority over the other (Bryman \& Bell, 2015; Morgan, 2013) 


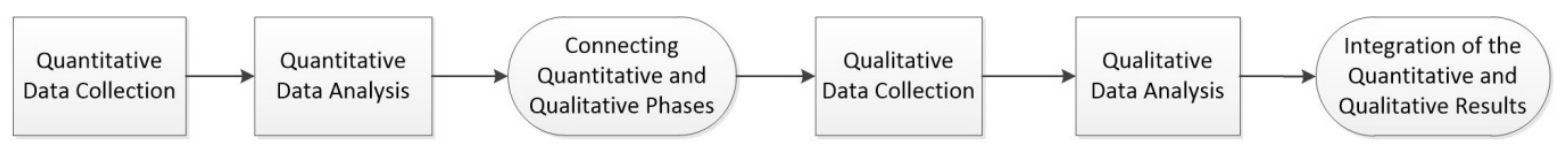

Figure 11: Visual Model for Mixed-Methods Sequential Explanatory Design Procedures. (Ivankova et al., 2006)

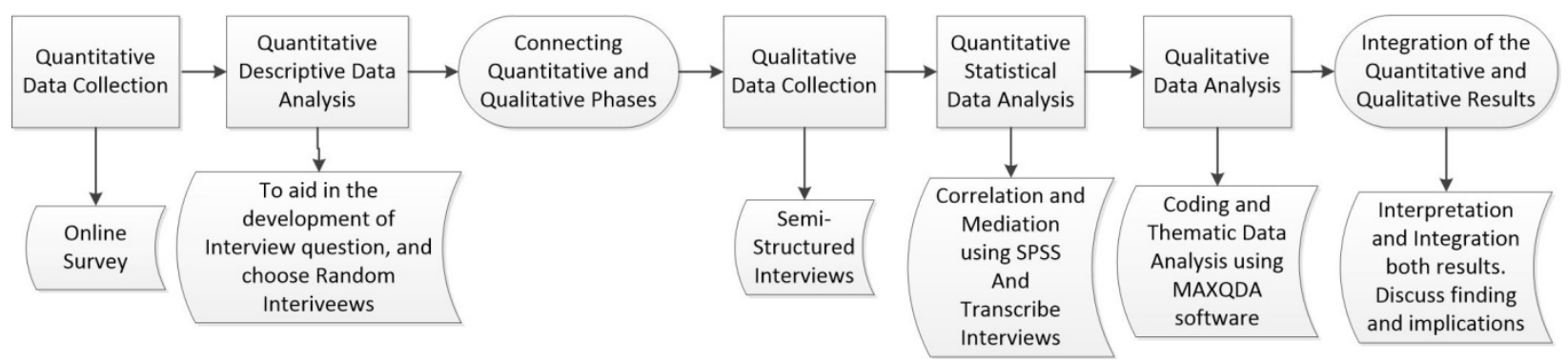

Figure 12: Visual Model for Mixed-Methods Sequential Explanatory Design Procedures modified for this study. Adapted from (Ivankova et al., 2006)

\subsection{Strategy for Connecting Quantitative and Qualitative Data}

The qualitative results will be used to explain and inform the researcher on aspects of the quantitative data. The data will be triangulated: in other words, it will be cross-examined to establish convergence or divergence, corroborate findings, mitigate threats to validity and improve the quality of inference (Creswell \& Creswell, 2018; Leech \& Onwuegbuzie, 2007; Teddlie \& Tashakkori, 2009). Conclusions will be drawn from both datasets, while crossreferencing will deepen the researcher's understanding of the findings. In addition, the data analysis will seek to examine important factors of the research questions. 


\section{Study One: The relationship between Authentic Leadership, Work-related stress, and Job Motivation (a quantitative analysis)}

The quantitative study comprised an online questionnaire to capture to what extent supervisors are currently perceived as authentic in their leadership style and enquire about their own current WRS and level of JM. Various aspects of this study are discussed below, including the methods used to conduct the study, data analysis, the results, and finally a summary of the findings.

\subsection{Aims, Objectives and Hypotheses}

The aim of Study One is to collect data using the online survey, complete the statistical analysis, and report and discuss the results. The objective is to test the hypotheses outlined below.

- H1a: Perceived AL is associated with WRS.

- H1b: Perceived AL is associated with JM.

- H1c: WRS is associated with JM.

- H2: Increased AL predicts reduced WRS.

- H3: The relationship between AL and JM is mediated by WRS.

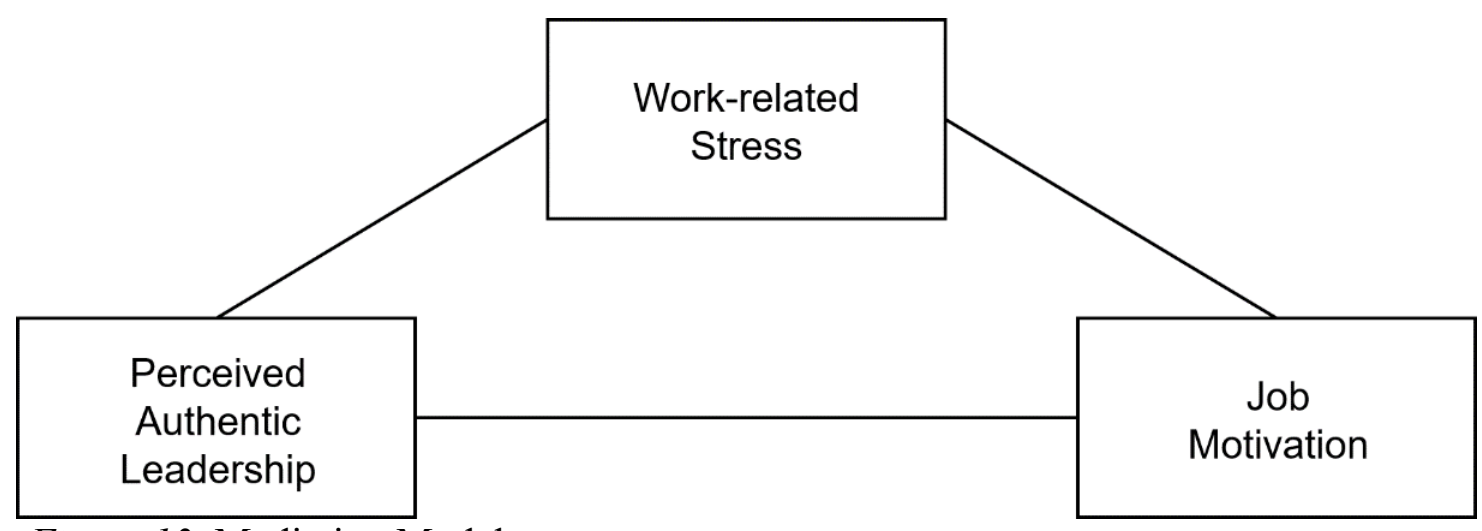

Figure 13: Mediation Model 


\subsection{Method}

\subsubsection{Participant Considerations}

This study was conducted in an organisation that provides services to adults with intellectual disabilities. Full approval was sought by the researcher and given by the organisation. In addition, a non-disclosure agreement was signed to ensure anonymity and confidentiality. Ethical issues were addressed in compliance with TUD, and prior to taking the survey, participants were informed that:

a) The survey is anonymous.

b) The responses will be kept strictly confidential and are stored on a secure server, hosted in the European Union.

c) The data gathered from the questionnaire will be aggregated with others via statistical analysis software (SPSS) by the research investigator.

d) Participants have the right to withdraw from the survey up to the point of data analysis.

The only required data that the participants must answer in the survey was the consent (see Appendix B, Figure 22).

An introductory email was sent to all employees of the organisation, inviting them to participate in the study (see Figure 14). As an incentive for participants to take part in the survey, for each completed survey the researcher donated two euros to charity, to a maximum of $€ 200$, as outlined in the invitation email (see Figure 14 and Appendix B, Figure 32 for the survey charity option). 


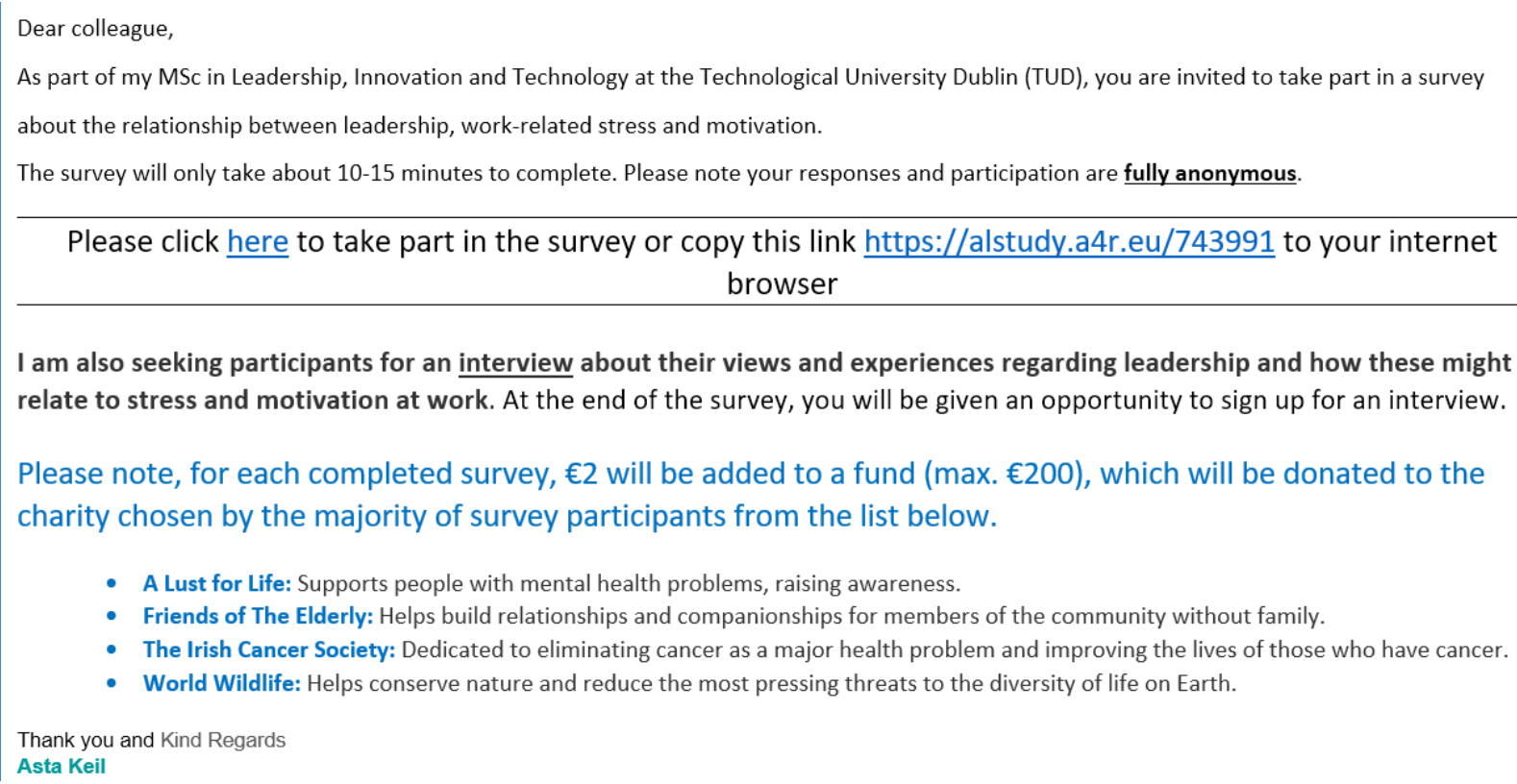

- A Lust for Life: Supports people with mental health problems, raising awareness.

- Friends of The Elderly: Helps build relationships and companionships for members of the community without family.

- The Irish Cancer Society: Dedicated to eliminating cancer as a major health problem and improving the lives of those who have cancer.

- World Wildlife: Helps conserve nature and reduce the most pressing threats to the diversity of life on Earth.

Thank you and Kind Regards

Asta Keil

Figure 14: Survey Email Invitation

\subsubsection{Survey Design}

The survey was developed using Lime Survey, which is an open-source survey tool (see Schmitz, 2017). In addition, the survey was developed in two parts: one to gather the survey responses and the second to gather interviewees' contact details. The interviewee details were not linked back to the respondents' survey answers, ensuring anonymity. Firstly, following a short introduction outlining the purpose of the study, the ethical considerations listed above were presented, followed by a consent form (see Appendix B, Figure 21 and 22). Secondly, some demographic questions were asked for the purpose of determining whether the participants were representative of the target population (Salkind, 2010). Thirdly, for each variable of the study hypothesis, a validated questionnaire was used (see Measures Section 4.2.4)

Using a validated questionnaire increases reliability, because such tools have been tested to ensure that they measure what they are designed to measure and make it easier to cross-reference the findings against other studies that have used the same questionnaire (Boynton \& Greenhalgh, 2004). Because the order in which questions are presented can influence how respondents might 
answer, each of the three scales had the questions randomised to mitigate against the question order effect (De Vaus, 2014). The last measure included an attention check question in the form of an instructed-response item that stated "Please answer this question by choosing "not at all" (see Bowling et al., 2016; Ward \& Pond, 2015). A study by Kung, Kwok and Brown (2018) verified whether attention check questions might cause the participant to deliberate when answering questions that follow and thus might threaten the validity of the responses. However, this study found no evidence to suggest that such questions significantly affected scale responses.

At the end of the questionnaire, participants were asked whether they were willing to sign up for a short, semi-structured interview (see Appendix B, Figure 34).

\subsubsection{Demographics}

Demographic data are categorised as independent variables because they cannot be manipulated and can be used to explore whether they affect the dependent variables (Salkind, 2010). Demographic variables were used in the analysis as covariates.

\subsubsection{Measures}

In this section, the measures used in the survey are discussed. Unless otherwise stated, Shapiro-Wilk tests (Razali \& Wah, 2011; Shapiro \& Wilk, 1965) and visual inspections of the respective histograms, normal Q-Q plots and box plots showed that the measures were adequately normally distributed.

Authentic Leadership. The 14-item Authentic Leadership Index scale (ALI; Neider \& Schriesheim, 2011) was used to measure follower perceived AL. To analyse each dimension of AL individually, the scale was aggregated along the four dimensions of AL, namely Balanced Processing (ALB), Internalised Moral Perspective (ALM), Relational Transparency (ALR) and Self-Awareness (ALS). All 14 items were also aggregated to determine the overall impact of AL. 
Authentic Leadership Index. ALI was measured using all 14 items on a five-point Likert scale $(1=$ disagree strongly, and 5 = agree strongly $)$. A lower score indicated a lower level of perceived AL of one's supervisor (see Appendix B, Figure 28). This applies to all four dimensions. The internal consistency of this measure was satisfactory, with a Cronbach's alpha of 0.92 .

Balanced Processing. ALB was measured using three items of the ALI measure. The internal consistency was satisfactory, with a Cronbach's alpha of 0.85 .

Internalized Moral Perspective. ALM was measured using four items of the ALI measure. The internal consistency was satisfactory, with a Cronbach's alpha of 0.74 .

Relational Transparency. ALR was measured using three items of the ALI measure. The internal consistency of this measure was satisfactory, with a Cronbach's alpha of 0.70 .

Self-Awareness. ALS was measured using four items of the ALI measure. The internal consistency was satisfactory, with a Cronbach's alpha of 0.86 .

Work-related stress. The 10-item Perceived Stress Scale (PSS; Cohen \& Williamson, 1988) was used to capture participants' current levels of WRS. The 10-item PSS was adapted from the original 14-item scale (see Cohen, Kamarck, \& Mermelstein, 1983) and was revalidated (see Lee, 2012). Moreover, studies have found the psychometric properties of the 10item PSS to be superior to those of the 14-item PSS (Lee, 2012; Maroufizadeh et al., 2018). The PSS is a self-reported questionnaire that aims to measure and evaluate the degree to which individuals consider themselves to be stressed due to unpredictable or uncontrollable events and to what extent they have been overloaded (Cohen et al., 1983; Lee, 2012). To ensure that the questions were asked in relation to WRS rather than personal stress, where appropriate, questions were adapted to reflect this. For example, the question "In the last month, how often have you felt confident about your ability to handle your personal problems?" was changed to "In the last 
month, how often have you felt confident about your ability to handle your work-related problems?" (see Appendix B, Figure 29 for the altered PSS scale used in this study and see Appendix B, Figure 35 for the original PSS scale.). WRS was measured using ten items on a five-point Likert scale $(1=$ never and $5=$ very often $)$. Lower scores indicated a lower level of stress. The internal consistency was satisfactory, with a Cronbach's alpha of 0.79 .

Job Motivation. The 19-item Multidimensional Work Motivation Scale (MWMS: Gagné et al., 2014) was used to measure JM (see Appendix B, Figures 30 and 31). In line with SDT, as suggested by Gagné and Deci (2005) and van der Burget et al. (2019), the scale was aggregated along two dimensions, namely autonomous motivation (AM) and controlled motivation (CM). For the aggregation of these measures (AM and CM), amotivation was not included because the data was highly positively skewed (see Figure 36 in Appendix C) for the histogram of amotivation). In other words, very few participants said that they did not put effort into their job because they felt that it was a waste of time or it was pointless work, not worth putting effort into (see, Table 11 in Appendix B for the three questions that make up the amotivation sub-scale).

Amotivation. Lack of motivation was measured using three items on a five-point Likert scale $(1=$ not at all and $5=$ completely $)$. Lower scores indicate a higher level of motivation. The internal consistency was satisfactory, with a Cronbach's alpha of 0.65 .

Autonomous motivation. AM or motivation through choice, interest and fun was measured using six items on a five-point Likert scale $(1=$ not at all and $5=$ completely $)$. A lower score indicates a lower level of AM. The internal consistency was satisfactory, with a Cronbach's alpha of 0.83 .

Controlled motivation. CM or acting due to a sense of pressure was measured using ten items on a five-point Likert scale $(1=$ not at all and $5=$ completely $)$. Lower scores indicate a lower level of CM. The internal consistency was satisfactory, with a Cronbach's alpha of 0.77 . 


\subsubsection{Participants}

Employees ${ }^{1}$ were invited via email to participate in the survey. Of those invited $N=122$ took part in the survey. Four participants (3.28\%) did not answer the attention check question correctly and were thus removed from the sample. This resulted in a final sample of $N=118$. Of the final sample, 97 participants $(82 \%)$ were female and 20 were male $(17 \%)$. The mean age was 41 (age-range $=20-64, S D=11.2)$. One hundred and nine participants $(92 \%)$ had third-level or higher education (see also Table 12 in Appendix C).

The average number of years for which participants reported being employed in the organisation was $M=8.7(S D=8.2)$, while the average number of years worked in the intellectual disability sector was $M=10.7(S D=7.9)$. The average weekly number of hours worked was $M=35.5(S D=9.2)$. Nine participants had a temporary part-time contract $(8 \%)$, four were temporary full-time (3\%), 44 were permanent part-time (37\%), 60 were permanent full-time staff (51\%), and only one participant reported being an agency or contract staff member (1\%). Twenty-six participants (22\%) were administrative staff, five were frontline nurses $(4 \%), 55$ were frontline social-care workers $(47 \%), 21$ were other frontline employees $(18 \%)$, and seven were in unspecified management roles $(6 \%)$.

\subsection{Analysis and Results}

\subsubsection{Descriptive statistics and correlations}

The overall mean of perceived AL of all supervisors was $3.59(S D=.78)$. The respective means of the ALI sub-dimensions were as follows: ALR was $M=3.83(S D=.79)$; ALS was $M=$ $3.51(S D=.90)$; ALM was $\mathrm{M}=3.64(S D=.72)$; and lastly, $\mathrm{ALB}$ was $M=3.42(S D=.96)$. The

\footnotetext{
${ }^{1}$ At the request of the organisation, number of staff were redacted
} 
mean of WRS was $2.85(S D=.60)$. The mean of controlled motivation was $M=2.64(S D=.76)$, whereas the mean of AM was $M=3.80(S D=.71)$. The following correlation analyses were carried out to test Hypotheses H1a, H1b and H1c.

Correlations between authentic leadership and work-related stress. The fully aggregated measure ALI was significantly negatively associated with WRS $(r=.51, p<.01)$. Moreover, three of the sub-dimensions of ALI were also significantly negatively associated with WRS (ALS; $r=-.49, p<.01$; ALM: $r=-.28, p=.002$; and ALB: $r=-.52, p<.01$ ). Because the fourth sub-dimension, ALR, was reverse coded or log-transformed to correct a negative skew in its distribution, the following correlation result needs to be understood in the opposite direction. Thus, while ALR was significantly positively associated with WRS $(r=.45, p<.01)$, the results indicate that as ALR increases, WRS is reduced. The results fully support Hypothesis H1a.

Correlations between authentic leadership and job motivation. As previously mentioned, JM was spilt into its sub-constructs, CM and AM, and tested accordingly. There was no significant association between ALI and CM, or between three of the ALI sub-dimensions (i.e., ALR, ALS and ALB) and CM. However, there was a significant positive relationship between ALM and CM $(r=.20, p=.03)$. In contrast, ALI was significantly positively associated with AM $(r=.42, p<.01)$ and AM was also significantly positively associated with three subdimensions of ALI, as follows: ALS $(r=.39 p<.01), \operatorname{ALM}(r=.35 p<.01)$, and $\operatorname{ALB}(r=.35, p<.01)$. While ALR was significantly negatively associated with AM $(r=-$ $.33, p<.01$ ), for reasons mentioned above, it should be understood in the opposite direction, i.e., as a significant positive association. The results thus lend partial support to Hypothesis H1b.

Correlations between work-related stress and job motivation. Lastly, while there was no significant association between WRS and CM, there was a significant negative association between WRS and AM $(r=-.35, p<.01)$. See Table 13 in Appendix C for further details of the 
correlation analysis. Again, the results lend partial support to Hypothesis H1c.

Overall, it should be noted that correlation never suggests causation. Therefore, it is not known if, for example, an increase in JM reduces stress, or if less stress is related to improved JM.

\subsubsection{Multiple regression analysis}

A series of multiple regression analyses were carried out to test whether ALI and its subdimensions significantly predicted a decrease in WRS (see H2) when accounting for age, gender, hours worked per week and role. Here, it is important to note that the initial five role categories were recoded into two categories, namely 'Administrator' and 'Frontline' staff. This was decided after carrying out a series of chi-square tests to determine the uniqueness of the pre-defined job role categories used in the survey. The results indicated that the categories were not fully unique. Moreover, the variable 'number of years worked in the organisation' was not included as a predictor, as it is strongly correlated with age $(r=.53, p<0.01)$.

For the fully aggregated ALI measure, the results of the regression analysis indicated that the final model explained $29 \%$ of the variance $\left(R_{2}=.29, F_{(5,100)}=8.1, p<.001\right)$ in WRS. The estimated unstandardized beta (B) denoted a significant negative relationship between ALI and WRS, indicating that a one-unit increase in ALI was associated with a 0.44-unit reduction in WRS.

In a further step, a regression analysis was carried out for each sub-dimension of ALI. ALB explained $29 \%$ of the variance $\left(R_{2}=.29, F_{(5,100)}=8.0, p<.001\right)$ in WRS, with an unstandardized beta of 0.33 , signifying a reduction in WRS. ALS explained $25 \%$ of the variance $\left(R_{2}=.25, F_{(5,100)}=6.81, p<.001\right)$ in WRS, with a beta value of 0.33 , again suggesting a reduction in WRS. ALM explained $12 \%$ of the variance $\left(R_{2}=.12, F_{(5,100)}=2.8, p<0.05\right)$ in WRS, with a beta value of 0.29 , indicating a reduction in WRS. ALR explained $22 \%$ of the 
variance $\left(R_{2}=.22, F_{(5,100)}=5.71, p<.001\right)$ in WRS, with an estimated unstandardized beta of 1.7, initially indicating that an increase in ALR results in an increase in WRS. However, as with the correlation analysis, ALR was reflected for log transformation-therefore, the relationship must be understood as a negative association, indicating, similarly to the other sub-dimensions, that as ALR increases, WRS decreases (see Table 14 to 18 in Appendix C for details of the regression analysis).

Overall, these above results fully support Hypothesis 2.

\subsubsection{Mediation analysis}

To test Hypothesis 3, i.e., if WRS explains some or all the relationship between AL and AM, a series of mediation analyses were carried out. As previously outlined, ALI consists of four sub-dimensions, and JM of two constructs, namely AM and CM. The previous correlation analyses showed that internalised moral perspective was the only sub-dimensions of ALI to significantly correlate with CM. Therefore, it was decided to only carry out a mediation analysis for ALI (and its sub-dimensions) and AM. All models were tested using the PROCESS plugin v3.4 for SPSS (Hayes, 2019), Model 4, with 5000 bootstrap samples. As in the previous regression analyses, age, gender, hours worked per week and role were included as covariates.

\section{Relationship between ALI (full measure) and autonomous motivation through work-}

related stress. To test Hypothesis 3, initial testing was between the fully aggregated measure ALI and AM. The analysis showed that there was no significant indirect effect of ALI on AM through WRS $(\mathrm{B}=0.11,95 \%$ CI $[-0.016,0.227])$ (see Figure 15). The total effect of ALI on AM alone was $R_{2}=.24, F_{(5,100)}=6.17, p<.001$. In conclusion, WRS does not mediate the relationship between the fully aggregated ALI measure and AM. 


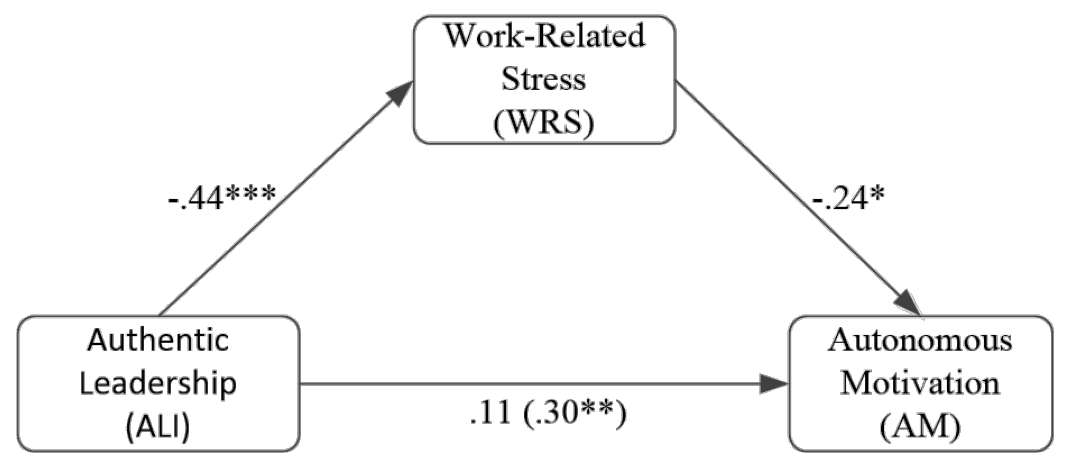

Figure 15: Mediation between Authentic Leadership and autonomous motivation through work-related stress. The direct effect (c-prime) is reported in brackets.

\section{Relationship between self-awareness and autonomous motivation through work-}

related stress. In the next step, mediation analyses were carried out for each sub-dimension of ALI and AM. The analysis showed that there was a significant indirect effect of ALS on AM through WRS $(\mathrm{B}=0.09,95 \% \mathrm{CI}[0.000,0.179])$ (see Figure 16). The total effect of ALS on AM alone was $R_{2}=.22, F_{(5,100)}=5.55, p<.001$. The proportion of the total effect through WRS was $26 \%$, with ALS, therefore, accounting for a direct effect of $71 \%$ on AM. Here, WRS partially mediates the relationship between ALS and AM, lending some support for Hypothesis 3.

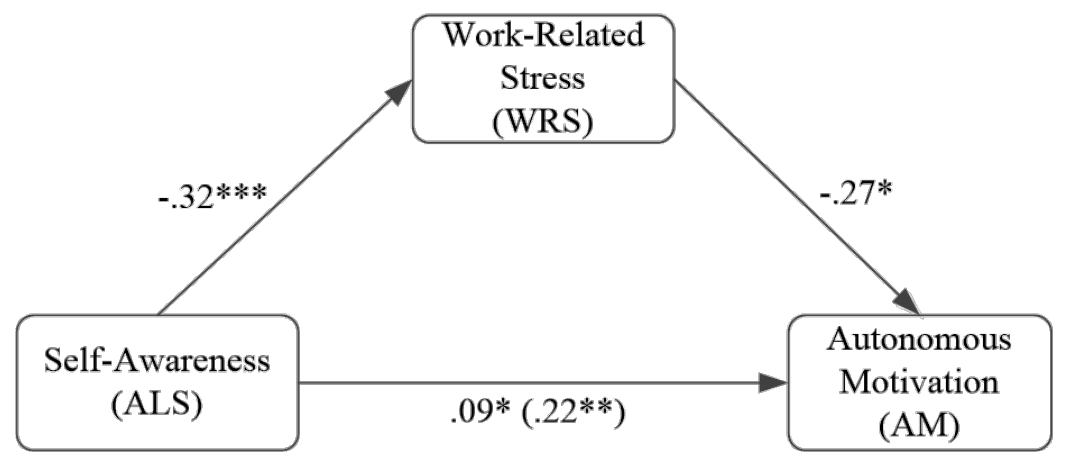

Figure 16: Mediation between Authentic Leadership - Self-awareness and autonomous motivation through WRS. The direct effect (c-prime) is reported in brackets. 


\section{Relationship between internalised moral perspective and autonomous motivation}

through work-related stress. The analysis showed that there was a significant indirect effect of ALM on AM through WRS $(B=0.094,95 \%$ CI $[0.024,0.197])$ (see Figure 17). The total effect of ALM on AM alone was $R 2=.18, F_{(5,100)}=4.53, p<.001$. The proportion of the total effect through WRS was $27 \%$, with ALM, therefore, accounting for a direct effect of $73 \%$ on AM. WRS partially mediates the relationship between ALM and AM, lending some further support to Hypothesis 3.

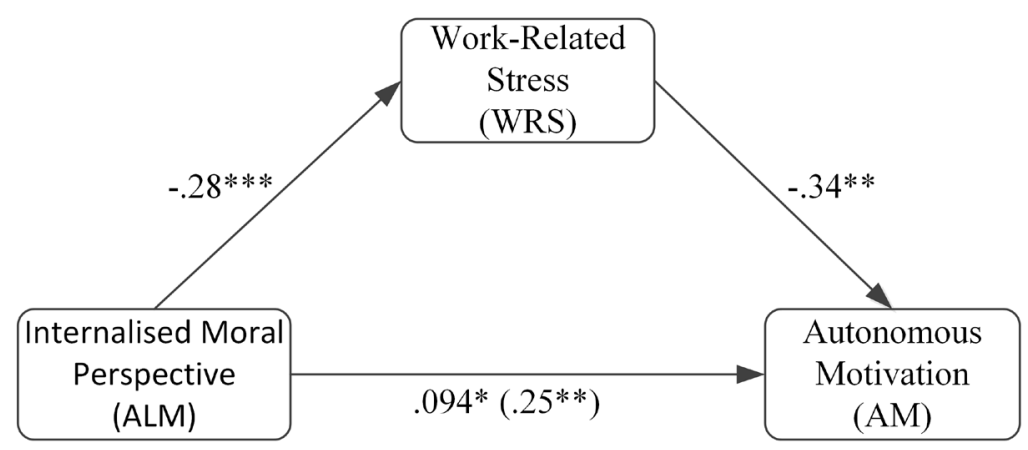

Figure 17: Mediation between Authentic Leadership - Internalised moral perspective and autonomous motivation through WRS. The direct effect (c-prime) is reported in brackets.

\section{Relationship between relational transparency and autonomous motivation through}

work-related stress. The analysis showed that there was a significant indirect effect of ALR on AM through WRS (B = -.56, 95\% CI [-1.159, -0.144]) (see Figure 18). The total effect of ALR on AM alone was $R_{2}=.17, F_{(5,100)}=4.01, p<.01$. The proportion of the total effect through WRS was $41 \%$, with ALR, therefore, accounting for a direct effect of $59 \%$ on AM. Please note that because ALR was log-transformed, the $a$ - and c-paths need to be understood in the opposite direction. Here, WRS thus fully mediates the relationship between ALR and AM, lending further support to Hypothesis 3 . 


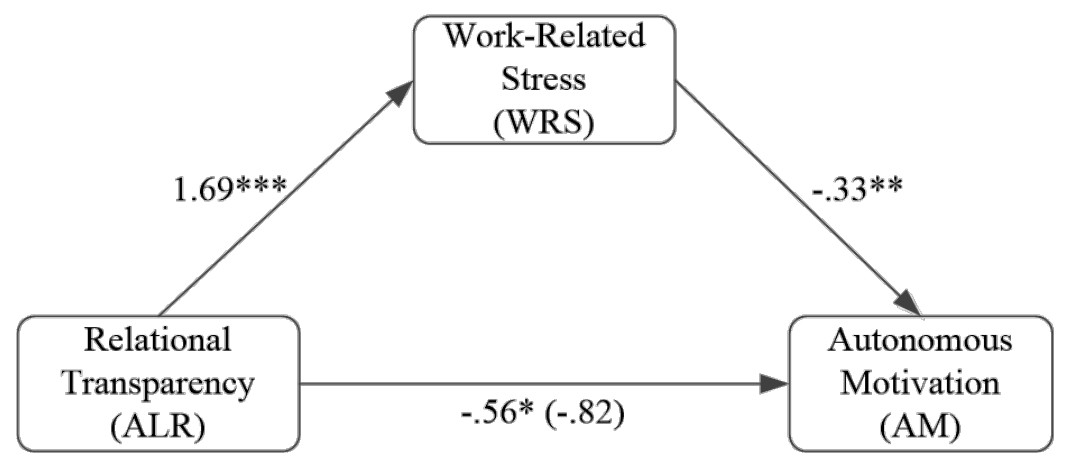

Figure 18: Mediation between Authentic Leadership - Relational transparency and autonomous motivation through WRS. The direct effect (c-prime) is reported in brackets.

\section{Relationship between balanced processing and autonomous motivation through}

work-related stress. The analysis showed that there was a significant indirect effect of ALB on AM through WRS $(B=0.97,95 \%$ CI $[0.010,0.195])$ (see Figure 19). The total effect of ALB on AM alone was $R_{2}=.19, F_{(5,100)}=4.80, p<.001$. The proportion of the total effect through WRS was $36 \%$, with ALB, therefore, accounting for a direct effect of $64 \%$ on AM. WRS partially mediates the relationship between ALB and AM, and thus lends further support to Hypothesis 3.

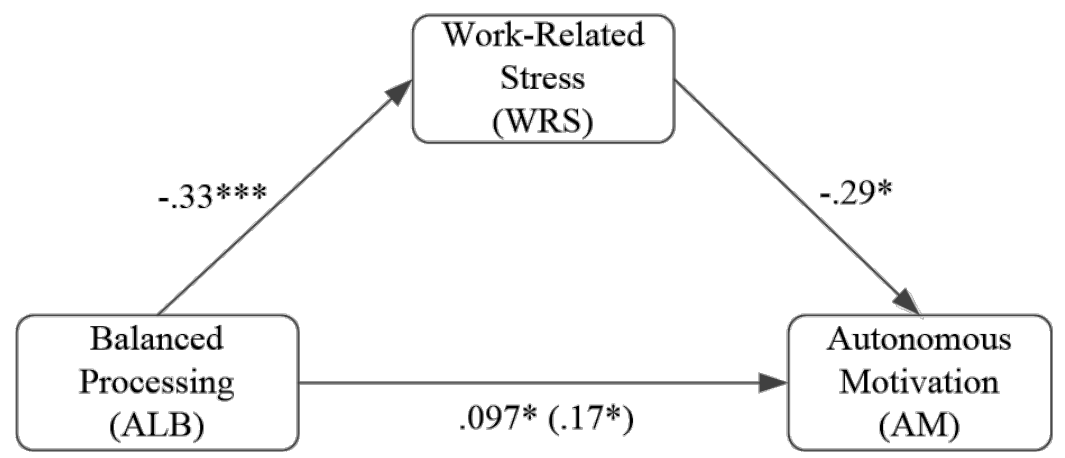

Figure 19: Mediation between Authentic Leadership - Balanced processing and autonomous motivation through work-related stress. The direct effect (c-prime) is reported in brackets.

In summary, although the results of the analyses did not show a significant mediation for the fully aggregated ALI measure, the results did show that WRS partially, and in one case fully, meditated the relationship between all sub-dimensions of ALI (ALS, ALM, ALR and ALB) and 
autonomous motivation. The meaning of the results is discussed in more detail in the discussion section that follows. Next, the quantitative analysis results are summarised.

\subsection{Summary of the Quantitative Study.}

Study one examined the relationship between AL, work-related stress, and JM. Selfdetermination theory was the motivation model used to determine to what level staff were motivated along the continuum between amotivation and intrinsic motivation. The number of staff who reported being not motivated to work (amotivation) was negligible. Therefore, no further statistical analysis was completed on amotivation. However, an analysis was done on controlled motivation and autonomous motivation (see Figure 3 of SDT). Interestingly, the only correlation between controlled motivation and AL or any of the authentic leadership subdimensions was between internalised moral perspective and controlled motivation. However, significant correlations were found between AL and WRS and between AL and autonomous motivation.

The regression analysis carried out between AL and WRS, and between all the individual sub-dimensions and WRS, fully supports hypothesis H2; that is, that increased AL predicts reduced WRS.

However, when all the ALI sub-dimensions were aggregated, AL did not significantly mediate the relationship between AL and autonomous motivation. This can be explained by the strength of the direct relationship between AL and autonomous motivation to the point that WRS does not significantly explain reduced autonomous motivation. That is not to say that WRS does not explain any of this relationship. Furthermore, although correlation does not explain causation, the direct relationship between AL and autonomous motivation does, as determined by the mediation analysis. Therefore, it can be stated that as supervisors' AL behaviours increase, followers' autonomous motivation increases significantly. However, when the AL sub-dimensions 
'self-awareness', 'internalised moral perspective' and 'balanced processing' are analysed individually, WRS partially explains why followers' autonomous motivation decreases. In addition, WRS fully explains why staff lose some of their autonomous motivation when they perceive their supervisors to be lacking in balanced processing.

These significant results, which overall support the hypotheses, provide evidence to encourage AL behaviours. The above results show that improving the AL behaviours of all managers will help to reduce WRS and improve autonomous motivation in the staff that follow them (report to them). The discussion section explores the meaning of these results in conjunction with the qualitative results. 


\section{Study Two: Relationship between Authentic Leadership, Stress and Job Motivation (a qualitative analysis)}

This section discusses the process, protocols, procedures, analysis, and results for the qualitative study.

\subsection{Aims and Objectives}

The aim of study two was to conduct face-to-face semi-structured interview, analyse those interviews and report the results. The objective was to elicit material to explain, expand or contest evidence gathered in study one.

\subsection{Method}

Each face-to-face interview took place in a private setting chosen by the participant, at a time agreed by both parties. Prior to the interview, the participants were given the following information:
a) The definition of AL.
b) The purpose of the study.
c) The expected interview length.
d) That the interview will be recorded and transcribed.
e) Confidentiality information.
f) Informed consent form.

Participants were required to sign the consent form before the interview took place (see Appendix E for the participant consent form). At the end of the interview, the participants were given a debriefing document which outlined the nature of the study in more detail than the consent form (see Appendix F). On completion of the interview, the researcher requested permission to contact the participant via their work email if the researcher had any follow-up questions or needed clarification on aspects discussed in the interview. 


\subsubsection{Interview Protocol}

The researcher's self-developed interview protocol was developed to gain insights on the research topic, the three variables - AL, WRS, and JM - and how they relate to each other. The interview was semi-structured to allow freedom in the sequence of questions and the amount of time given to various elements of the research topic (see Robson \& McCartan, 2016). Semistructured interviews lie in between structured and unstructured interviews. They allow the researcher freedom to expand on and probe a list of prepared questions in order to elicit rich descriptive data on the research themes (Qu \& Dumay, 2011).

The questions were formulated to ensure that all variables and their association with each other were covered. In addition, they were formulated in open-ended form to gain in-depth descriptive data and to ensure that they did not restrict the participants in replying freely and descriptively (Robson \& McCartan, 2016; Saunders et al., 2012). Moreover, semi-structured interviews allow the participant to respond using language and thought processes with which they are familiar and comfortable, which helps the researcher to understand how the participant perceives the area of study (Qu \& Dumay, 2011). The interviews were audio-recorded to allow transcription and analysis; each interview took between 25 and 35 minutes.

The first part of the interview asked some background questions about the participant, such as what the nature of their work is. This was followed by specific questions in relation to the research topic. No specific section was given to each of these constructs because there was a focus on the questions to discover the relationship between the three variables: AL, WRS, and JM. For example, one of the questions and linked probes were as follows:

"Can you give me an example of a situation that caused you to be stressed at work?"

- How did this affect you? Example?

- Did it affect your motivation? How? 
- Did this influence your performance? How?

- Did you discuss this with your supervisor?

○ How did your supervisor support you with your stress?

Probes were used to draw out more detailed and descriptive responses to otherwise consistent questions intended to direct the theme of the semi-structured interview (Qu \& Dumay, 2011; Robson \& McCartan, 2016). The probes were a guide for the interviewer and were not intended to be rigid. More probing questions could be asked $a d-h o c$ where required. They were used to explore a specific question further and keep the conversation on track (see Appendix G for the interview script).

\subsubsection{Analysis of Interview Transcripts}

Each interview was recorded and transcribed verbatim. Thematic analysis was used to analyse the data. Thematic analysis is a flexible qualitative method of analysis that is compatible with all research epistemological paradigms (Braun \& Clarke, 2006). Furthermore, thematic analysis is an analytical tool that facilitates the researcher to ascertain, analyse and report patterns or themes that are salient in the data (Attride-Stirling, 2001; Braun \& Clarke, 2006). To assist in the process of organising, categorising, and coding the data, the researcher used MAXQDA Plus software (Release 20.0.7), which is designed for data analysis of this type. Thematic analysis is an iterative and reflective process that helps to develop a deeper understanding of the interview data (Braun \& Clarke, 2006; Fereday \& Muir-Cochrane, 2006). Therefore, the assistance of software aided in this aspect of the process.

Transcripts were anonymised where it might have been possible to identify a person, organisation, or location. The following transcription symbols were inserted into the transcript where appropriate: Three dots (ellipses) denote the omissions of words or sections from the 
transcript. However, care was taken to ensure the original meaning was not lost. Words in square brackets have been substituted to ensure anonymity.

\subsubsection{Participants}

To be included as a potential participant for study two, one must first have taken the survey. From those that agreed in study one to be interviewed in study two, a random selection of two participants was made to take part in a pilot interview, and a further ten were randomly selected to take part in an interview. The remainder were notified that they were not selected; however, they were reserved as backups (see Appendix D, Figure 37, 38 and 39 for the interview invitation emails).

Of the ten interviewees who participated in study two, five were classed as frontline staff and five as administrative staff.

\subsection{Resulting Themes}

The thematic analysis resulted in three main themes related to the central research question. Theme one relates to participants who overall did not find their supervisor to be authentic and reported being stressed and demotivated. Alternatively, theme two relates to participants who overall perceived their supervisors as demonstrating authentic behaviours and had little to no WRS or demotivation. Lastly, theme three relates to participants who reported stressful working situations and reduced motivation, but perceived their supervisor as being authentic. These themes are presented below in the following sub-sections.

Additionally, all the participants reported that they were often motivated intrinsically by the desire to help the organisations' service users either directly or indirectly. Although this aspect is related to the research, it is not directly related to any of the hypotheses. Therefore, it is not reported as a theme, but rather is discussed in brief as follows. When asked what motivates them at work, most participants expressed similar intrinsic motivations: "I love the job I do. I love 
looking after clients and making sure the clients are happy and have a really good quality of life. That's what motivates me" (P2). Moreover, P7 shared "What motivates me genuinely is ensuring that the bundle of people that I'm responsible for get the best care that we can possibly provide. I enjoy looking at people doing well." In addition, P5 said "The thing that motivates me is the fact that my job [is around the support of clients and services]... my role... hopefully... improves service users' lives and service quality: that, for me, is the motivation". Moreover, P4 explained: "I think one of the principal motivations I have is a general empathy and care for the people we support" (see Appendix J Section 1 for additional extracts related to what motivates the participants). The three themes are reported below, followed by a summary of these findings.

\subsubsection{Theme One: When authentic leadership is perceived as increasing stress and reducing motivation.}

As explained above, theme one specifically relates to participants who reported that their supervisors were not demonstrating AL behaviours. However, the participants did report various stressful work-related situation or events. These participants also reported reduced motivation, which was sometimes attributed to being stressed. However, in some cases, the participant quotes presented below as part of theme one may also be quoted in relation to theme two or three. This is because often, participants reported both positive and negative aspects of their supervisors' AL behaviours. In addition, participant eight started the interview by discussing a previous supervisor and later switched to discussing their current supervisor.

Participant two had experienced a stressful work event; they said the following when asked if they had any examples of a stressful situation in work:

"Yes, lots... One stressful situation quite recent... A client was going

through a difficult time. I made a decision - I spoke to [the clients] family 
and, in fact, it's something that they had asked for... My manager completely undermined my decision and did so in front of my staff team... I was under stress at the time: I felt like they had made me out to be completely incompetent... When that initial email came through, I was so angry... My manager has an awful habit of a doing 360 on things, so they say something on the phone... a day later, "I didn't say that." So, every conversation now... I follow-up with a confirmation email just to clarify this is what they stated... it wouldn't be every conversation, but it would be depending on the conversation... it does give me more work..."

Participant four also reported being stressed at work when asked by their manager to do something that went against their moral compass:

"Interviewer: ... "What aspect of that caused you stress?" ...

P4: "I resented being asked to do that because I've been put in a very difficult situation. Then I was really stressed, that I actually had to stand up and say no, when I didn't really want to say no to my manager..."

Participants seven and eight also reported a stressful work situation (see Appendix J Section 2 for additional extracts related to these stressful working events).

When asked what support they received in relation to these stressful events, P2 said “... [My supervisor] said, "I didn't say that." It was my staff against my supervisor and with no disrespect, but I believe my staff member... For me, it was a very difficult situation and I tried to work it out..." Alternatively, P4 explained their supervisor does support them to an extent: “... in their own way, they do support..." This demonstrates that sometimes people may act in an unauthentic way and without being aware of it or the impact it causes others. However, participant eight felt that the support they received was inadequate; they said: 
“It was minimal, and I wasn't really impressed with the particular manager. I thought they could have done more... I think for what I have done since, the amount of money I have saved the organisation, and the amount of time-I'm very, very passionate about this job. I think for my time and effort... I think I should have been recognised earlier... No, I didn't think the support was great, to be honest ..."

Next, participants' view of their supervisors' lack of self-awareness is reported.

Participant two said the following regarding their supervisors' self-awareness: "I don't think they care how they are perceived by anybody... they don't realise how they come across to people and that they come across all poker-faced and not empathetic at all...”. Moreover, when asked if their supervisor was aware when they are making them feel stressed, participant four replied: "No they wouldn't'. In addition, participant seven also felt their supervisor was not aware of the stress they had caused by not recognising the good work they had done, they explained:

"No. In that instance, and it's probably unfair to measure just on that... you can only sometimes work on what's most current and recent to you to measure your experiences and that one I don't think my supervisor really had any concept of the impact that had on me as an employee."

Below are additional responses participants shared when asked various questions related to their supervisors’ AL styles. “... My manager is very poker-faced: there's no empathy, no transparency, no openness... That style of management doesn't work when you're dealing with people ..." (P2). However, P4 had mixed views on their supervisor's authenticity:

"I think they have a lot of authentic traits and at times doesn't employ them ... I think very much they go with their own gut feeling on things and will use their gut feeling and their own moral compass and their own ideas of 
how things should be done to make decisions. But it is also a case that the same person can be quite easily influenced by others... They can be reactive. Very often, they will make an informed decision as well, so it's a bit of both... (P4)".

In addition, participant seven expressed concerns about their current perceptions of their supervisor's values due to how the stressful event they experienced was dealt with. When asked "Do you feel your supervisor holds true to their beliefs and values?" they responded:

“... my faith has been shaken a little bit of late because I've always had a perception that the supervisor was a caring individual and was constantly aware of the welfare of the clients. That being said, that was damaged, the faith in that was damaged when I see how the recent situation were dealt with. It wasn't client-focused, it wasn't client-friendly...”

For more examples of non-AL behaviours, see Appendix J, Section 3.

It is not always a black and white story regarding whether someone sees their supervisor as being authentic or not: often, as demonstrated in some of the examples above, the level of perceived supervisor authenticity can be mixed. However, when a supervisor was not demonstrating authentic behaviours, this often led to or exacerbated employees' stress and reduced their motivation, albeit not permanently.

\subsubsection{Theme Two: When authentic leadership is perceived as reducing stress and increasing motivation.}

Theme two reflects comments made by participants who expressed that their supervisors' behaviours were in line with AL traits. Overall, these participants reported minimal nonsupervisory related stress or no WRS. These participants generally spoke positively about their 
supervisors and felt overall that any stress or lack of motivation they did have was alleviated by their supervisor.

Participant three reported having virtually no WRS, what little stress they did experience was positive motivational stress, as shown in the interview extract below:

"Interviewer: Can you give me an example of a situation that caused you stress at work?

P3: Actually, to date, I have not -

Interviewer: No stress whatsoever?

P3: [It is hard to find a stressful situation, but if I was to dig deep], it was [to do a specific piece of work for a high-level person] in a very short time span. Because they were new, I was stressed because I wanted to have [that job] done properly. It wasn't stressful in that anyone had a gun to my head and I was unhappy and stressed; it was motivational stress. (See Appendix J Section 4 for an expansion of this extract).”

Participant nine gave the following stress example for which they received positive support from their supervisor:

"Interviewer: ... Can you give me an example of a situation that caused you to be stressed at work?

P9: Yes, absolutely. A couple where people were almost dog-rude... [example too specific to elaborate further]

Interviewer: Have you ever discussed that with your supervisor and what kind of support did you get?

P9: They are good at reminding me, "You're doing a good job" ..." Moreover, as previously explained, participant eight initially started the interview by 
discussing a stress-related event (see theme one) for which their supervisor at the time was not giving enough credit for good work done. When asked about their levels of stress with their current supervisor, participant eight replied: “... I don't feel I have any stress, though I still worry about things, but it's not to the degree it was [a number of] years ago where that was really affecting me" (see Appendix J Section 5 for an expansion of this extract).

Next, a variety of positive AL behaviours reported by participants three, nine and eight are given, with an expansion of these extracts in the appendix (see Appendix J Section 6). Participant three viewed their supervisor as being "100\% authentic" and also said "Out of [all the supervisors I have had in this organisation to date], I have felt this particular manager has taken an active interest in what I do... also, in our interactions, they're very human". In addition, participant eight also thought their current supervisor valued them, and this increased their motivation and reduced their stress: "I feel more valuable in the team I work in. That would be [my supervisor's] strengths. I think that's been a motivational factor for me... at the moment, no. I don't think I'm stressed... I feel more comfortable approaching them if there's an issue because I know it will be dealt with". Moreover, participant nine said "I do... Because I have worked with them and seen how they are respected, and I've seen their level of knowledge and expertise, so they understand the challenges very well. That's why I feel they're authentic, because when I'm explaining a challenge, they understand it ..."

When asked "From your perspective, does your supervisor have a good sense of their own values and ethical outlook?" participant three said:

"Yes, absolutely ... I was in a position where I was able to talk to them freely... and I got to know them better and where they have come from in the organisation and their views. I was surprised because they were very human in their approach and their values were what I always believed this 
organisation has in the first place...”

In addition, participant eight said "Yes, I would think so... we have a lot of ethical concerns [related to safeguarding issues], and they do address them, and they feel passionate. I know that the care of the client is at the centre of everything that they do". In addition, participant nine explained that their supervisor explains when a blanket organisational decision has to be made, and they do fight their corner:

'P9: I would say, yes, some decisions, blanket decisions coming from finance or... HR, where they might say to me, "This is happening. I'm annoyed about it and this is what I'm doing."...

Interviewer: They fight their corner on those-

P9: They do fight their corner, yes, absolutely... And we would discuss things like that in staff meetings and I can see that their heart is in the right place and they've good morals..."

In relation to supervisors sharing their true thoughts and feelings, the participants in this theme said:

"From my perspective, definitely. Whatever you see, you get. There's no mask, but yet there is a professionalism as well. It's not like wearing the heart on the sleeve and everything. There is a boundary, but it's not a barbed wired boundary" (P3).

Moreover, participant eight said:

"Yes. I suppose going back to the same issue, yes, they do... If something comes up in audits and they have an issue with them, if it is regarding the safety of a client and maybe staff and the units aren't carrying out that role correctly, it would be addressed. That again goes back to the ethos of the 
organisation as well: that is, the care of the client as well, yes."

In relation to other authentic traits, such as self-awareness and openness to being challenged, participant nine had mixed views, further demonstrating that people are often not completely authentic or vice versa:

"Interviewer: ... Do you find your leader to be self-aware?

P9: Yes, I would... I've seen their good days and their bad days, and there have been just simple things like where they say 'sorry I'm a bit ratty today' - they certainly are self-aware I can definitely say that.

Interviewer: Do you find your supervisor to be reactive rather than making informed decisions?

P9: Sometimes, they're reactive. They're generally very level-headed, very logical and very practical, but I have seen some reactive decisions ..."

Moreover, participant eight felt that their supervisor made an informed decision; they said:

'I wouldn't think they're reactive. No. I think if there's an issue, they'd address it, they wait for you to come back with your evidence, the way you approach the situation, and then they make an informed choice about it. I think they do react. I don't think they're reactive. I don't feel that anyhow..."

The above examples and extended extracts demonstrate the positive impact that perceived authentic supervisor can have on staff. Generally, while under the supervision of a perceived authentic leader, followers felt less stress and were more motivated. The following section discusses the third theme. 


\subsubsection{Theme Three: Stressful experiences indirectly linked to AL}

The last theme identified during the thematic analysis looks at participants who did have one or more stressful work-related events and overall reported that during these times, motivation levels were diminished to some degree. However, these participants reported that overall, they perceived their supervisors to be authentic. Moreover, sometimes the supervisor's authentic traits

alleviated the WRS that was caused by someone or something else work-related. Firstly, the WRS experienced by the participants in this theme is reported more extensively in the appendix (see Appendix J Section 7 and 8). Participant one reported WRS due to decisions made at an organisational level related to service delivery. When asked about their WRS, they responded:

"Where to start? I suppose, even just presently, what's causing stress is the lack of the organisational vision and the change that it's bringing to our clients... For example, at the moment the senior managers are looking at how we deliver service [the offering of specific service] - we have been told that they have to stop."

Participant one also reported that this negatively impacted their motivation. Participant five reported a very serious WRS event that caused them to go on stress leave for a period of time. When asked about their WRS, they responded:

"P5: I can. A very specific one that happened this year, I have to say it's the most stressful situation I've ever been in, in any employment I've ever worked in my whole entire life.

Interviewer: Okay. It says a lot.

P5: ... It caused me to go on stress leave. To me, it was very serious, but I felt like I wasn't being treated seriously at all... To me, it felt like it was 
bullying”.

The next WRS example reported by participant six is directly related to the frontline work carried out in the intellectual disability sector:

“... some of the people I support, they can have behavioural concerns. [They

can have] physical outbursts, and that can be very stressful, and it's not so much the physical outbursts, it's the before and the after and ensuring that all the clients are safe...".

In addition, participant ten reported being stressed due to lack of staff, which also affects their motivation some of the time; they said:

"It can be very stressful at work. If people call in sick, me and my deputy have to be there. Like this week, [in two services] people called in sick, so I took to one and [my deputy] took to the other. You're not getting your other work done, and you're falling behind on bits ... It can be very stressful. Every day, [there are staff shortages] ..."

This stressful situation also has a positive motivational impact that relates to intrinsic motivation:

"To be honest, working on the floor is actually quite nice sometimes because you get to work with the people who technically in my mind are basically my employers... When I get to do things with them, I actually have a proper chat with them and find out what they want to do. It motivates me" (P10).

As explained, the above examples of WRS were not related to or caused by the supervisors directly; however, often the stress was alleviated by the authentic behaviours of the supervisor. Next, some of these perceived authentic behaviours are reported. Again, these interview extract examples are expanded in the appendix (see Appendix J Section 8). 
"Yes, they are very authentic... [they are] very much tied by operational problems... they're very passionate about their work, and they really can see what we're trying to do in trying to deliver a service for a person... their strengths are they are very much empathic... they are very natural, and they let us do our jobs. We're not managed into a corner... [The stress regarding service cuts does] affect my motivation. [However], you do the extra mile because you know that they are going to be behind you and they understand where you're trying to go... I think they're alleviating [the stress] because I think the stress is coming from something else" (P1)."

The authentic behaviours of participant five also alleviated the extensive levels of stress that this participant experienced, as explained in the following extracts:

"Interviewer: How did your own supervisor support you and/or not support you?

P5: They were fantastic. Actually, I have to say they were really really good. I actually feel if it was any of other of the managers that I was reporting to, I probably would have been fired. It was that level of-- ... They are a very rational person. They said, "Look, I understand why you're upset etc." ... I do think they are very authentic. They are very honest. They are very open and very transparent. I know they tell me and other colleagues reporting to them, exactly [what the] the lay of the land is.

Interviewer: Do you think your supervisor affects your levels of motivation? Maybe I'll put it in another way. The stress we talked about earlier... was your supervisor helping you in any way to recover from that [lost] motivation--? 
P5: Absolutely. They had made themselves more available... they are very supportive."

In addition, participant six explained how they find their supervisor's authentic traits to be of benefit to them; they said:

"I definitely find my supervisor to be an authentic leader-- ... [they are] Open, transparent and share their experiences. Yes, so communication, goes back to when I was discussing with them when I was going through the physical outburst, and they communicated well to me what they had been trying. I felt their door was always open and even sometimes they could have been in the thick of a difficult situation themselves, they are very good at communicating, "Okay, I just need 10 minutes, and then I'll come and find you," and then did that. Yeah, great values. Their values, there were some things that they could then bend on, but there were other things that they stuck very high and fast when it came to values. The clients were always front and centre for them. I find that my values aligned very much with their values ...

Interviewer: We may have touched on this, but do you think your supervisor then affects your motivation?

P6: Yes, I definitely do. In the past, I've had different supervisors that wouldn't instil a great [motivation]. I suppose it comes down to respect again, but I suppose if you see your leader working hard and going above and beyond, that inspires you to want to do that as well.

Interviewer: ... Do you think that your supervisor then affects your levels of stress, either positively or negatively? 
P6: Definitely. Yes, I think they do. I think positively in my case.”

Lastly, participant ten overall found their supervisor to be authentic, but was slightly put off by them being easily distracted. When asked "Do you feel your current supervisor to be or not to be authentic, participant ten said: “At times, yes. I feel like they can be preoccupied. They can be distracted quite easily...”. However, participant ten did report the following authentic behaviours:

“... I've had difficulties during the year, and they have been really supportive. Just personal stuff and they have been really supportive of that... If they said that they are going to do something or follow up with something, they will. I do think if there is ever an issue, [they will follow up and help get it sorted]. They see down the line - right where we need to have a meeting with this person or that person, and they chase people up as well."

The interview extracts above showed how authenticity in a supervisor could alleviate stress and reinvigorate lost motivation in the follower. Again, the appendix expands on many of the abstract outlines in all of the themes above and thereby puts the examples into more context (see Appendix J). However, as mentioned, some details have been excluded to ensure anonymity.

Next, a summary of the qualitative study is outlined. This is followed by the final section, in which both studies one and two are discussed in line with the implications. This section also includes the recommendations and limitations of the study. 


\subsection{Summary of the Qualitative study}

Study two undertook the interviewing of ten participants. Each participant was asked a series of semi-structured questions about their stress experiences.

The thematic analysis identified three major themes. The first theme related to staff who had experienced stressful events and found that their supervisors' lack of authentic behaviours increased their stress and reduced motivation, at least for a time. The second theme included participants who found their supervisors to be authentic overall and had little to no stress or reduced motivation levels. Lastly, the third theme relates to participants who experienced stressful events but found their supervisors to be authentic overall, and primarily reported that these supervisors were supportive and thereby helped to reduce their stress.

These findings converge with the results of the first study: that is, when followers perceive their supervisor to be authentic in their leadership style, stress is reduced, and motivation increased.

There are two interview questions that have not been covered in the results above but are discussed next. The first question is “is feedback and recognition important to you?" In all cases, the participants felt that feedback and recognition were important to them. Participant seven was the only exception, to some degree, expressing that feedback is and yet is not important to them: "It is, and it isn't. I can cope without it. I'm more stressed about what the people I manage think about me and the people that I care for" (see Appendix J, section 9 for the remainder of the extracts related to the importance of feedback and recognition).

Generally, positive feedback was appreciated by the participants and overall enhanced their mood. However, negative feedback was also sought. Some of the participants pointed out that negative feedback helped them take corrective action and learn from their mistakes.

Lastly, the participants who experienced stress were asked about the symptoms they felt 
when stressed (see Appendix J, section 10 for reported stress symptoms and negative feelings).

However, in this case, the participant's identifier has not been added to the extract for the purpose of ensuring anonymity. Because of the importance of anonymity, an extensive quantity of the interview transcripts has been excluded, and unfortunately, this has resulted in the loss of some rich descriptive data and context. There was extensive consultation with the participants to determine what could and could not be included and where paraphrasing was required. To give a synopsis of the reported causes of WRS, stress symptoms/negative feelings and reported authentic and non-authentic leadership behaviours identified during the thematic analysis, a list is provided below (see Table 2).

Table 2: Reported work-related stress causes, symptoms and feelings, Authentic and NonAuthentic Behaviours

\begin{tabular}{|c|c|c|c|}
\hline $\begin{array}{l}\text { Causes of } \\
\text { WRS }\end{array}$ & $\begin{array}{l}\text { Stress symptoms and } \\
\text { negative feelings }\end{array}$ & $\begin{array}{l}\text { Authentic } \\
\text { Leadership Behaviours }\end{array}$ & $\begin{array}{l}\text { Non-Authentic } \\
\text { Leadership Behaviours }\end{array}$ \\
\hline - Panicked supervisor & - Undermined & $\begin{array}{l}\text { Follows through and } \\
\text { sees down the line }\end{array}$ & - Is not self-aware \\
\hline - Supervisor conflict & - Frustrated & $\begin{array}{l}\text { - Makes staff feel } \\
\text { valued }\end{array}$ & $\begin{array}{l}\text { - Does not share true } \\
\text { thoughts and feelings }\end{array}$ \\
\hline $\begin{array}{l}\text { - Working with clients } \\
\text { is inherently stressful }\end{array}$ & - Worried & - Respects others & - Is not listening \\
\hline $\begin{array}{l}\text { Supervisor poor } \\
\text { communication }\end{array}$ & - Frightened & - Cares about the clients & - Is reactive \\
\hline $\begin{array}{l}\text { - Nowhere else to turn } \\
\text { for help }\end{array}$ & - Self-doubt & $\begin{array}{l}\text { - Takes an interest in } \\
\text { employees }\end{array}$ & $\begin{array}{l}\text { - Is insecure and feels } \\
\text { threatened by staff }\end{array}$ \\
\hline - Budgets cuts & - Unappreciated & - Is honest & $\begin{array}{l}\text { - Is disrespectful toward } \\
\text { staff }\end{array}$ \\
\hline - Clients' needs not met & - Lack of sleep & $\begin{array}{l}\text { - Looks at the big } \\
\text { picture }\end{array}$ & $\begin{array}{l}\text { - Is not open or } \\
\text { transparent }\end{array}$ \\
\hline - Rude staff & - Angry & - Is rational & $\begin{array}{l}\text { - Is not open to being } \\
\text { challenged }\end{array}$ \\
\hline $\begin{array}{l}\text { - Middle management } \\
\text { having to cover for } \\
\text { staff (linked to budget } \\
\text { and staff shortages) }\end{array}$ & - Upset & - Is self-aware & - Is not being honest \\
\hline $\begin{array}{l}\text { - Client challenging } \\
\text { behaviours }\end{array}$ & - Disappointed & - Has a passion for work & - Is not client-focused \\
\hline - Lack of trust & - Compromised & - Is passionate & $\begin{array}{l}\text { - Is easily influenced by } \\
\text { others }\end{array}$ \\
\hline
\end{tabular}




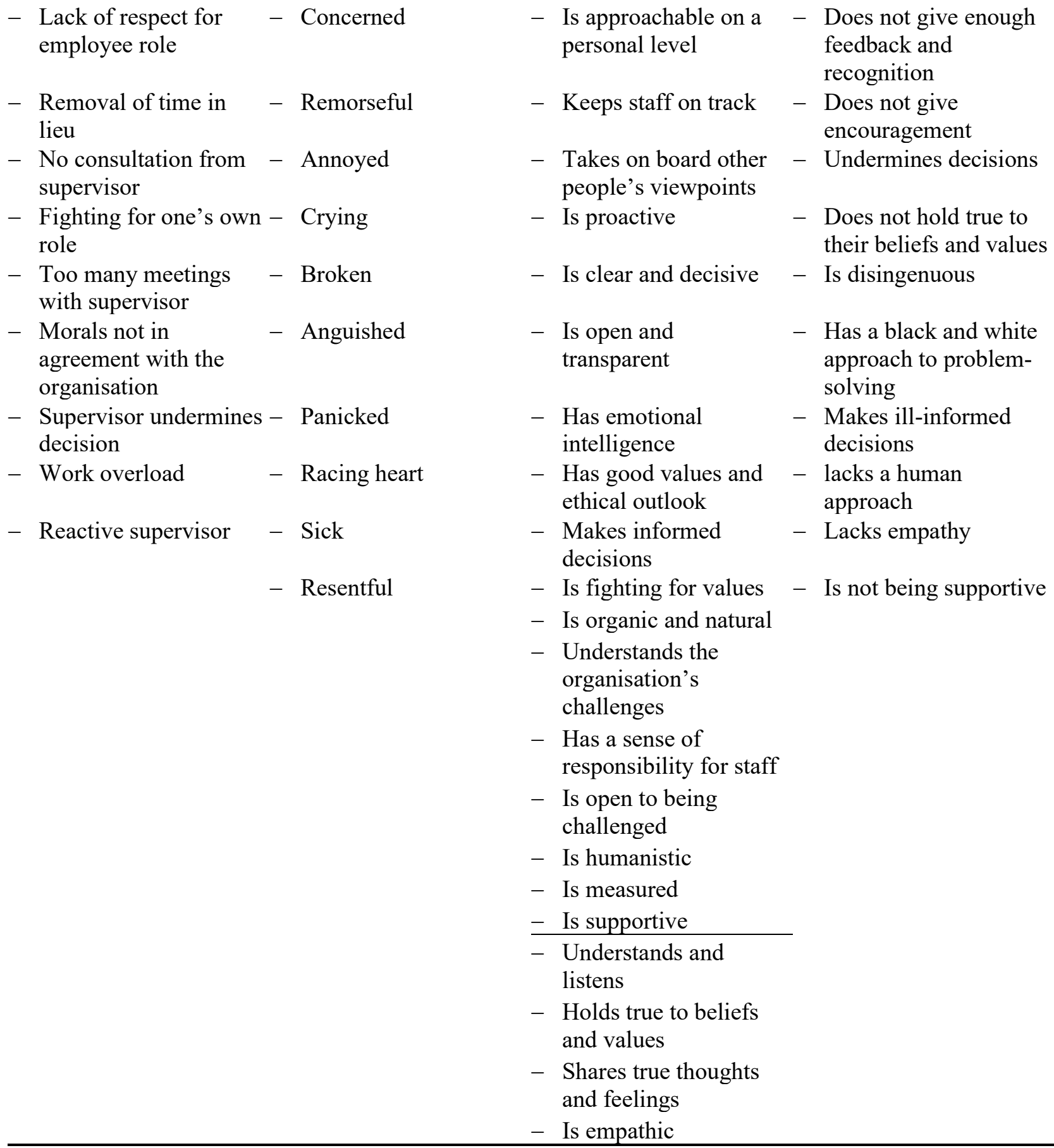

In the final section, the findings from both studies will be discussed in the context of their significant potential organisational impact. In addition, overall research limitations and future recommendations are discussed. 


\section{Discussion}

This final section reviews and summarises the purpose and overall findings of the study. In addition, conclusions are drawn, and the implications of the findings are discussed. Recommendations for organisational change and future research are also covered. Finally, the research limitations and what was done to address them are outlined.

The aim of this research was to provide supporting evidence for the central research question posed: “To what extent does AL contribute to followers' WRS and JM in the context of the intellectual disability sector in Ireland?" To reiterate the essence of authentic leadership that this research is based on Walumbwa et al. (2008, p. 94) specifically defined AL as:

A pattern of leader behaviour that draws upon and promotes both positive psychological capacities and a positive ethical climate, to foster greater self-awareness, an internalised moral perspective, balanced processing of information, and relational transparency on the part of leaders working with followers, fostering positive self-development.

The findings and results of the research undertaken in studies one and two are reported in detail in chapter four and five, above. To begin with the overall summarised findings, how they related to previous research and their implications are discussed below.

\subsection{Discussion and Implications}

The 'Internalised Moral Perspective' sub-dimension of AL refers to having a set of ethical and moral standards and the ability to self-regulate one's decision-making so that it is in line with those morals (Neider \& Schriesheim, 2011; Walumbwa et al., 2008). Self-awareness is therefore important for one's internalised moral perspective because one needs to be self-aware before one can self-regulate and make decisions based on one's own values. Moreover, Taylor-Bianco and 
Schermerhorn explained that the first step to self-regulation is self-awareness (2006).

Interestingly, moral perspective was the only sub-dimension of AL that had a relationship with controlled motivation as well as autonomous motivation. This demonstrates the importance employees put on their leaders having a highly ethical and moral outlook. In line with AL theory, it is important that leaders hold true to those values even when pressure is put on them to act immorally, noting that this takes courage (May et al., 2003). As we know, controlled motivation includes only external regulation and introjected regulation (the lesser self-determined state of extrinsic motivation). In study two interviewees were asked what motivated them at work (see Appendix J Section 1) this showed that most participants are motivated by the desire to improve the lives of service-users (a highly ethical and autonomous work motivation). Hickey (2014a) refers to prosocial motivation as "the desire to engage in work that is beneficial to others" (p. 1). Moreover, the prosocial motivation reported by the interview participants in study two, may explain why only ALM correlates with controlled motivation in study one and suggests that ethical leadership is of high importance to the participants. This further emphasises the importance of ethical and moral leadership for staff in the participating organisation. As pointed out by Ratelle et al. (2007), when a person has high autonomous motivation in conjunction with high controlled motivation, it leads to higher achievements and improved outcomes. These results are consistent with previous research (Avolio et al., 2004; Hidayat, 2016; Joo \& Jo, 2015) that found that leaders with high moral standards who conduct their business with integrity enhanced followers' levels of self-determination and therefore lend support to hypothesis H1b.

The direct relationship between AL and autonomous motivation, analysed via the mediation analysis (study one), found that as each of the AL sub-dimensions increase, autonomous motivation also increases. This is in line with previous research that has shown that 
autonomous motivation is related to work outcomes such as performance, satisfaction, trust, commitment and well-being in the workplace (Gagné \& Deci, 2005; Howard et al., 2016). In addition, Howard et al. (2016) found that material reward may have a negative impact on performance and well-being, whereas meaning, interest and pleasure have a positive impact on performance and well-being. This further emphasises the importance of keeping staff autonomously motivated, and as this study shows, AL can help to ensure that this is the case.

AL has been shown to improve autonomous motivation in staff; however, as the mediation analysis found, WRS negatively impacts on autonomous motivation through AL. In addition, the correlation analysis found a significant negative association between WRS and autonomous motivation, as predicted by hypothesis H1c. Research conducted by Hickey (2014b) in the intellectual disability services sector in Canada found that prosocial motivation acts as a buffer against the stresses frontline works experience, and prosocial motivation positively impacts employees' level of stress and burnout while study one found that when an employee is stressed, autonomous motivation decreases. However, a study by the same author (Hickey, 2014a), again in the intellectual disability services sector, found that "prosocial motivation, when interacted with positive emotions or perceptions of organisational support, was associated with increased emotional exhaustion" (p. 84). This is in part explained by the author as being associated with "the ideals of community living confronted by the shortcomings of a financially constrained service system" (p. 84). One of the key take-homes from the study attributes frontline staff burnout to the inability to support people in the manner they feel is required, which is in line with the findings of study two (see Appendix J, Section 7, P1). Interestingly, budget cuts were mentioned by a few times in the interview in study two as being a source of stress.

Study two has shown that work-related stress can arise due to a variety of factors, 
including direct conflict with one's supervisor, managerial perceived mismanagement, co-worker incivility, lack of supervisory support and wider organisational challenges, including lack of funding. However, both studies one and two have found that regardless of the causes of WRS, AL behaviours can significantly reduce this stress. Previous studies have found that co-worker incivility in new graduate nurses leads to burnout. However, this can be mitigated by AL behaviours (Laschinger, Leiter, et al., 2009; Wing et al., 2015). Moreover, within the nursing community, incivility has been associated with a number of negative organisational outcomes, including increased WRS and burnout, decreased job satisfaction, reduced commitment and intention to leave (Laschinger, Leiter, et al., 2009; Smith et al., 2010). In addition, studies have shown that incivility in the workplace can impact on productivity and cost to the organisation (Hutton, 2008; Laschinger, Finegan, et al., 2009; Lewis \& Malecha, 2011).

As outlined in the SLR, studies that specifically look at the impact of AL on WRS are scant. However, there have been several studies that look at the relationship between AL and burnout. Maslach et al. (2001) explain that Burnout is "a prolonged response to chronic emotional and interpersonal stressors on the job and is defined by the three dimensions of emotional exhaustion, cynicism, and inefficacy" (p. 397). Therefore, burnout, although a broader concept than WRS, is considered as synonymous.

Borgogni, Consiglio, Alessandri and Schaufeli (2012) proposed an expanded model of burnout that includes interpersonal strain at work as an additional dimension. They explain that interpersonal strain relates to the excessive emotional labour that often comes with social interactions and can lead to subsequent disengagement of interaction with co-workers. A study by Laschinger et al. (2015) that looked at the relationship between AL, burnout and mental health in new graduate nurses in Canada incorporated the expanded model of burnout that includes 
interpersonal strain. In congruence with the present study, Laschinger et al.'s (2015) findings suggest that when leaders demonstrate AL behaviours, employees - in this case, nurses - are less likely to suffer from burnout and mental health issues. In addition, Laschinger et al. (2015) found empirical support for the proposal by Borgogni and colleagues (2012) that interpersonal strain is a core dimension of burnout theory. Moreover, interpersonal strain and conflict emerged as an issue several times during the interviews conducted in study two. In addition, a study by Consiglio (2014) examined interpersonal strain in hospital staff as a facet of burnout and found that staff can suffer from chronic emotional exhaustion and demotivation, which can activate a negative, detached response to social interaction and is associated with health complaints.

Although bullying was mentioned by just one interview participant in study two (see Appendix J Section 7), it was a very difficult situation for the participant to cope with. The issues resulted in the participant suffering from stress and subsequently having to take some time off work. Bullying in the workplace is a serious issue which can lead to absenteeism, stress, poor mental health, and intention to leave (Berthelsen et al., 2011; Power et al., 2013). Workplace bullying was described by Hoel, Sparks and Cooper (2001) in a report commissioned by the International Labour Organisation to include behaviours such as "withholding information which may affect someone's work, attempts to find fault with someone's work, public humiliation, gossiping and social exclusion or isolation" (p. 19). The reported outlined that bullying can often lead to stress and found that there can be major cost savings when bullying is not tolerated in the workplace. A time-lagged study by Laschinger and Fida, (2014b) examined the relationship between AL and nurses' experiences of workplace bullying and burnout over one year. It found that AL behaviours were associated with reduced work-related bullying and burnout. These findings are consistent with study one in that AL was found to reduce follower stress, and study 
two, which showed that positive, supportive leadership can reduced stress. An example of this from study two is participant five (see Appendix J, Section 7), whose authentic supervisor supported them during their time of stress, which was reported to be due to perceived bullying by another manager. Laschinger and Fida (2014b) explain:

...being more sensitive to the requirements for effective work performance and ensuring resources are in place to empower employees to accomplish their work in a meaningful way, authentic leaders create conditions that are less amenable to the emergence of conflicts and frustration among employees. (p. 748).

The above findings by Laschinger and Fida (2014b) were consistent with a study that examined workplace bullying, burnout and retention outcomes and also found that AL decreases the likelihood of bullying and burnout in nurses, which in turn minimised intention to leave (Laschinger et al., 2012).

A recurring topic in study two showed that supervisors who are perceived to be supportive are also helpful in reducing follower stress. The results are consistent with previous research which found that when health care workers receive supervisory support, they experience less emotional exhaustion and better mental health (Balogun et al., 2002; Read \& Laschinger, 2015; Spence Laschinger et al., 2019). Moreover, emotional exhaustion is a cause of high-level stress (Spence Laschinger et al., 2019). One element of support is receiving enough feedback from one's supervisor, feedback is discussed next.

Study two also found that most participants viewed feedback and recognition as important. However, the feedback must be honest, non-biased and properly reflect the efforts, performance and results of their work, and should be based on accurate information before it is 
seen as fair (Sparr \& Sonnentag, 2008). However, when leaders-member-exchange - that is, the quality of the relationship between a supervisor and their followers is poor (Graen \& Uhl-Bien, 1995 ) - fairness perceptions of feedback can be damaged, which in turn can lead to job depression and turnover intentions (Sparr \& Sonnentag, 2008). Moreover, Sparr and Sonnentag (2008) also found that the more often negative feedback is given by a supervisor and received by a follower, the more likely it is that the follower will experience job anxiety. It is therefore important that organisations implement clear and fair feedback and performance procedures to ensure that all staff are treated equally in this regard. In addition, AL and authentic conversations are thought to be conducive to creating a culture where open and honest feedback and subsequent learning can flourish (Berson et al., 2006; Mazutis \& Natalie, 2007).

Finally, how the negative consequences of poor leadership - resulting in stress and demotivation of staff - affect the quality of care received by services users are discussed. A study by Robertson et al. (2005) identified (from previous research) the following seven potential sources of stress for staff working with people who have an intellectual disability: 1) service user challenging behaviours, 2) poor user skills, 3) lack of staff support, 4) lack of resources, 5) lowstatus job, 6) bureaucracy and 7) work-home conflict. Moreover, various staff behaviours, such as absenteeism and staff turnover, have an indirect negative effect on the quality of services users in the intellectual disability sector (Hatton, 1999; J. Robertson et al., 2005). In addition, a number of studies have shown that WRS, and related outcomes, have a negative impact on the quality of care received by users in health care settings (Boamah et al., 2017; Galletta et al., 2016; Van Bogaert et al., 2013; Wong \& Giallonardo, 2013). For example, Wong and Giallonardo (2013) examined the association between AL, areas of work-life and adverse patient outcomes with trust in one's manager as a mediator between AL and areas of work-life. They found that an increased 
level of trust in one's manager and perceived authenticity of one's manager resulted in significantly lower adverse events. In health care management and adverse event is unintended harm that may result in serious injuries including hospital stay, disability or death (Baker, 2004).

This study aimed to find evidence to answer the following research question "To what extent does AL contribute to follower WRS and JM in the context of the intellectual disability sector in Ireland?" The evidence found in the initial systematic literature review and the results of studies one and two clearly show that AL behaviours have a significant role to play in reducing WRS and increasing JM mainly in various organisational settings, including health care and the intellectual disability sector. Moreover, the supporting evidence shows that minimising WRS has positive organisational, employee and services-user benefits.

The next section outlines recommendations for organisations, policymakers, and future research and concludes with an outline of the limitations of studies one and two. 


\subsection{Recommendations}

The increase of WRS in the health care sector (see Russell et al., 2018) and the general issues faced by this sector, including the lack of funding and staff shortages (see Genio, n.d.; Inclusion Ireland, 2019; Jayaprakash, O’Sullivan, Bey, \& Ahmed, 2009; Rashwan, Abo-Hamad, \& Arisha, 2015) demonstrate the importance of running organisations in the most efficient and effective way possible, in order to achieve sustainable business performance. Authentic leadership can improve sustainable business performance, for example, a characteristic of AL is to empower employees and be supportive of their suggestions and ideas, because this increases employee involvement, commitment and proficiency, resulting in improved organisational performance (Leroy et al., 2012; Rego et al., 2012). Due to the limited studies found through the literature review in the intellectual disability sector, more research in this area is needed to further investigate the benefits of AL practices in organisations that provide services to people with an intellectual disability. Moreover, WRS, its causes, outcomes, and how it can be eradicated from the workplace represent a complex multi-faceted problem. Therefore, the researcher recommends further research in the area, with a broadening of scope to incorporate multiple variables such as leader-member exchange, performance, and service-user's outcomes, to mention just a few. More in-depth research such as this will give all interested parties a better understanding of how to improve leadership behaviours, reduce WRS and improve JM.

Given the evidence in support of AL practice regarding positive organisational, employee and service-user outcomes, there is strong evidence to suggest that developing authentic leaders at all levels within an organisation is a positive and worthwhile endeavour. Therefore, it is recommended that organisations develop AL behaviours in every person working in the organisation. How this may be accomplished is discussed next.

Training people to become authentic leaders is not an easy or straightforward task because 
we all have different personalities, while some may have a natural tendency toward authenticity traits others may not. Cooper (2005) argues that personality traits and cultural differences should be considered in AL development. Nevertheless, research has shown that AL and the associated personality traits can be developed, given the appropriate training and development (Cooper et al., 2005; May et al., 2003). Nevertheless, attempts have been made to create methods of developing and training people to be authentic leaders. For example, Baron and Parent's (2015) study on AL development found that there are five steps to take, as follows: 1) is for leaders to increase their self-awareness, to become aware of how they relate to others and recognise the way they act. 2) is to identify possible new or different ways of behaving and setting goals. 3) is to practice and try out these new ways of behaving to determine whether they are having the desired impact. 4) is to recognise the benefits brought about by the behavioural changes. 5) is to transfer these new skills and behaviours across the organisation.

Luthans and Avolio (2003), in their paper on AL development, emphasise the importance of integrating positive organisational behaviour such as vision, strategy and culture along with a full range of AL behaviours as part and parcel of developing AL (see Figure 20 below).

Moreover, Luthans and Avolio (2003) argue that "Ideally, AL behaviour should cascade from the very top of organisations down to the newest employee. Such diffusion will only become a reality based on the character, actions, and behaviours of the leaders" (p. 244). In addition, AL and authentic conversations in conjunction with feed-forward and feedback learning will help with the detection and correction of errors across all levels of analysis and thereby influence learning across an organisation (Mazutis \& Natalie, 2007). 


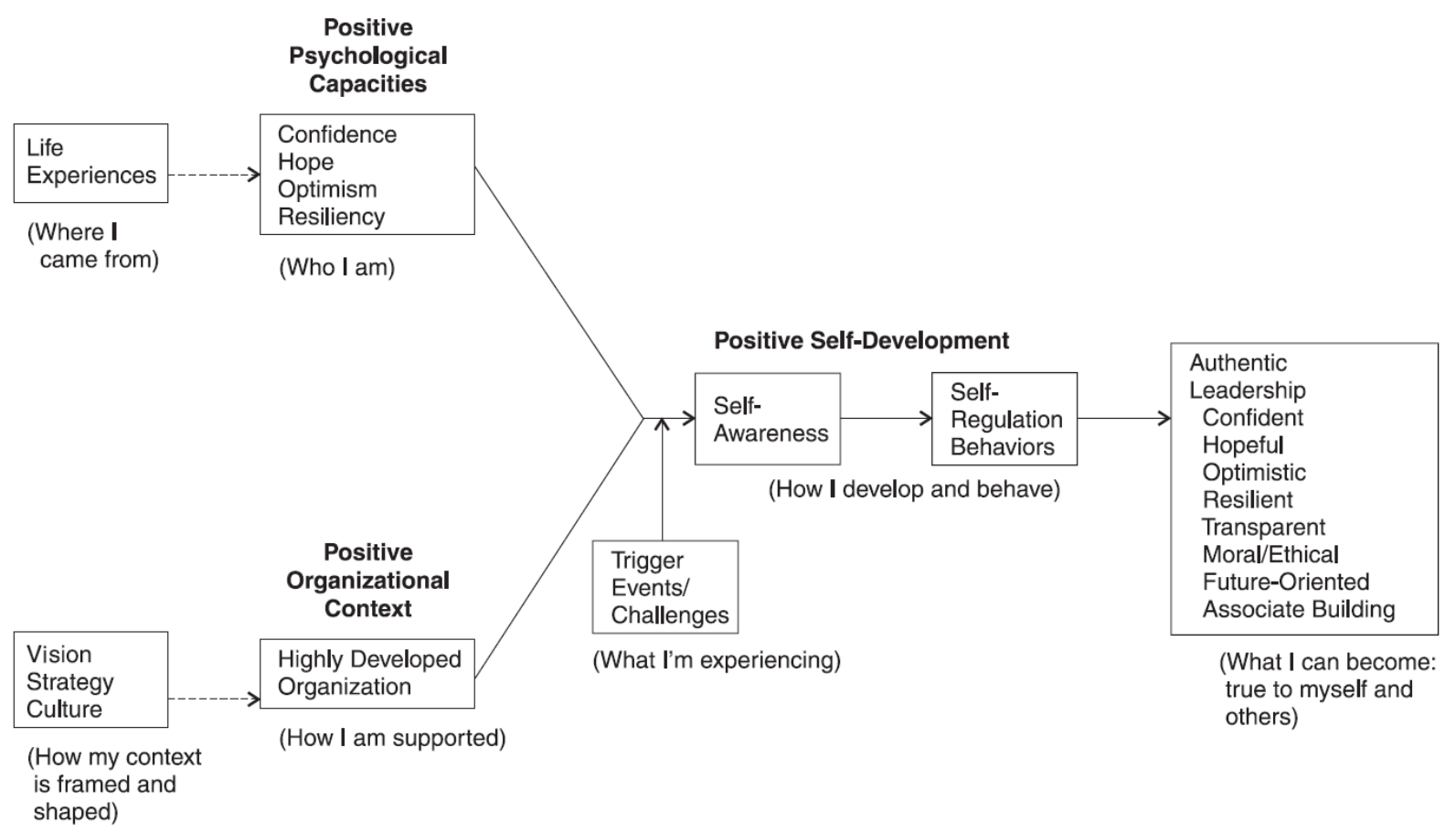

Figure 20: Authentic Leadership Development Model (Luthans \& Avolio, 2003)

Based on the evidence presented throughout this thesis, the development of AL is the most important recommendation offered and it is recommended, AL development become part of the participating organisation's strategic plan and vision. However, a focus on how stress in the workplace can be reduced is also important. For example, training around staff self-care and wellbeing may benefit staff who are feeling stressed in learning how to cope. Study two showed that some stressful situations are inherently unavoidable, such as dealing with clients' challenging behaviours. However, the development of AL behaviours aims where possible to prevent WRS from developing in the first instance. Nevertheless, not all WRS is preventable; therefore, giving staff the tools to deal with stress is a useful and valid measure to address the issue. The implementation of continuous professional development will also ensure that staff have the up-todate tools to deal with issues such as challenging behaviours and good managerial practices.

Lastly, study two found lack of funding can be an indirect cause of WRS (see Appendix J 
Section 2), tackling the issue head-on will help to prevent this source of stress from occurring in the first instance. One measure all organisations (private or public) can take to become more efficient and thereby save time and money is to incorporate Lean Six Sigma (LSS) into their dayto-day running of the organisation. Although LSS is not traditional in intellectual disability nonprofit organisations - rather, its origins lie in the manufacturing industry (see Womack \& Jones, 2003, p. 15) - Antony (2006) explains that it can bring benefits, including improved management decision-making based on evidence, improved organisation knowledge for problem-solving and a better understanding of customer needs. Each of these benefits can lead to increased job satisfaction and change the organisational culture from reactive to proactive thinking.

This concludes the recommendations for future research and organisational change. The next and last sub-sections will draw some conclusions from the overall study and outline the limitations of the research presented in this thesis.

\subsection{Conclusion}

The literature surrounding this topic suggests that AL behaviours from the top-level management down to the individual will have a positive impact on reducing WRS and improve JM, particularly autonomous motivation in the workplace. Moreover, the benefits of a stress-free workplace is multifaceted and affects every level of an organisation including both staff and service-user. However, the research in the area specific to the intellectual disability sector was scant. Moreover, the literature, although growing, is also limited in the wider area of health care. Therefore, this research provides new evidence and data for policymakers as well as adding to the existing body of knowledge. In addition, it is hoped that this research will provide a better understanding of WRS and motivation and how AL can address these issues in the intellectual disability sector. 


\subsection{Limitations}

The first limitation is concerned with the data collection strategy. Both the survey and interviews were participant retrospective self-reported measures. Examples of self-reported measures include social desirability responding and recall bias (see Stone et al., 1999). Although the mixed-methods design provides an element of validating the self-reported survey data with the qualitative data, which facilitates an understanding of personal experiences through the interviews, only approximately $10 \%$ of the survey participants were interviewed.

Secondly, this study was cross-sectional (a single snapshot in time) and not longitudinal (Arnett \& Claas, 2017; Levin, 2006). Arnett and Claas (2017) advise that "cross-sectional studies provide the least robust evidence that a risk factor plays a causal role in disease aetiology - hence the use of the word 'association' to cautiously describe the relationship between a risk factor and a disease" (p. 59). Furthermore, they explain due to the single point in time of cross-sectional studies, it is not possible to determine when the risk occurred. Moreover, cross-sectional studies are susceptible to prevalence-incidence bias (or Neyman bias) (Arnett \& Claas, 2017; Levin, 2006). For example, the researcher may recruit only people whom they know are stressed. To mitigate the risk of incidence bias, this study randomly selected the interview participants and all employees of the organisation were invited to take the survey. Nevertheless, longitudinal research gives cumulative effects of the research over a period of time (Rajulton, 2001; Understanding Society Insights, 2014) and therefore may be a more reliable option for future research to consider.

Lastly, the survey and interview sample size were relatively small due to the researchers limited time availability and may impact the validity of the analysis. 


\section{References}

Adil, A., \& Kamal, A. (2018). Impact of perceived authentic leadership and psychological capital on burnout: Mediating role of psychological ownership. Psychological Studies, 63, 243252. https://doi.org/10.1007/s12646-018-0446-x

Adil, A., \& Kamal, A. (2019). Authentic leadership and psychological capital in job demandsresources model among Pakistani university teachers. International Journal of Leadership in Education, 1-21. https://doi.org/10.1080/13603124.2019.1580772

Ahmad, I., Zafar, M. A., \& Shahzad, K. (2015). Authentic leadership style and academia's creativity in higher education institutions: Intrinsic motivation and mood as mediators. Transylvanian Review of Administrative Sciences, 46, 15.

AL Sahi AL Zaabi, M. S., Ahmad, K. Z., \& Hossan, C. (2016). Authentic leadership, work engagement and organizational citizenship behaviors in petroleum company. International Journal of Productivity and Performance Management, 65, 811-830. https://doi.org/10.1108/JJPPM-01-2016-0023

Anderson, M. H., \& Sun, P. Y. T. (2017). Reviewing leadership styles: Overlaps and the need for a new 'full-range' theory: Reviewing leadership styles. International Journal of Management Reviews, 19, 76-96. https://doi.org/10.1111/ijmr.12082

Antony, J. (2006). Six sigma for service processes. Business Process Management Journal, 12(2), 234-248. https://doi.org/10.1108/14637150610657558

Arnett, D. K., \& Claas, S. A. (2017). Introduction to Epidemiology. In Clinical and Translational Science (pp. 53-69). Elsevier. https://doi.org/10.1016/B978-0-12-802101-9.00004-1

Attride-Stirling, J. (2001). Thematic networks: An analytic tool for qualitative research. Qualitative Research, 1, 385-405. https://doi.org/10.1177/146879410100100307

Avolio, B. J., \& Gardner, W. L. (2005). Authentic leadership development: Getting to the root of positive forms of leadership. The Leadership Quarterly, 16, 315-338. https://doi.org/10.1016/j.leaqua.2005.03.001

Avolio, B. J., Gardner, W. L., Walumbwa, F. O., Luthans, F., \& May, D. R. (2004). Unlocking the mask: A look at the process by which authentic leaders impact follower attitudes and 
behaviors. The Leadership Quarterly, 15, 801-823.

https://doi.org/10.1016/j.leaqua.2004.09.003

Baker, G. R. (2004). The Canadian Adverse Events Study: The incidence of adverse events among hospital patients in Canada. Canadian Medical Association Journal, 170(11), 1678-1686. https://doi.org/10.1503/cmaj.1040498

Bakker, A. B., \& Demerouti, E. (2007). The Job Demands-Resources model: State of the art. Journal of Managerial Psychology, 22, 309-328. https://doi.org/10.1108/02683940710733115

Balogun, J. A., Titiloye, V., Oyeyemi, A., Katz, J., \& Balogun, A. (2002). Prevalence and determinants of burnout among physical and occupational therapists. Journal Allied Health, 31, 131-139.

Barends, E., Rousseau, D. M., \& Briner, R. B. (2014). Evidence-Based Management: The Basic Principles. Amsterdam: Center for Evidence-Based Management. http://www.cebma.org

Baron, L., \& Parent, É. (2015). Developing authentic leadership within a training context: Three phenomena supporting the individual development process. Journal of Leadership \& Organizational Studies, 22, 37-53. https://doi.org/10.1177/1548051813519501

Barsky, A., \& Kaplan, S. A. (2007). If you feel bad, it's unfair: A quantitative synthesis of affect and organizational justice perceptions. Journal of Applied Psychology, 92, 286-295. https://doi.org/10.1037/0021-9010.92.1.286

Berson, Y., Waldman, D. A., Galvin, B. M., \& Keller, R. T. (2006). Leadership and organizational learning: A multiple levels perspective. Leadership Quarterly, 17, 577-594.

Berthelsen, M., Skogstad, A., Lau, B., \& Einarsen, S. (2011). Do they stay or do they go?: A longitudinal study of intentions to leave and exclusion from working life among targets of workplace bullying. International Journal of Manpower, 32, 178-193.

https://doi.org/10.1108/01437721111130198

Bhui, K., Dinos, S., Galant-Miecznikowska, M., de Jongh, B., \& Stansfeld, S. (2016).

Perceptions of work stress causes and effective interventions in employees working in public, private and non-governmental organisations: A qualitative study. BJ Psych Bulletin, 40, 318-325. https://doi.org/10.1192/pb.bp.115.050823 
Blake, N., Blayney, F., Loera, T., Rowlett, C., \& Schmidt, D. (2012). A model of authentic leadership to support a healthy work environment. AACN Advanced Critical Care, 23(4), 358-361. Scopus. https://doi.org/10.1097/NCI.0b013e31826b4d1b

Boamah, S. A., Read, E. A., \& Laschinger, H. K. S. (2017). Factors influencing new graduate nurse burnout development, job satisfaction and patient care quality: A time-lagged study. Journal of Advanced Nursing, 73, 1182-1195. https://doi.org/10.1111/jan.13215

Bordei, I. (2019). The influence of authentic leadership on public employees analyzed through self-determination theory: A case study in the republic of Moldova. Journal of Spatial and Organizational Dynamics, 7, 125-143.

Borgogni, L., Consiglio, C., Alessandri, G., \& Schaufeli, W. B. (2012). "Don't throw the baby out with the bathwater!” Interpersonal strain at work and burnout. European Journal of Work and Organizational Psychology, 21, 875-898.

https://doi.org/10.1080/1359432X.2011.598653

Bowling, N. A., Huang, J. L., Bragg, C. B., Khazon, S., Liu, M., \& Blackmore, C. E. (2016). Who cares and who is careless? Insufficient effort responding as a reflection of respondent personality. Journal of Personality and Social Psychology, 111, 218-229. https://doi.org/10.1037/pspp0000085

Boynton, P. M., \& Greenhalgh, T. (2004). Selecting, designing, and developing your questionnaire. $B M J, 328,1312-1315$. https://doi.org/10.1136/bmj.328.7451.1312

Braun, V., \& Clarke, V. (2006). Using thematic analysis in psychology. Qualitative Research in Psychology, 3, 77-101. https://doi.org/10.1191/1478088706qp063oa

Bryman, A. (2006). Integrating quantitative and qualitative research: How is it done? Qualitative Research, 6, 97-113. https://doi.org/10.1177/1468794106058877

Bryman, A. (2009). Mixed methods in organisational research. In D. Buchanan, \& A. Bryman (Eds.) The SAGE Handbook of Organizational Research Methods (pp. 516-531). SAGE Publications Ltd.

Bryman, A., \& Bell, E. (2015). Business research methods (4th ed.). Oxford University Press.

Cartwright, S., \& Cooper, C. L. (2014). Towards organizational health: Stress, positive 
organizational behavior, and employee well-being. In G. F. Bauer \& O. Hämmig, Bridging Occupational, Organizational and Public Health (pp. 29-42). Springer Netherlands. http://link.springer.com/10.1007/978-94-007-5640-3_3

Cashman, K. (2003). Awakening the leader within: A story of transformation. Hoboken.

Cashman, K. (2008). Leadership from the inside out: Becoming a leader for life. (2nd ed.). Berret-Koehler.

Clarivate. (2019). Web of Science Core Collection. Clarivate. https://clarivate.com/products/webof-science/web-science-form/web-science-core-collection/

Cohen, S. (1994). Perceived Stress Scale—Mind Garden. https://www.mindgarden.com/132perceived-stress-scale

Cohen, S., Kamarck, T., \& Mermelstein, R. (1983). A global measure of perceived stress. Journal of Health and Social Behavior, 24, 385. https://doi.org/10.2307/2136404

Cohen, S., \& Williamson, G. M. (1988). Perceived stress in a probability sample of the united states. In The social psychology of health: Claremont Symposium on applied social psychology. (In S. Spacapan \& S. Oskamp (Eds.)).

Colquitt, A. J., Greenberg, J., \& Zapata-Phelan, C. P. (2005). What is organizational justice? A historical overview. In J. Greenberg \& A. J. Colquitt (Eds.), Handbook of Organizational Justice (Kindle Edition, pp. 3-56). Lawrence Erlbaum Associates.

Consiglio, C. (2014). Interpersonal strain at work: A new burnout facet relevant for the health of hospital staff. Burnout Research, 1, 69-75. https://doi.org/10.1016/j.burn.2014.07.002

Cooper, C. D., Scandura, T. A., \& Schriesheim, C. A. (2005). Looking forward but learning from our past: Potential challenges to developing authentic leadership theory and authentic leaders. The Leadership Quarterly, 16, 475-493. https://doi.org/10.1016/j.leaqua.2005.03.008

Cooper, C. L., Cartwright, S., \& Liukkonen, P. (1996). Stress prevention in the workplace: Assessing the costs and benefits to organisations. European Foundation for the Improvement of Living and Working Conditions; UNIPUB [distributor].

Cox, T., Griffiths, A., \& Rial-González, E. (2000). Research on work-related stress. Office for 
Official Publications of the European Communities; Bernan Associates [distributor]. https://osha.europa.eu/en/publications/reports/203/view

CRD. (2009). Systematic reviews: CRD's guidance for undertaking reviews in health care. York Publishing Services Ltd.

Creswell, J. W. (2003). Research design: Qualitative, quantitative, and mixed methods approaches. (2nd ed.). Thousand Oaks, CA: SAGE Publications, Inc.

Creswell, J. W., \& Creswell, D. J. (2018). Research design: Qualitative, quantitative, and mixed methods approaches. (5th Kindle). Thousand Oaks, CA: SAGE Publications, Inc.

Creswell, W. J., \& Plano Clark, V. L. (2011). Designing and conducting mixed methods research. (2nd ed.). Thousand Oaks, CA: Sage.

De Vaus, D. A. (2014). Surveys in social research (6th Kindle Edition). Routledge.

Deci, E. L., Olafsen, A. H., \& Ryan, R. M. (2017). Self-determination theory in work organizations: The state of a science. Annual Review of Organizational Psychology and Organizational Behavior, 4, 19-43. https://doi.org/10.1146/annurev-orgpsych-032516113108

Deci, E. L., \& Ryan, R. M. (1985). Intrinsic motivation and self-determination in human behavior. New York: Plenum.

Deci, E. L., \& Ryan, R. M. (2000). The 'what' and 'why' of goal pursuits: Human needs and the self-determination of behavior. Psychological Inquiry, 11, 227-268. https://doi.org/10.1207/S15327965PLI1104_01

Demerouti, E., Bakker, A. B., Nachreiner, F., \& Schaufeli, W. B. (2001). The job demandsresources model of burnout. Journal of Applied Psychology, 86, 499-512.

Denyer, D., \& Tranfield, D. (2009). Producing a systematic review. In D. Buchanan, \& A. Bryman (Eds.) The SAGE Handbook of Organizational Research Methods (pp. 671-689,). SAGE Publications Ltd.

Denyer, D., Tranfield, D., \& van Aken, J. E. (2008). Developing design propositions through research synthesis. Organization Studies, 29, 393-413. https://doi.org/10.1177/0170840607088020 
Deveau, R., \& McGill, P. (2014). Leadership at the front line: Impact of practice leadership management style on staff experience in services for people with intellectual disability and challenging behaviour. Journal of Intellectual \& Developmental Disability, 39, 6572. https://doi.org/10.3109/13668250.2013.865718

Devereux, J., Hastings, R., \& Noone, S. (2009). Staff stress and burnout in intellectual disability services: Work stress theory and its application. Journal of Applied Research in Intellectual Disabilities, 22, 561-573. https://doi.org/10.1111/j.1468-3148.2009.00509.x

Eagly, A. H., Johannesen-Schmidt, M. C., \& Engen, M. L. van. (2003). Transformational, transactional, and laissez-faire leadership styles: A meta-analysis comparing women and men. Psychological Bulletin, 129(4), 569-591. https://doi.org/10.1037/00332909.129.4.569

EBSCO. (2019a). Academic Search Complete | EBSCO. EBSCO Information Services, Inc. | Www.Ebsco.Com. https://www.ebsco.com/products/research-databases/academic-searchcomplete

EBSCO. (2019b). Business Source Complete | EBSCO. EBSCO Information Services, Inc. | Www.Ebsco.Com. https://www.ebsco.com/products/research-databases/business-sourcecomplete

Eigel, K. M., \& Kuhnert, K. W. (2005). Authentic leadership theory and practice: Origins, effects and development: In W. L. Gardner, B. J. Avolio, \& F. O. Walumbwa (Eds.), Authentic development: Leadership development level and executive effectiveness (pp. 357-385). Oxford, UK: Elsevier Science.

Elsevier. (2020). What is Scopus Preview? - Scopus: Access and use Support Center. https://service.elsevier.com/app/answers/detail/a_id/15534/supporthub/scopus/\#tips EPPI-Centre. (n.d.). History of Systematic Reviews. Retrieved 14 July 2019, from https://eppi.ioe.ac.uk/cms/Resources/EvidenceInformedPolicyandPractice/HistoryofSyste maticReviews/tabid/68/Default.aspx

EU-OSHA. (2015). Second European survey of enterprises on new and emerging risks (ESENER-2) (p. 18) [Summary]. European Agency for Safety and Health at Work. https://publications.europa.eu/en/publication-detail/-/publication/8e26fa1e-d502-4fbd- 
$908 c-d 0 c d b 83950 a 9$

Eurofound. (2010). Work-related stress (p. 51). European Foundation for the Improvement of Living and Working Conditions.

https://www.eurofound.europa.eu/publications/report/2010/work-related-stress

Fairbrother, K., \& Warn, J. (2003). Workplace dimensions, stress and job satisfaction. Journal of Managerial Psychology, 18, 8-21. https://doi.org/10.1108/02683940310459565

Faragher, E. B. (2005). The relationship between job satisfaction and health: A meta-analysis. Occupational and Environmental Medicine, 62, 105-112. https://doi.org/10.1136/oem.2002.006734

FedVol. (2013). Making sense of individualised supports. National Federation of Voluntary Bodies. http://www.fedvol.ie/_fileupload/Immersion/Making\%20Sense $\% 20$ of $\% 20$ Benefical\%20I ndividulised\%20Supports\%20Final.pdf

Fereday, J., \& Muir-Cochrane, E. (2006). Demonstrating rigor using thematic analysis: A hybrid approach of inductive and deductive coding and theme development. International Journal of Qualitative Methods, 1, 80-92. https://doi.org/10.1177/160940690600500107

Field, A. (2018). Discovering statistics using IBM SPSS statistics. SAGE Publications Ltd.

Ford, M. T., Matthews, R. A., Wooldridge, J. D., Mishra, V., Kakar, U. M., \& Strahan, S. R. (2014). How do occupational stressor-strain effects vary with time? A review and metaanalysis of the relevance of time lags in longitudinal studies. Work \& Stress, 28, 9-30. https://doi.org/10.1080/02678373.2013.877096

Franks, B. D. (1994). What Is Stress? Quest, 46, 1-7. https://doi.org/10.1080/00336297.1994.10484106

Gagné, M., \& Deci, E. L. (2005). Self-determination theory and work motivation: Selfdetermination theory and work motivation. Journal of Organizational Behavior, 26, 331362. https://doi.org/10.1002/job.322

Gagné, M., Forest, J., Vansteenkiste, M., Crevier-Braud, L., van den Broeck, A., Aspeli, A. K., Bellerose, J., Benabou, C., Chemolli, E., Güntert, S. T., Halvari, H., Indiyastuti, D. L., 
Johnson, P. A., Molstad, M. H., Naudin, M., Ndao, A., Olafsen, A. H., Roussel, P., Wang, Z., \& Westbye, C. (2014). The multidimensional work motivation scale: Validation evidence in seven languages and nine countries. European Journal of Work and Organizational Psychology, 24, 178-196. https://doi.org/10.1080/1359432X.2013.877892

Galletta, M., Portoghese, I., D’Aloja, E., Mereu, A., Contu, P., Coppola, R. C., Finco, G., \& Campagna, M. (2016). Relationship between job burnout, psychosocial factors and health care-associated infections in critical care units. Intensive and Critical Care Nursing, 34, 59-66. https://doi.org/10.1016/j.iccn.2015.11.004

Ganster, D. C., \& Fusilier, M. R. (1989). Control in the workplace. In I. T. Robertson \& C. L. Cooper (Eds.), International review of industrial and organizational psychology (pp. 235280). Chichester, England: Wiley.

Gardner, W. L., Cogliser, C. C., Davis, K. M., \& Dickens, M. P. (2011). Authentic leadership: A review of the literature and research agenda. Leadership Quarterly Yearly Review, 22, 1120-1145. https://doi.org/10.1016/j.leaqua.2011.09.007

Genio. (n.d.). Challenges we face in disability | Genio. Challenges We Face in Disability. Retrieved 2 September 2019, from https:/www.genio.ie/challenges-we-face/disability

George, B., Sims, P., McLean, A. N., \& Mayer, D. (2007). Discovering Your Authentic Leadership. Harvard Business Review, 10.

George, W. (2003). Authentic leadership: Rediscovering the secrets to creating lasting value. Jossey-Bass.

Gil-monte, P. R., Valcaárcel, P., \& Zornoza, A. (1993). Role stress: Burnout antecedent in nursing professionals. European Work and Organizational Psychologist, 3, 217-227. https://doi.org/10.1080/09602009308408591

Gough, D. O. S., \& Thomas, J. (2012). An introduction to systematic reviews. Thousand Oaks, CA: SAGE Publications, Inc.

Graen, G. B., \& Uhl-Bien, M. (1995). Relationship-based approach to leadership: Development of leader-member exchange (LMX) theory of leadership over 25 years: Applying a multilevel multi-domain perspective. The Leadership Quarterly, 6, 219-247. https://doi.org/10.1016/1048-9843(95)90036-5 
Gray-Stanley, J. A., Muramatsu, N., Heller, T., Hughes, S., Johnson, T. P., \& Ramirez-Valles, J. (2010). Work stress and depression among direct support professionals: The role of work support and locus of control: Work stress and depression. Journal of Intellectual Disability Research, 54, 749-761. https://doi.org/10.1111/j.1365-2788.2010.01303.x

Greenberg, J. (2004). Stress fairness to fare no stress: Managing workplace stress by promoting organizational justice. Organizational Dynamics, 33, 352-365. https://doi.org/10.1016/j.orgdyn.2004.09.003

Greenberger, D. B., \& Strasser, S. (1986). Development and application of a model of personal control in organizations. Academy of Management Review, 11, 164-177.

Greene, J. C., Caracelli, V. J., \& Graham, W. F. (1989). Toward a conceptual framework for mixed-method evaluation designs. Educational Evaluation and Policy Analysis, 11, 255274.

Griffin, M., A., \& Clarke, S. (2011). Stress and well-being at work. In S. Zedeck (Ed.), APA handbook of industrial and organizational psychology, Vol 3: Maintaining, expanding, and contracting the organization. (pp. 359-397). American Psychological Association. https://doi.org/10.1037/12171-010

Guerrero, S., Lapalme, M. E., \& Séguin, M. (2015). Board chair authentic leadership and nonexecutives' motivation and commitment. Journal of Leadership \& Organizational Studies, 22, 88-101. https://doi.org/10.1177/1548051814531825

Gupta, N., \& Beehr, T. A. (1979). Job stress and employee behaviors. Organizational Behavior and Human Performance, 23, 373-387. https://doi.org/10.1016/0030-5073(79)90004-7

Harms, P. D., Credé, M., Tynan, M., Leon, M., \& Jeung, W. (2017). Leadership and stress: A meta-analytic review. The Leadership Quarterly, 28, 178-194. https://doi.org/10.1016/j.leaqua.2016.10.006

Hatton, C. (1999). Staff stress. In Psychiatric and Behavioural Disorders in Developmental Disabilities and Mental Retardation (p. 427.438). Cambridge University Press.

Hatton, C., Emerson, E., Rivers, M., Mason, H., Mason, L., Swarbrick, R., Kiernan, C., Reeves, D., \& Alborz, A. (1999). Factors associated with staff stress and work satisfaction in services for people with intellectual disability. Journal of Intellectual Disability Research, 
43, 253-267. https://doi.org/10.1046/j.1365-2788.1999.00208.x

Hatton, C., Emerson, E., Rivers, M., Mason, H., Swarbrick, R., Mason, L., Kiernan, C., Reeves, D., \& Alborz, A. (2001). Factors associated with intended staff turnover and job search behaviour in services for people with intellectual disability. JOURNAL OF

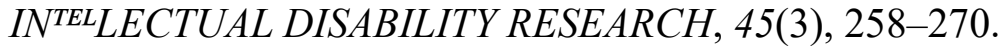
https://doi.org/10.1046/j.1365-2788.2001.00321.x

Hayes, A. F. (2019). PROCESS macro for SPSS and SAS. The PROCESS Macro for SPSS and SAS. http://processmacro.org/

Hickey, R. (2014a). When the desire to do good makes you feel bad: Quality indicators and workers stress. Journal on Developmental Disabilities, 20.

Hickey, R. (2014b). Prosocial motivation, stress and burnout among direct support workers. Journal of Applied Research in Intellectual Disabilities, 27, 134-144. https://doi.org/10.1111/jar.12058

Hidayat, S. (2016). The authentic leadership is source of intrinsic motivation in work engagement with moderating role of overall trust (cognitive and affective trust). Journal of Multidisciplinary Engineering Science and Technology, 3, 7.

Hoel, H., Sparks, K., \& Cooper, C. L. (2001). The cost of violence/stress at work and the benefits of a violence/stress-free working environment. Report commissioned by the International Labour Organization (ILO) Geneva, Manchester (p. 81). University of Manchester Institute of Science and Technology.

Howard, J., Gagné, M., Morin, A. J. S., \& Van den Broeck, A. (2016). Motivation profiles at work: A self-determination theory approach. Journal of Vocational Behavior, 95-96, 7489. https://doi.org/10.1016/j.jvb.2016.07.004

HSE. (2009). How to tackle work related stress. HSE.Gov.UK.

http://www.hse.gov.uk/pubns/indg430.pdf

HSE. (2017). Social care division operation plan 2017. HSE.

https://www.hse.ie/eng/services/publications/serviceplans/service-plan-2017/operationalplans-2017/social-care-operational-plan-2017.pdf 
HSE, I. (2018a). Disability Services-Community and Social Care. HSE.ie.

https://www.hse.ie/eng/services/list/4/disability/disability-services-.html

HSE, I. (2018b). Symptoms of autistic spectrum disorder. HSE.ie.

https:/www.hse.ie/eng/health/az/a/asperger-syndrome/symptoms-of-autistic-spectrumdisorder.html

Hutton, S. (2008). Workplace incivility and productivity losses among direct care staff. $A A O H N$ Journal, 56, 8.

Inclusion Ireland. (2019). Inclusion Ireland responds to significant funding cuts to the organisation in 2019 | Inclusion Ireland. Inclusion Ireland Responds to Significant Funding Cuts to the Organisation in 2019.

http://www.inclusionireland.ie/content/media/1767/inclusion-ireland-respondssignificant-funding-cuts-organisation-2019

Iqbal, M., Baig, M., Bhinder, M., \& Zahoor, M. (2016). Factors causing mental retardation. 5 , 11.

Ivankova, N. V., Creswell, J. W., \& Stick, S. L. (2006). Using Mixed-Methods Sequential Explanatory Design: From Theory to Practice. Field Methods, 18(1), 3-20. https://doi.org/10.1177/1525822X05282260

Jayaprakash, N., O’Sullivan, R., Bey, T., \& Ahmed, S. S. (2009). Crowding and delivery of healthcare in emergency departments: The European perspective. Western Journal of Emergency Medicine, $X, 7$.

Jenkins, R., Rose, J., \& Lovell, C. (1997). Psychological well-being of staff working with people who have challenging behaviour. Journal of Intellectual Disability Research, 41, 502511. https://doi.org/10.1111/j.1365-2788.1997.tb00743.x

Jeong, Y. K., Lee, Y. K., \& Kim, S. (2017). To be true or not to be true: Authentic leadership and its effect on travel agents. Asia Pacific Journal of Tourism Research, 22, 819-833. https://doi.org/10.1080/10941665.2017.1331921

Johnson, R. B., \& Onwuegbuzie, A. J. (2004). Mixed methods research: A research paradigm whose time has come. Educational Researcher, 33, 14-26. 
Joo, B. K., \& Jo, S. J. (2015). The effects of perceived authentic leadership and core selfevaluations on organizational citizenship behavior. Leadership \& Organization Development Journal, 38. https://doi.org/10.1108/LODJ-11-2015-0254

Judge, T. A., \& Colquitt, J. A. (2004). Organizational justice and stress: The mediating role of work-family conflict. Journal of Applied Psychology, 89, 395-404. https://doi.org/10.1037/0021-9010.89.3.395

Kalay, E., Brender-Ilan, Y., \& Kantor, J. (2016). Authentic leadership affecting subordinate job attitudes and intentions: The case of CPA profession. Journal of Management \& Organizations, 2016, 14533. https://doi.org/10.5465/ambpp.2016.14533abstract

Kanter, R. M. (2008). Men and Women of the Corporation: New Edition. Basic Books. https://books.google.ie/books?id=B-5GztW4IZQC

Karasek, R. A. (1979). Job demands, job decision latitude, and mental strain: Implications for job redesign. Administrative Science Quarterly, 24, 285. https://doi.org/10.2307/2392498

Kelly, J., Sadeghieh, T., \& Adeli, K. (2014). Peer review in scientific publications: Benefits, critiques, \& a survival guide. The Journal of the International Federation of Clinical Chemistry and Laboratory Medicine, 227-243.

Kernis, M. H. (2003). Toward a conceptualization of optimal self-esteem. Psychological Inquiry, 14, 1-26. https://doi.org/10.1207/S15327965PLI1401_01

Kessler, S. R., Bruursema, K., Rodopman, B., \& Spector, P. E. (2013). Leadership, interpersonal conflict, and counterproductive work behavior: An examination of the stressor-strain process. Negotiation and Conflict Management Research, 6, 180-190. Scopus. https://doi.org/10.1111/ncmr.12009

Kiersch, C. E., \& Byrne, Z. S. (2015). Is being authentic being fair? Multilevel examination of authentic leadership, justice, and employee outcomes. Journal of Leadership \& Organizational Studies, 22, 292-303. https://doi.org/10.1177/1548051815570035

Kleinginna, P. R., \& Kleinginna, A. M. (1981). A categorized list of motivation definitions, with a suggestion for a consensual definition. Motivation and Emotion, 5, 263-291. https://doi.org/10.1007/BF00993889 
Kompier, M. A. J., Geurts, S. A. E., \& Cooper, C. L. (2000). A multiple case study approach to work stress prevention in Europe. European Journal of Work and Organizational Psychology, 9, 371-400. https://doi.org/10.1080/135943200417975

Kung, F. Y. H., Kwok, N., \& Brown, D. J. (2018). Are attention check questions a threat to scale validity?: Attention checks and scale validity. Applied Psychology, 67, 264-283. https://doi.org/10.1111/apps.12108

Kunz, C. (2019). The influence of working conditions on health satisfaction, physical and mental health: Testing the effort-reward imbalance (ERI) model and its moderation with overcommitment using a representative sample of German employees (GSOEP). BMC Public Health, 19. https://doi.org/10.1186/s12889-019-7187-1

Kuvaas, B., Buch, R., Weibel, A., Dysvik, A., \& Nerstad, C. G. L. (2017). Do intrinsic and extrinsic motivation relate differently to employee outcomes? Journal of Economic Psychology, 61, 244-258. https://doi.org/10.1016/j.joep.2017.05.004

Laschinger, H. K. S., Borgogni, L., Consiglio, C., \& Read, E. (2015). The effects of authentic leadership, six areas of work-life, and occupational coping self-efficacy on new graduate nurses' burnout and mental health: A cross-sectional study. International Journal of Nursing Studies, 52, 1080-1089. https://doi.org/10.1016/j.ijnurstu.2015.03.002

Laschinger, H. K. S., \& Fida, R. (2014a). New nurses' burnout and workplace wellbeing: The influence of authentic leadership and psychological capital. Burnout Research, 1, 19-28. https://doi.org/10.1016/j.burn.2014.03.002

Laschinger, H. K. S., \& Fida, R. (2014b). A time-lagged analysis of the effect of authentic leadership on workplace bullying, burnout, and occupational turnover intentions. European Journal of Work and Organizational Psychology, 23, 739-753. https://doi.org/10.1080/1359432X.2013.804646

Laschinger, H. K. S., Finegan, J., \& Attoh, P. (2009). New graduate burnout: The impact of professional practice environment, workplace civility, and empowerment. Nursing Economics, 27.

Laschinger, H. K. S., Leiter, M., Day, A., \& Gilin, D. (2009). Workplace empowerment, incivility, and burnout: Impact on staff nurse recruitment and retention outcomes. Journal of 
Nursing Management, 17, 302-311.

Laschinger, H. K. S., Wong, C. A., \& Grau, A. L. (2012). The influence of authentic leadership on newly graduated nurses' experiences of workplace bullying, burnout and retention outcomes: A cross-sectional study. International Journal of Nursing Studies, 49, 12661276. https://doi.org/10.1016/j.jinurstu.2012.05.012

Laschinger, H. K. S., Wong, C. A., \& Grau, A. L. (2013). Authentic leadership, empowerment and burnout: A comparison in new graduates and experienced nurses: Authentic leadership and empowerment. Journal of Nursing Management, 21, 541-552. https://doi.org/10.1111/j.1365-2834.2012.01375.x

Lee, E. H. (2012). Review of the Psychometric Evidence of the Perceived Stress Scale. Asian Nursing Research, 6, 121-127. https://doi.org/10.1016/j.anr.2012.08.004

Lee, M., \& Koh, J. (2001). Is empowerment really a new concept? The International Journal of Human Resource Management, 12, 684-695. https://doi.org/10.1080/713769649

Lee, R. T., \& Ashforth, B. E. (1990). On the meaning of Maslach's three dimensions of burnout. Journal of Applied Psychology, 75, 5.

Leech, N. L., \& Onwuegbuzie, A. J. (2007). An array of qualitative data analysis tools: A call for data analysis triangulation. School Psychology Quarterly, 22, 557-584. https://doi.org/10.1037/1045-3830.22.4.557

Leiter, M. P., \& Maslach, C. (2003a). Areas of work-life: A structured approach to organizational predictors of job burnout. In Research in Occupational Stress and Well-being (Vol. 3, pp. 91-134). Emerald (MCB UP ). https://doi.org/10.1016/S1479-3555(03)03003-8

Leiter, M. P., \& Maslach, C. (2003b). Areas of worklife: A structured approach to organizational predictors of job burnout. In Research in Occupational Stress and Well-being (Vol. 3, pp. 91-134). Emerald (MCB UP ). https://doi.org/10.1016/S1479-3555(03)03003-8

Leka, S., Cox, T., \& Griffiths, A. (2003). Work organization and stress: Systematic problem approaches for employers, managers and trade union representatives. World Health Organization.

Lepine, J. A., Podsakoff, N. P., \& Lepine, M. A. (2005). A Meta-Analytic Test of the Challenge 
Stressor-Hindrance Stressor Framework: An Explanation for Inconsistent Relationships Among Stressors and Performance. Academy of Management Journal, 48(5), 764-775. https://doi.org/10.5465/amj.2005.18803921

Leroy, H., Anseel, F., Gardner, W. L., \& Sels, L. (2015). Authentic leadership, authentic followership, basic need satisfaction, and work role performance: A cross-level study. Journal of Management, 41, 1677-1697. https://doi.org/10.1177/0149206312457822

Leroy, H., Palanski, M. E., \& Simons, T. (2012). Authentic Leadership and Behavioral Integrity as Drivers of Follower Commitment and Performance. JOURNAL OF BUSINESS ETHICS, 107(3), 255-264. https://doi.org/10.1007/s10551-011-1036-1

Levin, K. A. (2006). Study design III: Cross-sectional studies. Evidence-Based Dentistry, 7, 2425. https://doi.org/10.1038/sj.ebd.6400375

Lewis, P. S., \& Malecha, A. (2011). The impact of workplace incivility on the work environment, manager skill, and productivity: The Journal of Nursing Administration, 41, 41-47. https://doi.org/10.1097/NNA.0b013e3182002a4c

Lunenburg, F. C. (2011). Goal-Setting Theory of Motivation. International Journal of Management, Business, and Administration, 15, 6.

Luthans, F., \& Avolio, B. (2003). Authentic Leadership Development. In K. S. Cameron, J. E. Dutton, \& R. E. Quinn (Eds.), Positive Organizational Scholarship (pp. 241-258). Berrett-Koehler Publishers, Inc.

Madlock, P. E. (2008). The link between leadership style, communicator competence, and employee satisfaction. Journal of Business Communication, 45, 61-78. https://doi.org/10.1177/0021943607309351

Marič, M., Miglič, G., \& Jordan, G. (2017). The impact of authentic leadership on psychological empowerment of the employees in the Slovenian local self-government institutions. $L E X$ LOCALIS-JOURNAL OF LOCAL SELF-GOVERNMENT, 15, 625-645. https://doi.org/10.4335/15.3.625-645(2017)

Maroufizadeh, S., Foroudifard, F., Navid, B., Ezabadi, Z., Sobati, B., \& Omani-Samani, R. (2018). The Perceived Stress Scale (PSS-10) in women experiencing infertility: A reliability and validity study. Middle East Fertility Society Journal, 23, 456-459. 
https://doi.org/10.1016/j.mefs.2018.02.003

Maslach, C. (2003). Burnout: The Cost of Caring (Kindle Edition). Malor Books.

Maslach, C., \& Jackson, S. E. (1981). The measurement of experienced burnout. Journal of Organizational Behavior, 2, 99-113. https://doi.org/10.1002/job.4030020205

Maslach, C., Shaufeli, W. B., \& Leiter, M. P. (2001). Job burnout. Annual Review of Psychology, $52,397-422$.

Maslow, A. H. (1970). Motivation personality. Harper \& Row, Publishers 1954.

May, D. R., Chan, A. Y. L., Hodges, T. D., \& Avolio, B. J. (2003). Developing the Moral Component of Authentic Leadership. Organizational Dynamics, 32, 247-260. https://doi.org/10.1016/S0090-2616(03)00032-9

Mazutis, D., \& Natalie, S. (2007). The art of conversation: How authentic leaders influence organizational learning. Learning Fusion, 662-675.

McGregor, D. (1960). Theory X and theory Y. Organisation Theory, 358, 374.

McLean, J., \& Andrew, T. (1999). Commitment, satisfaction, stress and control among social services managers and social workers in the UK. Administration in Social Work, 23, 93117. https://doi.org/10.1300/J147v23n03_06

Meissner, H., Creswell, J., Klassen, A. C., Plano, V., \& Smith, K. C. (2010). Best practices for mixed methods research in the health sciences. Office of Behavioral and Social Sciences Research (OBSSR).

Merrick, A. D., Grieve, A., \& Cogan, N. (2017). Psychological impacts of challenging behaviour and motivational orientation in staff supporting individuals with autistic spectrum conditions. Stress \& Motivation in ID Due to CB, 21, 872-880. https://doi.org/10.1177/1362361316654857

Milczarek, M., Schneider, E., \& González, E. R. (2009). OSH in figures: Stress at work - facts and figures. Office for Official Publications of the European Communities.

Moher, D., Liberati, A., Tetzlaff, J., \& Altman, D. G. (2009). Preferred Reporting Items for Systematic Reviews and Meta-Analyses: The PRISMA Statement. PLOS Medicine, 6, e1000097. https://doi.org/10.1371/journal.pmed.1000097 
Moher, D., Shamseer, L., Clarke, M., Ghersi, D., Liberati, A., Petticrew, M., Shekelle, P., \& Stewart, L. A. (2015). Preferred reporting items for systematic review and meta-analysis protocols (PRISMA-P) 2015 statement. Systematic Reviews, 4. https://doi.org/10.1186/2046-4053-4-1

Morgan, D. L. (2013). Integrating qualitative and quantitative methods: A pragmatic approach. SAGE Publications Ltd.

Mortier, A. V., Vlerick, P., \& Clays, E. (2016). Authentic leadership and thriving among nurses: The mediating role of empathy. JOURNAL OF NURSING MANAGEMENT, 24(3), 357365. https://doi.org/10.1111/jonm.12329

Mubarak, F., \& Noor, A. (2018). Effect of authentic leadership on employee creativity in projectbased organizations with the mediating roles of work engagement and psychological empowerment. Cogent Business \& Management, 5. https://doi.org/10.1080/23311975.2018.1429348

Mutkins, E., Brown, R. F., \& Thorsteinsson, E. B. (2011). Stress, depression, workplace and social supports and burnout in intellectual disability support staff: Stress, support and burnout in disability support staff. Journal of Intellectual Disability Research, 55, 500510. https://doi.org/10.1111/j.1365-2788.2011.01406.x

Neider, L. L., \& Schriesheim, C. A. (2011). The Authentic Leadership Inventory (ALI): Development and empirical tests. Leadership Quarterly Yearly Review, 22, 1146-1164. https://doi.org/10.1016/j.leaqua.2011.09.008

Nelson, K., Boudrias, J. S., Brunet, L., Morin, D., De Civita, M., Savoie, A., \& Alderson, M. (2014). Authentic leadership and psychological well-being at work of nurses: The mediating role of work climate at the individual level of analysis. SI: Burnout and HealthCare, 1, 90-101. https://doi.org/10.1016/j.burn.2014.08.001

Noor, S., \& Abdullah, A. S. (2019). The effect of school leaders' authentic leadership on teachers' job stress in the eastern part of peninsular Malaysia. International Journal of Instruction, 12, 67-80. https://doi.org/10.29333/iji.2019.1225a

O’Driscoll, M. P., \& Cooper, C. L. (2001). Organizational stress: A review and critique of theory, research and applications. Thousand Oaks, CA: SAGE Publications, Inc. 
OGCIO. (2014). Distinction between Section 38 \& 39 agencies. Department of Public Expenditure and Reform. https://www.per.gov.ie/en/public-accounts-committee-2014/

O’Keefe, L. C., Brown, K. C., \& Christian, B. J. (2014). Policy perspectives on occupational stress. Workplace Health \& Safety, 62, 432-438. https://doi.org/10.3928/2165079920140813-02

Onwuegbuzie, A. J., \& Leech, N. L. (2005). On Becoming a Pragmatic Researcher: The Importance of Combining Quantitative and Qualitative Research Methodologies. International Journal of Social Research Methodology, 8(5), 375-387. https://doi.org/10.1080/13645570500402447

Pardee, R. L. (1990). A Literature Review of Selected Theories Dealing With Job Satisfaction and Motivation. U.S. Department of Education: Educational Resources Information Center (ERIC), 24.

Parent-Thirion, A., Biletta, I., Cabrita, J., Llave Vargas, O., Vermeylen, G., Wilczynska, A., \& Wilkens, M. (2017). 6th European Working Conditions Survey: Overview report (2017 update). Publications Office of the European Union.

Pawson, R. (2006). Evidence-Based Policy: A Realist Perspective. London: Sage Publications.

Petticrew, M., \& Roberts, H. (2006). Systematic Reviews in the Social Sciences (1st ed.). Blackwell Publishing.

Pinder, C. C. (2008). Work Motivation in Organizational Behavior (2nd Kindle Edition). Taylor and Francis.

Power, J. L., Brotheridge, C. M., Blenkinsopp, J., Bowes-Sperry, L., Bozionelos, N., Buzády, Z., Chuang, A., Drnevich, D., Garzon-Vico, A., Leighton, C., Madero, S. M., Mak, W., Mathew, R., Monserrat, S. I., Mujtaba, B. G., Olivas-Lujan, M. R., Polycroniou, P., Sprigg, C. A., Axtell, C., Nnedumm, A. U. O. (2013). Acceptability of workplace bullying: A comparative study on six continents. Journal of Business Research, 66(3), 374-380. https://doi.org/10.1016/j.jbusres.2011.08.018

ProQuest. (2019). Products-ProQuest One Academic. https://www.proquest.com/productsservices/ProQuest-One-Academic.html 
PsycINFO. (2019). PsycINFO. Https://Www.Apa.Org.

https://www.apa.org/pubs/databases/psycinfo/index

Qu, S. Q., \& Dumay, J. (2011). The qualitative research interview. Qualitative Research in Accounting \& Management, 8, 238-264. https://doi.org/10.1108/11766091111162070

Qu, Sandy Q., \& Dumay, J. (2011). The qualitative research interview. Qualitative Research in Accounting \& Management, 8(3), 238-264. https://doi.org/10.1108/11766091111162070

Rahimnia, F., \& Sharifirad, M. S. (2015). Authentic leadership and employee well-being: The mediating role of attachment insecurity. Journal of Business Ethics, 132, 363-377. https://doi.org/10.1007/s10551-014-2318-1

Rajulton, F. (2001). The fundamentals of longitudinal research: An overview. Canadian Studies in Population, 28, 169. https://doi.org/10.25336/P6W897

Rashwan, W., Abo-Hamad, W., \& Arisha, A. (2015). A system dynamic view of the acute bed blockage problem in the Irish healthcare system. European Journal of Operational Research, 247, 276-293. https://doi.org/10.1016/j.ejor.2015.05.043

Ratelle, C. F., Guay, F., Vallerand, R. J., Larose, S., \& Senécal, C. (2007). Autonomous, controlled, and amotivated types of academic motivation: A person-oriented analysis. Journal of Educational Psychology, 99, 734-746. https://doi.org/10.1037/00220663.99.4.734

Razali, N. M., \& Wah, Y. B. (2011). Power comparisons of Shapiro-Wilk, Kolmogorov-Smirnov, Lilliefors and Anderson-Darling tests. Journal of Statistical Modelling and Analytics, 2, 14.

Read, E. A., \& Laschinger, H. K. S. (2015). The influence of authentic leadership and empowerment on nurses' relational social capital, mental health and job satisfaction over the first year of practice. Journal of Advanced Nursing, 71, 1611-1623. https://doi.org/10.1111/jan.12625

Reckinger, P., Strube, J., \& Plassmann, R. (2005). Work-related stress: Framework agreement on work-related stress. European Trade Union Confederation (ETUC).

Redmond, B. R., Suzanne, G., Nolan, B., Devitt, C., \& Egan, A. (2011). The retention of social 
workers in the health services: An evidence-based assessment. University College Dublin (UCD), 78 .

Rego, A., Sousa, F., Marques, C., \& Cunha, M. P. (2012). Authentic leadership promoting employees' psychological capital and creativity. Journal of Business Research, 65, 429437. https://doi.org/10.1016/j.jbusres.2011.10.003

Rice, D., \& Rosen, M. (1991). Direct-care staff: A neglected priority. Mental Retardation, 29.

Robertson, J., Hatton, C., Felce, D., Meek, A., Carr, D., Knapp, M., Hallam, A., Emerson, E., Pinkney, L., Caesar, E., \& Lowe, K. (2005). Staff Stress and Morale in Community-Based Settings for People with Intellectual Disabilities and Challenging Behaviour: A Brief Report. Journal of Applied Research in Intellectual Disabilities, 18, 271-277. https://doi.org/10.1111/j.1468-3148.2005.00233.x

Robson, C., \& McCartan, K. (2016). Real World Research (4th ed.). John Wiley \& Sons Ltd. Rosenberg, W. G. J., Sackett, D., Haynesh, R., \& Richardson, W. (1996). Evidence based medicine: What it is and what it isn't. BMJ. British Medical, 312, 71-72.

Rossman, G. B., \& Wilson, B. L. (1985). Numbers and words: Combining quantitative and qualitative methods in a single large-scale. Evaluation Review, 9, 627-643.

Rothstein, H., Sutton, A. J., \& Borenstein, M. (2005). Publication bias in meta-analysis: Prevention, assessment and adjustments. Wiley.

Russell, H., Maître, B., Watson, D., \& Fahey, É. (2018). Job stress and working conditions: Ireland in comparative perspective - An analysis of the European Working Conditions survey. ESRI. https://www.esri.ie/publications/job-stress-and-working-conditions-irelandin-comparative-perspective-an-analysis-of-the-european-working-conditions-survey/

Ryan, R. M., \& Koestner, R. (1999). A meta-analytic review of experiments examining the effects of extrinsic rewards on intrinsic motivation. American Psychological Association, 125, 42.

Salkind, N. J. (2010). Encyclopaedia of research design. Thousand Oaks, CA: SAGE Publications, Inc. doi: 10.4135/9781412961288.

Sato, T., Yamamoto, H., Sawada, N., Nashiki, K., Tsuji, M., Muto, K., Kume, H., Sasaki, H., 
Arai, H., Nikawa, T., Taketani, Y., \& Takeda, E. (2006). Restraint stress alters the duodenal expression of genes important for lipid metabolism in rat. Toxicology, 227, 248261. https://doi.org/10.1016/j.tox.2006.08.009

Saunders, M., Lewis, P., \& Thornhill, A. (2012). Research methods for business students (6th ed.). Pitman Publishing imprint.

Schmitz, C. (2017, November 10). LimeSurvey 2.72.4 build 171110 released! LimeSurvey - the Free \& Open Source Survey Software Tool! https://www.limesurvey.org/

Schoonenboom, J., \& Johnson, R. B. (2017). How to construct a mixed methods research design. KZfSS Kölner Zeitschrift Für Soziologie Und Sozialpsychologie, 69, 107-131. https://doi.org/10.1007/s11577-017-0454-1

Seibert, S. E., Wang, G., \& Courtright, S. H. (2011). Antecedents and consequences of psychological and team empowerment in organizations: A meta-analytic review. Journal of Applied Psychology, 96, 981-1003. https://doi.org/10.1037/a0022676

Shapira-Lishchinsky, O., \& Tsemach, S. (2014). Psychological empowerment as a mediator between teachers' perceptions of authentic leadership and their withdrawal and citizenship behaviors. Educational Administration Quarterly, 50, 675-712. https://doi.org/10.1177/0013161X13513898

Shapiro, S. S., \& Wilk, M. B. (1965). An analysis of variance test for normality (complete samples). Biometrika, 52, 591-611.

Shirey, M. R., \& Shirey, B. (2006). Authentic leaders creating healthy work environments for nursing practice. American Journal of Critical Care, 15, 14.

Shu, C. Y. (2015). The impact of intrinsic motivation on the effectiveness of leadership style towards on work engagement. Contemporary Management Research, 11, 327-350. https://doi.org/10.7903/cmr. 14043

Sieber, S. D. (1973). The integration of fieldwork and survey methods. American Journal of Sociology, 78(6), 1335-1359.

Siegrist, J. (1996). Adverse health effects of high effort/low reward conditions at work. Journal of Occupational Health Psychology, 1, 27-41. 
Smith, L. M., Andrusyszyn, M. A., \& Laschinger, H. K. S. (2010). Effects of workplace incivility and empowerment on newly graduated nurses' organizational commitment. Journal of Nursing Management, 18, 1004-1015.

Sparr, J. L., \& Sonnentag, S. (2008). Fairness perceptions of supervisor feedback, LMX, and employee well-being at work. European Journal of Work and Organizational Psychology, 17, 198-225. https://doi.org/10.1080/13594320701743590

Spence Laschinger, H. K., Wong, C., Read, E., Cummings, G., Leiter, M., Macphee, M., Regan, S., Rhéaume-Brüning, A., Ritchie, J., Burkoski, V., Grinspun, D., Gurnham, M. E., Huckstep, S., Jeffs, L., Macdonald-Rencz, S., Ruffolo, M., Shamian, J., Wolff, A., YoungRitchie, C., \& Wood, K. (2019). Predictors of new graduate nurses' health over the first 4 years of practice. Nursing Open, 6(2), 245-259. https://doi.org/10.1002/nop2.231

Stone, A. A., Bachrach, C. A., Jobe, J. B., Kurtzman, H. S., \& Cain, V. S. (1999). The Science of Self-report: Implications for Research and Practice. Psychology Press.

Sulsky, L., \& Smith, C. (2005). Work Stress. Thomson Wadsworth.

Szabo, S., Tache, Y., \& Somogyi, A. (2012). The legacy of Hans Selye and the origins of stress research: A retrospective 75 years after his landmark brief "Letter" to the Editor of Nature. Stress, 15, 472-478. https://doi.org/10.3109/10253890.2012.710919

Taris, T. W., \& Kompier, M. A. J. (2014). Cause and effect: Optimizing the designs of longitudinal studies in occupational health psychology. Work \& Stress, 28(1), 1-8. https://doi.org/10.1080/02678373.2014.878494

Tashakkori, A., \& Teddlie, C. (2010). SAGE Handbook of Mixed Methods in Social \& Behavioral Research. SAGE.

Taylor-Bianco, A., \& Schermerhorn, J. (2006). Self-regulation, strategic leadership and paradox in organizational change. Journal of Organizational Change Management, 19, 457-470. https://doi.org/10.1108/09534810610676662

Teddlie, C., \& Tashakkori, A. (2009). Foundations of mixed methods research: Integrating quantitative and qualitative approaches in the social and behavioral sciences. Thousand Oaks, CA: Sage. 
Theorell, T., \& Karasek, R. A. (1990). Healthy work: Stress, productivity and the reconstruction of working life. New York: Basic Books.

Thomas, K. W., \& Velthouse, B. A. (1990). Cognitive elements of empowerment: An 'interpretive' model of intrinsic task motivation. Academy of Management Review, 15, $666-681$.

Understanding Society Insights. (2014). Institute for Social \& Economic Research (IISER), University of Essex. https://www.understandingsociety.ac.uk/research/findings/insights2014

Van Bogaert, P., Clarke, S., Willems, R., \& Mondelaers, M. (2013). Nurse practice environment, workload, burnout, job outcomes, and quality of care in psychiatric hospitals: A structural equation model approach. Journal of Advanced Nursing, 69, 1515-1524. https://doi.org/10.1111/jan.12010

van der Burgt, S. M. E., Kusurkar, R. A., Wilschut, J. A., Tjin A Tsoi, S. L. N. M., Croiset, G., \& Peerdeman, S. M. (2019). Medical specialists' basic psychological needs, and motivation for work and lifelong learning: A two-step factor score path analysis. BMC Medical Education, 19. https://doi.org/10.1186/s12909-019-1754-0

Walumbwa, F. O., Avolio, B. J., Gardner, W. L., Wernsing, T. S., \& Peterson, S. J. (2008). Authentic leadership: Development and validation of a theory-based measure. Journal of Management, 34, 89-126. https://doi.org/10.1177/0149206307308913

Ward, M. K., \& Pond, S. B. (2015). Using virtual presence and survey instructions to minimize careless responding on Internet-based surveys. Computers in Human Behavior, 48, 554568. https://doi.org/10.1016/j.chb.2015.01.070

WHO. (2013). Health 2020: A policy framework and strategy for the 21 st century. The World Health Organisation. Regional Office for Europe. http://www.euro.who.int/_data/assets/pdf_file/0011/199532/Health2020-Long.pdf

WHO. (2020, March 14). Definition: Intellectual disability. http://www.euro.who.int/en/healthtopics/noncommunicable-diseases/mental-health/news/news/2010/15/childrens-right-tofamily-life/definition-intellectual-disability

Wilson, T. D., \& Lassiter, G. D. (1982). Increasing intrinsic interest with superfluous extrinsic 
constraints. Journal of Personality and Social Psychology, 42, 811-819.

https://doi.org/10.1037/0022-3514.42.5.811

Wing, T., Regan, S., \& Laschinger, H. K. S. (2015). The influence of empowerment and incivility on the mental health of new graduate nurses. Journal of Nursing Management, 23, 632643. https://doi.org/10.1111/jonm. 12190

Womack, J. P., \& Jones, D. T. (2003). Lean thinking: Banish waste and create wealth in your corporation. (Kindle Edition 2003). Simon \& Schuster Australia Sydney.

Wong, C. A., \& Cummings, G. G. (2009). The influence of authentic leadership behaviors on trust and work outcomes of health care staff. Journal of Leadership Studies, 3, 6-23. https://doi.org/10.1002/jls.20104

Wong, C. A., \& M. Giallonardo, L. (2013). Authentic leadership and nurse-assessed adverse patient outcomes. Journal of Nursing Management, 21, 740-752. https://doi.org/10.1111/jonm.12075

Yang, C., Hwang, M., \& Chen, Y. (2011). An empirical study of the existence, elatedness, and growth (ERG) theory in consumer's selection of mobile value-added services. African Journal of Business Management, 5, 7885-7898.

Yukl, G. A., \& Becker, W. S. (2006). Effective Empowerment in Organizations. Organization Management Journal, 3, 210-231. https://doi.org/10.1057/omj.2006.20

Zhang, J., Song, L. J., Wang, Y., \& Liu, G. (2018). How authentic leadership influences employee proactivity: The sequential mediating effects of psychological empowerment and core self-evaluations and the moderating role of employee political skill. Frontiers of Business Research in China, 12. https://doi.org/10.1186/s11782-018-0026-x 


\section{Appendices}

\section{Appendix A: Systematic Literature Review}

Table 3: Revised SLR principles by Denver and Transfield (2009)

Principle Description

Transparency. Openness and being explicit regarding the methods used in the SLRs are a core principle, which aims to ensure that the scope and boundaries of the SLR are clear to the reader. According to Denver and Transfield (2009), SLRs should include a protocol, the methodology used, and report of a full audit trail. Secondly, they state there should be a clear link between the findings of the SLR and the reviewer's conclusions. Lastly, the reviewer's prior beliefs and values regarding the research topic should be stated.

Inclusivity. Due to the inconsistencies and sometimes unreliable or sparely reported methods of data collection, it can sometimes be challenging to assess the quality of a study. Therefore, if the reviewer finds a study is fit for purpose, it adds something new, or develops the understanding and contributes to the theory of knowledge, it may be suited for inclusion. Moreover, selection and inclusion from a broad and diverse range of studies promotes a fuller understanding of the topic and helps mitigate bias. By including a wide variety of sources, one can mitigate the threat of "value judgement and uncontrolled validity threats". It is also advisable not to use quality ratings as a basis for exclusion. However, a quality checklist should be included, as well as a justification for the inclusion/exclusion applied. 


\section{Principle Description}

Explanatory. The use of an interpretive and explanatory synthesis is recommended as it brings together aspects from across the selected studies to build a complete narrative. The evidence in each study should not only be explored but also coded and reported while cross tabulating the findings to build and contribute to the emerging theory of the topic.

Heuristic. This principle proposes that the output of an SLR should result in what works in organisations and the field of management. Such outputs could include a set of rules, suggestions, guidelines or protocols, that, for example, provide solutions to problems. Nevertheless, care should be taken not to be over-prescriptive. It should still allow people to learn and discover for themselves what might work for them; in other words, allow exploration. 
Table 4: CIMO Concepts

\begin{tabular}{|c|c|c|}
\hline $\begin{array}{l}\text { CIMO } \\
\text { component }\end{array}$ & Concepts & Description \\
\hline $\begin{array}{l}\text { Context } \\
\text { (C) }\end{array}$ & Employees & $\begin{array}{l}\text { Employees of an organisation that provide services to adults } \\
\text { with intellectual disability, including frontline and } \\
\text { administration staff who report to a supervisor or direct line } \\
\text { manager. }\end{array}$ \\
\hline $\begin{array}{l}\text { Interventions } \\
\text { (I) }\end{array}$ & $\mathrm{AL}$ & AL style and behaviours \\
\hline $\begin{array}{l}\text { Mechanisms } \\
\text { (M) }\end{array}$ & $\begin{array}{l}\mathrm{AL} \\
\text { behaviours }\end{array}$ & $\begin{array}{l}\text { What are the mechanisms of authentic leadership that impact } \\
\text { work-related stress and job motivation? What is already } \\
\text { known about the relationship between authentic leadership } \\
\text { and employee work-related stress or job motivation? What are } \\
\text { the specific leadership behaviours and characteristics of } \\
\text { authentic leadership style that relate to employee work-related } \\
\text { stress or job motivation? }\end{array}$ \\
\hline $\begin{array}{l}\text { Outcomes } \\
\text { (O) }\end{array}$ & $\begin{array}{l}\text { Impact on } \\
\text { work- } \\
\text { related } \\
\text { stress or job } \\
\text { motivation }\end{array}$ & $\begin{array}{l}\text { Primary outcome: Discover what is known about the } \\
\text { relationship between authentic leadership behaviours in } \\
\text { relation to employee work-related stress or job motivation. } \\
\text { What is missing or lacking in the research (what is not } \\
\text { known)? Are there any contradictions in the current body of } \\
\text { knowledge? } \\
\text { Secondary outcomes: What are the potential consequences of } \\
\text { increased or decreased employee work-related stress or job } \\
\text { motivation on stakeholders including staff, managers, clients, } \\
\text { and the organisation. }\end{array}$ \\
\hline
\end{tabular}


Table 5: CIMO concepts search terms (keywords)

\begin{tabular}{|c|c|c|c|c|}
\hline Context (a) & Context (b) & Interventions & Outcome (a) & Outcome (b) \\
\hline staff OR & "intellectual & "authentic leader*" & stress* OR & motivat* OR \\
\hline employee OR & disabilit*" & OR & pressure OR & incentive* OR \\
\hline worker OR & OR & "authentic manage*" & strain OR & drive* OR \\
\hline follower OR & "intellectually & OR & anxiety OR & enthusias* OR \\
\hline follower OR & disabled" & "authentic & tension OR & commit* OR \\
\hline \multirow[t]{12}{*}{ personnel } & & supervis*" OR & apprehens* OR & engage* \\
\hline & & "authentic boss" & uneas* OR & \\
\hline & & & nervous* OR & \\
\hline & & & worr* OR & \\
\hline & & & psycholog* OR & \\
\hline & & & "mental health" OR & \\
\hline & & & emotion* OR & \\
\hline & ------------- & ------------- & role-stress OR & \\
\hline & On a broader & On a broader & cope OR & \\
\hline & level & level & coping OR & \\
\hline & ------------- & ------------- & well-being OR & \\
\hline & healthcare & leadership & well-being OR & \\
\hline
\end{tabular}


Table 6: Database Search Terms

\begin{tabular}{|c|c|c|}
\hline $\begin{array}{l}\text { Search } \\
\#\end{array}$ & Concepts searched & Actual search terms \\
\hline $1 \#$ & Leadership & (leader* OR “manage*” OR "supervis*” OR “boss") \\
\hline 2\# & Authentic Leadership & $\begin{array}{l}\text { (“authentic leader*” OR "authentic manage*” OR "authentic supervis*” OR "authentic } \\
\text { boss") }\end{array}$ \\
\hline $3 \#$ & Employee & (staff OR employee OR worker OR follower OR follower OR personnel) ti,ab,kw \\
\hline 4\# & Motivation & (motivat* OR incentive* OR drive* OR enthusias* OR commit* OR engage* ) ti,ab,kw \\
\hline $5 \#$ & Stress & $\begin{array}{l}\text { (stress* OR pressure OR strain OR anxiety OR tension OR apprehens* OR uneas* OR } \\
\text { nervous* OR worr* OR psycholog* OR “mental health" OR emotion* OR role-stress OR } \\
\text { cope OR coping OR well-being OR well-being) }\end{array}$ \\
\hline $6 \#$ & Healthcare & (healthcare) \\
\hline $7 \#$ & ID & (“intellectual disability*” OR “intellectually disabled”) \\
\hline $8 \#$ & Leadership AND Stress & $\begin{array}{l}\text { ((leader* OR “manage*” OR “supervis*” OR “boss”) AND (stress* OR pressure OR strain } \\
\text { OR anxiety OR tension OR apprehens* OR uneas* OR nervous* OR worr* OR psycholog* } \\
\text { OR “mental health” OR emotion* OR role-stress OR cope OR Coping OR well-being OR } \\
\text { well-being)) }\end{array}$ \\
\hline 9\# & $\begin{array}{l}\text { "Authentic Leadership" } \\
\text { AND Stress }\end{array}$ & $\begin{array}{l}\text { ((“authentic leader*” OR “authentic manage*” OR “authentic supervis*” OR “authentic } \\
\text { boss") AND (stress* OR pressure OR strain OR anxiety OR tension OR apprehens* OR } \\
\text { uneas* OR nervous* OR worr* OR psycholog* OR “mental health” OR emotion* OR role- } \\
\text { stress OR cope OR coping OR well-being OR well-being)) }\end{array}$ \\
\hline
\end{tabular}




\begin{tabular}{|c|c|c|}
\hline $\begin{array}{l}\text { Search } \\
\#\end{array}$ & Concepts searched & Actual search terms \\
\hline $10 \#$ & $\begin{array}{l}\text { Leadership AND } \\
\text { Motivation }\end{array}$ & $\begin{array}{l}\text { ((leader* OR “manage*” OR "supervis*” OR “boss") AND (motivat* OR incentive* OR } \\
\text { drive* OR enthusias* OR commit* OR engage* )) }\end{array}$ \\
\hline $11 \#$ & $\begin{array}{l}\text { "Authentic Leadership" } \\
\text { AND Motivation }\end{array}$ & $\begin{array}{l}\text { ((“authentic leader*” OR “authentic manage*” OR "authentic supervis*” OR "authentic } \\
\text { boss") AND (motivat* OR incentive* OR drive* OR enthusias* OR commit* OR engage*)) }\end{array}$ \\
\hline $12 \#$ & $\begin{array}{l}\text { Leadership AND } \\
\text { (Motivation OR Stress) }\end{array}$ & $\begin{array}{l}\text { ((leader* OR “manage*” OR “supervis*” OR “boss”) AND ((motivat* OR incentive* OR } \\
\text { drive* OR enthusias* OR commit* OR engage*) OR (stress* OR pressure OR strain OR } \\
\text { anxiety OR tension OR apprehens* OR uneas* OR nervous* OR worr* OR psycholog* OR } \\
\text { "mental health" OR emotion* OR role-stress OR cope OR coping OR well-being OR well- } \\
\text { being))) }\end{array}$ \\
\hline $13 \#$ & $\begin{array}{l}\text { "Authentic Leadership" } \\
\text { AND (Motivation OR } \\
\text { Stress) }\end{array}$ & $\begin{array}{l}\text { ((“authentic leader*” OR “authentic manage*” OR “authentic supervis*” OR “authentic } \\
\text { boss") AND ((motivat* OR incentive* OR drive* OR enthusias* OR commit* OR engage*) } \\
\text { OR (stress* OR pressure OR strain OR anxiety OR tension OR apprehens* OR uneas* OR } \\
\text { nervous* OR worr* OR psycholog* OR “mental health” OR emotion* OR role-stress OR } \\
\text { cope OR coping OR well-being OR well-being))) }\end{array}$ \\
\hline $14 \#$ & $\begin{array}{l}\text { Leadership AND } \\
\text { (Motivation OR Stress) } \\
\text { AND Staff }\end{array}$ & $\begin{array}{l}\text { ((leader* OR "manage*” OR "supervis*” OR “boss") AND ((motivat* OR incentive* OR } \\
\text { drive* OR enthusias* OR commit* OR engage*) OR (stress* OR pressure OR strain OR } \\
\text { anxiety OR tension OR apprehens* OR uneas* OR nervous* OR worr* OR psycholog* OR } \\
\text { "mental health” OR emotion* OR role-stress OR cope OR coping OR well-being OR well- } \\
\text { being)) AND (staff OR employee OR worker OR follower OR follower OR personnel)) }\end{array}$ \\
\hline $15 \#$ & "Authentic Leadership" & ((“authentic leader*” OR "authentic manage*" OR "authentic supervis*” OR "authentic \\
\hline
\end{tabular}




\begin{tabular}{|c|c|c|}
\hline $\begin{array}{l}\text { Search } \\
\#\end{array}$ & Joncepts searched & ictual search terms \\
\hline & $\begin{array}{l}\text { AND (Motivation OR } \\
\text { Stress) AND Staff }\end{array}$ & $\begin{array}{l}\text { boss") AND ((motivat* OR incentive* OR drive* OR enthusias* OR commit* OR engage*) } \\
\text { OR (stress* OR pressure OR strain OR anxiety OR tension OR apprehens* OR uneas* OR } \\
\text { nervous* OR worr* OR psycholog* OR “mental health" OR emotion* OR role-stress OR } \\
\text { cope OR coping OR well-being OR well-being)) AND (staff OR employee OR worker OR } \\
\text { follower OR follower OR personnel)) }\end{array}$ \\
\hline $16 \#$ & $\begin{array}{l}\text { Leadership AND } \\
\text { (Motivation OR Stress) } \\
\text { AND Healthcare }\end{array}$ & $\begin{array}{l}\text { ((leader* OR “manage*” OR “supervis*” OR “boss”) AND ((motivat* OR incentive* OR } \\
\text { drive* OR enthusias* OR commit* OR engage*) OR (stress* OR pressure OR strain OR } \\
\text { anxiety OR tension OR apprehens* OR uneas* OR nervous* OR worr* OR psycholog* OR } \\
\text { "mental health" OR emotion* OR role-stress OR cope OR coping OR well-being OR well- } \\
\text { being)) AND healthcare) }\end{array}$ \\
\hline $17 \#$ & $\begin{array}{l}\text { "Authentic Leadership" } \\
\text { AND (Motivation OR } \\
\text { Stress) AND Healthcare }\end{array}$ & $\begin{array}{l}\text { ((“authentic leader*” OR “authentic manage*” OR “authentic supervis*” OR “authentic } \\
\text { boss”) AND ((motivat* OR incentive* OR drive* OR enthusias* OR commit* OR engage*) } \\
\text { OR (stress* OR pressure OR strain OR anxiety OR tension OR apprehens* OR uneas* OR } \\
\text { nervous* OR worr* OR psycholog* OR “mental health” OR emotion* OR role-stress OR } \\
\text { cope OR coping OR well-being OR well-being)) AND healthcare) }\end{array}$ \\
\hline $18 \#$ & $\begin{array}{l}\text { Leadership AND } \\
\text { (Motivation OR Stress) } \\
\text { AND "ID" }\end{array}$ & $\begin{array}{l}\text { ((leader* OR “manage*” OR "supervis*” OR "boss") AND ((motivat* OR incentive* OR } \\
\text { drive* OR enthusias* OR commit* OR engage*) OR (stress* OR pressure OR strain OR } \\
\text { anxiety OR tension OR apprehens* OR uneas* OR nervous* OR worr* OR psycholog* OR } \\
\text { "mental health" OR emotion* OR role-stress OR cope OR coping OR well-being OR well- } \\
\text { being)) AND ("intellectual disability*” OR “intellectually disabled”)) }\end{array}$ \\
\hline
\end{tabular}




\begin{tabular}{|c|c|c|}
\hline $\begin{array}{l}\text { Search } \\
\#\end{array}$ & Concepts searched & Actual search terms \\
\hline $19 \#$ & $\begin{array}{l}\text { "Authentic Leadership" } \\
\text { AND (Motivation OR } \\
\text { Stress) AND "ID" }\end{array}$ & $\begin{array}{l}\text { ((“authentic leader*” OR "authentic manage*” OR "authentic supervis*” OR "authentic } \\
\text { boss") AND ((motivat* OR incentive* OR drive* OR enthusias* OR commit* OR engage*) } \\
\text { OR (stress* OR pressure OR strain OR anxiety OR tension OR apprehens* OR uneas* OR } \\
\text { nervous* OR worr* OR psycholog* OR "mental health" OR emotion* OR role-stress OR } \\
\text { cope OR coping OR well-being OR well-being)) AND (“intellectual disability*” OR } \\
\text { "intellectually disabled”)) }\end{array}$ \\
\hline $20 \#$ & $\begin{array}{l}\text { Leadership AND } \\
\text { (Motivation OR Stress) } \\
\text { AND Healthcare AND } \\
\text { Staff }\end{array}$ & $\begin{array}{l}\text { ((leader* OR “manage*” OR “supervis*” OR “boss”) AND ((motivat* OR incentive* OR } \\
\text { drive* OR enthusias* OR commit* OR engage* ) OR (stress* OR pressure OR strain OR } \\
\text { anxiety OR tension OR apprehens* OR uneas* OR nervous* OR worr* OR psycholog* OR } \\
\text { "mental health" OR emotion* OR role-stress OR cope OR coping OR well-being OR well- } \\
\text { being)) AND healthcare AND (staff OR employee OR worker OR follower OR follower OR } \\
\text { personnel)) }\end{array}$ \\
\hline $21 \#$ & $\begin{array}{l}\text { "Authentic Leadership" } \\
\text { AND (Motivation OR } \\
\text { Stress) AND Healthcare } \\
\text { AND Staff }\end{array}$ & $\begin{array}{l}\text { ((“authentic leader*” OR “authentic manage*” OR “authentic supervis*” OR “authentic } \\
\text { boss”) AND ((motivat* OR incentive* OR drive* OR enthusias* OR commit* OR engage*) } \\
\text { OR (stress* OR pressure OR strain OR anxiety OR tension OR apprehens* OR uneas* OR } \\
\text { nervous* OR worr* OR psycholog* OR “mental health" OR emotion* OR role-stress OR } \\
\text { cope OR coping OR well-being OR well-being)) AND healthcare and (staff OR employee } \\
\text { OR worker OR follower OR follower OR personnel)) }\end{array}$ \\
\hline $22 \#$ & $\begin{array}{l}\text { Leadership AND } \\
\text { (Motivation OR Stress) }\end{array}$ & $\begin{array}{l}\text { ((leader* OR "manage*” OR "supervis*” OR "boss") AND ((motivat* OR incentive* OR } \\
\text { drive* OR enthusias* OR commit* OR engage*) OR (stress* OR pressure OR strain OR }\end{array}$ \\
\hline
\end{tabular}




\begin{tabular}{|c|c|c|}
\hline $\begin{array}{l}\text { Search } \\
\#\end{array}$ & Concepts searched & Actual search terms \\
\hline & AND Staff & $\begin{array}{l}\text { anxiety OR tension OR apprehens* OR uneas* OR nervous* OR worr* OR psycholog* OR } \\
\text { "mental health" OR emotion* OR role-stress OR cope OR coping OR well-being OR well- } \\
\text { being)) AND (“intellectual disability*" OR “intellectually disabled") AND (staff OR } \\
\text { employee OR worker OR follower OR follower OR personnel)) }\end{array}$ \\
\hline $23 \#$ & $\begin{array}{l}\text { "Authentic Leadership" } \\
\text { AND (Motivation OR } \\
\text { Stress) AND "ID" AND } \\
\text { Staff }\end{array}$ & $\begin{array}{l}\text { ((“authentic leader*” OR “authentic manage*” OR “authentic supervis*” OR "authentic } \\
\text { boss") AND ((motivat* OR incentive* OR drive* OR enthusias* OR commit* OR engage*) } \\
\text { OR (stress* OR pressure OR strain OR anxiety OR tension OR apprehens* OR uneas* OR } \\
\text { nervous* OR worr* OR psycholog* OR "mental health" OR emotion* OR role-stress OR } \\
\text { cope OR coping OR well-being OR well-being)) AND (“intellectual disability*” OR } \\
\text { "intellectually disabled”) AND (staff OR employee OR worker OR follower OR follower OR } \\
\text { personnel)) }\end{array}$ \\
\hline $24 \#$ & Motivation AND Stress & $\begin{array}{l}\text { ((motivat* OR incentive* OR drive* OR enthusias* OR commit* OR engage*) AND } \\
\text { (stress* OR pressure OR strain OR anxiety OR tension OR apprehens* OR uneas* OR } \\
\text { nervous* OR worr* OR psycholog* OR “mental health" OR emotion* OR role-stress OR } \\
\text { cope OR coping OR well-being OR well-being)) }\end{array}$ \\
\hline $25 \#$ & $\begin{array}{l}\text { Motivation AND Stress } \\
\text { AND Staff }\end{array}$ & $\begin{array}{l}\text { ((motivat* OR incentive* OR drive* OR enthusias* OR commit* OR engage*) AND } \\
\text { (stress* OR pressure OR strain OR anxiety OR tension OR apprehens* OR uneas* OR } \\
\text { nervous* OR worr* OR psycholog* OR “mental health" OR emotion* OR role-stress OR } \\
\text { cope OR coping OR well-being OR well-being) AND (staff OR employee OR worker OR } \\
\text { follower OR follower OR personnel)) }\end{array}$ \\
\hline
\end{tabular}




\begin{tabular}{|c|c|c|}
\hline $\begin{array}{l}\text { Search } \\
\#\end{array}$ & Concepts searched & Actual search terms \\
\hline $26 \#$ & $\begin{array}{l}\text { Motivation AND Stress } \\
\text { AND Staff AND } \\
\text { Healthcare }\end{array}$ & $\begin{array}{l}\text { ((motivat* OR incentive* OR drive* OR enthusias* OR commit* OR engage* ) AND } \\
\text { (stress* OR pressure OR strain OR anxiety OR tension OR apprehens* OR uneas* OR } \\
\text { nervous* OR worr* OR psycholog* OR “mental health" OR emotion* OR role-stress OR } \\
\text { cope OR coping OR well-being OR well-being) AND (staff OR employee OR worker OR } \\
\text { follower OR follower OR personnel) AND healthcare) }\end{array}$ \\
\hline $27 \#$ & $\begin{array}{l}\text { Motivation AND Stress } \\
\text { AND Staff AND "ID" }\end{array}$ & $\begin{array}{l}\text { ((motivat* OR incentive* OR drive* OR enthusias* OR commit* OR engage*) AND } \\
\text { (stress* OR pressure OR strain OR anxiety OR tension OR apprehens* OR uneas* OR } \\
\text { nervous* OR worr* OR psycholog* OR "mental health" OR emotion* OR role-stress OR } \\
\text { cope OR coping OR well-being OR well-being) AND (staff OR employee OR worker OR } \\
\text { follower OR follower OR personnel) AND (“intellectual disability*” OR "intellectually } \\
\text { disabled")) }\end{array}$ \\
\hline
\end{tabular}


Table 7: Academic journal databases searched

\begin{tabular}{ll}
\hline Database & Justification for inclusion \\
\hline Academic Search & ASC provided by EBSCO is a multidisciplinary database designed for academia. ASC contains more than 6,300 \\
Complete (ASC) & full-text journals and magazines, and 5,700 active full test peer-reviewed journals (EBSCO, 2019a). \\
\hline Business Source & BSC provided by EBSCO contains peer-reviewed business and economic journals. BSC contains more than \\
Complete (BSC) & 2,000 full-text journals and magazines and over 1,200 full-text peer-reviewed journals (EBSCO, 2019b). \\
\hline Scopus & Scopus is a multidisciplinary database with 3.7 terabytes of data and includes over 71 million records including \\
& books, conference papers, trade publication and peer-reviewed journals. Scopus is highly functional and offers \\
& extensive search features (Elsevier, 2020). \\
\hline Web of Science & Web of Science is a multidisciplinary database with over 20,000 journals and 1.4 billion references, offering \\
& advanced search functionality (Clarivate, 2019). \\
\hline ProQuest & ProQuest offers a large number of multidisciplinary journals, eBooks, dissertations, news, and video. The \\
& database had advanced search features (ProQuest, 2019). \\
\hline PsycINFO & American Psychological Association's interdisciplinary source of behavioural and social science peer-reviewed \\
& research (PsycINFO, 2019).
\end{tabular}


Table 8: Database Search Results, Search Date: 16 Jun 2019

\begin{tabular}{|c|c|c|c|c|c|c|c|c|}
\hline Search & Concepts searched & \# Results & \# Results & \# Results & \# Results & \# Results & \# Results & Exported to \\
\hline \multirow[t]{2}{*}{$\#$} & & PsycINFO & $\mathrm{ASC}$ & $\mathrm{BSC}$ & Scopus\# & Web of & ProQuest & Zotero for \\
\hline & & & & & & \multicolumn{2}{|l|}{ Science } & screening \\
\hline 1 & Leadership & 256,621 & 955,276 & $1,934,470$ & 4673,129 & $3,133,827$ & $2,000,203$ & No \\
\hline 2 & Authentic Leadership & 312 & 225 & 344 & 713 & 722 & 455 & No \\
\hline 3 & Employee & 171,637 & 304,880 & 192,908 & $1,488,283$ & 813,345 & $1,275,470$ & No \\
\hline 4 & Motivation & 325,641 & 878,416 & 292,571 & $2,777,580$ & $1,766,717$ & $2,809,672$ & No \\
\hline 5 & Stress & 888,765 & $2,320,814$ & 210,216 & $10,028,706$ & $5,760,917$ & $2,809,672$ & No \\
\hline 6 & Healthcare & 100,041 & 292,114 & 55,489 & 345,691 & 371,176 & 91,759 & No \\
\hline 7 & ID & 8,674 & 14,581 & 283 & 27,590 & 33,790 & 20,852 & No \\
\hline 8 & Leadership AND Stress & 73,024 & 117,782 & 37,175 & 658,163 & 435,322 & 255,429 & No \\
\hline \multirow[t]{2}{*}{9} & "Authentic Leadership" AND & 113 & 72 & 87 & 266 & 324 & 158 & Yes \\
\hline & Stress & & & & & & & \\
\hline 10 & Leadership AND Motivation & 39,492 & 79,494 & 195 & 424,405 & 293,398 & 249,262 & No \\
\hline \multirow[t]{2}{*}{11} & "Authentic Leadership" AND & 77 & 55 & 82 & 192 & 241 & 123 & Yes \\
\hline & Motivation & & & & & & & \\
\hline \multirow[t]{2}{*}{12} & Leadership AND (Motivation OR & 101,155 & 183,072 & 95,166 & $1,004,341$ & 669,546 & 462,108 & No \\
\hline & Stress) & & & & & & & \\
\hline 13 & "Authentic Leadership" AND & 163 & 110 & 142 & 386 & 440 & 240 & Yes \\
\hline & (Motivation OR Stress) & & & & & & & \\
\hline
\end{tabular}




\begin{tabular}{|c|c|c|c|c|c|c|c|c|}
\hline $\begin{array}{l}\text { Search } \\
\#\end{array}$ & Concepts searched & $\begin{array}{l}\text { \# Results } \\
\text { PsycINFO }\end{array}$ & $\begin{array}{l}\text { \# Results } \\
\text { ASC }\end{array}$ & $\begin{array}{l}\text { \# Results } \\
\text { BSC }\end{array}$ & $\begin{array}{l}\text { \# Results } \\
\text { Scopus\# }\end{array}$ & $\begin{array}{l}\text { \# Results } \\
\text { Web of } \\
\text { Science }\end{array}$ & $\begin{array}{l}\text { \# Results } \\
\text { ProQuest }\end{array}$ & $\begin{array}{l}\text { Exported to } \\
\text { Zotero for } \\
\text { screening }\end{array}$ \\
\hline 14 & $\begin{array}{l}\text { Leadership AND (Motivation OR } \\
\text { Stress) AND Staff }\end{array}$ & 21,554 & 20,858 & 22,304 & 176,071 & 81,713 & 83,092 & No \\
\hline 15 & $\begin{array}{l}\text { "Authentic Leadership" AND } \\
\text { (Motivation OR Stress) AND Staff }\end{array}$ & 90 & 36 & 87 & 232 & 276 & 120 & Yes \\
\hline 16 & $\begin{array}{l}\text { Leadership AND (Motivation OR } \\
\text { Stress) AND Healthcare }\end{array}$ & 8,873 & 15,438 & 2,912 & 35,749 & 28,687 & 462,108 & No \\
\hline 17 & $\begin{array}{l}\text { "Authentic Leadership" AND } \\
\text { (Motivation OR Stress) AND } \\
\text { Healthcare }\end{array}$ & 12 & 10 & 9 & 13 & 23 & 6 & Yes \\
\hline 18 & $\begin{array}{l}\text { Leadership AND (Motivation OR } \\
\text { Stress) AND "ID" }\end{array}$ & 268 & 406 & 13 & 1,305 & 1,206 & 1,362 & No \\
\hline 19 & $\begin{array}{l}\text { "Authentic Leadership" AND } \\
\text { (Motivation OR Stress) AND "ID" }\end{array}$ & 0 & 0 & 0 & 0 & 0 & 0 & $\mathrm{~N} / \mathrm{A}$ \\
\hline 20 & $\begin{array}{l}\text { Leadership AND (Motivation OR } \\
\text { Stress) AND Healthcare AND Staff }\end{array}$ & 1,934 & 3,469 & 783 & 13,047 & 343,260 & 6,609 & No \\
\hline 21 & $\begin{array}{l}\text { "Authentic Leadership" AND } \\
\text { (Motivation OR Stress) AND } \\
\text { Healthcare AND Staff }\end{array}$ & 7 & 5 & 6 & 9 & 11 & 2 & Yes \\
\hline 22 & Leadership AND (Motivation OR & 74 & 68 & 4 & 359 & 228 & 224 & Yes \\
\hline
\end{tabular}




\begin{tabular}{|c|c|c|c|c|c|c|c|c|}
\hline $\begin{array}{l}\text { Search } \\
\#\end{array}$ & Concepts searched & $\begin{array}{l}\text { \# Results } \\
\text { PsycINFO }\end{array}$ & $\begin{array}{l}\text { \# Results } \\
\text { ASC }\end{array}$ & $\begin{array}{l}\text { \# Results } \\
\text { BSC }\end{array}$ & $\begin{array}{l}\text { \# Results } \\
\text { Scopus\# }\end{array}$ & $\begin{array}{l}\text { \# Results } \\
\text { Web of } \\
\text { Science }\end{array}$ & $\begin{array}{l}\text { \# Results } \\
\text { ProQuest }\end{array}$ & $\begin{array}{l}\text { Exported to } \\
\text { Zotero for } \\
\text { screening }\end{array}$ \\
\hline & Stress) AND "ID" AND Staff & & & & & & & \\
\hline 23 & $\begin{array}{l}\text { "Authentic Leadership" AND } \\
\text { (Motivation OR Stress) AND "ID" } \\
\text { AND Staff }\end{array}$ & 0 & 0 & 0 & 0 & 0 & 0 & $\mathrm{~N} / \mathrm{A}$ \\
\hline 24 & Motivation AND Stress & 92,168 & 134,825 & 28,457 & 521,496 & 343,260 & 751,996 & No \\
\hline 25 & Motivation AND Stress AND Staff & 8,721 & 7,703 & 5,328 & 48,115 & 27,610 & 77,113 & No \\
\hline 26 & $\begin{array}{l}\text { Motivation AND Stress AND Staff } \\
\text { AND Healthcare }\end{array}$ & 817 & 1,137 & 210 & 3,662 & 1,830 & 1,958 & No \\
\hline 27 & $\begin{array}{l}\text { Motivation AND Stress AND Staff } \\
\text { AND "ID" }\end{array}$ & 39 & 41 & 3 & 172 & 116 & 120 & Yes \\
\hline
\end{tabular}


Table 9: Filters applied to academic database searched in table 7

\begin{tabular}{ll}
\hline Database name & Filters applied \\
\hline ASC & Subject Area (all), Publication Type (all) Language (English), Limited to (Peer Reviewed Journals), Time (All), \\
& Fields (TI,ABS,KW) \\
\hline Scopus & Subject Area (all), Document type (all), Time (all), Fields (TI,ABS,KW) \\
\hline BSC & Subject Area (all), Publication Type (all) Language (English), Limited to (Peer Reviewed Journals), Time (All), \\
& Fields (TI,ABS,KW) \\
\hline Web of Science & Language (English), Document type (all), Time (all), Fields(all) \\
\hline ProQuest & Language (English), Limit to (Peer Reviewed), Fields(anywhere except full text) \\
\hline PsycINFO & Subject Area (all), Publication Type (all) Language (English), Limited to (Peer Reviewed Journals), Time (All), \\
& Fields (TI,ABS,KW) \\
\hline
\end{tabular}


Table 10: SLR Data Extraction

\begin{tabular}{|c|c|c|c|c|c|c|}
\hline Study & Research Aim & Theme(s) & Demographics & Method and Measures & $\begin{array}{l}\text { Hypothesis, Results } \\
\text { relevant to SLR }\end{array}$ & $\begin{array}{l}\text { Journal } \\
\text { Ranking }\end{array}$ \\
\hline $\begin{array}{l}\text { (Zhang et } \\
\text { al., 2018) }\end{array}$ & $\begin{array}{l}\text { The study is based } \\
\text { on the self- } \\
\text { determination } \\
\text { theory and } \\
\text { explores whether } \\
\text { AL has any } \\
\text { impact on } \\
\text { employee } \\
\text { proactive } \\
\text { behaviours. In } \\
\text { addition, the study } \\
\text { looks at the } \\
\text { relationship and } \\
\text { possible } \\
\text { mediation of } \\
\text { psychological } \\
\text { empowerment and } \\
\text { core self- } \\
\text { evaluation on the } \\
\text { relationship } \\
\text { between AL and } \\
\text { proactive } \\
\text { behaviours. }\end{array}$ & $\begin{array}{l}\text { AL } \\
\text { Self- } \\
\text { determination } \\
\text { theory } \\
\text { Psychological } \\
\text { empowerment } \\
\text { Core Self- } \\
\text { Evaluations } \\
\text { Proactive } \\
\text { behaviour } \\
\text { Political skills }\end{array}$ & $\begin{array}{l}\text { China } \\
\text { Two private } \\
\text { enterprises } \\
\text { Respondents } \\
\mathrm{N}=65 \text { leaders } \\
\text { and } \mathrm{N}=275 \\
\text { followers }\end{array}$ & $\begin{array}{l}\text { Quantitative, Time } \\
\text { lagged Study, Statistical } \\
\text { Analysis, Survey } \\
\text { Model: } \\
\text { PsyEmp mediates AL and } \\
\text { Proactive behaviour } \\
\text { Measures: } \\
\text { AL: ALI (Neider and } \\
\text { Schriesheim, 2011) } \\
\text { Psychological } \\
\text { empowerment 12-item } \\
\text { scale (Spreitzer,1995) } \\
\text { Core Self-Evaluations } \\
\text { 12-item scale (Judge et } \\
\text { al., 2003) }\end{array}$ & $\begin{array}{l}\text { Hypothesis 1: } \\
\text { "Authentic leadership } \\
\text { is positively related to } \\
\text { employees' proactive } \\
\text { behaviour." } \\
\text { Hypothesis 2: } \\
\text { "Employees' core self- } \\
\text { evaluations mediate the } \\
\text { relationship between } \\
\text { authentic leadership } \\
\text { and employees' } \\
\text { proactive behaviour." } \\
\text { Hypothesis 3: } \\
\text { "Psychological } \\
\text { empowerment } \\
\text { mediates the } \\
\text { relationship between } \\
\text { authentic leadership } \\
\text { and core self- } \\
\text { evaluations." } \\
\text { Hypothesis 5: } \\
\text { "Employees' } \\
\text { psychological } \\
\text { empowerment and core } \\
\text { self-evaluations } \\
\text { sequentially mediate }\end{array}$ & $\begin{array}{l}\text { SJR: } 0.12 \\
\text { JCR: N/A } \\
\text { Journal based } \\
\text { in Singapore } \\
\text { SJR ranking } \\
\text { since } 2008\end{array}$ \\
\hline
\end{tabular}




\begin{tabular}{|c|c|c|c|c|c|c|}
\hline Study & Research Aim & Theme(s) & Demographics & Method and Measures & $\begin{array}{l}\text { Hypothesis, Results } \\
\text { relevant to SLR }\end{array}$ & $\begin{array}{l}\text { Journal } \\
\text { Ranking }\end{array}$ \\
\hline & & & & & $\begin{array}{l}\text { the relationship } \\
\text { between authentic } \\
\text { leadership and } \\
\text { employees' proactive } \\
\text { behaviour." } \\
\text { Results show a } \\
\text { marginally significant } \\
\text { relationship between } \\
\text { AL and employee } \\
\text { proactive behaviour, } \\
\text { while psychological } \\
\text { empowerment and core } \\
\text { self-evaluation mediate } \\
\text { this relationship. }\end{array}$ & \\
\hline $\begin{array}{l}\text { (AL Sahi } \\
\text { AL Zaabi et } \\
\text { al., 2016) }\end{array}$ & $\begin{array}{l}\text { Look at the } \\
\text { association } \\
\text { between AL, work } \\
\text { engagement, OCB } \\
\text { and the mediating } \\
\text { effect of } \\
\text { psychological } \\
\text { empowerment. }\end{array}$ & $\begin{array}{l}\text { AL } \\
\text { Psychological } \\
\text { Empowerment } \\
\text { Work } \\
\text { engagement } \\
\text { OCB }\end{array}$ & $\begin{array}{l}\text { United Arab } \\
\text { Emirates } \\
\text { Oil Industry } \\
\text { Respondents } \\
\mathrm{N}=189 \\
\text { employees }\end{array}$ & $\begin{array}{l}\text { Quantitative, Statisicle } \\
\text { Analaysis, Survey } \\
\text { Model: } \\
\text { PsyEmp mediates AL and } \\
\text { OCB. PsyEmp AL and } \\
\text { work engagement. } \\
\text { Measures: } \\
\text { AL - ALQ 16-item scale } \\
\text { (Walumbwa et al., 2008) } \\
\text { Utrecht Work } \\
\text { Engagement Scale } \\
\text { (UWES) (Schaufeli et al., }\end{array}$ & $\begin{array}{l}\text { Hypothesis H1: } \\
\text { "Authentic leadership } \\
\text { is positively related to } \\
\text { employees" } \\
\text { psychological } \\
\text { empowerment } \\
\text { attitudes." } \\
\text { Results AL was } \\
\text { significantly positively } \\
\text { related to } \\
\text { psychological } \\
\text { empowerment. }\end{array}$ & $\begin{array}{l}\text { SJR: } 0.64 \\
\text { JCR: N/A } \\
\text { Journal based } \\
\text { in the UK } \\
\text { SJR ranking } \\
\text { since } 2005\end{array}$ \\
\hline
\end{tabular}




\begin{tabular}{|c|c|c|c|c|c|c|}
\hline Study & Research Aim & Theme(s) & Demographics & Method and Measures & $\begin{array}{l}\text { Hypothesis, Results } \\
\text { relevant to SLR }\end{array}$ & $\begin{array}{l}\text { Journal } \\
\text { Ranking }\end{array}$ \\
\hline \multirow{3}{*}{$\begin{array}{l}\text { (Shapira- } \\
\text { Lishchinsky } \\
\text { \& Tsemach, } \\
\text { 2014) }\end{array}$} & \multirow{3}{*}{$\begin{array}{l}\text { Examine the } \\
\text { mediating effect } \\
\text { of psychological } \\
\text { empowerment on } \\
\text { AL, OCB and } \\
\text { withdrawal } \\
\text { behaviours }\end{array}$} & \multirow{3}{*}{$\begin{array}{l}\text { AL } \\
\text { Psychological } \\
\text { empowerment } \\
\text { OCB } \\
\text { Withdrawal } \\
\text { behaviours }\end{array}$} & \multirow{3}{*}{$\begin{array}{l}\text { Israel } \\
\text { Teachers } \\
\text { Respondents } \\
\mathrm{N}=366\end{array}$} & $\begin{array}{l}\text { 2002) } \\
\text { OCB scale: The OCB } \\
\text { scale was developed by } \\
\text { (Podsakoff et al., 1990). } \\
\text { Psychological } \\
\text { empowerment } \\
\text { questionnaire original 12- } \\
\text { item (Spreitzer's 1995) }\end{array}$ & & \\
\hline & & & & $\begin{array}{l}\text { Quantitative, Statisicle } \\
\text { Analaysis, Survey } \\
\text { Model: } \\
\text { PsyEmp mediates AL and } \\
\text { OCB. PsyEmp mediates } \\
\text { AL and Withdrawal } \\
\text { behaviours. } \\
\text { Measures: } \\
\text { AL-ALQ 16-item scale } \\
\text { (Walumbwa et al., 2008) } \\
\text { OCB 23-item scale } \\
\text { (Somech and Drach- } \\
\text { Zahavy, 2000) }\end{array}$ & $\begin{array}{l}\text { Hypothesis 1: } \\
\text { "Perceptions of the } \\
\text { principals' authentic } \\
\text { leadership among } \\
\text { teachers is positively } \\
\text { related to their } \\
\text { psychological } \\
\text { empowerment } \\
\text { attitudes." } \\
\text { The dimensions of } \\
\text { psychological } \\
\text { empowerment are } \\
\text { Impact, self- } \\
\text { determination, meaning } \\
\text { sand competence. }\end{array}$ & $\begin{array}{l}\text { SJR: } 1.99 \\
\text { JCR: } 2.313 \\
\text { Journal based } \\
\text { in the USA } \\
\text { SJR ranking } \\
\text { since } 1999\end{array}$ \\
\hline & & & & $\begin{array}{l}\text { Psychological } \\
\text { empowerment } \\
\text { questionnaire original 12- }\end{array}$ & $\begin{array}{l}\text { Impact mediated the } \\
\text { relationship between } \\
\text { AL and OCB. }\end{array}$ & \\
\hline
\end{tabular}




\begin{tabular}{|c|c|c|c|c|c|c|}
\hline Study & Research Aim & Theme(s) & Demographics & Method and Measures & $\begin{array}{l}\text { Hypothesis, Results } \\
\text { relevant to SLR }\end{array}$ & $\begin{array}{l}\text { Journal } \\
\text { Ranking }\end{array}$ \\
\hline \multirow[b]{2}{*}{$\begin{array}{l}\text { (Joo \& Jo, } \\
2015)\end{array}$} & \multirow[b]{2}{*}{$\begin{array}{l}\text { Explore the } \\
\text { impact of } \\
\text { perceived AL of } \\
\text { staff and } \\
\text { employees' core } \\
\text { self-evaluations } \\
\text { on their OCB. } \\
\text { Test the mediating } \\
\text { role of } \\
\text { psychological } \\
\text { empowerment on } \\
\text { the relationships. }\end{array}$} & & \multirow[b]{2}{*}{$\begin{array}{l}\text { Korea } \\
\text { For-profit } \\
\text { organizations } \\
\text { employees. } \\
\text { Respondents } \\
\mathrm{N}=374\end{array}$} & item (Spreitzer's 1995) & $\begin{array}{l}\text { Self-determination, } \\
\text { meaning and } \\
\text { competence mediated } \\
\text { the relationship } \\
\text { between AL and } \\
\text { absence frequency. } \\
\text { Psychological } \\
\text { empowerment did not } \\
\text { mediate the } \\
\text { relationship between } \\
\text { AL and withdrawal } \\
\text { behaviours: lateness } \\
\text { and intent to leave. }\end{array}$ & \\
\hline & & $\begin{array}{l}\text { AL } \\
\text { Psychological } \\
\text { empowerment } \\
\text { OCB } \\
\text { Core self- } \\
\text { evaluation }\end{array}$ & & $\begin{array}{l}\text { Quantitative, Statisicle } \\
\text { Analaysis, Survey } \\
\text { Model: } \\
\text { PsyEmp mediates AL and } \\
\text { OCB. } \\
\text { Measures: } \\
\text { AL - ALQ 16-item scale } \\
\text { (Walumbwa et al., 2008) } \\
\text { Psychological } \\
\text { Empowerment scale 12- } \\
\text { item (Spreitzer, 1995) }\end{array}$ & $\begin{array}{l}\text { Hypothesis H1. } \\
\text { "Perceived authentic } \\
\text { leadership of the } \\
\text { supervisor (i.e. self- } \\
\text { awareness, } \\
\text { moral/ethical, balanced } \\
\text { processing, and } \\
\text { transparency) will be } \\
\text { positively related to } \\
\text { employees' } \\
\text { psychological } \\
\text { empowerment (i.e. } \\
\text { meaning, competence, } \\
\text { self-determination, and } \\
\text { impact)." }\end{array}$ & $\begin{array}{l}\text { SJR: } 0.52 \\
\text { JCR: } 1.462 \\
\text { Journal based } \\
\text { in the UK } \\
\text { SJR ranking } \\
\text { since } 1999\end{array}$ \\
\hline
\end{tabular}




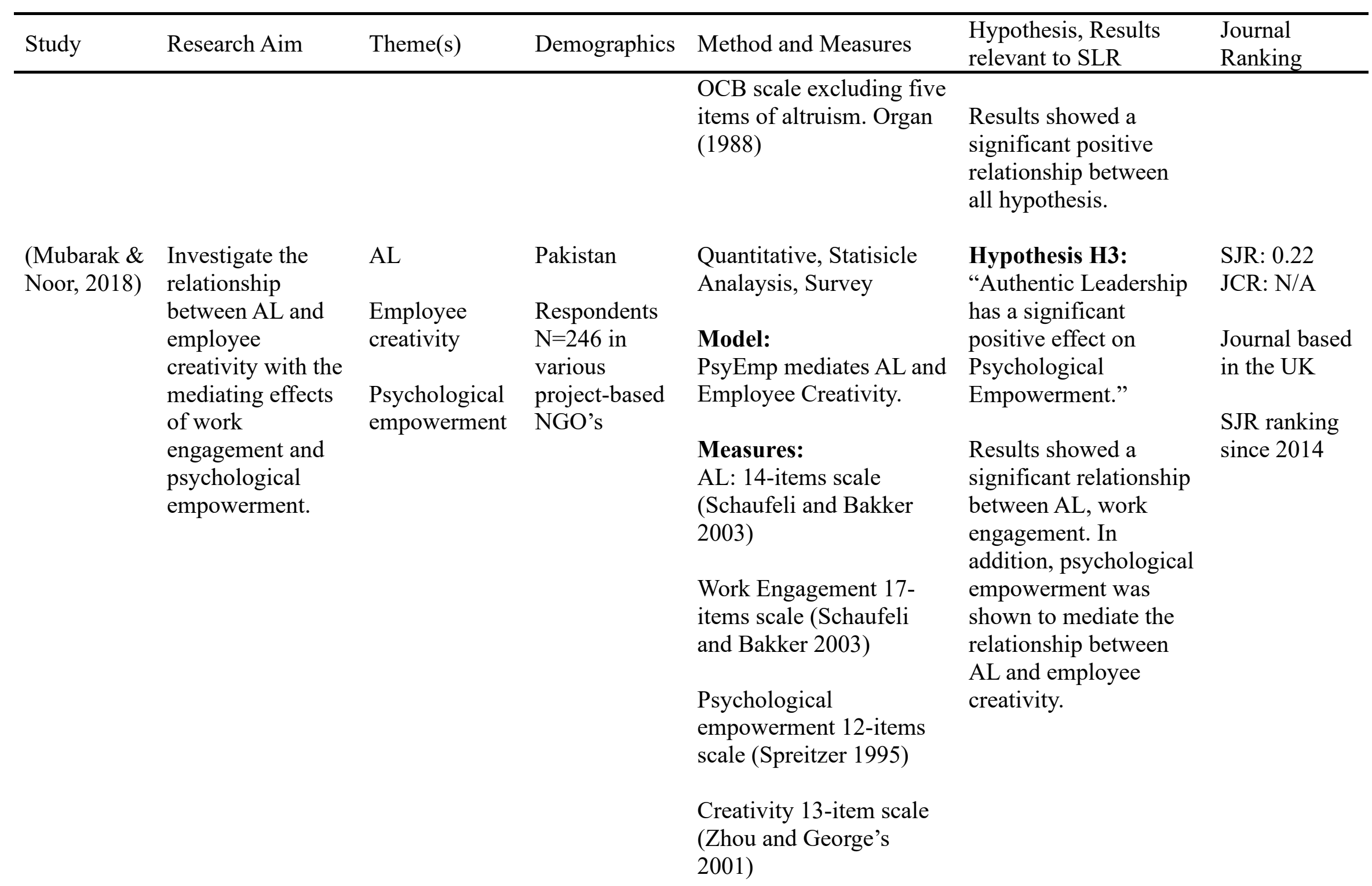




\begin{tabular}{|c|c|c|c|c|c|c|}
\hline Study & Research Aim & Theme(s) & Demographics & Method and Measures & $\begin{array}{l}\text { Hypothesis, Results } \\
\text { relevant to SLR }\end{array}$ & $\begin{array}{l}\text { Journal } \\
\text { Ranking }\end{array}$ \\
\hline $\begin{array}{l}\text { (Marič et } \\
\text { al., 2017) }\end{array}$ & $\begin{array}{l}\text { Explore the } \\
\text { relationship } \\
\text { between AL and } \\
\text { the four } \\
\text { independent } \\
\text { constructs } \\
\text { representing } \\
\text { followers' } \\
\text { psychological } \\
\text { empowerment. }\end{array}$ & $\begin{array}{l}\text { AL } \\
\text { Psychological } \\
\text { empowerment. }\end{array}$ & $\begin{array}{l}\text { Slovenia } \\
\begin{array}{l}\text { Local self- } \\
\text { government } \\
\text { institutions. }\end{array} \\
\text { Respondents } \\
\mathrm{N}=169 \\
\text { employees of } \\
\text { Slovenian } \\
\text { municipalities }\end{array}$ & $\begin{array}{l}\text { Quantitative, Statistical } \\
\text { Analysis, Survey } \\
\text { Model: } \\
\text { AL direct impact on four } \\
\text { demions of PsyEmp } \\
\text { Measures: } \\
\text { AL: 17-item scale } \\
\text { Supervisors'AL Measure } \\
\text { (Marič, Dimovski, } \\
\text { Djurica, Černe and } \\
\text { Đurica 2013). } \\
\text { Psychological } \\
\text { Empowerment } \\
\text { Questionnaire (PEQ) 12- } \\
\text { item scale (Spreitzer } \\
\text { 1995). }\end{array}$ & $\begin{array}{l}\text { Hypothesis: } \\
\text { "Determine relations } \\
\text { between authentic } \\
\text { leadership and sub- } \\
\text { dimensions of } \\
\text { psychological } \\
\text { empowerment." } \\
\text { Results found that } \\
\text { supervisor AL has a } \\
\text { positive impact on } \\
\text { psychological } \\
\text { empowerment and } \\
\text { significantly, so for the } \\
\text { self-determination } \\
\text { dimension. However, } \\
\text { less so for the } \\
\text { 'meaning and } \\
\text { competence' } \\
\text { dimensions. }\end{array}$ & $\begin{array}{l}\text { SJR: N/A } \\
\text { JCR: } 0.728 \\
\text { Journal based } \\
\text { in Slovenia }\end{array}$ \\
\hline $\begin{array}{l}\text { (Guerrero et } \\
\text { al., 2015) }\end{array}$ & $\begin{array}{l}\text { Test the } \\
\text { relationship } \\
\text { between chairs' } \\
\text { AL on board } \\
\text { members } \\
\text { motivation and } \\
\text { commitment via } \\
\text { testing AL impact } \\
\text { on participative } \\
\text { safety climate. }\end{array}$ & $\begin{array}{l}\text { AL } \\
\text { Participative } \\
\text { safety climate } \\
\text { Pro- } \\
\text { organisational } \\
\text { motivation } \\
\text { Organisational }\end{array}$ & $\begin{array}{l}\text { Canada } \\
\text { Credit Union } \\
\text { nonexecutives } \\
\text { boards } \\
\text { members } \\
\text { Respondents } \\
\mathrm{N}=606\end{array}$ & $\begin{array}{l}\text { Quantitative, Statisicle } \\
\text { Analaysis, Survey } \\
\text { Model: } \\
\text { Participative safety } \\
\text { climate mediates AL and } \\
\text { Pro-organisational } \\
\text { motivation and } \\
\text { Organisational } \\
\text { Commitment }\end{array}$ & $\begin{array}{l}\text { Hypothesis 1a: } \\
\text { "Perceptions of the } \\
\text { board participative } \\
\text { safety climate act as a } \\
\text { mediating variable in } \\
\text { the relationship } \\
\text { between chair authentic } \\
\text { leadership and } \\
\text { nonexecutives' pro- } \\
\text { organization }\end{array}$ & $\begin{array}{l}\text { SJR: } 0.85 \\
\text { JCR: } 1.597 \\
\text { Journal based } \\
\text { in the USA } \\
\text { SJR ranking } \\
\text { since } 1999\end{array}$ \\
\hline
\end{tabular}




\begin{tabular}{|c|c|c|c|c|c|c|}
\hline Study & Research Aim & Theme(s) & Demographics & Method and Measures & $\begin{array}{l}\text { Hypothesis, Results } \\
\text { relevant to SLR }\end{array}$ & $\begin{array}{l}\text { Journal } \\
\text { Ranking }\end{array}$ \\
\hline & & Commitment & & $\begin{array}{l}\text { Measures: } \\
\text { AL-ALQ 16-item scale } \\
\text { (Walumbwa et al., 2008) } \\
\text { Prosocial motivation } \\
\text { scale (Grant, 2008) } \\
\text { Participative safety } \\
\text { climate four items scale } \\
\text { (Kivimaki \& Elovainio, } \\
\text { 1999) } \\
\text { Affective Commitment } \\
\text { 6-item Scale (Meyer \& } \\
\text { Allen 1997) }\end{array}$ & $\begin{array}{l}\text { motivation." } \\
\text { Hypothesis 1b: } \\
\text { "Perceptions of the } \\
\text { board participative } \\
\text { safety climate act as a } \\
\text { mediating variable in } \\
\text { the relationship } \\
\text { between chair authentic } \\
\text { leadership and } \\
\text { nonexecutives' } \\
\text { organizational affective } \\
\text { commitment." } \\
\text { Results found } \\
\text { Chairpersons who } \\
\text { demonstrate AL have a } \\
\text { positive effect on board } \\
\text { members motivation } \\
\text { and commitment when } \\
\text { there is transparency, } \\
\text { idea-sharing, i.e. there } \\
\text { is a participative safety } \\
\text { climate. }\end{array}$ & \\
\hline $\begin{array}{l}\text { (Ahmad et } \\
\text { al., 2015) }\end{array}$ & $\begin{array}{l}\text { Explore AL style } \\
\text { on creativity with } \\
\text { the mediating role } \\
\text { of intrinsic } \\
\text { motivation and } \\
\text { mood. }\end{array}$ & $\begin{array}{l}\mathrm{AL} \\
\text { Intrinsic } \\
\text { Motivation } \\
\text { Creativity } \\
\end{array}$ & $\begin{array}{l}\text { Pakistan } \\
\text { Respondents } \\
\mathrm{N}=302 \text { paired } \\
\text { supervisor- } \\
\text { employee } \\
\end{array}$ & $\begin{array}{l}\text { Quantitative, Statisicle } \\
\text { Analaysis, Survey } \\
\text { Model: } \\
\text { AL impact creativity. } \\
\text { Intrinsic motivation }\end{array}$ & $\begin{array}{l}\text { Hypothesis H2a: } \\
\text { "Authentic Leadership } \\
\text { Style of 'Head of } \\
\text { Departments' will } \\
\text { positively influence } \\
\text { academia's intrinsic }\end{array}$ & $\begin{array}{l}\text { SJR: } 0.2 \\
\text { JCR: } 0.757 \\
\text { Journal } \\
\text { based in } \\
\text { Transylvanian }\end{array}$ \\
\hline
\end{tabular}




\begin{tabular}{|c|c|c|c|c|c|c|}
\hline Study & Research Aim & Theme(s) & Demographics & Method and Measures & $\begin{array}{l}\text { Hypothesis, Results } \\
\text { relevant to SLR }\end{array}$ & $\begin{array}{l}\text { Journal } \\
\text { Ranking }\end{array}$ \\
\hline & & Mood & $\begin{array}{l}\text { dyads } \\
\text { in academia }\end{array}$ & $\begin{array}{l}\text { mediates the relationship } \\
\text { between AL and } \\
\text { creativity. } \\
\text { Measures: } \\
\text { AL - ALQ 16-item scale } \\
\text { (Walumbwa et al., 2008) } \\
\text { Intrinsic motivation } \\
\text { Questionnaire WEIMS } \\
\text { based on (Ryan and Deci, } \\
\text { 2000) } \\
\text { Creativity 3-items scale } \\
\text { (Oldham \& Cummings, } \\
\text { 1996) }\end{array}$ & $\begin{array}{l}\text { motivation." } \\
\text { The study found } \\
\text { support for the } \\
\text { hypothesis } \mathrm{H} 2 \mathrm{a} \text {; AL } \\
\text { style has a positive } \\
\text { influence on employee } \\
\text { motivation. }\end{array}$ & $\begin{array}{l}\text { SJR ranking } \\
\text { since } 2008\end{array}$ \\
\hline (Shu, 2015) & $\begin{array}{l}\text { Explore the } \\
\text { relationship } \\
\text { between } \\
\text { Authoritarian } \\
\text { leadership and AL } \\
\text { and what aspects } \\
\text { of these } \\
\text { leadership } \\
\text { behaviours impact } \\
\text { employee needs, } \\
\text { specifically } \\
\text { employee } \\
\text { engagement and } \\
\text { the moderating }\end{array}$ & $\begin{array}{l}\text { AL } \\
\text { Authoritarian } \\
\text { leadership } \\
\text { Intrinsic } \\
\text { motivation } \\
\text { Self- } \\
\text { Determination } \\
\text { Employees' } \\
\text { engagement }\end{array}$ & $\begin{array}{l}\text { Taiwan } \\
\text { various } \\
\text { organisations } \\
\text { Respondents } \\
\mathrm{N}=350 \\
\text { follower- } \\
\text { supervisor } \\
\text { dyads. }\end{array}$ & $\begin{array}{l}\text { Quantitative, Statisicle } \\
\text { Analaysis, Survey } \\
\text { Model: } \\
\text { Intrinsic motivation } \\
\text { moderates AL and } \\
\text { Employees' engagement } \\
\text { Measures: } \\
\text { AL: ALI (Neider and } \\
\text { Schriesheim, 2011) } \\
\text { Work Extrinsic and } \\
\text { Intrinsic Motivation }\end{array}$ & $\begin{array}{l}\text { Hypothesis H1: } \\
\text { "Motivation moderates } \\
\text { the relationship } \\
\text { between authentic } \\
\text { leadership and work } \\
\text { engagement. High } \\
\text { intrinsic motivation } \\
\text { increases the positive } \\
\text { influence of authentic } \\
\text { leadership on work } \\
\text { engagement." } \\
\text { This study found that } \\
\text { when workers are }\end{array}$ & $\begin{array}{l}\text { SJR: N/A } \\
\text { JCR: N/A } \\
\text { Journal based } \\
\text { in Taiwan }\end{array}$ \\
\hline
\end{tabular}




\begin{tabular}{|c|c|c|c|c|c|c|}
\hline Study & Research Aim & Theme(s) & Demographics & Method and Measures & $\begin{array}{l}\text { Hypothesis, Results } \\
\text { relevant to SLR }\end{array}$ & $\begin{array}{l}\text { Journal } \\
\text { Ranking }\end{array}$ \\
\hline & $\begin{array}{l}\text { effect of intrinsic } \\
\text { motivation } \\
\text { between these } \\
\text { leadership styles } \\
\text { and work } \\
\text { engagement. }\end{array}$ & Bicultural Self & & $\begin{array}{l}\text { Scale (WEIMS) } \\
\text { (Tremblay, Blanchard, } \\
\text { Taylor, Pelletier, } \\
\text { Villeneuve, 2009) } \\
\\
\text { Utrecht Work } \\
\text { Engagement Scale } \\
\text { (UWES-9) } \\
\text { (Schaufeli, Bakker, \& } \\
\text { Salanova 2006) }\end{array}$ & $\begin{array}{l}\text { highly motivated to } \\
\text { work, engagement } \\
\text { increased for both } \\
\text { leadership styles. } \\
\text { However, when } \\
\text { employees that are } \\
\text { lacking in motivation, } \\
\text { authentic leadership } \\
\text { effectiveness on work } \\
\text { engagement is not } \\
\text { significant while } \\
\text { authoritarian leadership } \\
\text { decreases work } \\
\text { engagement. }\end{array}$ & \\
\hline $\begin{array}{l}\text { (Hidayat, } \\
\text { 2016) }\end{array}$ & $\begin{array}{l}\text { To investigate the } \\
\text { relationship } \\
\text { between AL and } \\
\text { work engagement. } \\
\text { Determine if } \\
\text { intrinsic } \\
\text { motivation is a } \\
\text { mediator between } \\
\text { AL and work } \\
\text { engagement and } \\
\text { to examine the } \\
\text { moderating effect } \\
\text { of cognitive and } \\
\text { affective trust on } \\
\text { AL and intrinsic } \\
\text { motivation. }\end{array}$ & $\begin{array}{l}\text { AL } \\
\text { Intrinsic } \\
\text { motivation } \\
\text { Work } \\
\text { engagement } \\
\text { Trust }\end{array}$ & $\begin{array}{l}\text { Pakistan } \\
\text { Private sector } \\
\text { employees } \\
\text { Respondents } \\
\mathrm{N}=350\end{array}$ & $\begin{array}{l}\text { Quantitative, Statisicle } \\
\text { Analaysis, Survey } \\
\text { Model: } \\
\text { Intrinsic motivation } \\
\text { mediates AL and work- } \\
\text { engagement. Trust } \\
\text { moderates the } \\
\text { relationship between AL } \\
\text { and Intrinsic motivation. } \\
\text { Measures: } \\
\text { AL-ALQ 16-item scale } \\
\text { (Walumbwa et al., 2008) } \\
\text { Intrinsic motivation: }\end{array}$ & $\begin{array}{l}\text { Hypothesis H2: } \\
\text { Authentic leadership } \\
\text { has a positive effect on } \\
\text { employees through } \\
\text { intrinsic motivation } \\
\text { Hypothesis H4: } \\
\text { Intrinsic motivation has } \\
\text { a positive effect } \\
\text { between authentic } \\
\text { leadership and work } \\
\text { engagement. } \\
\text { Results showed a } \\
\text { significant mediating } \\
\text { effect of intrinsic }\end{array}$ & $\begin{array}{l}\text { SJR: N/A } \\
\text { JCR: N/A } \\
\text { International } \\
\text { Journal } \\
\text { since } 2014\end{array}$ \\
\hline
\end{tabular}




\begin{tabular}{|c|c|c|c|c|c|c|}
\hline Study & Research Aim & Theme(s) & Demographics & Method and Measures & $\begin{array}{l}\text { Hypothesis, Results } \\
\text { relevant to SLR }\end{array}$ & $\begin{array}{l}\text { Journal } \\
\text { Ranking }\end{array}$ \\
\hline \multirow{3}{*}{$\begin{array}{l}\text { (Bordei, } \\
\text { 2019) }\end{array}$} & \multirow{3}{*}{$\begin{array}{l}\text { Through the lens } \\
\text { of self- } \\
\text { determination } \\
\text { theory, this study } \\
\text { investigates the } \\
\text { relationship } \\
\text { between AL, } \\
\text { positive attitudes } \\
\text { toward unethical } \\
\text { behaviour and } \\
\text { work motivation. }\end{array}$} & & \multirow{3}{*}{$\begin{array}{l}\text { Republic of } \\
\text { Moldova } \\
\text { Public sector } \\
\text { organisations } \\
\text { Respondents } \\
\mathrm{N}=98\end{array}$} & $\begin{array}{l}\text { Revised sport motivation } \\
\text { scale (SMS-II)17-item } \\
\text { scale (Deci, E. L., \& } \\
\text { Ryan, R. M. 2013) }\end{array}$ & $\begin{array}{l}\text { motivation in the } \\
\text { relationship between } \\
\text { authentic leadership } \\
\text { and work engagement. }\end{array}$ & \multirow{3}{*}{$\begin{array}{l}\text { SJR: N/A } \\
\text { JCR: N/A } \\
\text { Journal based } \\
\text { in Portugal } \\
\text { Journal since } \\
2015\end{array}$} \\
\hline & & $\begin{array}{l}\text { AL } \\
\text { Motivation, } \\
\text { Job } \\
\text { Satisfaction } \\
\text { Unethical } \\
\text { Behaviour } \\
\text { Self- } \\
\text { determination } \\
\text { Motivation }\end{array}$ & & $\begin{array}{l}\text { Quantitative, Statisicle } \\
\text { Analaysis, Survey } \\
\text { Model: The hypotheses } \\
\text { were tested through } \\
\text { Multiple Hierarchical } \\
\text { Regression. } \\
\text { Measures: } \\
\text { AL: ALI (Neider and } \\
\text { Schriesheim, 2011) } \\
\text { Work Extrinsic and } \\
\text { Intrinsic Motivation } \\
\text { Scale 18-items scale } \\
\text { (Blais, Brière, Lachance, } \\
\text { Riddle and Vallerand, } \\
\text { 1993) } \\
\text { Global Job Satisfaction: } \\
\text { Global Job Satisfaction } \\
\text { scale 15-items scale } \\
\text { (Warr, Cook and Wall, } \\
\text { 1979) }\end{array}$ & \multirow[t]{2}{*}{$\begin{array}{l}\text { Hypothesis 1: The } \\
\text { authentic leadership } \\
\text { behavior in public } \\
\text { organizations has a } \\
\text { positive influence on } \\
\text { employees' work } \\
\text { motivation level. } \\
\text { Hypothesis 2: The } \\
\text { increase work } \\
\text { motivation level of } \\
\text { public employees is } \\
\text { positively related to } \\
\text { their job satisfaction. } \\
\text { Result found that AL } \\
\text { has a positive impact on } \\
\text { work motivation. Job } \\
\text { satisfaction was also } \\
\text { positively related to } \\
\text { motivation. }\end{array}$} & \\
\hline & & & & $\begin{array}{l}\text { Attitude of public } \\
\text { employees toward }\end{array}$ & & \\
\hline
\end{tabular}




\begin{tabular}{|c|c|c|c|c|c|c|}
\hline Study & Research Aim & Theme(s) & Demographics & Method and Measures & $\begin{array}{l}\text { Hypothesis, Results } \\
\text { relevant to SLR }\end{array}$ & $\begin{array}{l}\text { Journal } \\
\text { Ranking }\end{array}$ \\
\hline $\begin{array}{l}\text { (Leroy et } \\
\text { al., 2015) }\end{array}$ & $\begin{array}{l}\text { To examine the } \\
\text { notion that AL } \\
\text { and authentic } \\
\text { followership } \\
\text { together impact } \\
\text { follower } \\
\text { satisfaction } \\
\text { through the lens } \\
\text { of self- } \\
\text { determination } \\
\text { theory and } \\
\text { thereby promotes } \\
\text { follower work } \\
\text { role performance. }\end{array}$ & $\begin{array}{l}\text { AL } \\
\text { Authentic } \\
\text { followership } \\
\text { Basic need } \\
\text { satisfaction } \\
\text { self- } \\
\text { determination } \\
\text { theory } \\
\text { work role } \\
\text { performance }\end{array}$ & $\begin{array}{l}\text { Belgium } \\
\text { Service } \\
\text { Industry } \\
\text { Respondents } \\
\mathrm{N}=30 \text { leaders } \\
\text { and } \mathrm{N}=252 \\
\text { followers in } \\
\mathrm{N}=25 \text { service } \\
\text { companies. }\end{array}$ & $\begin{array}{l}\text { unethical behaviour 10- } \\
\text { item scale (Haberfeld } \\
\text { et al., 2000) } \\
\text { Quantitative, Statisicle } \\
\text { Analaysis, Survey } \\
\text { Model: } \\
\text { Authentic followership } \\
\text { mediates basic needs } \\
\text { satisfaction (based on } \\
\text { SDT framework) and } \\
\text { work-performance. AL } \\
\text { moderates authentic } \\
\text { followership and basic } \\
\text { needs satisfaction. } \\
\text { Measures: } \\
\text { AL-ALQ 16-item scale } \\
\text { (Walumbwa et al., 2008) } \\
\text { Authentic followership: } \\
16 \text { Authenticity Inventory } \\
\text { self-report instrument } \\
\text { (Kernis and Goldman } \\
\text { 2006) } \\
\text { Basic need satisfaction: } \\
\text { 21-item self-report } \\
\text { instrument (Deci et al., }\end{array}$ & $\begin{array}{l}\text { Hypothesis 2: } \\
\text { "Authentic leadership } \\
\text { is positively related to } \\
\text { basic need } \\
\text { satisfaction." } \\
\text { Hypothesis 5: "Basic } \\
\text { needs satisfaction } \\
\text { mediates the positive } \\
\text { relationship of AL with } \\
\text { follower work role } \\
\text { performance." } \\
\text { Hypothesis 6: } \\
\text { Authentic leadership } \\
\text { moderates the indirect } \\
\text { effect of authentic } \\
\text { followership on } \\
\text { follower work role } \\
\text { performance via } \\
\text { follower basic need } \\
\text { satisfaction. } \\
\text { Results showed a } \\
\text { positive association } \\
\text { between AL and } \\
\text { followers basic need } \\
\text { satisfaction and found } \\
\text { basic needs satisfaction }\end{array}$ & $\begin{array}{l}\text { SJR: } 7.94 \\
\text { JCR: } 9.056 \\
\text { Journal based } \\
\text { in the USA } \\
\text { SJR ranking } \\
\text { since } 1999\end{array}$ \\
\hline
\end{tabular}




\begin{tabular}{|c|c|c|c|c|c|c|}
\hline Study & Research Aim & Theme(s) & Demographics & Method and Measures & $\begin{array}{l}\text { Hypothesis, Results } \\
\text { relevant to SLR }\end{array}$ & $\begin{array}{l}\text { Journal } \\
\text { Ranking }\end{array}$ \\
\hline $\begin{array}{l}\text { (Adil \& } \\
\text { Kamal, } \\
\text { 2018) }\end{array}$ & $\begin{array}{l}\text { Looks at the } \\
\text { association } \\
\text { between } \\
\text { promotive and } \\
\text { preventative } \\
\text { psychological } \\
\text { ownership in } \\
\text { relation to AL and } \\
\text { psychological } \\
\text { capital (PsyCap) } \\
\text { with burnout. }\end{array}$ & $\begin{array}{l}\text { AL } \\
\text { Burnout } \\
\text { PsyCap } \\
\text { Promotive } \\
\text { Psychological } \\
\text { Ownership } \\
\text { Preventative } \\
\text { Psychological } \\
\text { Ownership }\end{array}$ & $\begin{array}{l}\text { Pakistan } \\
\text { Public sector } \\
\text { universities } \\
\text { teachers } \\
\text { Respondents } \\
\mathrm{N}=500 \\
\text { teachers }\end{array}$ & $\begin{array}{l}\text { Quantitative, Statisicle } \\
\text { Analaysis, Survey } \\
\text { Model: } \\
\text { AL directly impacts } \\
\text { burnout. Promotive } \\
\text { ownership mediates the } \\
\text { relationship. } \\
\text { Measures: } \\
\text { AL-Authentic } \\
\text { Leadership Questionnaire } \\
\text { (ALQ) 16-item scale } \\
\text { (Walumbwa et al., 2008) } \\
\text { Burnout: Maslach } \\
\text { Burnout Inventory (MBI) } \\
\text { (Maslach et al. 1996) }\end{array}$ & $\begin{array}{l}\text { mediates the } \\
\text { relationship between } \\
\text { authentic followership } \\
\text { and follower work } \\
\text { performance. While AL } \\
\text { moderated the } \\
\text { relationship. } \\
\text {. } \\
\text { Hypothesis 3: } \\
\text { "Authentic leadership } \\
\text { will be negatively } \\
\text { related to burnout." } \\
\text { The result found the } \\
\text { higher authentic } \\
\text { leadership is perceived, } \\
\text { the more likely it is } \\
\text { promotive ownership } \\
\text { will be experienced by } \\
\text { the follower, which in } \\
\text { turn reduces the } \\
\text { likelihood of burnout. } \\
\text { However, the more a } \\
\text { follower perceives their } \\
\text { leaders to be authentic, } \\
\text { the less preventative } \\
\text { ownership is felt, } \\
\text { which also has a } \\
\text { positive impact on } \\
\text { reducing the chance of }\end{array}$ & $\begin{array}{l}\text { SJR: } 0.17 \\
\text { JCR: N/A } \\
\text { Journal based } \\
\text { in India } \\
\text { SJR ranking } \\
\text { since } 1999\end{array}$ \\
\hline
\end{tabular}




\begin{tabular}{|c|c|c|c|c|c|c|}
\hline Study & Research Aim & Theme(s) & Demographics & Method and Measures & $\begin{array}{l}\text { Hypothesis, Results } \\
\text { relevant to SLR }\end{array}$ & $\begin{array}{l}\text { Journal } \\
\text { Ranking }\end{array}$ \\
\hline $\begin{array}{l}\text { (Laschinger } \\
\text { \& Fida, } \\
\text { 2014b) }\end{array}$ & $\begin{array}{l}\text { Explore the } \\
\text { impact of AL on } \\
\text { new graduate } \\
\text { nurses' } \\
\text { experiences of } \\
\text { bullying and } \\
\text { burnout in the } \\
\text { workplace. Also, } \\
\text { look at the process } \\
\text { taking place from } \\
\text { workplace } \\
\text { bullying to } \\
\text { subsequent } \\
\text { burnout and } \\
\text { turnover } \\
\text { intentions. }\end{array}$ & $\begin{array}{l}\text { AL } \\
\text { Work-related } \\
\text { bullying } \\
\text { Burnout } \\
\text { Turnover } \\
\text { Intention }\end{array}$ & $\begin{array}{l}\text { Canadian } \\
\text { healthcare } \\
\text { settings } \\
\text { Respondents } \\
\text { N-205 new } \\
\text { graduate } \\
\text { nurses }\end{array}$ & $\begin{array}{l}\text { Quantitative, Time- } \\
\text { lagged Study over } 1 \text { year, } \\
\text { Statistical Analysis, } \\
\text { Survey } \\
\text { Model: } \\
\text { Burnout mediates the } \\
\text { relationship between AL } \\
\text { and turnover. } \\
\text { Work-related bullying } \\
\text { mediates the relationship } \\
\text { between AL and } \\
\text { turnover. } \\
\text { Measures: } \\
\text { AL-ALQ 16-item scale } \\
\text { (Walumbwa et al., 2008) } \\
\text { Bullying Negative Acts } \\
\text { Questionnaire, revised } \\
\text { (NAQ-R; Einarsen \& } \\
\text { Hoel, 2001). } \\
\text { Burnout: Maslach } \\
\text { Burnout Inventory (MBI) } \\
\text { (Maslach et al. 1996) } \\
\text { Job Turnover Intentions } \\
\text { Scale: Kelloway et al.'s }\end{array}$ & $\begin{array}{l}\text { burnout. } \\
\text { Hypothesis 1: "Higher } \\
\text { perception of } \\
\text { immediate supervisor } \\
\text { AL behaviours at T1 } \\
\text { (AL) are related to } \\
\text { lower levels of } \\
\text { workplace bullying at } \\
\text { T2 (Workplace } \\
\text { bullying, Burnout - } \\
\text { emotional exhaustion } \\
\text { and cynicism)" } \\
\text { Hypothesis 2a and 2b, } \\
\text { respectively: "Higher } \\
\text { perceptions of } \\
\text { immediate supervisor } \\
\text { AL behaviours at T1 } \\
\text { will be related to lower } \\
\text { levels of burnout } \\
\text { (emotional exhaustion } \\
\text { and cynicism) at T2." } \\
\text { Results showed AL } \\
\text { behaviours impact } \\
\text { workplace bullying and } \\
\text { burnout, which in turn } \\
\text { has a negative effect on } \\
\text { turnover and career } \\
\text { intention. }\end{array}$ & $\begin{array}{l}\text { SJR: } 1.71 \\
\text { JCR: } 2.598 \\
\text { Journal based } \\
\text { in the UK } \\
\text { SJR ranking } \\
\text { since } 2005\end{array}$ \\
\hline
\end{tabular}




\begin{tabular}{|c|c|c|c|c|c|c|}
\hline Study & Research Aim & Theme(s) & Demographics & Method and Measures & $\begin{array}{l}\text { Hypothesis, Results } \\
\text { relevant to SLR }\end{array}$ & $\begin{array}{l}\text { Journal } \\
\text { Ranking }\end{array}$ \\
\hline \multirow[b]{2}{*}{$\begin{array}{l}\text { (Jeong et } \\
\text { al., 2017) }\end{array}$} & \multirow[b]{2}{*}{$\begin{array}{l}\text { Test the impact } \\
\text { AL behaviours } \\
\text { has on } \\
\text { supervisory and } \\
\text { organisation trust. } \\
\text { Also, test if trust } \\
\text { impacts on } \\
\text { employee } \\
\text { burnout. }\end{array}$} & & & (1999) & & \\
\hline & & $\begin{array}{l}\text { AL } \\
\text { Trust } \\
\text { Burnout }\end{array}$ & $\begin{array}{l}\text { South Korea, } \\
\text { Travel Agent } \\
\text { Tour } \\
\text { operators } \\
\text { Respondents } \\
\mathrm{N}=215\end{array}$ & $\begin{array}{l}\text { Quantitative, Statistical } \\
\text { Analaysis, Survey } \\
\text { Model: } \\
\text { Supervisor and } \\
\text { organisation trust } \\
\text { mediate AL and Burnout. } \\
\text { Measures: } \\
\text { AL: Authentic } \\
\text { Leadership Inventory } \\
\text { (ALI) (Neider and } \\
\text { Schriesheim, 2011) } \\
\text { Trust (Nyhan, 2000) } \\
\text { Burnout: The measure } \\
\text { adopted from } \\
\text { (Singh,Goolsby \& } \\
\text { Rhoads 1994) and } \\
\text { Maslach Burnout } \\
\text { Inventory (MBI) } \\
\text { (Maslach et al. 1996) }\end{array}$ & $\begin{array}{l}\text { Hypothesis H1, 2, } 4 \\
\text { and 5: "The } 4 \\
\text { dimensions of AL will } \\
\text { have a positive } \\
\text { influence on supervisor } \\
\text { and organisational trust } \\
\text { which in turn will have } \\
\text { a negative effect on } \\
\text { reduced personal } \\
\text { accomplishment, } \\
\text { emotional exhaustion } \\
\text { and depersonalisation." } \\
\text { Results AL promotes } \\
\text { supervisory and } \\
\text { organisational trust, } \\
\text { and supervisory trust } \\
\text { has a significant impact } \\
\text { on organisational trust, } \\
\text { which in turn has a } \\
\text { significant impact on } \\
\text { employee burnout. }\end{array}$ & $\begin{array}{l}\text { SJR: } 0.73 \\
\text { JCR: } 1.44 \\
\text { Journal based } \\
\text { in the UK } \\
\text { SJR ranking } \\
\text { since } 2003\end{array}$ \\
\hline $\begin{array}{l}\text { (Spence } \\
\text { Laschinger } \\
\text { et al., 2019) }\end{array}$ & $\begin{array}{l}\text { To explore the } \\
\text { predictors and } \\
\text { health outcomes } \\
\text { of new graduate } \\
\text { nurse over a one- }\end{array}$ & $\begin{array}{l}\text { AL } \\
\text { Structural } \\
\text { Empowerment }\end{array}$ & $\begin{array}{l}\text { Canada } \\
\text { New graduate } \\
\text { nurses }\end{array}$ & $\begin{array}{l}\text { Quantitative Time-lagged } \\
\text { study, Statisicle } \\
\text { Analaysis, Survey } \\
\text { Model: }\end{array}$ & $\begin{array}{l}\text { Research Found } \\
\text { Incivility is } \\
\text { psychologically } \\
\text { harmful, while }\end{array}$ & $\begin{array}{l}\text { SJR: } 1.86 \\
\text { JCR: N/A } \\
\text { Journal based } \\
\text { in the USA }\end{array}$ \\
\hline
\end{tabular}




\begin{tabular}{|c|c|c|c|c|c|c|}
\hline Study & Research Aim & Theme(s) & Demographics & Method and Measures & $\begin{array}{l}\text { Hypothesis, Results } \\
\text { relevant to SLR }\end{array}$ & $\begin{array}{l}\text { Journal } \\
\text { Ranking }\end{array}$ \\
\hline & year period. & $\begin{array}{l}\text { Person- Job } \\
\text { Fit } \\
\text { Burnout } \\
\text { Health } \\
\text { Incivility } \\
\text { Mental health } \\
\text { Nursing, } \\
\text { occupational } \\
\text { coping } \\
\text { self - efficacy } \\
\text { Risk of Post- } \\
\text { traumatic } \\
\text { stress disorder } \\
\text { (PTSD) } \\
\text { Psychological } \\
\text { capital }\end{array}$ & $\begin{array}{l}\text { Respondents } \\
\mathrm{N}=406 \\
\text { November } \\
\text { 2012-March } \\
2013 \\
\text { (Time 1 } \\
\text { predictors) } \\
\text { and May-July } \\
2014 \text { (Time2 } \\
\text { outcomes). }\end{array}$ & $\begin{array}{l}\text { Work outcomes (work } \\
\text { stressor and Incivility) } \\
\text { mediate the Acntecedents } \\
\text { (AL and more) and } \\
\text { Health outcomes (mental } \\
\text { health and PTSD) } \\
\text { Measures: } \\
\text { Authentic leadership } \\
\text { questionnaire } \\
\text { (Walumbwa et al., 2008) } \\
\text { Also, see the article itself } \\
\text { for a further 11 } \\
\text { instruments used to } \\
\text { measure the following: } \\
\text { Structural Empowerment, } \\
\text { Person - job fit, New } \\
\text { graduate nurse Support, } \\
\text { Occupational coping } \\
\text { self - efficacy, } \\
\text { Psychological capital, } \\
\text { Incivility, Burnout, Work } \\
\text { interference with } \\
\text { personal life, Self-rated } \\
\text { Health, Mental health, } \\
\text { PTSD risk. }\end{array}$ & $\begin{array}{l}\text { intrapersonal resources } \\
\text { (Psychological capital } \\
\text { and occupational } \\
\text { coping self - efficacy) } \\
\text { can be beneficial to } \\
\text { health and well-being. } \\
\text { Burnout is harmful to } \\
\text { health and well-being } \\
\text { as sown in previous } \\
\text { studies. This study } \\
\text { found that burnout can } \\
\text { contribute to the } \\
\text { likelihood of PTSD. } \\
\text { AL and positive } \\
\text { empowering working } \\
\text { condition promote } \\
\text { healthy working } \\
\text { conditions and act as a } \\
\text { buffer against negative } \\
\text { health outcomes. }\end{array}$ & $\begin{array}{l}\text { SJR ranking } \\
\text { since } 2014\end{array}$ \\
\hline $\begin{array}{l}\text { (Laschinger } \\
\text { et al., 2013) }\end{array}$ & $\begin{array}{l}\text { Explore the } \\
\text { impact of AL and } \\
\text { empowerment on }\end{array}$ & $\begin{array}{l}\text { AL } \\
\text { Burnout }\end{array}$ & $\begin{array}{l}\text { Canada } \\
\text { Nurses }\end{array}$ & $\begin{array}{l}\text { Quantitative, Statisicle } \\
\text { Analaysis, Survey }\end{array}$ & $\begin{array}{l}\text { Hypothesis: "Higher } \\
\text { staff nurse ratings of } \\
\text { their supervisor's AL }\end{array}$ & $\begin{array}{l}\text { SJR: } 1.07 \\
\text { JCR: } 2.386\end{array}$ \\
\hline
\end{tabular}




\begin{tabular}{|c|c|c|c|c|c|c|}
\hline Study & Research Aim & Theme(s) & Demographics & Method and Measures & $\begin{array}{l}\text { Hypothesis, Results } \\
\text { relevant to SLR }\end{array}$ & $\begin{array}{l}\text { Journal } \\
\text { Ranking }\end{array}$ \\
\hline & the burnout. & $\begin{array}{l}\text { Structural } \\
\text { empowerment }\end{array}$ & $\begin{array}{l}\text { Respondents } \\
\mathrm{N}-342 \text { new } \\
\text { graduates and } \\
\mathrm{N}=273 \\
\text { experienced } \\
\text { acute-care } \\
\text { nurses. }\end{array}$ & $\begin{array}{l}\text { Measures: } \\
\text { Structural empowerment } \\
\text { mediates AL and } \\
\text { Emotional exhaustion (an } \\
\text { element of burnout). AL } \\
\text { has a direct impact of } \\
\text { Cynicism (an element of } \\
\text { burnout) } \\
\text { Model: } \\
\text { AL-ALQ 16-item scale } \\
\text { (Walumbwa et al., 2008) } \\
\text { Burnout: Maslach } \\
\text { Burnout Inventory (MBI) } \\
\text { (Maslach et al. 1996) } \\
\text { Conditions of Work } \\
\text { Effectiveness } \\
\text { Questionnaire-II' } \\
\text { (CWEQ-II) (Cho et al. } \\
\text { 2006, Greco et al. 2006). }\end{array}$ & $\begin{array}{l}\text { behaviours would be } \\
\text { related to higher levels } \\
\text { of structural } \\
\text { empowerment in their } \\
\text { current work settings, } \\
\text { which in turn, would } \\
\text { be related to lower } \\
\text { emotional exhaustion } \\
\text { and ultimately lower } \\
\text { levels of cynicism and } \\
\text { the pattern of } \\
\text { relationships among } \\
\text { these variables would } \\
\text { be the same for both } \\
\text { experienced and newly } \\
\text { graduated nurses." } \\
\text { Results: AL has a } \\
\text { significant adverse } \\
\text { effect on emotional } \\
\text { exhaustion and } \\
\text { cynicism (burnout) } \\
\text { through the mediation } \\
\text { effects of workplace } \\
\text { empowerment in both } \\
\text { groups of nurses. }\end{array}$ & $\begin{array}{l}\text { Journal based } \\
\text { in the UK } \\
\text { SJR ranking } \\
\text { since } 1999\end{array}$ \\
\hline $\begin{array}{l}\text { (Laschinger } \\
\text { \& Fida, } \\
\text { 2014a) }\end{array}$ & $\begin{array}{l}\text { Investigates the } \\
\text { effects of AL, } \\
\text { organisational } \\
\text { resources and }\end{array}$ & $\begin{array}{l}\text { AL } \\
\text { Psychological } \\
\text { capital }\end{array}$ & $\begin{array}{l}\text { Canada } \\
\text { Respondents } \\
\mathrm{N}=205 \text { Nures }\end{array}$ & $\begin{array}{l}\text { Quantitative, Time- } \\
\text { lagged study, Statisicle } \\
\text { Analaysis, Survey }\end{array}$ & $\begin{array}{l}\text { Hypothesis 1: 'New } \\
\text { graduates' perceptions } \\
\text { of their immediate } \\
\text { supervisors' authentic }\end{array}$ & $\begin{array}{l}\text { SJR: } 0.95 \\
\text { JCR: N/A } \\
\text { Journal based }\end{array}$ \\
\hline
\end{tabular}




\begin{tabular}{|c|c|c|c|c|c|c|}
\hline Study & Research Aim & Theme(s) & Demographics & Method and Measures & $\begin{array}{l}\text { Hypothesis, Results } \\
\text { relevant to SLR }\end{array}$ & $\begin{array}{l}\text { Journal } \\
\text { Ranking }\end{array}$ \\
\hline & $\begin{array}{l}\text { psychological } \\
\text { capital on } \\
\text { burnout, } \\
\text { occupational } \\
\text { satisfaction, and } \\
\text { workplace mental } \\
\text { health. }\end{array}$ & $\begin{array}{l}\text { Intrapersonal } \\
\text { resources } \\
\text { Burnout } \\
\text { Occupational } \\
\text { satisfaction } \\
\text { Workplace } \\
\text { mental health }\end{array}$ & $\begin{array}{l}\text { Two-wave } \\
\text { survey of } \\
\text { newly } \\
\text { graduated } \\
\text { nurses with } \\
\text { less than two } \\
\text { years of } \\
\text { experience in } \\
\text { acute care } \\
\text { hospitals } \\
\text { across Ontario } \\
\text { (T1 in 2010; } \\
\text { T2 in 2011). }\end{array}$ & $\begin{array}{l}\text { Model: } \\
\text { Burnout mediates, AL } \\
\text { and Mental Health and } \\
\text { Job satisfaction. } \\
\text { Measures: } \\
\text { AL-ALQ 16-item scale } \\
\text { (Walumbwa et al., 2008) } \\
\text { Burnout: Maslach } \\
\text { Burnout Inventory (MBI) } \\
\text { (Maslach et al. 1996) } \\
\text { Mental Health 5-item } \\
\text { Mental HealthIndex } \\
\text { (MHI-5) of the SF-36 } \\
\text { (Ware and Sherbourne, } \\
\text { 1992) }\end{array}$ & $\begin{array}{l}\text { leadership behaviour } \\
\text { are negatively related } \\
\text { to their likelihood of } \\
\text { developing burnout } \\
\text { (EE and CYN) in the } \\
\text { first year of } \\
\text { employment. } \\
\text { Specifically, the more } \\
\text { nurses perceive their } \\
\text { supervisor as authentic } \\
\text { the less likely they are } \\
\text { to experience } \\
\text { emotional exhaustion } \\
\text { and cynicism in the } \\
\text { first year of practice } \\
\text { and consequently the } \\
\text { less likely they are to } \\
\text { experience an increase } \\
\text { in burnout over a } 1 \\
\text { year timeframe." } \\
\text { Hypothesis } 3: \text { "Higher } \\
\text { initial levels of burnout } \\
\text { and subsequent } \\
\text { increases over the first } \\
\text { year of practice (both } \\
\text { EE and CYN) will be } \\
\text { related to poorer } \\
\text { mental health." }\end{array}$ & $\begin{array}{l}\text { in the } \\
\text { Netherlands } \\
\text { SJR ranking } \\
\text { since } 2014\end{array}$ \\
\hline & & & & & The study found & \\
\hline
\end{tabular}




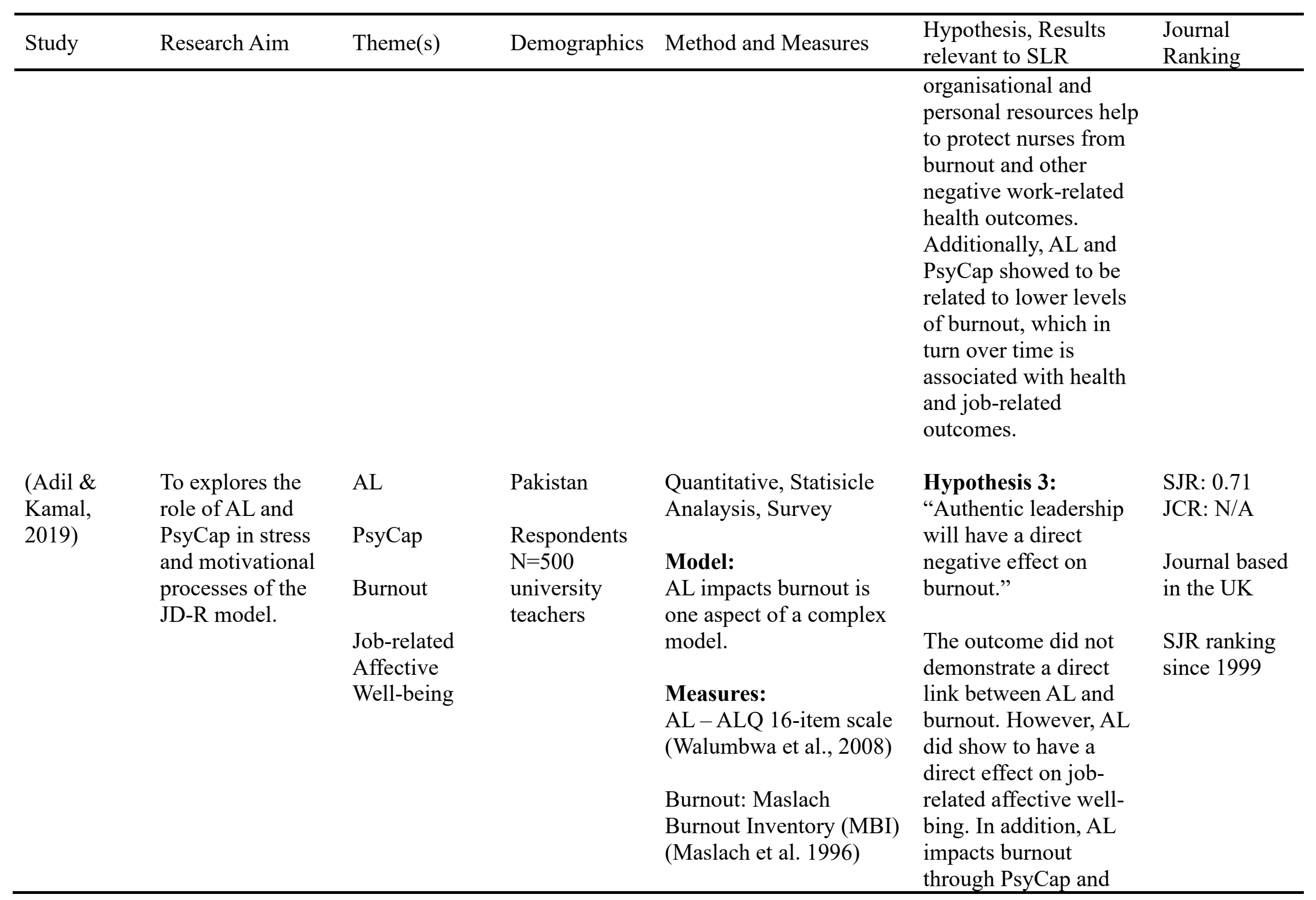




\begin{tabular}{|c|c|c|c|c|c|c|}
\hline Study & Research Aim & Theme(s) & Demographics & Method and Measures & $\begin{array}{l}\text { Hypothesis, Results } \\
\text { relevant to SLR }\end{array}$ & $\begin{array}{l}\text { Journal } \\
\text { Ranking }\end{array}$ \\
\hline $\begin{array}{l}\text { (Boamah et } \\
\text { al., 2017) }\end{array}$ & $\begin{array}{l}\text { Test relationship } \\
\text { between } \\
\text { perceptions of } \\
\text { managers AL } \\
\text { behaviours to } \\
\text { structural } \\
\text { empowerment, } \\
\text { work-life } \\
\text { interference and } \\
\text { short-staffing. } \\
\text { Also, explore } \\
\text { subsequent } \\
\text { burnout, job } \\
\text { satisfaction and } \\
\text { patient care } \\
\text { quality. }\end{array}$ & $\begin{array}{l}\text { AL } \\
\text { Structural } \\
\text { empowerment } \\
\text { Short staffing } \\
\text { Work-life } \\
\text { interference } \\
\text { Burnout, } \\
\text { Job } \\
\text { satisfaction, } \\
\text { Patient care } \\
\text { quaility }\end{array}$ & $\begin{array}{l}\text { Canada, } \\
\text { New graduate } \\
\text { nurses } \\
\text { Respondents } \\
\mathrm{N}=450\end{array}$ & $\begin{array}{l}\text { Quantitative time-lagged } \\
\text { study, Statisicle } \\
\text { Analaysis, Survey } \\
\text { Study 1: Nov } 2012 \text { - Mar } \\
2013 \text { (AL, structural } \\
\text { empowerment, short- } \\
\text { staffing and work-life } \\
\text { interference) } \\
\text { Study 2: May - Jun 2014 } \\
\text { (short-staffing, work-life } \\
\text { interference, burnout, job } \\
\text { satisfaction and nurse- } \\
\text { assessed quality of care) } \\
\text { Model: } \\
\text { AL impacts Structural } \\
\text { empowerment, which in } \\
\text { turn impacts short- } \\
\text { staffing and work-life } \\
\text { balance. Short-staffing } \\
\text { and work-life balance } \\
\text { mediate the relationship } \\
\text { between structural } \\
\text { empowerment and } \\
\text { burnout. While short- } \\
\text { staffing moderates work- }\end{array}$ & $\begin{array}{l}\text { overload; however, not } \\
\text { significantly. } \\
\text { The study found that } \\
\text { nurses perceptions of } \\
\text { AL are positively } \\
\text { related to structural } \\
\text { empowerment, which } \\
\text { in turn negatively } \\
\text { influences short- } \\
\text { staffing and work-life } \\
\text { interference, which in } \\
\text { turn results in nurse } \\
\text { burnout. Burnout } \\
\text { showed to impact on } \\
\text { job satisfaction } \\
\text { negatively. Both job } \\
\text { satisfaction and } \\
\text { burnout harm the } \\
\text { nurse-assessed patient } \\
\text { quality of care. }\end{array}$ & $\begin{array}{l}\text { SJR: } 1.01 \\
\text { JCR: } 2.376 \\
\text { Journal based } \\
\text { in the UK } \\
\text { SJR ranking } \\
\text { since } 1999\end{array}$ \\
\hline
\end{tabular}




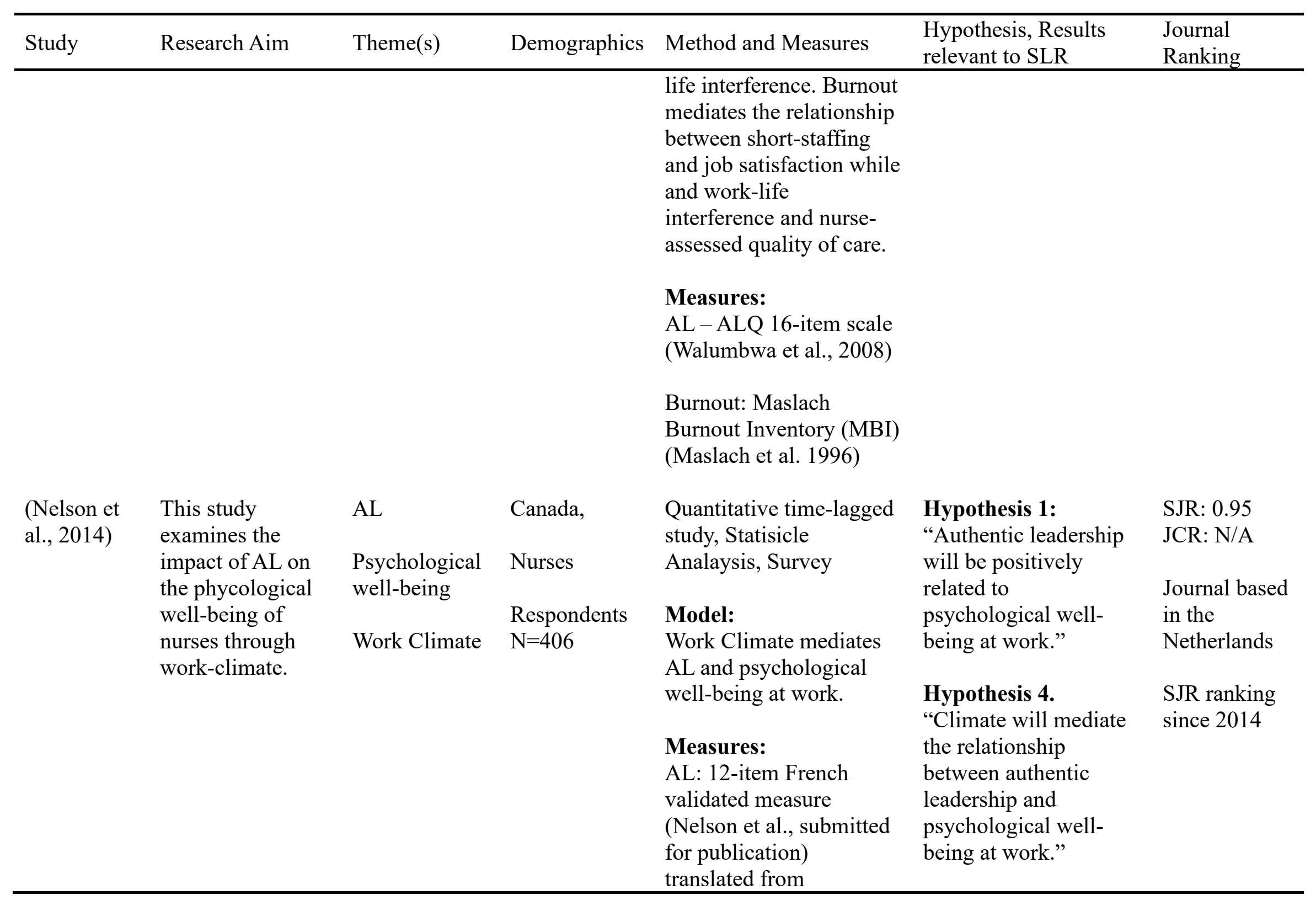




\begin{tabular}{|c|c|c|c|c|c|c|}
\hline Study & Research Aim & Theme(s) & Demographics & Method and Measures & $\begin{array}{l}\text { Hypothesis, Results } \\
\text { relevant to SLR }\end{array}$ & $\begin{array}{l}\text { Journal } \\
\text { Ranking }\end{array}$ \\
\hline \multirow[b]{2}{*}{$\begin{array}{l}\text { (Noor \& } \\
\text { Abdullah, } \\
\text { 2019) }\end{array}$} & \multirow[b]{2}{*}{$\begin{array}{l}\text { Explore the } \\
\text { relationship } \\
\text { between school } \\
\text { leaders' AL style } \\
\text { and its effects on } \\
\text { teachers' job } \\
\text { stress. }\end{array}$} & \multirow[b]{2}{*}{$\begin{array}{l}\text { AL } \\
\text { Work stress }\end{array}$} & \multirow[b]{2}{*}{$\begin{array}{l}\text { Peninsular } \\
\text { Malaysia. } \\
\text { Respondents } \\
\mathrm{N}=330 \\
\text { teachers }\end{array}$} & $\begin{array}{l}\text { Walumbwa et al.'s (2008) } \\
\text { original English } \\
\text { Authentic Leadership } \\
\text { Questionnaire (ALQ), } \\
\text { Work climate: 17-item } \\
\text { scale initially developed } \\
\text { by (Roy, 1989). } \\
\text { Psychological well-being } \\
\text { at work was assessed } \\
\text { with a 25-item validated } \\
\text { scale (Gilbert et al., 2011, } \\
\text { 2006) }\end{array}$ & $\begin{array}{l}\text { The results found that } \\
\text { the work climate } \\
\text { mediated the } \\
\text { relationship between } \\
\text { AL and psychological } \\
\text { well-being at work. }\end{array}$ & \\
\hline & & & & $\begin{array}{l}\text { Quantitative, Statisicle } \\
\text { Analaysis, Survey } \\
\text { Model: } \\
\text { The relationship between } \\
\text { AL and job stress. } \\
\text { Measures: } \\
\text { AL-ALQ 16-item scale } \\
\text { (Walumbwa et al., 2008) } \\
\text { Work Stress instrument } \\
\text { (TWS) (Collie et al. } \\
\text { 2012) and (Boyle, Borg, } \\
\text { Falzon, \& Jr. 1995) }\end{array}$ & $\begin{array}{l}\text { Research Question 3: } \\
\text { “Is there any } \\
\text { significant relationship } \\
\text { between school } \\
\text { leaders' authentic } \\
\text { leadership and } \\
\text { teachers' job stress?" } \\
\text { This study found that } \\
\text { AL style had a } \\
\text { significant impact on } \\
\text { predicting teachers job } \\
\text { stress. That is teachers } \\
\text { who perceive the } \\
\text { headmaster as being } \\
\text { authentic showed to }\end{array}$ & $\begin{array}{l}\text { SJR: } 0.35 \\
\text { JCR: N/A } \\
\text { Journal based } \\
\text { in Turkey } \\
\text { SJR ranking } \\
\text { since } 2013\end{array}$ \\
\hline
\end{tabular}




\begin{tabular}{|c|c|c|c|c|c|c|}
\hline Study & Research Aim & Theme(s) & Demographics & Method and Measures & $\begin{array}{l}\text { Hypothesis, Results } \\
\text { relevant to SLR }\end{array}$ & $\begin{array}{l}\text { Journal } \\
\text { Ranking }\end{array}$ \\
\hline $\begin{array}{l}\text { (Kiersch \& } \\
\text { Byrne, } \\
2015)\end{array}$ & $\begin{array}{l}\text { Examine if AL } \\
\text { influences } \\
\text { follower } \\
\text { perceptions of } \\
\text { fairness and create } \\
\text { a fair climate } \\
\text { which in turn } \\
\text { impacts follower } \\
\text { well-being, } \\
\text { turnover intention, } \\
\text { and organizational } \\
\text { commitment }\end{array}$ & $\begin{array}{l}\text { AL } \\
\text { Follower } \\
\text { fairness } \\
\text { perceptions } \\
\text { Subordinate } \\
\text { well-being } \\
\text { Turnover } \\
\text { intention } \\
\text { Organizational } \\
\text { commitment. }\end{array}$ & $\begin{array}{l}\text { The United } \\
\text { States and } \\
\text { Canada } \\
\text { Various } \\
\text { organisations } \\
\text { Respondents } \\
\mathrm{N}=25 \\
\text { different } \\
\text { organisations } \\
\text { (e.g., health } \\
\text { care, banking, } \\
\text { information } \\
\text { technology, } \\
\text { public safety, } \\
\text { social service, } \\
\text { legal, and } \\
\text { accounting). } \\
\text { Respondents } \\
\mathrm{N}=187 \\
\text { employees, } \\
\text { clustered } \\
\text { under } \mathrm{N}=37 \\
\text { leaders. }\end{array}$ & $\begin{array}{l}\text { Quantitative, Statisicle } \\
\text { Analaysis, Survey } \\
\text { Model: } \\
\text { Level 1 (individual } \\
\text { employee): Justice } \\
\text { perception mediates AL } \\
\text { stress, turnover intention } \\
\text { and organisational } \\
\text { commitment. } \\
\text { Level } 2 \text { (Group): Justice } \\
\text { climate mediates AL } \\
\text { stress, turnover intention } \\
\text { and organisational } \\
\text { commitement. } \\
\text { Measures: } \\
\text { AL-ALQ 16-item scale } \\
\text { (Walumbwa et al., 2008) } \\
\text { Perceived Stress Scale } \\
\text { (PSS) (S. Cohen, } \\
\text { Kamarck, \& } \\
\text { Mermelstein, 1983). } \\
\text { Turnover intention: 3- } \\
\text { items (G. A. Adams and } \\
\text { Beehr, 1998). }\end{array}$ & $\begin{array}{l}\text { have less stress. } \\
\text { Hypothesis } 1 \text { and } 2 \\
\text { (Individual H1 and } \\
\text { Group H2 level): } \\
\text { "Authentic leadership } \\
\text { negatively relates to (a) } \\
\text { employee stress and (b) } \\
\text { turnover intentions and } \\
\text { (c) positively relates to } \\
\text { organizational } \\
\text { commitment at the } \\
\text { individual and group } \\
\text { level." } \\
\text { The finding supports } \\
\text { hypothesis 1a to 1c and } \\
\text { 2a to 2c. }\end{array}$ & $\begin{array}{l}\text { SJR: } 0.85 \\
\text { JCR: } 1.597 \\
\text { Journal based } \\
\text { in the USA } \\
\text { SJR ranking } \\
\text { since } 1999\end{array}$ \\
\hline
\end{tabular}




\begin{tabular}{|c|c|c|c|c|c|c|}
\hline Study & Research Aim & Theme(s) & Demographics & Method and Measures & $\begin{array}{l}\text { Hypothesis, Results } \\
\text { relevant to SLR }\end{array}$ & $\begin{array}{l}\text { Journal } \\
\text { Ranking }\end{array}$ \\
\hline $\begin{array}{l}\text { (Rahimnia } \\
\& \\
\text { Sharifirad, } \\
\text { 2015) }\end{array}$ & $\begin{array}{l}\text { To explore the } \\
\text { relationship } \\
\text { between AL and } \\
\text { employee well- } \\
\text { being, specifically } \\
\text { the } 3 \text { dimensions } \\
\text { of work-related } \\
\text { wellness: job } \\
\text { satisfaction } \\
\text { perceived work } \\
\text { stress and stress } \\
\text { symptoms. In } \\
\text { addition, } \\
\text { attachment } \\
\text { insecurity was } \\
\text { investigated as a } \\
\text { possible } \\
\text { mediation factor } \\
\text { between AL and } \\
\text { well-being } \\
\text { dimension. }\end{array}$ & $\begin{array}{l}\text { AL } \\
\text { Employee } \\
\text { well-being } \\
\text { (perceived } \\
\text { stress, stress } \\
\text { symptoms and } \\
\text { Job } \\
\text { satisfaction), } \\
\text { Attachment } \\
\text { insecurity }\end{array}$ & $\begin{array}{l}\text { Iran } \\
\text { Health Care } \\
\text { Respondents } \\
\mathrm{N}=212 \text { health } \\
\text { care providers }\end{array}$ & $\begin{array}{l}\text { Affective Organizational } \\
\text { Commitment. The 8-item } \\
\text { affective subscale of the } \\
\text { Organizational } \\
\text { Commitment } \\
\text { Questionnaire (OCQ; } \\
\text { Allen \& Meyer, 1990). } \\
\text { Quantitative, Statistical } \\
\text { Analysis, Survey } \\
\text { Model: } \\
\text { Attachment insecurity } \\
\text { mediates the relationship } \\
\text { between employee well- } \\
\text { being and job } \\
\text { satisfaction. } \\
\text { Measures: } \\
\text { AL: ALI (Neider and } \\
\text { Schriesheim, 2011) } \\
\text { Stress: } 2 \text { items from } \\
\text { perceived work stress } \\
\text { measure. (Siu et al., } \\
\text { 2007, 2006) and six } \\
\text { items from ASSET, } \\
\text { Organizational Stress } \\
\text { Screening Tool } \\
\text { (Cartwright and Cooper } \\
\text { 2002) }\end{array}$ & $\begin{array}{l}\text { Hypothesis H1b: "The } \\
\text { followers perceiving } \\
\text { their leaders as } \\
\text { authentic are less likely } \\
\text { to feel job stress." } \\
\text { Hypothesis H1c: } \\
\text { "Those followers } \\
\text { perceiving their leaders } \\
\text { are authentic are less } \\
\text { likely to show stress } \\
\text { symptoms." } \\
\text { Both H1b and H1c } \\
\text { were found to be } \\
\text { insignificant and } \\
\text { therefore removed } \\
\text { from the final model. } \\
\text { The results did show } \\
\text { that higher levels of } \\
\text { attachment insecurity } \\
\text { resulted in higher }\end{array}$ & $\begin{array}{l}\text { SJR: } 1.86 \\
\text { JCR: } 3.796 \\
\text { Journal based } \\
\text { in the } \\
\text { Netherlands } \\
\text { SJR ranking } \\
\text { since } 1999\end{array}$ \\
\hline
\end{tabular}




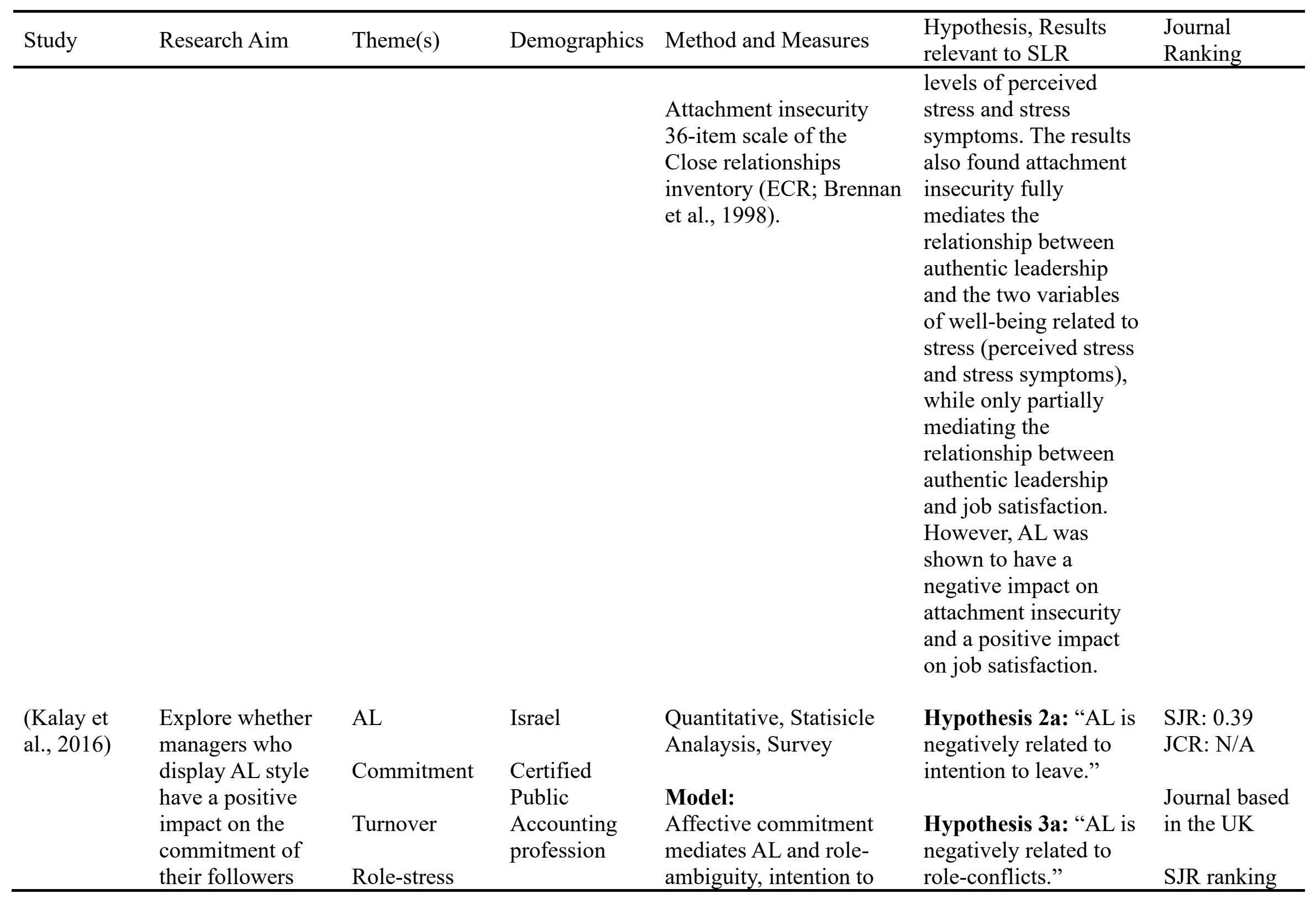




\begin{tabular}{|c|c|c|c|c|c|c|}
\hline Study & Research Aim & Theme(s) & Demographics & Method and Measures & $\begin{array}{l}\text { Hypothesis, Results } \\
\text { relevant to SLR }\end{array}$ & $\begin{array}{l}\text { Journal } \\
\text { Ranking }\end{array}$ \\
\hline & $\begin{array}{l}\text { while also } \\
\text { reducing their } \\
\text { role-stress and } \\
\text { intention to leave. }\end{array}$ & & $\begin{array}{l}\text { Respondents } \\
\mathrm{N}=512 .\end{array}$ & $\begin{array}{l}\text { leave and role-conflicts. } \\
\text { Measures: } \\
\text { AL-ALQ 16-item scale } \\
\text { (Walumbwa et al., 2008) } \\
\text { Role-conflicts and role- } \\
\text { ambiguity Rizzo, House, } \\
\text { and Lirtzman (1970) } \\
\text { Intention to leave Walsh, } \\
\text { Ashford, and Hill's } \\
\text { (1985) 5-item scale. }\end{array}$ & $\begin{array}{l}\text { Hypothesis 3b: } \\
\text { "Affective commitment } \\
\text { mediates the negative } \\
\text { relationship between } \\
\text { AL and role-conflicts." } \\
\text { Hypothesis 4a: "AL is } \\
\text { negatively related to } \\
\text { role-ambiguity." } \\
\text { Hypothesis 4b: } \\
\text { "Affective commitment } \\
\text { mediates the negative } \\
\text { relationship between } \\
\text { AL and role- } \\
\text { ambiguity." } \\
\text { Study shows follower } \\
\text { who perceive their } \\
\text { manager to } \\
\text { demonstrate AL style } \\
\text { experience more } \\
\text { affective commitment, } \\
\text { which in turn leads to } \\
\text { less perceived role- } \\
\text { stress and intention to } \\
\text { leave. }\end{array}$ & since 1999 \\
\hline $\begin{array}{l}\text { (Laschinger } \\
\text { et al., 2015) }\end{array}$ & $\begin{array}{l}\text { Explore the } \\
\text { relationship }\end{array}$ & $\mathrm{AL}$ & Canada & $\begin{array}{l}\text { Quantitative, Statisicle } \\
\text { Analaysis, Survey }\end{array}$ & $\begin{array}{l}\text { Finding support } \\
\text { linkage between AL }\end{array}$ & $\begin{array}{l}\text { SJR: } 3.19 \\
\text { JCR: } 5.631\end{array}$ \\
\hline
\end{tabular}




\begin{tabular}{|c|c|c|c|c|c|c|}
\hline Study & Research Aim & Theme(s) & Demographics & Method and Measures & $\begin{array}{l}\text { Hypothesis, Results } \\
\text { relevant to SLR }\end{array}$ & $\begin{array}{l}\text { Journal } \\
\text { Ranking }\end{array}$ \\
\hline & $\begin{array}{l}\text { between AL and } \\
\text { the } 6 \text { areas of } \\
\text { work-life. } \\
\text { Validate the idea } \\
\text { of interpersonal } \\
\text { strain in the } \\
\text { workplace a facet } \\
\text { of burnout. } \\
\text { Six areas of } \\
\text { work-life: } \\
\text { Workload, } \\
\text { Control, Reward, } \\
\text { Community, } \\
\text { Fairness and } \\
\text { Value } \\
\text { Congruence. }\end{array}$ & $\begin{array}{l}\text { OCSE } \\
\text { Six areas of } \\
\text { the work-life } \\
\text { model } \\
\text { Burnout }\end{array}$ & $\begin{array}{l}\text { A cross- } \\
\text { sectional } \\
\text { national } \\
\text { survey. } \\
\text { New graduate } \\
\text { nurses. } \\
\text { Respondents } \\
\mathrm{N}=1009\end{array}$ & $\begin{array}{l}\text { Model: } \\
\text { Mediation model linking } \\
\text { AL with six areas of } \\
\text { work-life, OCSE, } \\
\text { burnout and mental } \\
\text { health. } \\
\text { Measures: } \\
\text { AL-ALQ 16-item scale } \\
\text { (Walumbwa et al., 2008) } \\
\text { Worklife 18-item scale } \\
\text { Leiter and Maslach } \\
\text { (2011) } \\
\text { Occupational Coping } \\
\text { Self-Efficacy scale } \\
\text { consisting (Pisanti et } \\
\text { al.'s, 2008) } \\
\text { Burnout: Maslach } \\
\text { Burnout Inventory (MBI) } \\
\text { (Maslach et al. 1996) } \\
\text { Mental Health: General } \\
\text { Health Questionnaire } \\
\text { (Goldberg and Williams, } \\
\text { 1988) }\end{array}$ & $\begin{array}{l}\text { and new nurses } \\
\text { perceptions of the } 6 \\
\text { areas of work-life, } \\
\text { occupational coping } \\
\text { self-efficacy, } \\
\text { subsequent burnout and } \\
\text { mental health, thus } \\
\text { supporting. Finding } \\
\text { show AL plays a role in } \\
\text { creating positive } \\
\text { outcomes for new } \\
\text { nurses, including the } \\
\text { reduction of burnout } \\
\text { levels. }\end{array}$ & $\begin{array}{l}\text { Journal based } \\
\text { in the UK } \\
\text { SJR ranking } \\
\text { since } 1999\end{array}$ \\
\hline (Laschinger & To explore the & $\mathrm{AL}$ & Canada & Quantitative, Statisicle & This study found that & SJR: 1.56 \\
\hline
\end{tabular}




\begin{tabular}{|c|c|c|c|c|c|c|}
\hline Study & Research Aim & Theme(s) & Demographics & Method and Measures & $\begin{array}{l}\text { Hypothesis, Results } \\
\text { relevant to SLR }\end{array}$ & $\begin{array}{l}\text { Journal } \\
\text { Ranking }\end{array}$ \\
\hline et al., 2012) & $\begin{array}{l}\text { impact of AL on } \\
\text { the experiences of } \\
\text { follower } \\
\text { workplace } \\
\text { bullying, burnout, } \\
\text { job satisfaction } \\
\text { and intention to } \\
\text { leave. }\end{array}$ & $\begin{array}{l}\text { Workplace } \\
\text { Bullying } \\
\text { Emotional } \\
\text { Exhaustion } \\
\text { Job } \\
\text { Satisfaction } \\
\text { Turnover } \\
\text { Intentions }\end{array}$ & $\begin{array}{l}\text { Respondents } \\
\mathrm{N}=342 \text { new } \\
\text { graduate } \\
\text { nurses }\end{array}$ & $\begin{array}{l}\text { Analaysis, Survey } \\
\text { Model: } \\
\text { Workplace bullying } \\
\text { mediates AL and } \\
\text { emotional exhaustion (a } \\
\text { dimension of burnout) } \\
\text { and job satisfaction, } \\
\text { which in turn impacts } \\
\text { turnover intentions. } \\
\text { Measures: } \\
\text { AL - ALQ (Walumbwa et } \\
\text { al., 2007 Retrieved from } \\
\text { Mindgarden.com) } \\
\text { Bullying behaviours - } \\
\text { Negative Acts } \\
\text { Questionnaire-Revised } \\
\text { (Einarsen and Hoel, } \\
\text { 2001) } \\
\text { The emotional } \\
\text { exhaustion - Subscale of } \\
\text { the Maslach Burnout } \\
\text { Inventory-General } \\
\text { Survey (MBI-GS) } \\
\text { (Schaufeli et al., 1996). } \\
\text { Retention outcomes - Job } \\
\text { satisfaction scale }\end{array}$ & $\begin{array}{l}\text { AL can help create a } \\
\text { supportive working } \\
\text { environment and can } \\
\text { help reduce workplace } \\
\text { bullying, burnout and } \\
\text { increase job } \\
\text { satisfaction, which in } \\
\text { turn will help prevent } \\
\text { nurse's intention to } \\
\text { leave. }\end{array}$ & $\begin{array}{l}\text { JCR: } 3.57 \\
\text { Journal based } \\
\text { in the UK } \\
\text { SJR ranking } \\
\text { since } 1999\end{array}$ \\
\hline
\end{tabular}




\begin{tabular}{|c|c|c|c|c|c|c|}
\hline Study & Research Aim & Theme(s) & Demographics & Method and Measures & $\begin{array}{l}\text { Hypothesis, Results } \\
\text { relevant to SLR }\end{array}$ & $\begin{array}{l}\text { Journal } \\
\text { Ranking }\end{array}$ \\
\hline \multirow{11}{*}{$\begin{array}{l}\text { (Hickey, } \\
\text { 2014b) }\end{array}$} & \multirow{11}{*}{$\begin{array}{l}\text { Examine if the } \\
\text { motivation to } \\
\text { partake in } \\
\text { beneficial work } \\
\text { moderates the } \\
\text { effects of stress on } \\
\text { burnout }\end{array}$} & \multirow[b]{2}{*}{$\begin{array}{l}\text { Prosocial } \\
\text { motivation, }\end{array}$} & \multirow{3}{*}{$\begin{array}{l}\text { Canada } \\
\text { ID services } \\
\text { direct support } \\
\text { professionals }\end{array}$} & $\begin{array}{l}\text { (Hackman and Oldham, } \\
\text { 1975) and turnover } \\
\text { intentions scale } \\
\text { (Kelloway et al.'s 1999) }\end{array}$ & \multirow{4}{*}{$\begin{array}{l}\text { This study found that } \\
\text { prosocial motivation } \\
\text { buffers the support } \\
\text { relationship from the } \\
\text { stresses direct support } \\
\text { workers experience in } \\
\text { work. }\end{array}$} & \\
\hline & & & & $\begin{array}{l}\text { Quantitative, Statisicle } \\
\text { Analaysis, Survey }\end{array}$ & & $\begin{array}{l}\text { SJR: } 0.79 \\
\text { JCR: } 1.769\end{array}$ \\
\hline & & Stress & & \multirow{7}{*}{$\begin{array}{l}\text { Model: } \\
\text { Relationship between } \\
\text { prosocial motivation, } \\
\text { stress and burnout. } \\
\text { Measures: } \\
\text { Prosocial motivation: } \\
\text { Positive and Negative } \\
\text { Affect Schedule } \\
\text { (PANAS) 20-item scale } \\
\text { (Watson et al. 1988). }\end{array}$} & & $\begin{array}{l}\text { Journal based } \\
\text { in the UK }\end{array}$ \\
\hline & & Burnout & $\begin{array}{l}\text { Respondents } \\
\mathrm{N}=1570\end{array}$ & & & $\begin{array}{l}\text { SJR ranking } \\
\text { since } 1999\end{array}$ \\
\hline & & & & & & \\
\hline & & & & & & \\
\hline & & & & & & \\
\hline & & & & & & \\
\hline & & & & & & \\
\hline & & & & $\begin{array}{l}\text { Stress - Occupational } \\
\text { Role Questionnaire } \\
\text { (ORQ) to ten-item scales } \\
\text { (Osipow, 1998) }\end{array}$ & & \\
\hline & & & & $\begin{array}{l}\text { Burnout: Maslach } \\
\text { Burnout Inventory (MBI) } \\
\text { (Maslach et al. 1996) }\end{array}$ & & \\
\hline $\begin{array}{l}\text { (Kuvaas et } \\
\text { al., 2017) }\end{array}$ & $\begin{array}{l}\text { Test how both } \\
\text { intrinsic and }\end{array}$ & $\begin{array}{l}\text { Intrinsic and } \\
\text { Extrinsic }\end{array}$ & Norway & $\begin{array}{l}\text { Quantitative, Statisicle } \\
\text { Analaysis, Survey }\end{array}$ & $\begin{array}{l}\text { Hypothesis } \mathbf{3 b} \text {. } \\
\text { "Intrinsic motivation is }\end{array}$ & $\begin{array}{l}\text { SJR: } 1.04 \\
\text { JCR: } 1.561\end{array}$ \\
\hline
\end{tabular}




\begin{tabular}{|c|c|c|c|c|c|c|}
\hline Study & Research Aim & Theme(s) & Demographics & Method and Measures & $\begin{array}{l}\text { Hypothesis, Results } \\
\text { relevant to SLR }\end{array}$ & $\begin{array}{l}\text { Journal } \\
\text { Ranking }\end{array}$ \\
\hline & $\begin{array}{l}\text { extrinsic } \\
\text { motivation } \\
\text { affected } \\
\text { supervisor-rated } \\
\text { work } \\
\text { performance, } \\
\text { affective and } \\
\text { continuance } \\
\text { commitment, } \\
\text { turnover intention, } \\
\text { burnout, and } \\
\text { work-family } \\
\text { conflict. }\end{array}$ & $\begin{array}{l}\text { motivation } \\
\text { Burnout } \\
\text { Work-family } \\
\text { conflict, } \\
\text { Continuance } \\
\text { commitment } \\
\text { Turnover } \\
\text { intention } \\
\text { Work } \\
\text { performance. } \\
\text { Affective } \\
\text { commitment. }\end{array}$ & $\begin{array}{l}3 \text { studies two } \\
\text { cross- } \\
\text { sectional and } \\
\text { one cross- } \\
\text { lagged } \\
\text { Study1: N=52 } \\
\text { employees } \\
\text { and N=78 } \\
\text { store } \\
\text { managers } \\
\text { across N=106 } \\
\text { gas stations. } \\
\\
\text { Study } 2 \text { Time } \\
1: \mathrm{N}=6571 \\
\text { employees } \\
\text { Study } 2 \text { Time } \\
2: \mathrm{N}=4518 \\
\text { employees } \\
\text { both in the } \\
\text { finance-sector } \\
\text { trade union } \\
\text { Study } 3 \\
\text { Sector } 1: \\
\text { Medical } \\
\text { technology } \\
\text { organization } \\
\text { with N=349 } \\
\text { employees }\end{array}$ & $\begin{array}{l}\text { Model: } \\
\text { Relationship between } \\
\text { intrinsic/extrinsic } \\
\text { motivation and } \\
\text { supervisor-rated work } \\
\text { performance, affective } \\
\text { and continuance } \\
\text { commitment, turnover } \\
\text { intentions, burnout and } \\
\text { work-family conflict. } \\
\text { Measures: } \\
\text { Burnout: 14-item scale } \\
\text { (Shirom, 1989) } \\
\text { Work-family conflict } \\
\text { four-item scale that } \\
\text { Gutek, Searle, and } \\
\text { (Klepa, 1991) } \\
\text { Turnover intention five- } \\
\text { item scale that (Kuvaas, } \\
\text { 2008) }\end{array}$ & $\begin{array}{l}\text { negatively related to } \\
\text { (a) burnout, (b) work- } \\
\text { family conflict, (c) } \\
\text { continuance } \\
\text { commitment, and (d) } \\
\text { turnover intention." } \\
\text { The study found across } \\
\text { all studies that intrinsic } \\
\text { motivation was } \\
\text { positively associated } \\
\text { with positive } \\
\text { outcomes, while } \\
\text { negatively associated } \\
\text { with negative work } \\
\text { outcomes. While } \\
\text { extrinsic motivation } \\
\text { was negatively or } \\
\text { unrelated to positive } \\
\text { outcomes and } \\
\text { positively associated } \\
\text { with negative } \\
\text { outcomes. }\end{array}$ & $\begin{array}{l}\text { Based in the } \\
\text { Netherlands } \\
\text { SJR since } \\
1994\end{array}$ \\
\hline
\end{tabular}




\begin{tabular}{|c|c|c|c|c|c|c|}
\hline Study & Research Aim & Theme(s) & Demographics & Method and Measures & $\begin{array}{l}\text { Hypothesis, Results } \\
\text { relevant to SLR }\end{array}$ & $\begin{array}{l}\text { Journal } \\
\text { Ranking }\end{array}$ \\
\hline \multirow{3}{*}{$\begin{array}{l}\text { (Merrick et } \\
\text { al., 2017) }\end{array}$} & \multirow[b]{2}{*}{$\begin{array}{l}\text { Examine the } \\
\text { relationship } \\
\text { between } \\
\text { eudemonic or } \\
\text { hedonic } \\
\text { motivation, client } \\
\text { challenging } \\
\text { behaviours and } \\
\text { staff } \\
\text { psychological } \\
\text { impacts such as } \\
\text { anxiety, } \\
\text { depression and } \\
\text { life satisfaction. }\end{array}$} & & $\begin{array}{l}\text { and } \mathrm{N}=45 \\
\text { supervisors } \\
\text { Study } 3 \\
\text { Sector 2: } \\
\text { Financial } \\
\text { industry } \\
\mathrm{N}=480 \\
\text { employees } \\
\text { and } \mathrm{N}=58 \\
\text { supervisors. }\end{array}$ & & \multirow[b]{2}{*}{$\begin{array}{l}\text { Results found that in } \\
\text { order to improve and } \\
\text { correctly quantify staff } \\
\text { well-being, } \\
\text { considerations should } \\
\text { be given to staff } \\
\text { motivational } \\
\text { orientation and the } \\
\text { regularity of their } \\
\text { exposure to } \\
\text { challenging behaviours } \\
\text { (both positive and } \\
\text { negative psychological } \\
\text { outcomes of staff } \\
\text { exposure to } \\
\text { challenging } \\
\text { behaviours) }\end{array}$} & \multirow[b]{2}{*}{$\begin{array}{l}\text { SJR: } 2.34 \\
\text { JCR: } 3.898 \\
\text { Journal based } \\
\text { in the USA } \\
\text { SJR ranking } \\
\text { since } 1999\end{array}$} \\
\hline & & $\begin{array}{l}\text { Stress, well- } \\
\text { being, anxiety, } \\
\text { depression, } \\
\text { life } \\
\text { satisfaction } \\
\text { Motivation } \\
\text { Challenging } \\
\text { behaviours } \\
\text { (service users } \\
\text { on the autistic } \\
\text { spectrum) } \\
\text { Intellectual } \\
\text { Disability } \\
\text { adult services }\end{array}$ & $\begin{array}{l}\text { Scotland } \\
\text { Respondents } \\
\mathrm{N}=99 \text { staff } \\
\text { working in six } \\
\text { organisations } \\
\text { providing } \\
\text { autism- } \\
\text { specific adult } \\
\text { services }\end{array}$ & $\begin{array}{l}\text { Quantitative, Statistical } \\
\text { Analysis, Survey } \\
\text { Model: } \\
\text { Relationship between } \\
\text { eudemonic/hedonic } \\
\text { motivation, client } \\
\text { challenging behaviours } \\
\text { and staff psychological } \\
\text { impact. } \\
\text { Measures: } \\
\text { Hedonic and Eudaimonic } \\
\text { Motives for Activities } \\
\text { (Revised) scale (HEMA- } \\
\text { R) 9-item scale (Huta, } \\
\text { 2015). }\end{array}$ & & \\
\hline & & & & The Satisfaction with & The study found that & \\
\hline
\end{tabular}




\begin{tabular}{|c|c|c|c|c|c|c|}
\hline Study & Research Aim & Theme(s) & Demographics & Method and Measures & $\begin{array}{l}\text { Hypothesis, Results } \\
\text { relevant to SLR }\end{array}$ & $\begin{array}{l}\text { Journal } \\
\text { Ranking }\end{array}$ \\
\hline & & & & $\begin{array}{l}\text { Life (SWL) Scale, } \\
\text { (Diener et al. 1985). } \\
\text { The Hospital Anxiety and } \\
\text { Depression Scale } \\
\text { (HADS) (Zigmond and } \\
\text { Snaith, } \\
\text { 1983) }\end{array}$ & $\begin{array}{l}\text { staff whose motivation } \\
\text { was orientated toward } \\
\text { eudaimonic motivation } \\
\text { were significantly less } \\
\text { likely to experience } \\
\text { anxiety; however, had } \\
\text { higher levels of life } \\
\text { satisfaction. } \\
\text { Eudaimonic motivation } \\
\text { was also found to } \\
\text { moderates } \\
\text { the impact of exposure } \\
\text { to challenging } \\
\text { behaviours. }\end{array}$ & \\
\hline
\end{tabular}




\section{Appendix B: Study One - Surveys}

\section{Welcome, and thank you for your interest in this survey}

You are invited to take part in a survey that focusses on organisational research in the intellectual disability sector. The purpose of this study is to investigate the relationship between leadership, work-related stress and motivation

The study will take about 10-15 minutes to complete. The survey is fully anonymous. This means that no information that can be used to identify you is collected. You are free to leave out any question you feel uncomfortable with. Your responses will be kept strictly confidential and are stored on a secure server, hosted in the European Union. Your responses in this survey will be aggregated with responses from other participants and analysed with a statistical software package (SPSS) by the researcher, Asta Keil. In the future, the findings of this study may be disseminated, for example, in academic conferences, journals etc.

You are free to withdraw from the study at any time, up to the point the data is being analysed. Participation in this study is entirely voluntary. No personal remuneration will be given. If you have any questions about this survey, please contact me via email at asta.keil@organisation.ie or by phone [phone number]. In addition, if you have any concerns/queries about this research you can contact Dr Mary Kinahan (Mary.Kinahan@TUDublin.ie) at the Technology University Dublin.

\section{Figure 21: Survey Introduction Page}

\section{Before proceeding, please indicate your agreement with each of the following statements.}

(- Please consider the following statements

I am 18 years of age or older

I understand that I may withdraw from the study at any time

$\square$ I understand the nature of this study and give my informed consent for participation

Please enter a personal code that will help to identify your responses, in case you wish to withdraw from the survey at a later point (max. 20 chars.)

Figure 22: Survey Consent 
Please answer the following questions about yourself. Please note, you are free to leave out any question you are uncomfortable with.

How old are you?

(6) Your answer must be between 18 and 99

(- Only an integer value may be entered in this field.

\section{Figure 23: Demographic Question 1}

\section{What is your highest level of education?}

No Formal Education

Primary Education

Lower Secondary (Junior/Intermediate/Group Certificate, 'O' Levels/GCSEs, NCVA Foundation Certificate, Basic Skills Training Cert or equivalent)

Upper Secondary (Leaving Certificate including Applied and Vocational programmes, 'A' Levels, NCVA Lev. 1 Certificate or equivalent)

Technological or Vocational qualification (completed apprenticeship, NCVA Lev. 2/3 Certificate, Teagasc Certificate/Diploma or equivalent)

Both Upper Secondary and Technical or Vocational qualification

Third Level: Non-Degree (National Certificate, Diploma NCEA/Institute of Technology or equivalent, Nursing Diploma)

Primary Degree (Third Level Bachelor Degree)

Professional Qualification (of Degree Status at least)

Both a Degree and a Professional qualification

Postgraduate Certificate or Diploma

Postgraduate (Masters)

Doctorate $(\mathrm{PhD})$

Other:

Figure 24: Demographic Question 2 


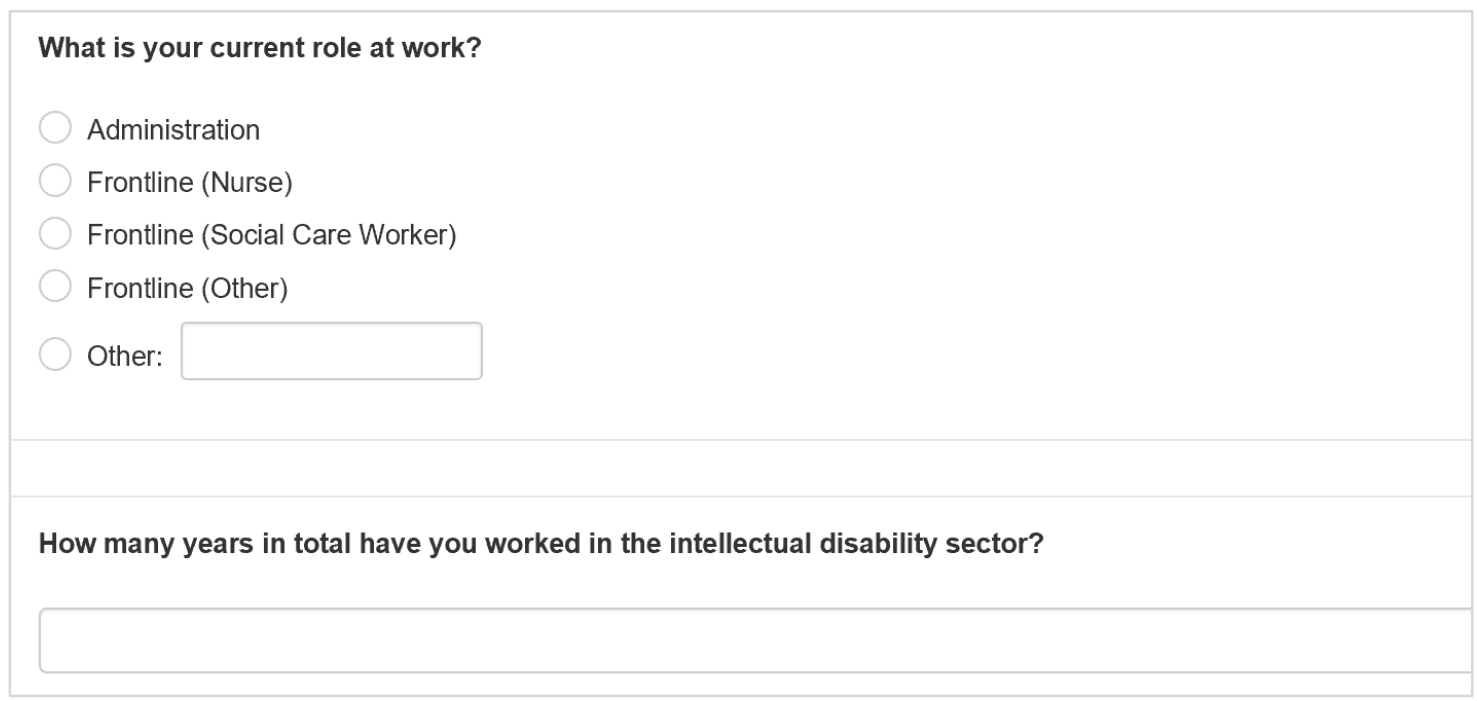

Figure 25: Demographic Question 3 \& 4

How many years have you been working in this organisation?

(- Your answer must be at least 1

(- Only an integer value may be entered in this field.

ara

How many hours per week do you normally work?

(- Your answer must be at least 1

() Only an integer value may be entered in this field.

Figure 26: Demographic Question 5 
How many hours per week do you normally work?

(- Your answer must be at least 1

(- Only an integer value may be entered in this field.

What type of contract do you currently have with this organisation?

Agency or Contract Staff

Temporary Part-Time

Temporary Full-Time

Permanent Part-Time

Permanent Full-Time

Other:

Figure 27: Demographic Question 6 \& 7 
Please read each statement and indicate the extent to which you agree or disagree.

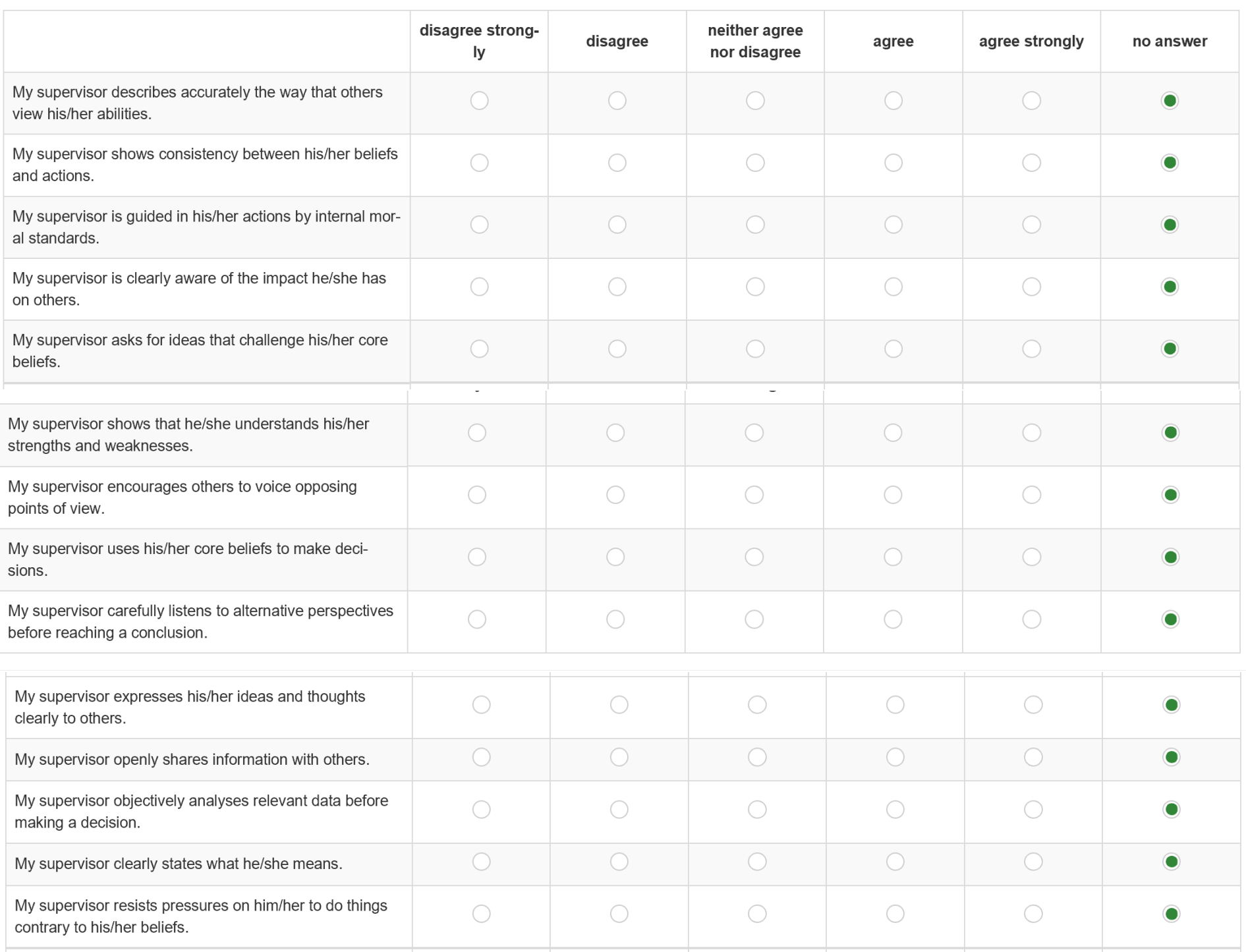

\section{Figure 28: ALI questions}


The following questions ask you about your feelings and thoughts during the last month. The best approach is to answer each question fairly quickly. That is, don't try to count up the number of times you felt a particular way, but rather indicate the alternative that seems like a reasonable estimate.

\begin{tabular}{|c|c|c|c|c|c|c|}
\hline & never & almost never & sometimes & fairly often & very often & no answer \\
\hline $\begin{array}{l}\text { In the last month, how often have you been upset be- } \\
\text { cause of something that happened unexpectedly in work? }\end{array}$ & & & & & & 0 \\
\hline $\begin{array}{l}\text { In the last month, how often have you found that you } \\
\text { could not cope with all the things that you had to do in } \\
\text { work? }\end{array}$ & & & & & & ( \\
\hline $\begin{array}{l}\text { In the last month, how often have you been able to con- } \\
\text { trol irritations in your work life? }\end{array}$ & & & & & & (-) \\
\hline $\begin{array}{l}\text { In the last month, how often have you felt that work relat- } \\
\text { ed difficulties were piling up so high that you could not } \\
\text { overcome them? }\end{array}$ & & & & & & (-) \\
\hline $\begin{array}{l}\text { In the last month, how often have you felt nervous and } \\
\text { "stressed" about a work situation? }\end{array}$ & & & & & & - \\
\hline $\begin{array}{l}\text { In the last month, how often have you felt that things } \\
\text { were going your way in work? }\end{array}$ & & & & & & 0 \\
\hline $\begin{array}{l}\text { In the last month, how often have you felt that you were } \\
\text { unable to control the important things in your work life? }\end{array}$ & & & & & & 0 \\
\hline $\begin{array}{l}\text { In the last month, how often have you been angered be- } \\
\text { cause of things that happened that were outside of your } \\
\text { control in work? }\end{array}$ & & & & & & 0 \\
\hline $\begin{array}{l}\text { In the last month, how often have you felt that you were } \\
\text { on top of things in work? }\end{array}$ & 0 & & & O & & 0 \\
\hline $\begin{array}{l}\text { In the last month, how often have you felt confident about } \\
\text { your ability to handle your work-related problems? }\end{array}$ & & & & & & ( \\
\hline
\end{tabular}

\section{Figure 29: PSS Questions}


Why do you put efforts into your current job?

\begin{tabular}{|c|c|c|c|c|c|c|}
\hline & not at all & a little & moderately & strongly & completely & no answer \\
\hline I don't know why l'm doing this job; it's pointless work. & & & & & & ( \\
\hline $\begin{array}{l}\text { Because others will reward me financially only if I put } \\
\text { enough effort in my job (e.g., employer, supervisor). }\end{array}$ & & & & & & (2) \\
\hline $\begin{array}{l}\text { Because putting efforts in this job has personal signifi- } \\
\text { cance to me. }\end{array}$ & & & & & & (2) \\
\hline Because it makes me feel proud of myself. & & & & & & ( \\
\hline $\begin{array}{l}\text { I don't, because I really feel that I'm wasting my time at } \\
\text { work. }\end{array}$ & & & & & & (2) \\
\hline Because the work I do is interesting. & & & & & & (2) \\
\hline Because I have fun doing my job. & & & & & & 0 \\
\hline Because what I do in my work is exciting. & & & & & & (2) \\
\hline $\begin{array}{l}\text { Because putting efforts in this job aligns with my personal } \\
\text { values. }\end{array}$ & & & & & & (2) \\
\hline $\begin{array}{l}\text { To get others' approval (e.g., supervisor, colleagues, } \\
\text { family, clients). }\end{array}$ & & & & & & ( \\
\hline
\end{tabular}

Figure 30: MWMS questions part A 


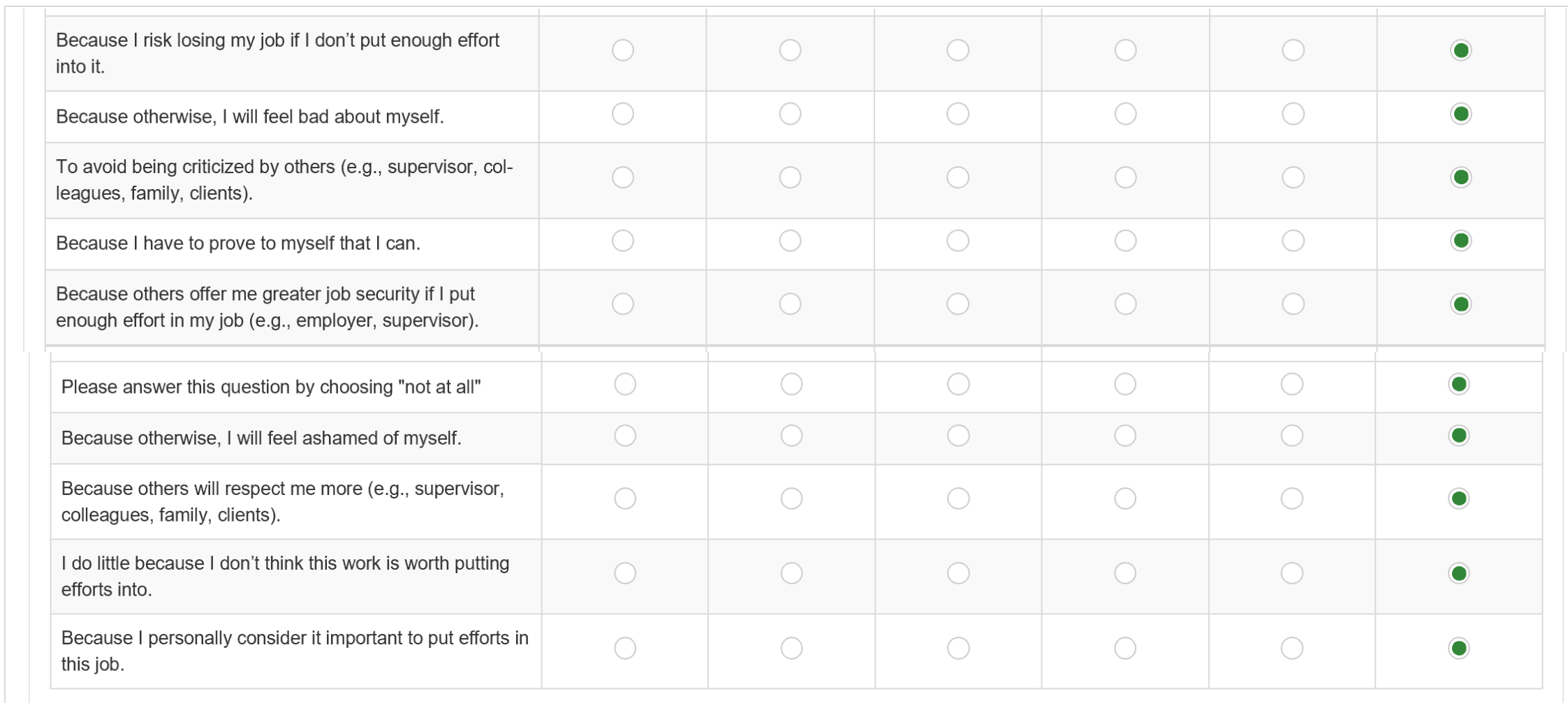

\section{Figure 31: MWMS questions part B}

For each completed survey, $€ 2$ will be added to a fund (max. $€ 200$ ), which will be donated to the charity chosen by the majority of survey participants. Please choose a charity from the list below.

A Lust for Life: Supports people with mental health problems, raising awareness.

Friends of The Elderly: Helps build relationships and companionships for members of the community without family.

The Irish Cancer Society: Dedicated to eliminating cancer as a major health problem and improving the lives of those who have cancer.

World Wildlife: Helps conserve nature and reduce the most pressing threats to the diversity of life on Earth.

\section{Figure 32: Survey Charity Choice}


Thank you very much for your participation!

\section{Invitation to participate in a follow-up interview}

We would like to invite you to take part in a short interview about your views on leadership.

Click here, to indicate your interest in taking part.

\section{More information about this research}

\section{Nature of Project}

The purpose of this research is to analyse the relationship between perceived authentic leadership, work-related stress and job motivation in the context of the intellectual disability sector in Ireland. Authentic leadership is a management style that focuses on leaders being ethical and honest. Authentic leaders are thought to be genuine and lead in an open, honest and transparent way while staying true to themselves and what they believe in (Avolio \& Gardner, 2005; Walumbwa, Avolio, Gardner, Wernsing, \& Peterson, 2008).

Why is this topic important to investigate?

Poor leadership and stress can be significant contributors to decreased job motivation, satisfaction, and performance. This not only affects staff but more importantly, can also have a major impact on the welfare of the people who avail of the services provided by the intellectual disability sector.

\section{What will happen to my data?}

Your data will be handled according to the General Data Protection Regulations (GDPR) and will be kept strictly confidential. Moreover, all data will be stored on a secure computer that only the researcher has access to.

\section{What should I do if I have concerns about this study?}

Please contact either myself Asta Keil (asta.keil@organisation.ie) or Dr Mary Kinahan (Mary.Kinahan@TUDublin.ie) from Technology University Dublin, if you have any questions or concerns about this study.

\section{Researcher}

Asta Keil, MSc student at TU Dublin. Contact by email (asta.keil@organisation.ie) or phone [phone number]

\section{Reference}

Avolio, B. J., \& Gardner, W. L. (2005). Authentic leadership development: Getting to the root of positive forms of leadership. The Leadership Quarterly, 16, 315-338. https://doi.org/10.1016/j.leaqua.2005.03.001

Walumbwa, F. O., Avolio, B. J., Gardner, W. L., Wernsing, T. S., \& Peterson, S. J. (2008). Authentic leadership: Development and validation of a theory-based measure. Journal of Management, 34, 89-126. https://doi.org/10.1177/0149206307308913

\section{Figure 33: Survey Debrief}


Invitation to participate in an interview about leadership

We are seeking participants for an interview about their views and experiences regarding leadership and how these might relate to stress and motivation at work. If you are interested in participating in an interview, please provide your email address below, so that we can contact you to arrange a suitable time and date.

The interview will be held in a private setting, in a location that suits you, and will take approximately 20-30 minutes. We are seeking between 6-10 participants to interview, therefore not everyone willing to take part will be invited for an interview. Interview participants will be chosen randomly from those that sign-up here.

* Please enter your email address:

(P Please note, we cannot link your email address back to your previous survey responses

Figure 34: Survey Interview Invitation

Table 11: Study 1 - Amotivation items

\section{Why do you put efforts into your current job?}

I don't, because I really feel that I'm wasting my time at work.

I do little because I don't think this work is worth putting efforts into.

I don't know why 'm doing this job: it's pointless work. 


\section{$0=$ Never $\quad \mathbf{1}=$ Almost Never $\quad 2=$ Sometimes $\quad 3=$ Fairly Often $\quad 4=$ Very Often}

1. In the last month, how often have you been upset because of something that happened unexpectedly?

$\begin{array}{lllll}0 & 1 & 2 & 3 & 4\end{array}$

2. In the last month, how often have you felt that you were unable to control the important things in your life?

3. In the last month, how often have you felt nervous and "stressed"?

$\begin{array}{lllll}0 & 1 & 2 & 3 & 4\end{array}$

$\begin{array}{lllll}0 & 1 & 2 & 3 & 4\end{array}$

4. In the last month, how often have you felt confident about your ability to handle your personal problems?

5. In the last month, how often have you felt that things were going your way?

6. In the last month, how often have you found that you could not cope with all the things that you had to do?

$\begin{array}{lllll}0 & 1 & 2 & 3 & 4 \\ 0 & 1 & 2 & 3 & 4 \\ 0 & 1 & 2 & 3 & 4 \\ 0 & 1 & 2 & 3 & 4 \\ 0 & 1 & 2 & 3 & 4\end{array}$

7. In the last month, how often have you been able to control irritations in your life?

8. In the last month, how often have you felt that you were on top of things?

9. In the last month, how often have you been angered because of things that were outside of your control?

10. In the last month, how often have you felt difficulties were piling up so high that you could not overcome them?

Figure 35: PSS 10-item scale (Cohen, 1994) 
Appendix C: Study - One Data Statistical Results

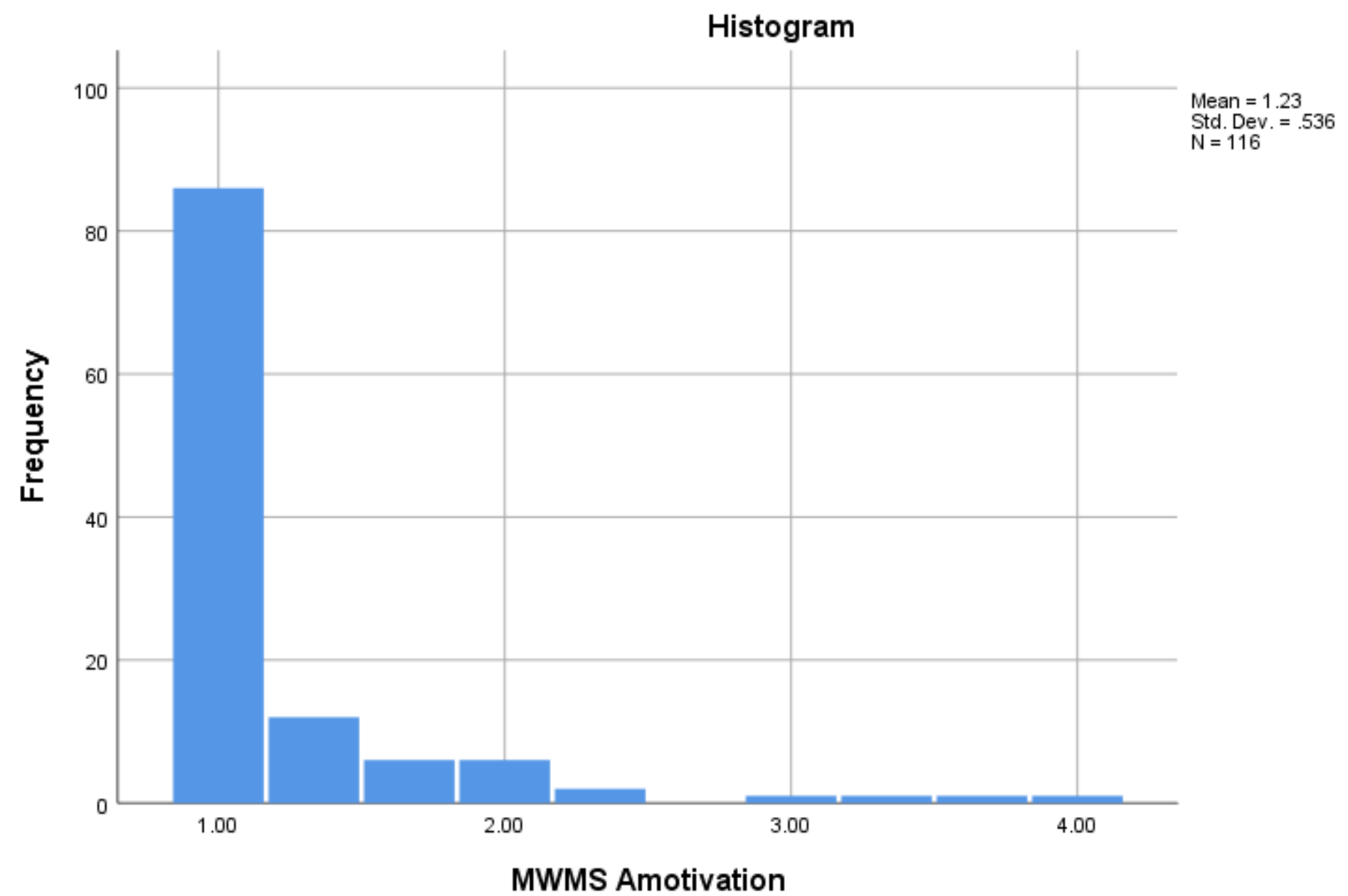

Figure 36: Study 1 - Histogram of Amotivation 
Table 12: Participant Education, Study 1

\begin{tabular}{lrc}
\hline What is your highest level of education? & $\mathrm{N}$ & $\%$ \\
\hline $\begin{array}{l}\text { Upper Secondary (Leaving Certificate including Applied and Vocational } \\
\text { programmes, 'A' Levels, NCVA Lev. 1 Certificate }\end{array}$ & 2 & 1.7 \\
Technological or Vocational qualification (completed apprenticeship, NCVA & 3 & 2.5 \\
Lev. 2/3 Certificate, Teagasc Certificate/Diploma & & \\
Both Upper Secondary and Technical or Vocational qualification & 3 & 2.5 \\
Third Level: Non-Degree (National Certificate, Diploma NCEA/Institute of & 15 & 12.7 \\
Technology or equivalent, Nursing Diploma) & & \\
Primary Degree (Third Level Bachelor Degree) & 36 & 30.5 \\
Professional Qualification (of Degree Status at least) & 12 & 10.2 \\
Both a Degree and a Professional qualification & 18 & 15.3 \\
Postgraduate Certificate or Diploma & 9 & 7.6 \\
Postgraduate (Masters) & 19 & 16.1 \\
\hline Total & 117 & 99.2 \\
\hline
\end{tabular}


Table 13: Means, Standard Deviations and Correlations - Study 1

\begin{tabular}{|c|c|c|c|c|c|c|c|c|c|c|}
\hline Measures & $N$ & $M$ & $S D$ & 1 & 2 & 3 & 4 & 5 & 6 & 7 \\
\hline 1. Authentic Leadership (AL) & 118 & 3.59 & 0.72 & - & & & & & & \\
\hline 2. Relational Transparency $(\mathrm{ALR})^{3}$ & 118 & 0.31 & 0.16 & $-.83^{* *}$ & - & & & & & \\
\hline 3. Self-Awareness (ALS) & 118 & 3.51 & 0.90 & $.96^{* *}$ & $-.67^{* *}$ & - & & & & \\
\hline 4. Internalised Moral Perspective (ALM) & 118 & 3.64 & 0.72 & $.83^{* *}$ & $-.63^{* *}$ & $.68^{* *}$ & - & & & \\
\hline 5. Balanced Processing (ALB) & 118 & 3.42 & 0.96 & $.86^{* *}$ & $-.65^{* *}$ & $.74^{* *}$ & $.55^{* *}$ & - & & \\
\hline 6. Work related stress (work-related stress) & 118 & 2.85 & 0.60 & $-.51^{* *}$ & $.45^{* *}$ & $-.49^{* *}$ & $-.28^{* *}$ & $-.52^{* *}$ & - & \\
\hline \multicolumn{11}{|l|}{ Job Motivation ${ }^{1}$} \\
\hline 7. Controlled Motivation $(\mathrm{CM})^{2}$ & 117 & 2.64 & 0.72 & .09 & -.02 & .06 & $.20^{*}$ & .06 & -.01 & - \\
\hline 8. Autonomous Motivation (AM) & 118 & 3.80 & 0.71 & $.42^{* *}$ & $-.33^{* *}$ & $.39^{* *}$ & $.35^{* *}$ & $.35^{* *}$ & $-.35^{* *}$ & $.22^{*}$ \\
\hline
\end{tabular}

Note. ${ }^{* *} p<.01,{ }^{*} p<.05$ (2-tailed); Pearson Product-Moment correlation ${ }^{1}$ Excluding amotivation from the original MWMS measure; ${ }^{2} \mathrm{CM}$, slightly reduced $\mathrm{N}$, due to missing data. ${ }^{3}$ Due to reflection and the use of $\log$ transformation for negatively skewed data, the direction of the correlations for ALR needs to be understood in a reversed manner.

Table 14: Regression Analysis Summary for Authentic Leadership predicting Work-related stress - Study 1

\begin{tabular}{lccccc}
\hline \multicolumn{1}{c}{ Variables } & $\mathrm{B}$ & $95 \%$ CI & $\beta$ & \multicolumn{1}{c}{$t$} & $p$ \\
\hline Authentic Leadership (Full scale) & -0.435 & {$[-0.574,-0.296]$} & -.526 & -6.205 & .000 \\
Age* & -0.004 & {$[-0.014,-0.006]$} & -.073 & -.789 & .432 \\
Hrs worked per week* & 0.004 & {$[-0.007,-0.015]$} & .064 & .753 & .453 \\
Gender* & -0.050 & {$[-0.321,-0.221]$} & -.031 & -.365 & .716 \\
Role Frontline or Admin* & -0.017 & {$[-0.260,-0.225]$} & -.013 & -.142 & .887 \\
\hline
\end{tabular}

Note. $*$ = covariates; $\mathrm{CI}=$ confidence interval for unstandardised coefficients $\mathrm{B}$ 
Table 15: Regression Analysis Summary for Authentic Leadership Sub-Dimension Self-awareness predicting Work-related stress - Study 1

\begin{tabular}{lccccc}
\hline \multicolumn{1}{c}{ Variables } & $\mathrm{B}$ & $95 \% \mathrm{CI}$ & $\beta$ & $t$ & $p$ \\
\hline Self-awareness & -0.325 & {$[-0.439,-0.211]$} & -.490 & -5.673 & .000 \\
Age* & -0.005 & {$[-0.015,-0.006]$} & -.086 & -.908 & .366 \\
Hrs worked per week* & 0.004 & {$[-0.007,-0.016]$} & .070 & .799 & .426 \\
Gender* & -0.007 & {$[-0.284,-0.269]$} & -.005 & -.052 & .958 \\
Role Frontline or Admin* & -0.007 & {$[-0.255,-0.242]$} & -.005 & -.053 & .958 \\
\hline
\end{tabular}

Note. $*=$ covariates $; \mathrm{CI}=$ confidence interval for unstandardised coefficients $\mathrm{B}$

Table 16: Regression Analysis Summary for Authentic Leadership Sub-Dimension Internalised Moral Perspective predicting Work-related stress - Study 1

\begin{tabular}{lcccrc}
\hline \multicolumn{1}{c}{ Variables } & $\mathrm{B}$ & $95 \% \mathrm{CI}$ & $\beta$ & \multicolumn{1}{c}{$t$} & $p$ \\
\hline Internalised Moral Perspective & -0.278 & {$[-0.435,-0.121]$} & -.335 & -3.515 & .001 \\
Age* & -0.004 & {$[-0.015,-0.007]$} & -.068 & -.664 & .508 \\
Hrs worked per week* & 0.006 & {$[-0.006,-0.018]$} & .093 & .977 & .331 \\
Gender* & -0.079 & {$[-0.383,-0.225]$} & -.049 & -.516 & .607 \\
Role Frontline or Admin* & -0.006 & {$[-0.276,-0.263]$} & -.005 & -.048 & .962 \\
\hline
\end{tabular}

Note. $*=$ covariates; $\mathrm{CI}=$ confidence interval for unstandardised coefficients $\mathrm{B}$ 
Table 17: Regression Analysis Summary for Authentic Leadership Sub-Dimension Relational Transparency predicting Work-related stress - Study 1

\begin{tabular}{lccccc}
\hline \multicolumn{1}{c}{ Variables } & $\mathrm{B}$ & $95 \%$ CI & $\beta$ & \multicolumn{1}{c}{$t$} & $p$ \\
\hline Relational Transparency & 1.695 & {$[1.043,-2.341]$} & .459 & 5.174 & .000 \\
Age* & -0.004 & {$[-0.014,-0.006]$} & -.072 & -.750 & .455 \\
Hrs worked per week* & 0.004 & {$[-0.008,-0.015]$} & .056 & .625 & .534 \\
Gender* & -0.016 & {$[-0.298,-0.267]$} & -.010 & -.111 & .912 \\
Role Frontline or Admin* & -0.050 & {$[-0.304,-0.204]$} & -.038 & -.392 & .696 \\
\hline
\end{tabular}

Note. $*=$ covariates $; \mathrm{CI}=$ confidence interval for unstandardised coefficients $\mathrm{B}$

Table 18: Regression Analysis Summary for Authentic Leadership Sub-Dimension Balanced Processing predicting Work-related stress - Study 1

\begin{tabular}{lccccc}
\hline \multicolumn{1}{c}{ Variables } & $\mathrm{B}$ & $95 \% \mathrm{CI}$ & $\beta$ & \multicolumn{1}{c}{$t$} & $p$ \\
\hline Balanced Processing & -0.329 & {$[-0.435,-0.223]$} & -.523 & -6.150 & .000 \\
Age* & -0.003 & {$[-0.013,-0.007]$} & -.055 & -.596 & .552 \\
Hrs worked per week* & 0.002 & {$[-0.009,-0.013]$} & .035 & .410 & .683 \\
Gender* & -0.019 & {$[-0.290,-0.252]$} & -.012 & -.142 & .887 \\
Role Frontline or Admin* & 0.002 & {$[-0.241,-0.245]$} & .002 & .017 & .987 \\
\hline
\end{tabular}

Note. $*=$ covariates; $\mathrm{CI}=$ confidence interval for unstandardised coefficients $\mathrm{B}$ 


\section{Appendix D: Study Two - Interview Invitation Emails}

\section{Hello Participants Name}

Thank you for agreeing to participate in an interview for my MSc Study on "The relationship between leadership, work-related stress and motivation". Quite a few colleagues have put their name forward for an interview, of which I can only interview 10 participants. I also require two people to take part in a pilot interview. All 12 names have now been randomly selected.

It is my pleasure to inform you that you have been selected to participate in a pilot interview.

To arrange a suitable time and place for the interview, I would appreciate if you could give me a call on [research phone number] or email me at asta.keil@organisation.ie to arrange this. As the pilot interview must come before the study interview, this needs to take place over the next two weeks. Thank you again for your help.

Kind Regards

Asta Keil

Figure 37: Pilot Interview Invitation - E-mail.

Hello Participants Name

Thank you for agreeing to participate in an interview for my MSc Study on "The relationship between leadership, work-related stress and motivation". Quite a few colleagues have put their name forward for an interview, of which I can only interview 10 participants . I also require two people to take part in a pilot interview. All 12 names have now been randomly selected.

It is my pleasure to inform you that you have been selected to participate in an interview.

To arrange a suitable time and place for the interview, I would appreciate if you could give me a call under [research phone number] or email me at asta.keil@organisation.ie to arrange this. I am planning for the interviews to take place between $26^{\text {th }}$ Nov 2019 and $13^{\text {th }}$ Dec 2019 . Thank you again for your help.

Kind Regards

Asta Keil

Figure 38: Interview Invitation - E-mail 
Dear Participant

Thank you for agreeing to participate in an interview for my MSc Study on "The relationship between leadership, work-related stress and motivation". Quite a few colleagues have put their name forward for an interview, of which I can only interview 10 participants . I also require two people to take part in a pilot interview. All 12 names have now been randomly selected.

Unfortunately, on this occasion, you have not been randomly selected. However, I would like to retain your details for future random selection for this study in case one of the selected participants declines to be interviewed or changes their mind at short notice. Thank you again for your help and for taking part in this study.

Kind Regards

Asta Keil

Figure 39: Interview to survey participants who have not been selected - E-mail 


\section{Appendix E: Study Two - Participant Informed Consent}

MSc in Leadership, Innovation and Technology at the Technological University Dublin (TUD)

\section{The relationship between authentic leadership, work-related stress and job motivation. \\ Participant Informed Consent}

\section{Purpose of the Study}

The purpose of this research is to analyse the relationship between perceived authentic leadership, workrelated stress and job motivation in the context of the ID sector in Ireland.

\section{Interview}

The interview will be about your experiences while working in your organisation. It will last approximately 20-30 minutes; however, it might take longer. The interview will be audio-recorded, and during the interview, the researcher may take notes.

\section{Remuneration}

There is no remuneration for taking part in this interview.

\section{Potential Risks and Ethical Considerations}

Although not intended, the interview may include questions of a personal nature that could cause discomfort. Please be assured that you are totally free to not answer any questions that you do not feel comfortable with. You may also end the interview at any time without giving a reason for doing so.

\section{Confidentiality}

The audio recorded interview will be transcribed and anonymized. Names of people, details of locations and any other data that could be used to identify you or others, will be replaced with suitable pseudonyms or codes. Demographic information will be linked to your interview transcript, in a manner that will not undermine your anonymity. After transcription, the audio files of your interview will be permanently deleted, after completion of the study. This consent form will be stored in a private, secure location that only the researcher has access to. All data will be handled in compliance with current data protection (EUGDPR) laws.

\section{What should I do if I have further questions about this study?}

Please contact either myself Asta Keil (asta.keil@organisation.ie) or Dr Mary Kinahan

(Mary.Kinahan@TUDublin.ie) from Technology University Dublin.

\section{Researcher}

Asta Keil, MSc student at TU Dublin. Contact by email (asta.keil@organisation.ie) or phone [phone number] 


\section{Consent}

If you are happy to proceed, please complete the consent form below and sign:

I confirm that I have read and understood the above information. I have had the opportunity to consider the information, ask questions, and these have been answered satisfactorily.

I understand that any information given by me may be used in future reports, articles or presentations by the research team. However, my name will not appear in any reports, articles or presentations, but anonymised extracts and quotes from the interview data may.

I confirm that I am 18 years of age or older.

I give my informed consent to participate in this study (The relationship between authentic leadership, work-related stress and job motivation). Upon signing below, I will receive a copy of the consent form from the researcher.

Name of Participant

Researcher
Date

Date
Signature

Signature 


\section{Appendix F: Study Two - Participant Debriefing Document}

MSc in Leadership, Innovation and Technology at the Technological University Dublin

(TUD)

\section{The relationship between authentic leadership, work-related stress and job motivation.}

\section{Interview Debrief}

\section{NATURE OF PROJECT}

The purpose of this research is to analyse the relationship between perceived authentic leadership, workrelated stress and job motivation in the context of the ID sector in Ireland. Authentic leadership is a management style that focuses on leaders being ethical and honest. Authentic leaders are thought to be genuine and lead in an open, honest and transparent way while staying true to themselves and what they believe in (Avolio \& Gardner, 2005; Walumbwa, Avolio, Gardner, Wernsing, \& Peterson, 2008).

\section{WHY IS THIS TOPIC IMPORTANT TO INVESTIGATE?}

Poor leadership and stress can be significant contributors to decreased job motivation, satisfaction, and performance. This not only affects staff but more importantly, can also have a major impact on the welfare of the people who avail of the services provided by the ID sector.

\section{WHAT SHOULD I DO IF I HAVE CONCERNS ABOUT THIS STUDY?}

Please contact either myself Asta Keil (asta.keil@organisationname.ie) or Dr Mary Kinahan (Mary.Kinahan@TUDublin.ie) from Technology University Dublin, if you have any questions or concerns about this study.

\section{RESEARCHER}

Asta Keil, MSc student at TU Dublin. Contact by email (asta.keil@organisation.ie) or phone 0861301122 REFERENCES

Avolio, B. J., \& Gardner, W. L. (2005). Authentic leadership development: Getting to the root of positive forms of leadership. The Leadership Quarterly, 16, 315-338.

https://doi.org/10.1016/j.leaqua.2005.03.001

Walumbwa, F. O., Avolio, B. J., Gardner, W. L., Wernsing, T. S., \& Peterson, S. J. (2008). Authentic leadership: Development and validation of a theory-based measure. Journal of Management, 34, 89-126. https://doi.org/10.1177/0149206307308913 


\section{Appendix G: Study Two - Interview Questions}

\section{Interview Preamble}

Thank you for taking part in this follow-up interview and for doing the survey. Before we start, I'd like to remind you that everything you say is strictly confidential and will be anonymised. The interview will be recorded and transcribed and will be kept in a secure location to which only I have access.

Both the recording and the transcript will be deleted once the study is completed. Also, you can stop this interview at any time, without giving a reason. Before we start, have you read the consent form, and can I please ask you to sign it?

\section{Semi-Structured Questions (Start Recording)}

\section{Opening Personal Questions}

Q. Can you tell me about the nature of your work in the organisation?

Q. How many years' service has you with the organisation?

Q. How many supervisors have you had during this time?

Q. How long have you been reporting to your current supervisor?

\section{Authentic leadership, Stress and motivation questions}

Q. Can you tell me about something that really motivated you at work?

Q. Can you give me an example of a situation that caused you to be stressed at work?

- How did this affect you? Example

- Did it affect your motivation? How?

- Did this influence your performance? How?

- Did you discuss this with your supervisor?

- How did your supervisor support you with your stress?

Q. Do you feel your current supervisor to be/not to be authentic?

- What made you feel that they were/were not authentic?

- Can you tell me their strengths/weaknesses?

- How did this affect you in work? Example

Q. Do you think this supervisor affected your motivation?

- How / Example?

- Did this influence your performance? How?

- What could this supervisor have done to make you feel more/less motivated?

Q. Do you think this supervisor affected your levels of stress? 
- How did it affect your stress?

- What were your symptoms?

- Did that affect you outside of work? How?

- Did that affect you outside of motivation? How?

- Did this influence your performance? How?

- Did this influence your attendance? How?

Q. Is feedback and recognition important to you? Why?

- Do you often receive feedback from your supervisor? How often?

- Is your supervisor open to being challenged? Example?

- From your perspective does your supervisor have a good sense of their own values and ethical outlook? Why? Examples?

Q. Do you feel your supervisor holds true to their believes and values?

- Can you give me an example of when they did/did not?

- How did this make you feel?

Q. Do you find your leader to be self-aware?

- Can you give me an example of when you experienced this?

Q. Do you find you supervisor to be reactive rather than making informed decisions.

- Can you give me an example of when you experienced this?

- How did this affect you?

Thank you for taking the time to be interviewed.

Q. Is there anything else you would like to add that has not been covered so far?

(Stop Recording)

\section{Ending Statement}

Thank you again. Please take this interview debrief, which will give you some more information about the nature of this study. Might I contact you again via your work email if I have any follow up question on the interview? If you have further questions, please don't hesitate to contact me. Thanks again. 


\section{Appendix H: Study Two - Interview Authentic Leadership Definition}

\section{Short Definition of Authentic Leadership}

Authentic leaders are genuine people that know themselves. They have values they believe in and don't compromise those values. They are open, transparent and share their experiences. They openly communicate and give credit where credit is due in a consistent and fair manner. They are rational people who make leadership decision based on evidence and data objectively. Authentic leaders have high emotional intelligence and self-awareness.

The four constructs that define of Authentic Leadership and which this study is based on. (Walumbwa, Avolio, Gardner, Wernsing \& Peterson, 2008, p. 95).

Self-Awareness: Demonstrating an understanding of how one derives and makes meaning of the world and how that meaning-making process impacts the way one views himself or herself over time. It also refers to showing an understanding of one's strengths and weaknesses and the multifaceted nature of the self, which includes gaining insight into the self through exposure to others and being cognizant of one's impact on other people.

Relational Transparency: Presenting one's authentic self (as opposed to fake or distorted self) to others. Such behaviour promotes trust through disclosures that involve openly sharing information and expressions of one's true thoughts and feelings while trying to minimize displays of inappropriate emotions.

Balanced Processing: Showing that they objectively analyse all relevant data before coming to a decision. Such people also solicit views that challenge their deeply held positions. Internalized Moral Perspective: Refers to an internalized and integrated form of selfregulation. The sort of self-regulation is guided by internal moral standards and values versus group, organizational, and societal pressures, and it results in expressed decision making and behaviour that is consistent with these internalized values.

\section{References}

Walumbwa, F. O., Avolio, B. J., Gardner, W. L., Wernsing, T. S., \& Peterson, S. J. (2008). Authentic leadership: Development and validation of a theory-based measure. Journal of Management, 34, 89-126. https://doi.org/10.1177/0149206307308913 


\section{Appendix J: Interview Extracts}

\section{Section 1: Staff Intrinsic Motivation}

Interviewer: ... can you tell me about something that really motivated you at work?

P1: I love my job. I love supporting people to do their best and be their best. That is motivating. It's lovely to see people grow and change.

P3: ... work in general and being employed gives me personally a purpose. I absolutely love my work. I love working, here especially, it's structured. I have been very fortunate so far to have had worked under [x number of] very good managers to my mind. My work, I feel is valued ...

P6: ... My motivation comes from the client satisfaction. If people we support are getting something out of what I am doing, that will motivate me. Say I run an advocacy class during the week, it motivates me seeing that the guys are learning how to speak up for themselves, how to make complaints if they're not happy about the service and learning to use their own voice. I suppose it motivates me if the people we support are using the skills that I'm teaching them. Interviewer: You see the result? ...

P6: Yes, because I think this job is very difficult to find an end result. It's often a long road to reach anything.

P6: I support [number of clients] and they could have six goals each and none of them have achieved any of their goals and I've been working with them for, say two years but they're all making large steps towards achieving them. I suppose it is difficult to find motivators sometimes in this role, but when the guys are learning skills, that's a motivator. 
P7: What motivates me is genuinely is ensuring that the bundle of people that I'm responsible for get the best care that we can possibly provide. I enjoy looking at people doing well ...

[P7 gave a specific example] ...

P7: Yes, in one of the locations I worked in, the client mix was poor, clients weren't happy, and it had been that way for a very significant amount of time. [I was involved in the process in getting] one of those clients to move to their own location, and it's had a huge positive impact on all of the clients ...

Interviewer: It must be complicated to resolve that type of situation, is it?

P7: It's beyond complicated. You think you've resolved the situation three or four times before you actually get to the point of it being actually resolved.

Interviewer: What did you feel when you accomplished that? In regard to your motivation...? P7: Yes, I felt proud. I did feel proud about that one. It was a proper accomplishment nobody else had achieved ...

P8: Yes, I suppose when I did my [external training], and I saw that some of the... training was being done outside. It sort of encouraged me and motivated me to bring that internally [to benefit the organisation and clients] ... That was something that really did motivate me... I think the biggest motivational factor has been over the last [number of] years in well, especially one of the units, where a client [benefited from that training] ... That's something that really did motivate me and gave me a great sense of satisfaction ... 
P9: ... There was a particular situation where I found some things... which could have had a massive potential safeguarding issues for people. What motivated me was that I saw the process [through] from start to finish... Then I just got some positive feedback around it as well the fact that I've done the right thing because it was quite an upsetting thing to find out ...

P10: What motivates me at work? Well, I suppose when you see the [service users] getting set up with the task that they-- Like something they wanted to achieve, some of their goals that they wanted to do... What really motivate me is one example would be [P10 gave a specific example about a major change and improvement of a service].

Interviewer: What was it about that event, that task, that job, that motivated you? Was it development of client's lives or was it just the whole--?

P10: I suppose the challenge of the whole thing because it is a [interesting improvement]. Interviewer: Challenge?

P10: Because even to start there would have been a bit of a backlash from some families who were like, "Why are you changing this?"... It's difficult for everyone to see. Then when you see the rewards at the end for the [service users] and how it's worked out and the staff as well, it had a huge impact on the staff members... they have a better work-life balance [now because of the this change] ... 


\section{Section 2: Theme One - Work-related stress examples}

Interviewer: What's was the support [you received]?

P2: They said I didn't say that. It was my staff against my supervisor and with no disrespect, but I believe my staff member, my manager tried to backtrack...

P2: For me, it was a very difficult situation and I tried to work it out.

Interviewer: It was going to get into, "Well, sorry but your lying."?

P2: Yes.

Interviewer: There was nowhere to go with that? ...

Interviewer: Can I ask you?

P2: Yes.

Interviewer: How did that physically make you feel?

P2: How did it physically make me feel? I was very upset. I couldn't stop crying...

P2: At that time? to be very honest, I found it very, very hard to be positive and to motivate my staff team and I knew that I wasn't in a right place.

[Another stressful situation reported by P2]

Interviewer: Okay, grand. Can you give me an example of a situation that caused you stress at work?

P2: Yes lots, I suppose a stressful situation is where I cannot receive or not getting funding and I'm constantly battling with senior managers for more money so I can add, additional resources on the floor with the clients...

[P7 gives an extensive example of an issue they had in work with the position the company took pertaining to service provision specific to care issues. P7 flags that variance of approach to care issues can be highly stressful. However, to ensure anonymity the example cannot be included.]

Interviewer: That's a situation where you obviously went back to your supervisors, challenged them on that, had a discussion ... How did that conversation go? ...

[P7 was listened to however supervisor would not change their mind]

Interviewer: ... was there no compromise to be had?

P7: No ... [and it was] absolutely [a] stressful [situation]... 
Interviewer: ... Did you get an apology?

P7: No.

[P8 gave a detailed example that explained how they had brought a lot of needed benefit to the organisation and the clients, however had to fight hard to have that recognised in the organisation and at one point were considering if they would stay (for anonymity the details cannot be explained further)]

P8 I don't think I should have gone through that because I had pointed out the whole reason. Staff were saying to me it was needed. The whole organisation knew it was needed ... That did cause me real stress and I really had lost my motivation. I didn't like it because I actually do like working for the organisation, it is a good organisation to work for. It was very good work done. I think that was a real thing that did cause me stress. Yes, that's the main factor that caused me stress during my time here.... 


\section{Section 3: Theme One - Non-Authentic Leadership Behaviours}

Interviewer: ... do you feel your current supervisor to be or not to be authentic?

P2: No. Definitely not.

Interviewer: Okay. Can you elaborate on that?

P2: ... My manager is very poker-faced, there's no empathy, no transparency, no openness, ... That style of management doesn't work when you're dealing with people ... I think strengths for them would be definitely, they are a doer like if you need something done, in fairness to them, they go and fight the case and they will try and do it. Weaknesses [would be they lack the] human approach and that people-person ...

Interviewer: Is your supervisor open to being challenged?

P2: Doesn't like being challenged at all and can get quite agitated if questioned or doesn't like what you're saying or how you're saying it. No, definitely not...

$\cdots$

Interviewer: ... Do you find your supervisor to be reactive rather than making informed decisions? ...

P2: In fairness to them, I do think they makes informed decisions.

Interviewer: Okay.

P2: I do think they are good at their job, but I think there's just that side that is missing. It's the whole "look after your staff." ... That's the piece missing... In fairness, they won't just go ahead and make a decision. They want to know all the facts. ... It's all about getting the full picture or getting all the information before they make decisions and stuff like that which is good. I think it's better to be that way.

Interviewer: ... Do you find your supervisor to be reactive rather than making an informed decision?

P4: They are reactive. They can be reactive. Very often, they will make an informed decision as well, so it's a bit of both.

Interviewer: A little bit of both. Do you have any examples where they are making an informed decision versus a reactive decision?

P4: I find in my role as ......., they will sit and discuss with me different aspects of what has to be 
done, and they will listen really well and take good heed of what I'm saying and build on the information I'm giving them to come up with a decision, which is really good. Sometimes when things are stressful and there's a bit of firefighting, that quality of making an informed decision goes down and the reactive decision making. That's natural as well.

P7: ... There's a very stressful recruitment situation in social care right now. You talk to any-- I talk to managers, my colleagues they'll all say the same thing. The thing that they find most stressful is covering shifts.

Interviewer: When that happens, is happened to you now, how does that physically, emotionally make you feel?

P7: It can make you feel cornered. That you've no choice in the matter. That you can't leave the shift vacant, otherwise you're not providing a service. There's sometimes a lack of choice about it. Interviewer: The choice is taken away from you because you're the last resort to fill that gap. P7: Yes. It's you or you ring a parent. If I didn't fill a shift tomorrow myself and the only option would be to ring a parent and say that their relative couldn't come through our service.

Interviewer: Have you talked to your supervisor or looked for support when those stressful situations happen?

P7: Yes, most supervisors would be aware of them.

Interviewer: Do they support you?

P7: They do in so far as they have an ability or perceived ability to support you. If support is acknowledged in that it's a difficult situation for you, and yes that's the support.

Interviewer: Yes, because it's acknowledgement to you...Is it ever a situation where the manager will say, "Well, you've done too much over the past few weeks. I'll go and do that." ... Does that happen?

P7: No, that doesn't happen .... The book stopped at middle management.

Interviewer: Right, even if you had to do that 20 times this year?

P7: Yes, the book stops at middle management.

Interviewer: You get support. What kind of support do you get? Pat on the back kind of support, or just an acknowledgment that they understand it's difficult, is that what you're saying?

P7: An acknowledgment that is difficult, but I don't perceive it to be much wider than that. Interviewer: Is that enough, do you feel like, "I'm being supported here in these situations?" 
P7: No, because I think and that's not necessarily the fault of the person that's supervising you. When it's your job to ensure that everything is okay, you tend to fall into a trap of coping and the path of least resistance. The path of least resistance is you're solving the problem yourself hook or by crook. 


\section{Section 4: Them Two - An example of motivational positive work-related stress}

Interviewer: Can you give me an example of a situation that caused you stress at work?

P3: Actually, to date, I have not.

Interviewer: No stress whatsoever?

P3: [It is hard to find a stressful situation, but if I was to dig deep], it was [do a specific piece of work for a high-level person] in a very short time span. Because they were new, I was stressed because I wanted to have [that job] done properly. It wasn't stressful in that anyone had to gun to my head, and I was unhappy and stressed, it was motivational stress.

Interviewer: Okay. Cool. How did it make you feel? ...

P3: I'm anxious to do the work properly. To do it properly, to [do that work correctly], and that it would be what they were looking for. Two, I felt that my work had value and meaning. Sometimes I think what I do may not really make a difference in the world ... It motivated me, definitely.... There was a purpose to what I did, and I could feel that ...

Interviewer: Did it improve your performance?

P3: Yes, I think. Yes. It focused me more. 


\section{Section 5: Theme Two - An example of reduced stress in improved motivation.}

P8: ... Their strengths is that they actually take an interest in you. I actually feel valued as a person. I feel valued in my role. I actually feel-- I suppose as time goes on, I feel more valuable in the team I work in. That would be the strengths. I think that's been a motivational factor for me. Interviewer: ... Do you think that your supervisor affects your levels of motivation?

P8: Definitely.

Interviewer: Can you give me an example of that?

P8: I suppose, yes. Since they have been addressing these issues, it's made me more determined. Not that I wasn't determined, it's just maybe more determined to get things done. I've identified areas that I prioritised ...

Interviewer: What about your levels of stress with this current supervisor?

P8: No, I don't think there is. No, actually, since I've grown more through, I don't feel I have any stress though I still worry about things but it's not to the degree it was two or three years ago where that was really affecting me.

Interviewer: Yes. Right.

P8: I kept having sleepless nights and it really was demotivating at that time.

Interviewer: Now, you are not stressed?

P8: At the moment, no. I don't think I'm stressed. I feel comfortable in what I'm doing. I think that's part of the confidence too that goes on as well into the role. Certainly, with my current supervisor, I feel more comfortable. I feel more comfortable approaching them if there's an issue because I know it will be dealt with. If they can't deal with it, that's fine but at least I know they've made an effort to do that.

Interviewer: Yes. That alleviates any stress that you might have had?

P8: Yes. Exactly. Yes. Absolutely. 


\section{Section 6: Theme Two - Reported Authentic Leadership Behaviours}

Interviewer: .... Do you feel that they are authentic or not authentic?

P3: $100 \%$ authentic.

Interviewer: Okay, and can you explain to me why you feel they're $100 \%$ authentic?

P3: ... Out of [all the supervisor I have had in this organisation to date], I have felt this particular person has taken an active interest in what I do, has made a lot of effort into seeing how I can further what I do here, and has actually said that they feel I am capable of doing even more. Comes in every so often randomly just to see how things are going... Also, in our interactions, they're very human. There's not a sense of "I'm up here and you're down there." Yet, there is the respect of a higher position.

Interviewer: Can you tell me something about their strengths and their weaknesses?

P3: They are very proactive, to my mind. They see something that has to be done and they address it straight away and put things in place to make them happen, to make it happen. Their weaknesses?

Interviewer: They might not have any.

P3: Well, I think obviously, everyone has weaknesses, but they're not apparent.

Interviewer: From your perspective, does your supervisor have a good sense of their own values and ethical outlooks?

P3: Yes, absolutely.

Interviewer: ... Can you give me an example for why you think that they do.

P3: Actually, you can only really find this out by having conversations. I was in a position where I was able to talk to them freely ... and I got to know them better and where they have come from in the organisation and their views. I was surprised because they were very human in their approach and their values of here was what I always believed this organisation has in the first place, what I admired about it and because they have worked from the ground up.... The way they spoke about the clients was so lovely to hear, just genuinely great. Love for them, knowing them ...

P8: ... Their strength is that they actually take an interest in you. I actually feel valued as a person. I feel valued in my role. I actually feel-- I suppose as time goes on, I feel more valuable in the team I work in. That would be the strengths. I think that's been a motivational factor for me. 
Interviewer: ... Do you think that your supervisor affects your levels of motivation?

P8: Definitely.

Interviewer: Can you give me an example of that?

P8: I suppose, yes. Since they have been addressing these issues, it's made me more determined. Not that I wasn't determined, it's just maybe more determined to get things done. I've identified areas that I prioritised ...

Interviewer: What about your levels of stress with this current supervisor?

P8: No, I don't think there is. No, actually, since I've grown more through, I don't feel I have any stress though I still worry about things but it's not to the degree it was two or three years ago where that was really affecting me.

Interviewer: Yes. Right.

P8: I kept having sleepless nights and it really was demotivating at that time.

Interviewer: Now, you are not stressed?

P8: At the moment, no. I don't think I'm stressed. I feel comfortable in what I'm doing. I think that's part of the confidence too that goes on as well into the role. Certainly, with my current supervisor, I feel more comfortable. I feel more comfortable approaching them if there's an issue because I know it will be dealt with. If they can't deal with it, that's fine but at least I know they've made an effort to do that.

Interviewer: Yes. That alleviates any stress that you might have had?

P8: Yes. Exactly. Yes. Absolutely.

…

Interviewer: OK. From your perspective, does your supervisor have a good sense of their own values and ethical outlooks?

P8: Yes, I would think so.

Interviewer: Again, are you able to elaborate?

P8: I suppose in relation to maybe certain issues with HIQA inspections and like you know if there are issues, I see at the meetings like other areas we talk about safeguarding issues. We have a lot of ethical concerns over that and they do address them, and they feel passionate. I know that the care of the client is at the centre of everything that they do, and this team does as well. -..

Interviewer: ... Do you find your supervisors to be reactive rather than making informed 
decisions? Again, if you have any examples.

P8: I wouldn't think they're reactive. No. I think if there's an issue, they'd address it, they wait for you to come back with your evidence, the way you approach the situation and then they make an informed choice about it. I think they do react. I don't think they're reactive. I don't feel that anyhow ...

Interviewer: How does your supervisor react when you challenge their viewpoint?

P8: I suppose they're open to it. Yes, they're open to it. They wouldn't dismiss it. They wouldn't, I suppose, go on a power trip either. "I'm a supervisor, you're the person." They all work as a part of the team and they take it on board. I suppose, when you come away from a situation that you feel that your views are respected, it's mutual respect then. Do you know what I mean? Because that earns mutual respect ... Obviously, you have to respect the position they're in as well. I think it works both ways. Yes, it works both ways ...

Interviewer: Do you feel that your current supervisor to be authentic or not?

P9: I do ... Because I have worked with them and seen how they're respected, and I've seen they're level of knowledge and expertise, so they understand the challenges very well. That's why I feel they're authentic because when I'm explaining a challenge, they understand it very quickly and because they're not directly involved in it, they can think of possible ways of tackling it. I would say that they're genuine in that way and they're authentic in that way because they do understand the challenges. When you're dealing with people ...

$\ldots$

Interviewer: ... Does your supervisor have a good sense of their own values and ethical outlooks? P9: I would say so. Yes, I think they do. Yes.

Interviewer: Absolutely.

P9: As I just said there, I've learned a massive amount from them and they are very-- Outside of work I can see they are a very morally good person themselves.

Interviewer: From within work then have you any examples of where you've been able to see that they have a sense of their own values, that they're in touch with their values and ethics? It's not an easy question.

P9: I would say, yes, some decisions, blanket decisions coming from finance or blanket decisions from HR, where they might say to me, "This is happening. I'm annoyed about it and this is what 
I'm doing."....

Interviewer: They voice their corner on those-

P9: They do fight the corner, yes, absolutely ... And we would discuss things like that in staff meetings and I can see that their heart is in the right place and they've good moral

$\ldots$

Interviewer: Do you feel your supervisor-- this is a little bit related to the last question, do you feel your supervisor holds true to their beliefs and values?

P9: I don't know, not all the time. I couldn't say they do all the time, ... I can think of two little examples which make my head, not $100 \%$ agree with that.

Interviewer: The question was, do you feel your supervisor holds true to their beliefs and values?

But I think what I'm getting from what you've said, and correct me if I'm wrong--

P9: There're a couple of suspicious things that happened recently.

Interviewer: It's like you're saying that's not the person I know.

P9: That's fair to say, yes. There's been a couple of things there that I think there's another agenda there, but I could be wrong.

Interviewer: Do you find your supervisor to be reactive rather than making informed decisions?

P9: Sometimes they're reactive. They're generally very level-headed, very logical and very

practical, but I have seen some reactive decisions which I've explained recently.

Interviewer: When do you think that happened, under what circumstance did you think that's happening? Do you think when they'd be reactive rather than-

P9: I'd imagine high-level stresses of governance and deadlines and different levels of responsibility that are putting them under pressure, that's what I imagine that is.

Interviewer: Have you got some examples of when your supervisor has made a reactive decision and another example where they made an informed decision?

P9: The reactive one certain was, get this done now while they're there, even if it's not due for another month and a half......

Interviewer: How does your supervisor react when you challenge their viewpoint?

P9: Sometimes I would say healthily most of the time because we're quite different in our own ways of seeing things. At the end of the day, we have to go back to the regulations so if we're ever unsure we go and then sometimes the devil is in the detail. No, I would say because I think I 
expect that they have learned things off me.

Interviewer: The last question is, do you find your supervisor share their true thoughts and feelings?

P9: Not all the time, they, couldn't possibly because they have to play the game because they're at one level of being your supervisor and manager and your support in that way, but of course, they have a role in the higher level of the organisation. It's not to be negative, but I can say that there are issues at the moment and there have been issues in the past at a more senior level and board level. It wouldn't take a genius, so I know that they are involved in the stressful side of that... Interviewer: They do share, would you say they do share their true thoughts and feelings when they're able to-

P9: Absolutely, yes.

Interviewer: But when it's politically not correct, they don't?

P9: That's a good sign of a manager as well, I have to see that that is a good sign of a good leader. Interviewer: Debatably, yes, it's complicated

P9: I can see the difficult situation that they can be in sometimes, so they don't share their true thoughts all the time, A, sometimes because I don't think they should. B, possibly confidentiality, that they can't, and then I suppose their struggle is when should I, when shouldn't I. I can understand the challenges that they're under. 


\section{Section 7: Theme Three - work-related stress and Demotivation examples}

P1: Where to start? I suppose, even just presently what's causing stress is the lack of the organization with vision and the change that it's bringing to our clients....For example, at the moment the senior managers are looking at how we deliver service [offering of specific service] We have been told that they have to stop.

Interviewer: The activities for the clients have to stop, is that what you're saying?

P1: Yes, the activities for the clients have to stop ... The problem is that it's affecting the clients at the moment, [and it's affecting the staff and other stakeholders] It affects me personally because [I can't deliver the full service].

Interviewer: Okay, and from a stress perspective, how did that make you feel physically or emotionally?

P1: Very annoyed, because I had built this, and I had created this. [we have to re-think how we run the service] ...

Interviewer: So now you have to take that away from the clients and you have to tell the families. How did that feel? Maybe that's obvious.

P1: That was very stressful to do that, and we have loads of complaints in at the moment. It's stressful moving beyond, what is going to be the end product, which I think is everything stopping. The other stress is, what am I going to offer my clients now?

Interviewer: Okay, now, do you think that that has affected your motivation?

P1: Yes, of course, it has. Yes, absolutely.

Interviewer: Okay, and do you think it's affecting your performance?

P1: Yes, of course. It will affect my performance because I'm now in a situation where I have to do report after report to justify what I've done, in regards to what I used to do because the senior managers need to take it to the CEO and justify what they have done by stopping us without any consultation. I feel very put out because I put a lot of passion and lots of energy into what I do. It also has made me very cross, very annoyed. I have to rethink it and it's going to make me take time out to try and work out where are we going to go with a future vision.

Interviewer: ... What support or did you seek support, and if you did, what kind of support did you get from your manager regarding the stress that you're feeling in regard to this issue?

P1: ... I've looked for support [from my supervisor] ... but their hands are very much tied because they're suggesting it's a funding issue and to get us in line with the HSE. I would disagree with 
that because it actually gets us totally in line with new directions and it's a self-directed service.

Interviewer: Can you give me an example of a situation that caused you to be stressed at work? P5: I can. Very specific one that happened this year. I have to say it's the most stressful situation I've ever been in any employment I've ever worked in my whole entire life.

Interviewer: Okay. It says a lot.

P5: It actually caused me to go on stress leave. Yes. It caused me to go on stress leave. To me, it was very serious, but I felt like I wasn't being treated seriously at all ... [P5 gives a detailed account of the work situation that lead up to the stress. Noting it was not the work situation that caused the stress rather how they were treated by one particular manager when dealing with the situation. The situation involved both staff and services users.]

Interviewer: How did this affect you emotionally and physically?

P5: This had the worst effect on me ever. I felt very frustrated and upset for the service user or happened to that service user whilst that management went down to meet with the person. It was more of a "How dare you?" as opposed to "We're here to help you." I was completely shut out of the process. I was told to mind my own business and not to question what was going on, because these people knew what they were doing ...

To me, it felt like it was bullying. The fallout from that was, I had a showdown with my manager. I shouted, I swore, I cried, I got really upset ... My manager is very, very good, very supportive, but I personally felt like having worked as someone [in the organisation in various positions], I felt that I wasn't being taken seriously ... [it was] their misunderstanding of why I was asking the questions ... [my relative] happened to call just after I had the discussions with my manager and I wasn't able to speak, I was so upset I couldn't speak.

I was that upset. I was really the highest level of upset. I'm starting to get upset now thinking of it. My [relative] ... actually thought someone had died, that's how upset I was. I couldn't speak .... There's been other things throughout my role-- Since I've come into the job, there's been other situations, but this was the worst. [My relative] came, got me, brought me to my doctor and he was like, "This is crazy. I'm signing you off for [certain period], because you need to take a break." 
Interviewer: Thank you. Can you give me an example of a situation that caused you to be stressed at work?

P6: yes, with some of the people I support, they can have behaviours of concerns. I suppose become physical outbursts and that can be very stressful and it's not so much that the physical outbursts, it's the before and the after and ensuring that all the clients are safe.

Interviewer: Is that what they refer to as challenging behaviours?

P6: Yes. It's just a different term. I'm dealing with challenging behaviours. I suppose it would be one of the most stressful parts of the job I think.

Interviewer: How does it affect your motivation?

P6: My motivation, when I say it affects your confidence then it makes you doubt every decision then that you're making in work. I suppose or I'm not doing that right for that person because they are then having the outburst. I wonder am I not doing it right with other clients then? You're trying to teach skills and you're trying to teach the person to use a different communication style instead of becoming physically aggressive and then when they do have an outburst it is. I suppose you feel you're not teaching them the skills that they need then.

Interviewer: Perfect. Can you give me an example of a situation that caused you to be stressed at work?

P10: A situation where I was caused to be stressed at work. I've lots of them ... I would have helped out and I would have [P10 give specific example of taking on additional work on a temporary bases to help their supervisor]. I took on [this additional work] as a favour. I now [have being doing this extra work for over a year]. That's not a favour anymore ... It can be very stressful at work. If people call in sick, me and my deputy have to be there. Like this week, both places people called in sick, so I took to one [my deputy] took to the other. You're not getting your other work done and you're falling behind on bits ... It can be very stressful.

Every day, I don't have [enough staff] ...

Interviewer: Now you mentioned that you've had to cover for your staff because you have such a minimum amount of staff that you require. If somebody goes sick and you can't get cover, you have to cover. How often does that happen?

P10: In the last three weeks, I'd say I worked on the floor six days. [There have been a few] horrendous month ... 
Interviewer: ... What does that stress feel like when you're just by the sound of it overworked ...?

P10: For me, I suppose I'd be quite a conscientious person, I like to get my stuff done so ... I have to maybe sometimes work after the shift is finished, [staff] have gone home, to catch up on stuff and things like that. Sometimes I would presume staff would say I'm a bit frazzled, maybe sometimes I'm running from one place to the other.

Interviewer: You're putting in extra hours by the sound of it, is that right?

P10: Yes.

Interviewer: Do you get compensated with that or how does that work?

P10: Time in lieu.

Interviewer: Do you get to take it then?

P10: I definitely take my time in lieu.

Interviewer: When things are calm or when there's--?

P10: When things are calm or-- Yes, I work with my deputy because they obviously works off time in lieu as well. I might go home half an hour earlier or I might just take a full day or something like that.

Interviewer: Does it compensate for the level of stress?

P10: Some weeks, no. It's great to have a Friday off and things like that but I couldn't tell you ... but I couldn't tell you the last time I took a Friday off because I haven't been able to. Even tomorrow I'm working at a location.

Interviewer: I imagine then if you build up lieu time and then you have to take time off well then you're coming back into more work because you've taken time off.

P10: Yes, exactly.

Interviewer: Because the fact that you had to cover a shift just means that if there's no one coming in, am I right -- to do your work?

P10: No, no one's doing [my work].

Interviewer: It's going to build up no matter what.

P10: Because even the deputy can do a certain amount. They are brilliant. They will do a certain amount but there's things that they just can't do or wouldn't even know what to do.

Interviewer: You have to take the final responsibility.

P10: Yes, exactly.

Interviewer: How does that affect your motivation? 
P10: I would struggle sometimes with my motivation I suppose because-- We have a staff psychologist. I have mentioned to him before about struggling with motivation. Sometimes you're just like, "Why my am I bothering?" Because you hear of other people who don't put in the effort and you're putting in so much effort. You're like, why am I bothered? But then, to be honest, that's always in the tough weeks. To be honest working on the floor is actually quite nice sometimes because you get to work with the people who technically in my mind are basically my employers. They're not here, I'm not here - so they are my employers. When I get to do things with them, I actually have a proper chat with them and find out what they want to do. It motivates me.

Interviewer: There is benefits when you're working on the floor?

P10: There is. Obviously, when there's high stress, it's not always best because I'm trying to do different things and talk to them but, yes. Even, I said, last week, I went to the client ... party, which was on in the ... and I actually said it's good for your soul and I'd like that because it's just so much fun. It's great and just everyone letting loose and it's a lovely night. 


\section{Section 8: Theme Three - Positive Authentic Leadership examples}

Interviewer: Do you feel your current supervisor to be or not to be authentic?

P1: Yes, they are very authentic ... [they are] very much tied by operational problems ...

Interviewer: Right, okay. What makes you feel that they-- Because you've said that they're authentic, so can you give me some examples of what makes you feel that they are indeed authentic?

P1: Because they're very passionate about their work and they really can see what we're trying to do in trying to deliver a service for a person. When you're delivering a service for a person, it's messy, so you have to go with your gut ... I think they are fighting for what they believe in. I think that we're living in a very turbulent time ... I think you need to have a mixture between management and leaders because we're delivering services for people's lives. You can't manage people's lives.

Interviewer: Can you give me some example then of your supervisor's strengths and then maybe some of their weaknesses?

P1: Okay, their strengths are they are very much empathic. They very much are passionate at their job. They walked the walk for many years, and they understand where everything goes ... they are good at their job. I mean, they are very organic in their management style and their leadership style and their organic ... they are very natural and they let us do our jobs. We're not managed into a corner. It flows, do you know what I mean? I only ring them when I need them and then they will respond to me ....

Interviewer: Okay. Basically, you're telling me, they are authentic, but their hands are tied?

P1: I think their hands are tied.

Interviewer: But you're still stressed ...?

P1: Yes, because I'm losing something [for the clients].

Interviewer: Yes, okay, I understand. Okay. Do you think that this specific supervisor affects your motivation? Now that could be negatively or positively.

P1: It does affect my motivation. You do the extra mile because you know that they are going to be behind you and they understands where you're trying to go.

Interviewer: Okay, so next question is do you think that this supervisor affects your levels of stress? Again, it could be positive or negative? ....

P1: Yes and no. No, I think they're alleviating, because I think the stress is coming from 
something else.

Interviewer: The stress is coming from somewhere else, so they're actually helping you with that stress?

P1: Yes.

Interviewer: It wasn't actually caused by them.

P1: Yes.

Interviewer: Okay. How did your supervisor-- Because obviously this stress was coming not directly from a conflict between you and your supervisor, between you and [another manager]. It sounded like that, would that be right?

P5: Yes.

Interviewer: How did your own supervisor support you and/or not support you?

P5: They were fantastic. Actually, I have to say they were really really good. I actually feel if it was any of other of the managers that I was reporting to, I probably would have been fired. It's was that level of--

Interviewer: Because you went in and you said you had a showdown. You had a showdown just because you were frustrated. Not at them.

P5: Not at them. Just frustrated by the whole process.

Interviewer: Just need to vent to somebody.

P5: Yes. They are a very rational person. They said, "Look, I understand why you're upset etc." "I feel like I'm being treated. The people here are not listening to what I have to say. I've been shut out of this [the process] I have a lot of concerns around how it's managed. I have huge concern for the person at the centre of it." They said, "Obviously where you're coming from and the danger that comes. I'm actually going to end the conversation there."

They managed it very well, they said, "Look, you're really upset. There's no point in us carrying on this conversation until you calm down." At that time, I was like, "Fuck you I'm not going to calm down ... I think their reaction with someone is at that heightened state, they said, "Look, there's no point in us carrying on with this." They said, "Go home for the day and check-in with you later." And they did. They rang me that evening and they said, "Look--" they go, "are you okay ... "Don't feel very good. Don't feel very good about the organization, because we're here to look after people who have an intellectual disability, and to see one of them treated the way they 
are treated, so I was absolutely furious. I said I'm not sure if this is where I want to work anymore. To see someone treated this way is awful." They said, "I agree 100\%." .... "I'm in conversations with the people I need." They had started to speak to the people that are involved in this and the other managers ... They had already started discussions, to see exactly what was going on........ Interviewer: They there for you during that time.

P5: Yes ...

Interviewer: How did that level of stress affect your motivation during that time and maybe it generally, soon after or, or even now.

P5: My motivation at the time - I came very close to quitting my job I have to say I was kind of. As I was saying there were other things that had led to this point but with that like I was "I'm Done with it. We're not doing right by the people we support, and I can't stand over this type of behaviour." Since I came back, I have to say my motivation is completely gone.

Interviewer: Really?

P5: The only thing that keeps me in the organization is the fact that I would worry for the service users because I actually don't think [what I do is valued] by management at all ...

Interviewer: OK so your motivation is gone.

P5: Gone.

Interviewer: ... do you feel your current supervisor to be or not to be authentic?

P5: I do think they are very authentic. They are very honest. They are very open and very transparent. I know they tell me and other colleagues reporting to them, exactly the lay of the land. Whereas some of the other managers I know are not as honest or open with their staff. They don't tell them things that they're supposed ....

Interviewer: Can you give me an example of that authenticity?

P5: Very, very recently as in this week, I met with them ... I met with them last week and they disclosed something that they had not been made aware regarding me and my role ... "Look, .... I don't know how this going to land, but I'm just making you very aware that this something has been considered. I don't agree with it. I've explained my stans. I have explained your role ... "Just so you're aware ..."

P5: ... there's been other situations where things have come up or things are being considered, if 
you like, [about me] or there were suggestions made to them [about me and the work I do] and they always run them by me. Whereas other managers might make decisions and say "Yes, absolutely [they can] do that. They have always consulted me ...

Interviewer: Can you tell me about your supervisor's strengths and weaknesses?

P5: Again, I would have to say their openness, their honesty or transparency and [the amount of time they have to give you] is definitely a weakness [however, they do have a very busy role] but I think besides that, they are always very decisive [and] very clear. They are always very measured I think which sometimes I don't see in a lot of the other managers.

She would take time and think things over. It's where you actually make a snap decision to go, "Yes, absolutely. That's the way to go." Even if it's not the right decision, I have seen them make mistakes, but they put her hands up and say, "Yes, I've made a mistake but it won't happen again and it won't happen again."

Interviewer: Great.

P5: I think they are really good.

Interviewer: How does that authenticity affect you in work ...?

P5: I like that I know where I stand .... they look at the bigger picture or they look further down the line [at the impact]. For me, that gives me very clear direction of where I'm going or how I can develop what I am doing.

Interviewer: Do you think your supervisor affects your levels of motivation? Maybe I'll put it in another way. The stress we talked about earlier ... was your supervisor helping you in any way to recover from that [lost] motivation--?

P5: Absolutely. They had made themselves more available. I hear from them within a day or two ... they are very supportive. I had my appraisal with them recently, and they were actually a

little upset at how much I underscored myself. They feels that I actually undervalue myself but they ... quite clearly said, "I think that's an impact of what's happened this year, that you don't feel valued in your role and that has led to you under valuing yourself in your role." They are very good ... I think she helped me to manage my stress.

Interviewer: Is your supervisor open to being challenged? 
P5: Absolutely.

Interviewer: Have you got an example?

P5: So, my manager [did something related to what I do in the organisation and did not follow the policy and process correctly and turn did not deal with a specific issue correctly]

Interviewer: How do you deal with it when you challenged them on it?

P5: ... My manager was not following the process, and that could have been questioned. They were putting themselves in a very vulnerable position, but also myself and the other managers, and so by them trying to help, they was actually creating probably a more severe breaking off the rules, I suppose ... but I've made it very clear to them that they were not to do that again and that they was not following protocol ... They took it on board, and they accepted that it was a mistake and it wasn't handling very well, but they agreed that it wouldn't happen again ...

Interviewer: Good. From your perspective, does your supervisor have a good sense of their own values and ethical outlook? Can you expand?

P5: Yes. I think they are very aware and [ I have seen them work when I was not reporting into them]. I've seen them challenge decisions that don't even affect there area, but they always play devil's advocate go look from a total outside view, this is what I think or this has an impact maybe that has not been considered. They would always I think ethically, absolutely the decisions. They always made sure that their input is there, and always give it whether it's right or whether not, whether it's right or wrong, whether it's received well or not ... Ethically I think they really look-- I think their moral compass is very much towards the service users ... I've actually seen them upset with like when they have made mistakes and things had an impact on services, I have seen them visibly upset as well.

Interviewer: ... do you feel your supervisor holds true to their beliefs and values?

P5: Absolutely without a doubt ... I think because they holds true to their beliefs, they would say what they believes in and give their opinion, they will be the devil's advocate and I don't think their colleagues at their ... level appreciate that level of accountability being pushed in their face by someone who they feel is not an appropriate person, sometimes. I do think that happens.

Interviewer: Do you feel that your leader is self-aware? ...

P5: I don't think so actually. I think their level of awareness sometimes is what kind of get through those situations with their colleagues and that they would just say it if they feel it needs to be said, it would be said. 
Interviewer: It's almost a conflict there. It's just values.

P5: I don't know if it's [they are] aware or unaware of it or maybe they are aware and they just say it because it has to be said. I actually don't know on that one. I don't know if it's intentional or unintentional.

Interviewer: It's a tough question to answer.

P5: Yes. I've seen them apologise to people and even myself, they go, "I know you've picked that up that way, but that's not what I meant," but afterwards they will say "look I'm after thinking about that and maybe I shouldn't have said that. Or maybe I shouldn't have said that in front of that person. I'm really sorry." Yes, I suppose they are.

Interviewer: Do you know, if they said something that's upset you, do they then realises, "Oh, I've upset you."

P5: They rectify it, yes.

Interviewer: Okay. Do you find your supervisor to be reactive rather than making informed decisions? Again, if you have examples--

P5: ... I suppose again that comes into their role and they would be in charged [of a really high budget], that kind of stuff. I suppose their approach has to be measured and has to be considered. I think they do.

Interviewer: Do you have any specific examples of her making a really informed decision as opposed to just reacting?

P5 [give very specific example] ....

Interviewer: ... Do you find your supervisor shares their true thoughts and feelings?

P5: Absolutely ... They are very genuine. I think they are very, very genuine. They'd have conversations with me, and I haven't liked what they said and I've gone away, going feck them like. Then when you think about it, you go, "No, they're right."

Interviewer: When those times arise, do you discuss that with your supervisor?

P6: Yes. I actually found discussing it with my supervisor very helpful. They also experienced situations of physical outburst from a -- It was one specific client. It was very helpful, good to use as a sounding board. What techniques they were using to deal with the situation, and then I could put that into my practice and what was working for me may not be working for her. I find-Interviewer: ok good support then? 
P6: Yes, great support.

Interviewer: ok do you feel your current supervisor to be or not to be an authentic leader?

P6: I definitely find my supervisor to be an authentic leader --

Interviewer: Yes, can you give me examples or elaborate on that a little bit?

P6: Open, transparent and share their experiences. Yes, so communication, goes back to when I was discussing with them when I was going through the physical outburst and they communicated well to me what they had been trying. I felt their door was always open and even some times they could have been in the thick of a difficult situation themselves, they are very good at communicating, "Okay, I just need 10 minutes and then I'll come and find you," and then did that. Yeah great values. Their values, there were some things that they could then bend on but there were, other things that they stuck very high and fast when it came to values. The clients were always front and centre for them. I find that my values aligned very much with their values. Interviewer: .... Tell me something about their strengths and then something about their weaknesses.

P6: Their strengths were probably their approachability I suppose, like everyone-- I can't speak for everyone, but I always felt that I could approach them with any professional issue that I was having and then that would probably lead to one of their weaknesses as well then was that trying to make time for themselves as well. That they were always there then as a sounding board and I'm not saying that I went to them for every little thing but sometimes I think, "Oh, my God, they probably have a lot on their plate as well."

Interviewer: That doesn't sound like a weakness.

P6: Yes, I suppose. It is the strength for you would worry their other work but yes their strengths, they just have great values, great morals. I aligned a lot with myself as I've said. Their strengths they are great at time keeping which I find very important, very respectful to the clients and to staff alike.

Interviewer: Great. How is that overall, of having a leader like that, How does that affect your work? You think.

P6: I think it makes you step up to the mark. I think that if you feel that your leader is that's the benchmark, that's how good you're trying to be, then that makes you-- That's a good motivator and it makes you want to work harder.

Interviewer: Almost like a role model. 
P6: Yes. That's the word for it, so If I didn't have respect or-- Not respect, but if I didn't feel that they were an authentic leader, I don't think I would work as hard.

...

Interviewer: It sounds like you had a lot of respect for them

P6: Yes, definitely.

Interviewer: We may have touched on this, but do you think your supervisor then affects your motivation?

P6: Yes, I definitely do. In the past, I've had different supervisors that wouldn't instil a great. I suppose it comes down to respect again, but I suppose if you see your leader working hard and going above and beyond, that inspires you to want to do that as well.

Interviewer: ... Do you think that your supervisor then affects your levels of stress either positively or negatively?

P6: Definitely. Yes, I think they do. I think positively in my case.

Interviewer: Yes, alleviate the stress that--

P6: Yes, definitely.

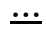

Interviewer: Is your supervisor open to being challenged?

P6: Yes, I definitely think so.

Interviewer: Can you give some example. Have you ever challenged them?

P6: Yes, an example would be, I wanted to change somebody's support plan, start supporting them in the community. My supervisor, their first thought was, "No. We can't do that. We don't have enough resources." Then they came back to me later that day and said, "We'll give it a go. We'll try it." She didn't make any promises that this would be--

Interviewer: Did you have to fight hard or?

P6: No. It was just I throw an idea out there and their gut reaction was No, but then went away and thought about it and came back. I think yes, that's a--

Interviewer: .... From your perspective then, does your supervisor have a good sense of their own values and ethical outlook?

P6: Yes, definitely. I think they knows their mind; they know their values and they know if things don't fall into line with that ... It is their own sense of values and ethical outlook. I think with some things that come down from management, from senior management, and you could tell that the 
authentic leader wasn't happy with a decision and it didn't fall into their values and the way that they wanted to run the service here. They had a lot of discussions with senior management, and they did a lot of advocating on behalf of the clients to get around things. I think that was a good reflection, very good communication that both the clients and the staff of saying, "I'm not happy about this, but this is what I'm doing about it."

Interviewer: ... do you feel your supervisor holds true to their beliefs and values? ....

P6: Yes, advocation.

Interviewer: Advocation for up to the senior management level.

P6: Yes. Yes.

Interviewer: Are you able to give me an example of that or is that too specific?

P6: I suppose [specific service delivery] would be an example of funding cuts really, and the resources they advocated for that there was a cut on resources and one of our big things as part of our services, [activity as part of the service], "No, we're [not providing that service any longer] came down from the highest level--"... I suppose they advocated that there is a lot of aging clients with aging parents that they can't [will miss out]. They did a lot of advocating around that. Unfortunately, since that it has been cut, but at the time-- I think they didn't take it personally but it didn't align with their values that we could supply a service one year and then say, No, we can't do that the next.

Interviewer: Interesting. Great. Thank you. They really fought for that?

P6: Yes.

Interviewer: Next question is-- ... Do you find your leader to be self-aware, and if you can give me an example?

P6: Self-aware?

Interviewer: If she is upsetting you or making you feel really happy or one or the other. Does she realise that she's doing--?

P6: Personally, from my experience, I think they have great self-awareness. Yes, I think that they are very good at identifying emotion in other people and understanding. Maybe an example would be after a situation, like a physical outburst from my client, they would be aware that you may be finding it difficult. 
For you realise that and they would be very good at explaining how those situations make them feel and then identifying the commonality may be between. That's how I feel.

..

Interviewer: Great. Do you find your supervisors to be reactive rather than making informed decisions? Again, do you have any examples?

P6: Reactive rather than making informed decisions? I think in this line of work, you're going to be reactive a lot of the time, unfortunately, but making decisions, back to my other example when I was saying about supporting the person in the community rather than supporting [the client] here, that would have been a reactive decision to say "No, that won't work."

Interviewer: Then she went away.

P6: Then she went away and came back .... I think what they said what they did was go and looked at the incident reports for the physical outburst. There were making an informed choice then.

Interviewer: Excellent. Both then. Reactive but actually reflecting and then informing?

P6: Yes.

Interviewer: Ok so that is interesting

P6: God I'm make sound like a saint, aren't I

Interviewer: They are well they are in your eyes.

P6: Yes.

Interviewer: It's great. Do you find your supervisor shares their true thoughts and feelings?

P6: I think when it comes to work, yes. I think if we all share our true thoughts and feelings all the time, we wouldn't be very good sometimes. I think when it comes to professionally, yes, but personally, I think they would have feelings about things. Let's say, the [removal of a service] being pushed. I think they probably felt "This is ridiculous. Why should I have to fight for this at all?" But professionally, they explained to the team. "This is what's happening, and this is the discussions we're having."...

Interviewer: ... Unless you want to add anything else ...

P6: No. It's very good for the self-reflection, actually. I didn't think about all of those things until the questions are asked. God, I may tell them. 
Interviewer: ... Do you feel your current supervisor to be or not to be authentic?...

P10: .... At times, yes. I feel like they can be preoccupied. They can be distracted quite easily. They will listen and they will pay attention to what I have to say but other times, something could happen, and they feel like they must respond to it immediately. Either a phone call or an email or something that. I have said in my supervision before.... I feel like you should be there listening to that person because if they about to tell you something and like it Oh they are on my phone, honestly, it's just like you're not paying attention. That's just my view ...

Interviewer: Okay, anything else that you feel makes them authentic or not authentic?

P10: I've had difficulties during the year and they have been really supportive. Just personal stuff and they have been really supportive of that ...

Interviewer: Okay, can you just tell me about your supervisor's strengths and their weaknesses. P10: Their weakness will [they get distracted while having a conversation with you].

... [a strength] If they said that he's going to do something or follow up with something, they will. I do think if there's ever issues, [they will follow up and help get it sorted]. They see down the lineright where we need to have a meeting with this person or that person and they chase people up as well.

Interviewer: .... Does your supervisor affect your stress levels, your motivation levels, your work in general?

P10: ... I would have found one with previous manager with meetings and stuff that they were very focused on what you were saying, a good workout plan and very direct in saying yes or no. Yes, that's a good idea, or no, I don't think that's going to work. Obviously, it gave me the reasons why they don't think it would work.

Interviewer: You don't get that from your current?

P10: It suppose I would to an extent. The other manager was just better at maybe delivering it. I don't know but, yes. Obviously, there's been a lot of challenges in my current locations ...

Interviewer: Is your supervisor open to being challenged?

P10: Yes, I think so.

Interviewer: Can you give me an example?

P10: Open to being challenged? I suppose yes, actually I would challenge them because even things like I deputies, they're talking about doing a review of deputy hours and all of this. I would 
challenge them on why would residential hours, get more deputy hours than day-service. I have more clients, generally for the majority of the week. All of this, so I would- we would get into like some debates.

Interviewer: How does that go?

P10: It goes fine. Like, because the two of us realise that like it's both of us are coming from our point. It's not going to hold it against anyone after ... Like we'd have a little bit of a laugh after. We'd be like, "Oh, that got a bit heated." and then just move on. They fine with being challenged ...

Interviewer: From your perspective, does your supervisor have a good sense of their own values and ethical outlook?

P10: Yes, I would say so ... I do you feel that they have a perspective of their own sense of values? ... I do think they [things for the right reason]. In my mind, I don't see them coming in to be like, they are purely here for the money or anything like that ... I do think they are coming in because they want to make things better. I do think when I'm sitting with them and talking about any issues with them, they do want to help ....

Interviewer: Ok, do you feel your supervisor holds true to their beliefs and values?

P10: ... Yes, because I suppose I only see them in like a smaller context. I don't see them very often. When it comes to my stuff that I deal with them, yes, I would see them as following up with stuff and doing things for the right reasons and stuff like that.

Interviewer: How does all that make you feel? Does it help with your motivation? How would that address stress?

P10: Yes, because honestly, sometimes it's good, and sometimes like, I even have supervision today and I know I'm going to go down and have a big old rant. They listened to my rant, then if we can come up with some good plan out, then it's good ...

Interviewer: You're not afraid of going down to have a rant?

P10: No, I may go have notes for my rant for later.

Interviewer: Feeling perfectly okay afterwards? You're not going to be stressed afterwards and some good might come out of it is that correct?

P10: Yes, because we talked through it all and be like well what happened here? What happened there? What is this and you know even just different situations would like-- Then it could even be, they can make notes and it could be going to like the senior management team for them to discuss 
further cause it's concerns the wider organisation ...

Interviewer: ... Do you find your leader to be self-aware?

P10: ... I don't think they are aware that they [get distracted as much as they do] and I don't think they realise what impact that has on people when it's happened. I don't think they are aware as to how other people feel about [that]

Interviewer: That's a good example. Is that the only example? Can you think of any? ...

P10: They are quite busy all the time. Like I'm personally, I'm just like 'take a breath and relax' you know, and maybe that's just the type of work person they are, cause I don't know them, obviously, apart from being a manager or now my manager, so I don't know if they are different person outside of work or is that just who they are ...

Interviewer: ... Do you ever find your supervisor to be reactive rather than making informed decisions?

P10: I suppose in certain circumstances the whole organisation is reactive, but we are looking at situations now and we're trying to be proactive. We're trying to like get things in order before something happens because we know when something will happen. In terms of like we've- I have some people who have, obviously, mental health problems as well. Things happen from time to time and at the minute we're in a very good space but we're meeting even till today would be a big talk about what is going to happen and I'm trying to pre-empt for the next situation what's going to happen.

Interviewer: So, you are trying to look forward. You're trying to do some forward planning. Have any specific example of where a decision was made by your supervisor, that was actually just reactive as opposed to really gathering all the data and make an informed decision ......

P10: The reactive ones?

Interviewer: There may not be any.

Interviewer: The examples where actually you've witnessed them making really good informed decisions as opposed to,

P10: .... we're dealing with like the situation at the moment and with somebody with mental health problems and we're trying to link in now with mental health services on the HSE. I suppose, and this is looking at the future, like does this person's future lie within our organisation? So, what trumps what? 
Interviewer: How is that decision made?

P10: Basically, the organisation is saying that mental health trumps ID. The mental health services are saying that their ID trumps their mental health. Ok now the person the person, I'm obviously not going to say.

Interviewer: Ok now when you say trumps is a bigger issue, you know what I mean?

P10: Yes. The person who has mild intellectual disability but also has mental health issues, the mental health services are saying that there the reason they don't know that's a voice is because they have ID, but that's the nature of mental health you know. Nobody knows that it's a voice in their head you know.

Interviewer: It's right. That's really interesting.

P10: Isn't it? It's like we're having like, and I know to be fair to that person,

Interviewer: You're having to make some future decisions around the care for that person.

P10: We're looking at everything with the HSE, the family, everybody.

Interviewer: Is your supervisor getting into making an informed decision about that?

P10: An Informed? Yes, I suppose so I would keep them very up to date on what's happening and hopefully next week we're going to have a meeting to find out more information about their mental health care ....

Interviewer: Data-driven to an extent as far as you can be? I mean I assume you can be datadriven in making those decisions.

P10: ... There is like an increase in the need for going into health and stuff. It is, I suppose a lot more like even like on our own systems, like putting in the information so I can pull it back and go, okay, well this is what we have. This is how many incidents we have compared to this. We are looking at all day stats and like, I now sent to them a report on that information.

Interviewer: Having talked about all of that, would you say yes, they make informed decisions more often than not?

P10: Yes, Yes, ... Even if it's on a decision that needs to be made today about tomorrow, they will ask me for the information on what has happened, what is going on. We have a chat about it. They will ask what I think. They will say what they think and then we will come up with a plan.

Interviewer: .... Do you find your supervisor shares their true thoughts and feelings?

P10: Yes. I can answer that one straight away. Yes.

Interviewer: Great. No fakeness there. 
P10: No.

Interviewer: No hidden agendas.

P10: No.

Interviewer: What you see is what you get and it's the truth.

P10: Yes. Yes.

Interviewer: Cool. Can you give me--

P10: ... Just even in our meetings and stuff like that, they just tell me straight out what they think of something and I know. ... Sometimes they will say something like "I probably shouldn't have said that."

Interviewer: ... Overall, what impact is your supervisor having on you, your motivation your stress?

P10: we can have that, just that conversation where I'm not overly conscious. Yes, I know they are my manager and everything like that, but they are not like "Oh, I'm your manager" and breathing down your neck type of person. You can have a normal conversation. You can say things just as you're thinking it. You can say that, and they obviously do the same. The conversation more just flows than just watching your P's and Q's, so I quite like that.

[apart from their getting distracted a lot, which I find frustrating], I find them-They are a pretty decent manager as they go. 


\section{Section 9: Recognition is important to all participants}

Interviewer: ... Is feedback and recognition important to you, and if so why?

P1: Feedback and recognition is important to everybody. Absolutely, and how it's done, I suppose you need to understand who your person is and who I am. So standing up and applauding me in front of everybody would absolutely embarrass me but if you just tell me that I've been doing a good job, that would be great.

Interviewer: You would, okay. How often do you receive that from your supervisor? You don't have to tell me the exact number of times, but is it a regular-

P1: I'd say you do sometimes. Yes, you do sometimes.

Interviewer: Sometimes?...

Interviewer: ... is feedback and recognition important to you?

P2: Absolutely.

Interviewer: Okay.

P2: $100 \%$.

\section{Interviewer: Why?}

P2: Because it makes you feel appreciated for the good work you do and acknowledgments of that would be - getting a good HIQA report or you know when the senior managers that are emailing me saying, "Congratulations, well done. That's excellent." You know I love passing that on to my staff because it continues to keep them motivated them as well ...

Interviewer: Would I be right in saying this, that recognition heightens the mood, alleviates the stress, and creates motivation?

P2: Yes, absolutely.

Interviewer: How often would you get that kind of recognition from your supervisor?

P2: Not very often, it would only be like after a HIQA inspection.

Interviewer: ... Is feedback and recognition important to you?

P3: Yes.

Interviewer: Tell me why.

P3: Well, as I said earlier, it's important because it reaffirms that what I'm doing in some way can 
make a difference to the organisation as a whole.

Interviewer: How do you feel when you get ...

P3: Well, obviously, great.

Interviewer: ... is feedback and recognition important to you?

P4: Very much, yes...

Interviewer: .... Why is it important?

P4: Why? It motivates me if I get positive feedback

Interviewer: ... Is feedback and recognition important to you?

P5: No. I think feedback for me is very important because I suppose [I'm new enough to this type of work] ... So that feedback, this for me is really important because I thought I need direction, I need to know that this is the right way to it or this is the best way to go with this. So, we do need our feedback.

Interviewer: What was the recognition, praise?

P5: I suppose it's based on the thing with the appraisal. I probably don't value it, but I think it'd be average.

Interviewer: How did you feel when you got that recognition from your supervisor during the appraisal for positive feedback?

P5: I'm embarrassed. I don't know if I receive, I have nothing. I don't know if it's an Irish thing, but I don't take stuff like that very well.

Interviewer: Great. You get all the feedback you need?

P5: Yes.

Interviewer: Great. Is feedback and recognition important to you?

P6: Hugely, yes. I think if I was doing a job and it was a lot of work and I didn't get any recognition for it, it would be very disheartening. I think the leader that I'm thinking of was very good at identifying and even things, little jobs, that may not have been the standout, just doing the work in the background, very good at identifying it yeah.

Interviewer: Just giving you the recognition for it?

P6: Yes, and quietly. Not always having to make a -- 
Interviewer: Great. How often do you think that you get that do you think? Is it regular?

P6: Yes, I would say regularly. It depends if I was doing it or not, but yes, I think-- I would say 8 times out of 10 probably.

Interviewer: that you would get a word of thanks?

P6: Yes, definitely.

Interviewer: ... Is feedback and recognition important to you?

P8: Yes. It's very important. Yes, absolutely.

Interviewer: How often do you feel you get that? Why is it important?

P8: Well, I suppose it's important status. I suppose it acknowledges and reinforces if I'm doing a good job, maybe it highlights areas or maybe if I'm not doing a good job then I need to address this. I'd be quite open to that. That's part of constructive criticism anyhow as a mature adult I have to accept that obviously...

Interviewer: ... is feedback and recognition important to you?

P9: Yes. That's important to everybody...

Interviewer: Absolutely. I think that's come through in some of what you've said already. How often do you feel that you get that feedback and recognition from your supervisor?

P9: You generally would know-- No, regularly from them. It depends because I've other little tasks to do because ... At the moment, I'm [doing a specific item of work] and that was very complimentary of the work I've done on it so far .... It depends on what's scheduled and stuff like that. It depends [what work is on], ... No, it happens regularly enough. It does. Yes.

Interviewer: Okay. Is feedback and recognition important to you?

P10: Yes. Both sides but obviously, if it's negative or positive because, I want to know where I'm going wrong. I don't want someone just to let me off on a free rain and then next thing I've made a disaster or something, if someone sees I'm going wrong with something, I want to know, because I like to correct it and learn from it. Then obviously, everyone likes positive feedback. Who doesn't? Interviewer: Fair enough? How often do you get both?

P10: I suppose my current manager, they would be fairly good to be honest. .... we have to deal with a lot of reports and stuff and even quarterly stuff and see the work that's being done. Then to 
be honest, if there's something that I'm not sure of, I generally ring them and I just double check things to see if I'm going the right way with something. Sometimes they are like, "No, maybe we'll just try it a different way," or something like that. Yes, it's kind of regular.

Interviewer: You feel like you're getting enough anyway?

P10: Yes. 


\section{Section 10: Reported stress symptoms}

- I was very upset.

- I felt really broken.

- Actually, at the time I was just very, very angry.

- There have been other times that I've been very stressed, and I'd have more of a physical reaction to it. That was more of a mental anguish reaction and I was worried about, and I thought about it a lot.

- I get a terrible fright every time I open an email.

- I felt compromised.

- $60 \%$ of the time, I'm operating on a panic to get something done.

- This had the worst effect on me ever. I felt very frustrated and upset.

- I was so upset I couldn't speak.

- It can make you feel cornered.

- The physical would be that your heart would race a little bit and that you'd be a little bit kind of felt that you weren't being appreciated.

- Well, you're bringing it home. You're waking up in the middle of night. You don't have enough time to do it.

- Yes. I think that a lot of people go out on sick leave as a result of various conditions and things like that, but we don't look at the stress that goes beyond that. 


\section{Authorship Statement}

This project has been prepared in its entirety by the author alone and in accordance with TUD postgraduate regulations. Where required to draw from the work of others, published or unpublished, the author has acknowledged such work in accordance with established scholarly and editorial principles. This project has not been submitted in whole or part for any other award in any other Institute or University. The work reported on in this project conforms to the principles and requirements of the Institute's guidelines for ethics in research. Furthermore, no part of this work has been previously submitted for any award to any institution or university.

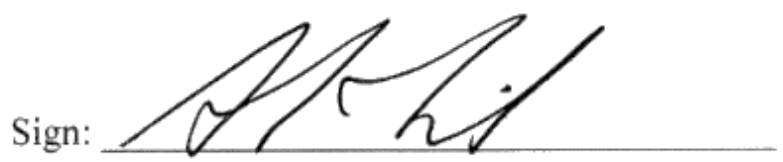

Asta Keil 